\title{
The effects of dietary nutrient balance on life-history traits and sexual selection in the field cricket, Gryllus veletis
}

\author{
by
}

Sarah J. Harrison

A thesis submitted to the Faculty of Graduate and Postdoctoral Affairs in partial fulfillment of the requirements for the degree of

Doctor of Philosophy

in

Biology

\author{
Carleton University \\ Ottawa, Ontario
}

(C) 2018

Sarah J. Harrison 


\begin{abstract}
Nutrition is an important driver of biological variation. Macronutrients such as protein and carbohydrates, and elemental nutrients such as phosphorus, are known to affect animal fitness traits. No study, however, has investigated the importance of phosphorus relative to dietary protein or carbohydrates, or their interactive effects, on animal performance. To advance our understanding of the impact of nutrition on individual fitness, my thesis examined the influence of dietary protein, carbohydrate, and phosphorus balance on fitness-related life-history traits, including those involved in intraand inter-sexual selection, of Gryllus veletis field crickets. My findings revealed that adult lifespan, weight gain, males' acoustic mate attraction signals, and females' egg production were maximized on diets with different protein:carbohydrate ratios, such that not all fitness traits could simultaneously be maximized on the same diet. Similarly, juvenile females could not simultaneously maximize their growth, development rate, survival, and dispersal capability at adulthood on the same dietary protein:carbohydrate ratio. Adult males and females also had different optimal nutrient intake ratios for reproductive performance. My results support theoretical predictions for the conditiondependence of traits involved in inter- and intra-sexual selection; both male mate attraction signals, and female sexual responsiveness and preferences for such signals, were influenced by dietary protein:carbohydrate ratio. However, male aggressiveness in agonistic contests with rivals was not influenced by dietary nutrient balance. Contrary to my expectations, dietary phosphorus had little influence on fitness traits, with the exception of a negative influence of high phosphorus diets on male mate attraction
\end{abstract}


signals. When given a choice between diets containing differing but complementary nutrient compositions, both adults and juveniles demonstrated an ability to regulate their protein and carbohydrate intakes, but not their phosphorus intake. These self-selected diets often represented a compromise between the differing nutrient requirements of multiple fitness traits. Overall, my findings suggest that environmental heterogeneity in nutrient availability is an important driver of variation in animal fitness, and highlight the importance of disentangling the influences of different nutrients on animal fitness traits. 


\section{Preface}

\section{Thesis format and statement of co-authorship:}

This dissertation is written as an 'integrated thesis' and contains four data chapters and a General Methods chapter, 'bookended' by a General Introduction chapter and a General Conclusions chapter. The data chapters are written in manuscript format and, for this reason, there is some repetition across chapters in their introduction and discussion sections that was necessary to properly frame my research within the existing scientific literature. Two data chapters ( $3 \& 4)$ have been published, and the remaining chapters $(5 \& 6)$ are ready to be submitted for publication. While the research contained within this thesis is entirely my own, several co-authors contributed to the experimental designs and the writing of manuscripts. Below I list the contributions of myself and any co-authors for each data chapter.

\section{Chapter 3: Influence of dietary nutrient balance on male and female lifespan, growth, egg production and acoustic mate attraction signals}

This chapter is published as:

Harrison, S. J., Raubenheimer, D., Simpson, S. J., Godin, J.-G. J., \& Bertram, S. M. (2014). Towards a synthesis of frameworks in nutritional ecology: interacting effects of protein, carbohydrate and phosphorus on field cricket fitness. Proceedings of the Royal Society B: Biological Sciences, 281, 20140539.

For this chapter, my co-supervisors, Drs. Susan M. Bertram and Jean-Guy J. Godin, and I collaboratively developed the research questions and designed the experiments. Drs. D. 
Raubenheimer and S.J. Simpson assisted with the diet treatment aspect of experimental design and advised on data analysis. I collected the data, performed the data analysis, and wrote the first draft of the manuscript. Dr. Raubenheimer assisted with writing the Introduction in the final draft of the manuscript. All co-authors provided comments and editorial suggestions which greatly improved the manuscript.

\section{Chapter 4: The influence of dietary nutrient balance on male aggression and signalling}

This chapter is published as:

Harrison, S. J., Godin, J.-G. J., \& Bertram, S. M. (2017). Influence of dietary nutrient balance on aggression and signalling in male field crickets. Animal Behaviour, 134, 123-134.

For this chapter, Dr. Bertram, Dr. Godin, and I collaboratively developed the research question and designed the experiment. I collected the data, performed the data analysis, and wrote the manuscript. Drs. Bertram and Godin provided comments and editorial suggestions which greatly improved the manuscript.

\section{Chapter 5: The influence of dietary nutrient balance on female life-history traits throughout development and adulthood}

and 


\section{Chapter 6: The influence of dietary nutrient balance on female sexual responsiveness and mate preferences}

For these chapters, Dr. Bertram, Dr. Godin, and I collaboratively developed the research questions and designed the experiments. I collected the data, performed the data analyses, and wrote the manuscripts. Drs. Bertram and Godin provided comments and editorial suggestions which greatly improved these manuscripts.

\section{Permissions to include previously published, co-authored materials in this thesis:}

I have obtained permission from all co-authors to use our collaborative published papers in this thesis. Additionally, I have obtained permission from Royal Society Publishing and Elsevier Publishing to use the published papers associated with Chapters 3 and 4 in this thesis.

\section{To cite this thesis, I recommend:}

Harrison, S.J. 2018. The effects of dietary nutrient balance on life-history traits and sexual selection in the field cricket, Gryllus veletis. Ph.D. thesis, Carleton University, Ottawa, Ontario, Canada. 


\section{Acknowledgements}

I am immensely grateful to my supervisors, Drs. Susan Bertram and Jean-Guy Godin, for their patience, encouragement, support and guidance over the past eight years. I thank them for their enormous contribution to my research and the completion of this thesis, and especially for putting up with my writing at a 'snail's pace'. Without their mentorship, I would not be the scientist I am today. A special thanks to Sue for twisting my arm into doing a Master's degree, and then when I was almost free, convincing me to stay to do a Ph.D.

I am also grateful to Carleton University staff and faculty for their support during my doctoral studies. I would especially like to thank the Biology Department's amazing support staff for their ability to fix all of my administrative and greenhouse problems. I would also like to thank Drs. Howard Rundle and Jeff Dawson for serving on my thesis advisory committee, and for their thought-provoking questions, helpful advice, and encouragement over these past few years. A special thanks to Dr. Dawson for frequently helping me with experimental equipment repairs, design, and construction.

Also a big thank you to all of the Bertram lab members both past and present for their assistance with animal care and experimental brainstorming, including Genevieve Ferguson, Mykell Reifer, Emily McAuley, Amy Villarreal, Michelle Loranger, Ian Thomson, Karen Pacheco, Caitlin Grant, Lauren Fitzsimmons, as well as countless undergraduate students. Likewise, thanks to my 'half lab mates' in the Godin lab. A special thanks to my friend and 'lab wife' Genevieve, my shoulder to complain on and 
partner in procrastination, without whom these past few years would have been significantly less entertaining and awesome.

The completion of this doctoral thesis would not have been possible without the support of my family. An enormous thank you to my partner, Joe Chaput, for being an unending source of support, for always being there for me, and not letting me give up when finishing this thesis seemed too far from my grasp. Thanks to my parents, Bev and Maria, for providing me with the guidance, encouragement, and opportunities in life that got me to where I am today. I am especially grateful for their combined love of science and nature, which most definitely inspired my own love of biology.

Funding for the research presented in this thesis was provided through research grants awarded to my supervisors, Drs. Susan Bertram and Jean-Guy Godin, from the Natural Sciences and Engineering Research Council (NSERC) of Canada Discovery Grants, the Canadian Foundation for Innovation, the Ontario Research Fund, and the Carleton University Research Fund. I was directly supported by Departmental Scholarships from Carleton University, an NSERC Canadian Graduate Scholarship, and an Ontario Graduate Scholarship.

Lastly, I would also thank the journal editors and anonymous reviewers for their extensive helpful comments on the published manuscripts which were based on Chapters 3 and 4. 


\section{Table of Contents}

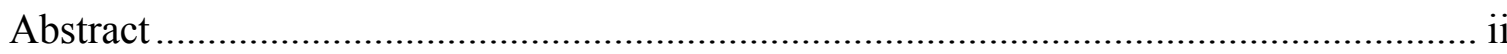

Preface

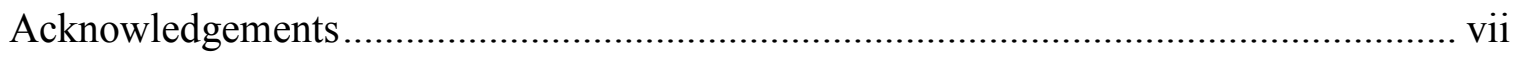

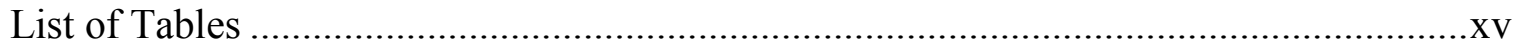

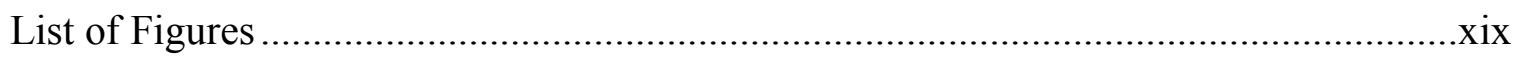

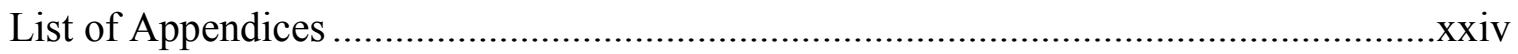

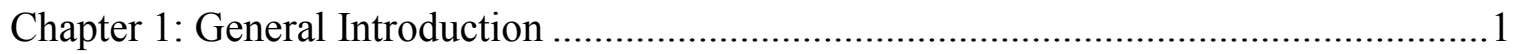

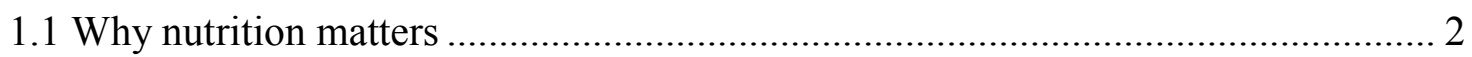

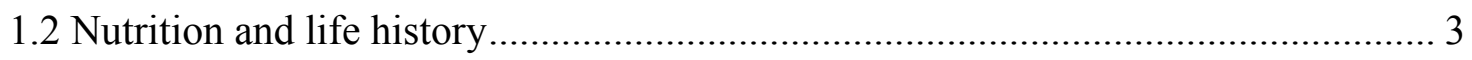

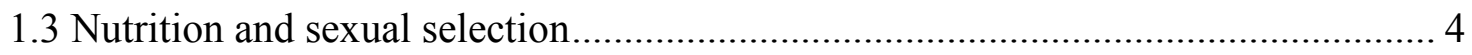

1.4 A more nutritionally explicit framework for studying nutrition .............................. 6

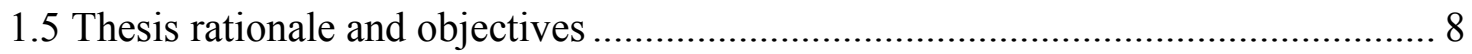

Chapter 2: General Methods .....................................................................................11

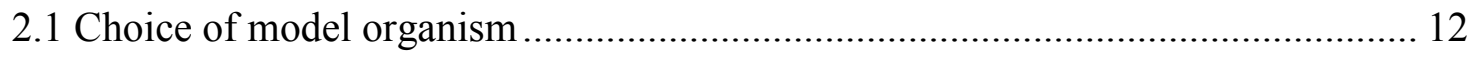

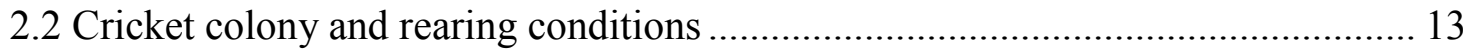

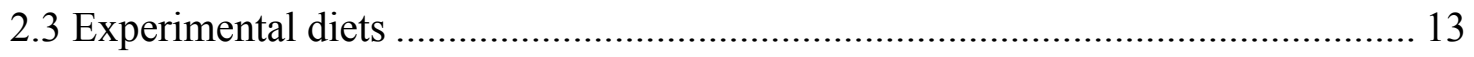

2.4 Electronic acoustic recording system (EARS II) .............................................. 14 
Chapter 3: Influence of dietary nutrient balance on male and female lifespan, growth, egg production and acoustic mate attraction signals

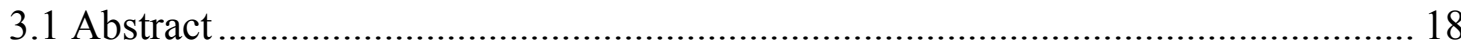

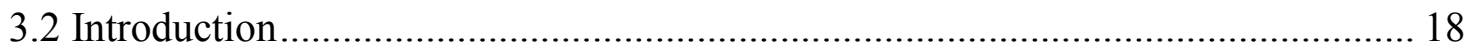

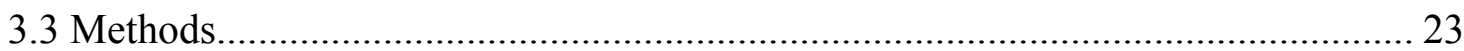

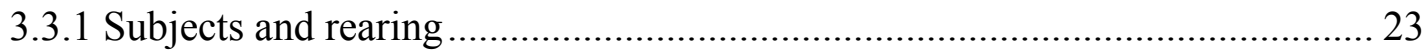

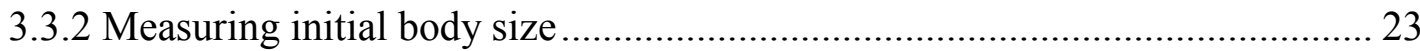

3.3.3 Experiment 1: Influence of dietary nutrient ratio on fitness traits ................... 24

3.3.4 Experiments 2 and 3: Influence of dietary nutrient ratio on diet selection...... 30

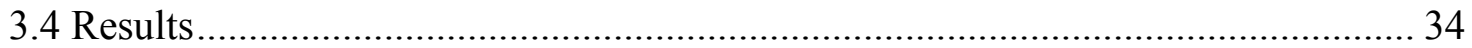

3.4.1 Experiment 1: Influence of dietary nutrient ratio on fitness traits .................. 34

3.4.2 Experiment 2: Influence of dietary phosphorus on diet selection.................. 41

3.4.3 Experiment 3: Influence of dietary protein:carbohydrate ratio on diet selection

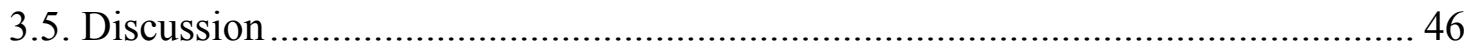

3.5.1 Experiment 1: Influence of dietary nutrient ratio on fitness traits ................. 46

3.5.2 Experiments 2 and 3: Influence of dietary nutrient ratio on diet selection...... 51

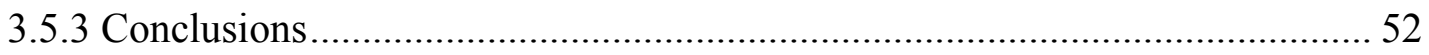

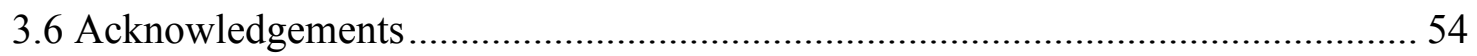


Chapter 4: The influence of dietary nutrient balance on male aggression and signalling .55

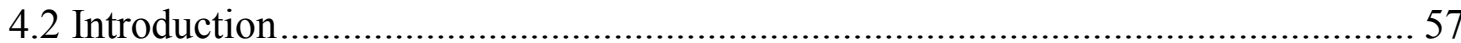

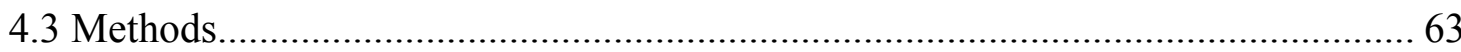

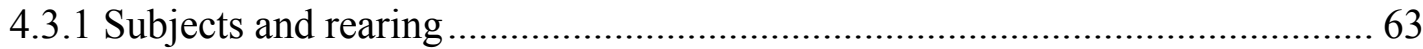

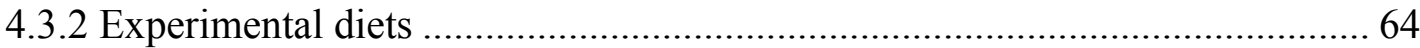

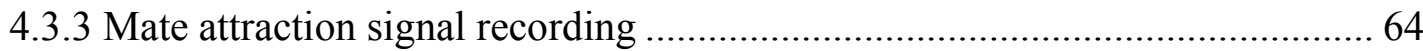

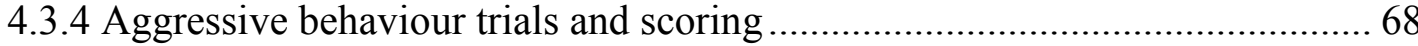

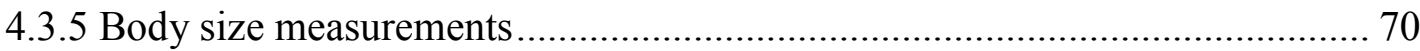

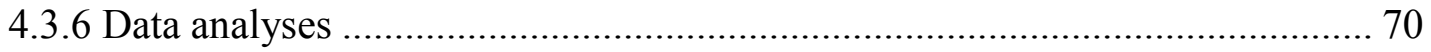

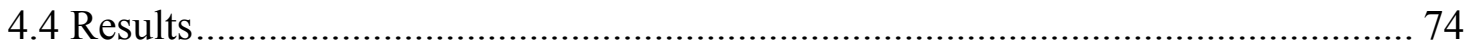

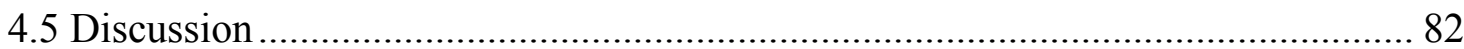

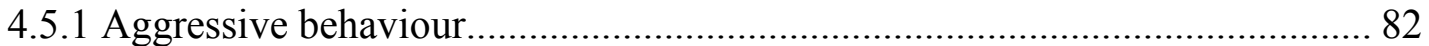

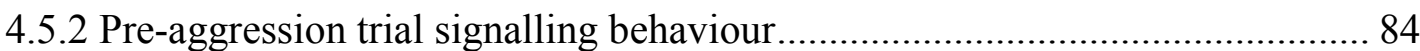

4.5.3 Changes in signalling behaviour following aggression trial........................ 87

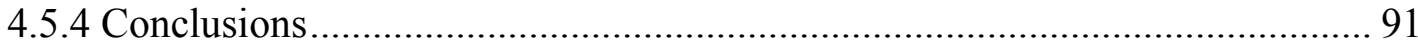

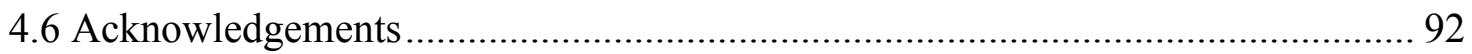

Chapter 5: The influence of dietary nutrient balance on female life-history traits

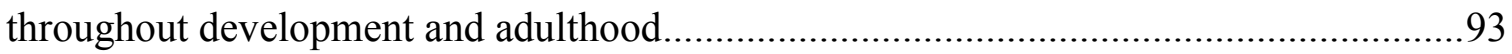

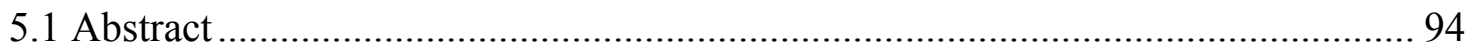


5.2 Introduction

5.3 Methods 103

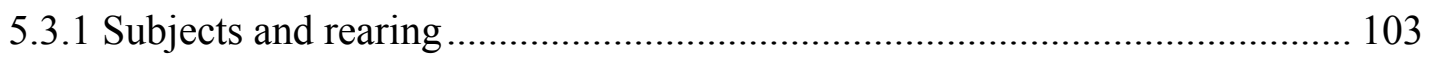

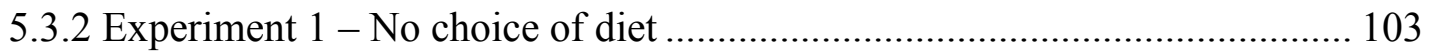

5.3.3 Experiment 2 - Diet choice ............................................................ 110

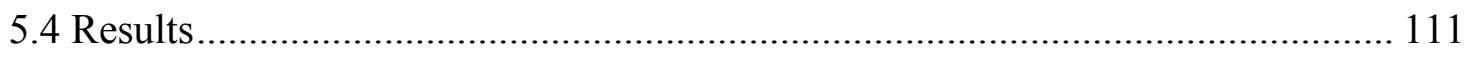

5.4.1 Experiment 1 - No choice of diet ..................................................... 111

5.4.2 Experiment 2 - Diet choice............................................................... 121

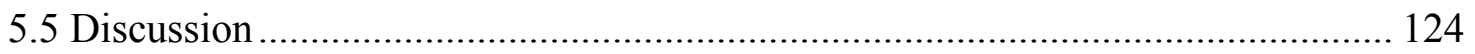

5.5.1 Juvenile growth, development, and survival.......................................... 125

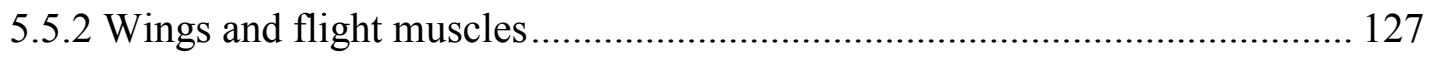

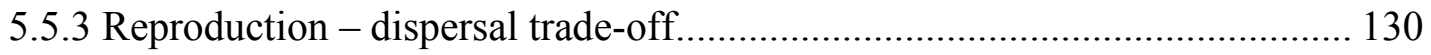

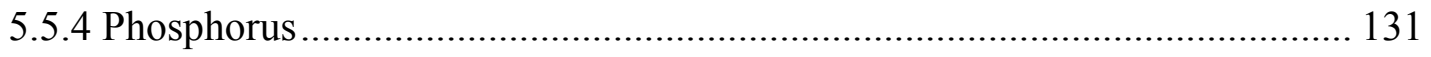

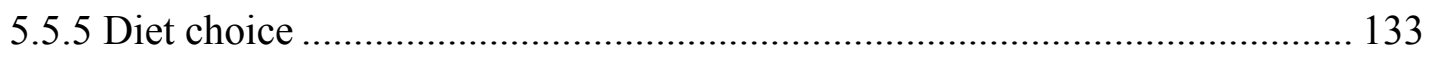

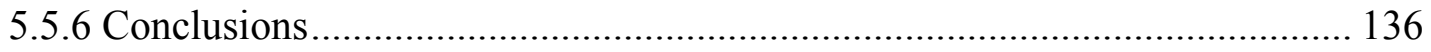

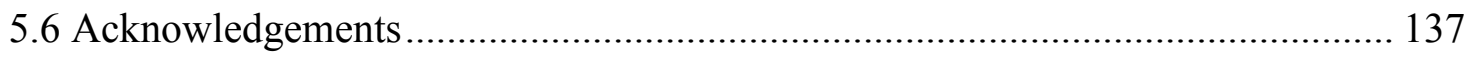

Chapter 6: The influence of dietary nutrient balance on female sexual responsiveness and

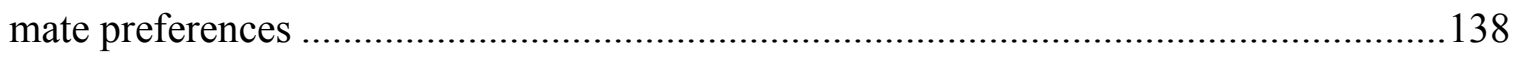

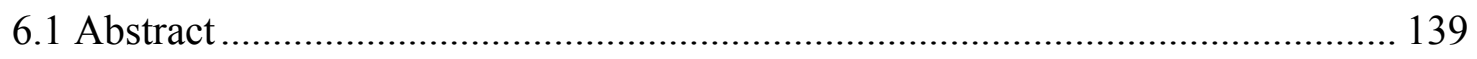


6.2 Introduction

6.3 Methods. 146

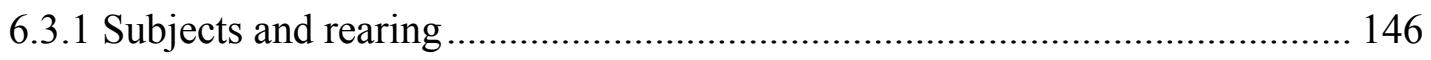

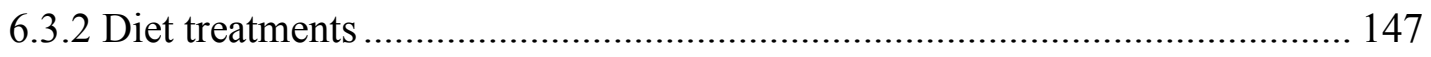

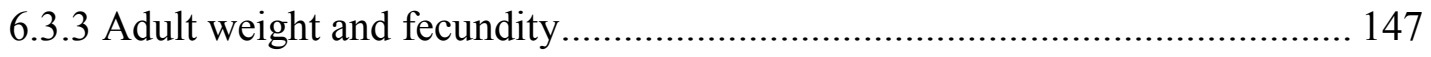

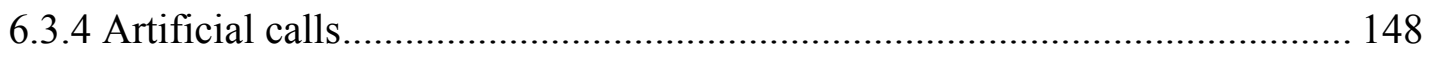

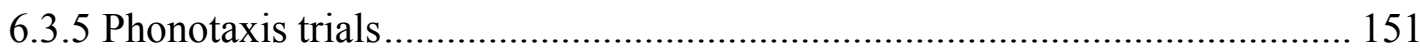

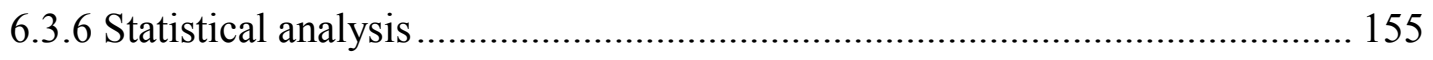

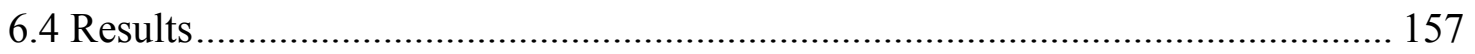

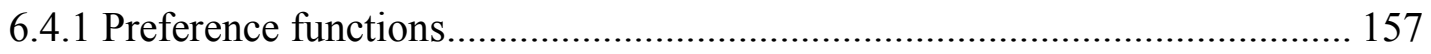

6.4.2 Preference function traits ................................................................... 160

6.4.3 Preference function shape ...................................................................... 163

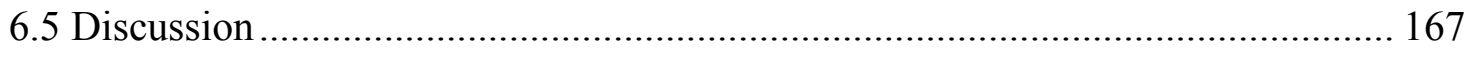

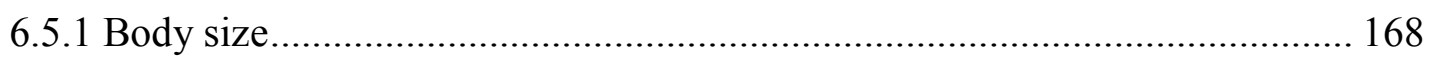

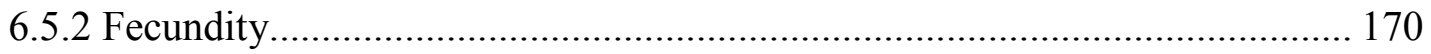

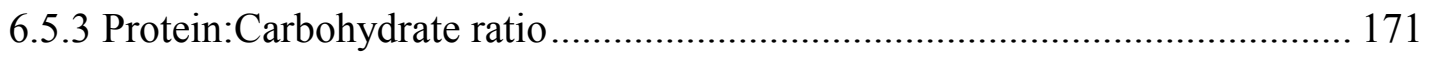

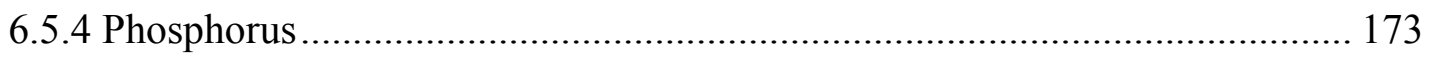

6.5.5 Order of artificial call presentation ................................................... 175 


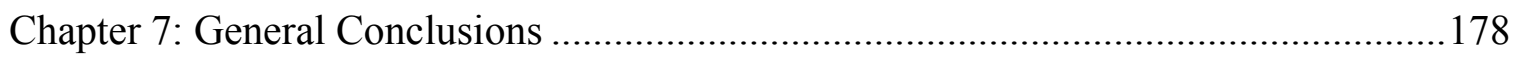

7.1 The influence of dietary protein to carbohydrate ratio on life-history traits........ 179

7.2 The influence of dietary phosphorus on life-history traits .............................. 180

7.3 Nutritional requirements change across development and contexts ................... 181

7.4 Nutrient intake regulation changes with sex and developmental stage .............. 183

7.5 Influence of nutrition on sexual selection ................................................... 184

7.6 Study limitations, criticisms, and future directions ..................................... 187

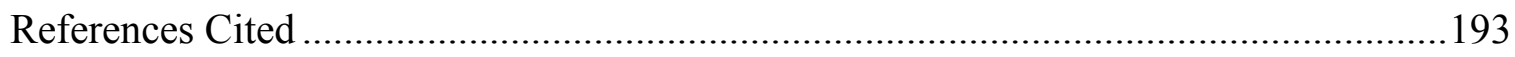

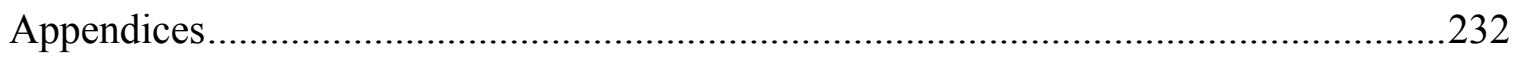

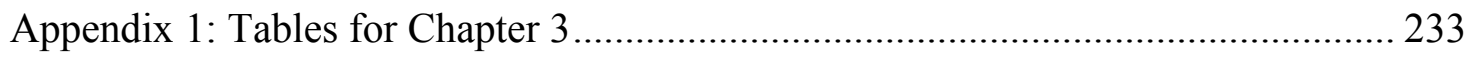

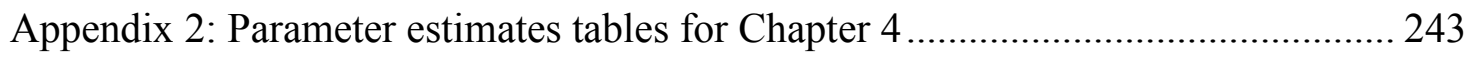

Appendix 3: Parameter estimates tables for Chapter 5 ....................................... 247

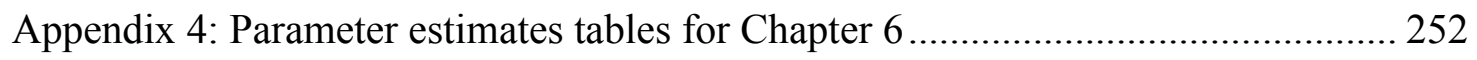




\section{List of Tables}

Table 3.1. Composition of foods used in Experiment 1. All values are calculated as a percentage of total mass unless otherwise stated.................................26

Table 3.2. Composition of foods used in Experiment 2. All values are calculated as a percentage of total mass unless otherwise stated.................................... 31

Table 3.3. Composition of foods used in Experiment 3. All values are calculated as a percentage of total mass unless otherwise stated....................................

Table 4.1. Rotated factor loadings for individual signalling parameters measured prior to aggression trials (signalling factors 1-3), and changes in signalling parameters following aggression trials (signalling change factors 1-3). Bolded loadings indicate the factor on which each signalling parameter loaded most heavily. Signs (+/-) on loadings indicate that higher levels of a factor are either (i) positively/negatively associated with a signalling parameter prior to aggression trials (signalling factors), or (ii) associated with an increase/decrease in a signalling parameter following aggression trials (signalling

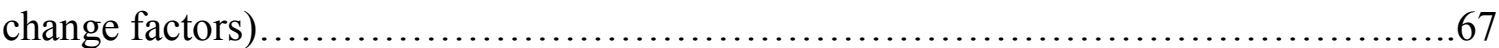


Table 4.2. Model effects tests for the linear mixed model examining factors influencing aggression (aggPC1). FDR $\mathrm{B}_{\mathrm{Y}}$ corrected level of significance is $P=0.024$. Significant terms are bolded. Parameter estimates for this model can be found in Appendix 2, Table A2. 1 .76

Table 4.3. Model effects tests for linear mixed models examining factors influencing prefight signalling (signalling factors $1-3$ ). FDR $_{\mathrm{B}-\mathrm{Y}}$ corrected level of significance is $P=$ 0.022. Significant terms are bolded. Parameter estimates for these models can be found in

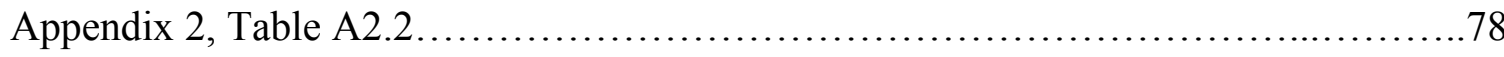

Table 4.4. Repeatability estimates for the signalling parameters of 219 males measured before and after their aggressive behaviour trial (i.e. $\mathrm{k}=2$ measurements per individual). ICC $=$ intraclass correlation coefficient, $\mathrm{CI}=$ confidence interval.

Table 4.5. Model effects tests for linear mixed models examining factors influencing signalling change following aggressive behaviour trials (signalling change factors 1-3). FDR $_{\mathrm{B}-\mathrm{Y}}$ corrected level of significance is $P=0.022$ for signalling change factors $1 \& 2$, and $P=0.020$ for signalling change factor 3. Significant terms are bolded. Parameter estimates for these models can be found in Appendix 2, Table A2.3 $\ldots \ldots \ldots \ldots \ldots \ldots \ldots . \ldots 0$ 
Table 5.1. Dietary protein to carbohydrate ratio and phosphorus concentration of artificial diets

Table 5.2. Effects tests for the models examining factors influencing juvenile and adult female life-history traits. Significant model effects and parameters are bolded. The FDR $\mathrm{B}_{-}$ y corrected level of significance is $P=0.018$ for the wing-muscle morph model, $P=$ 0.015 for the egg model, and $P=0.019$ for all remaining models. Parameter estimates for these models are located in Appendix 3, Table A3.1

Table 5.3. Effects tests for the models examining factors influencing the amount of food juvenile females ate when given pairs of diets differing in either protein:carbohydrate ratio (diet $\mathrm{B} ; 3_{\mathrm{P}}: 1_{\mathrm{C}}, 1.45 \% \mathrm{pH}_{\mathrm{PH}}$ and $\operatorname{diet} \mathrm{F} ; 1_{\mathrm{P}}: 3_{\mathrm{C}}, 1.45 \% \mathrm{opH}_{\mathrm{PH}}$ ) or phosphorus level (diet $\mathrm{C}$; $1_{\mathrm{P}}: 1_{\mathrm{C}}, 0.45 \% \mathrm{PH}$ and diet $\left.\mathrm{D} ; 1_{\mathrm{P}}: 1_{\mathrm{C}}, 1.45 \% \mathrm{PH}\right)$. Significant model effects and parameters are bolded. The $\mathrm{FDR}_{\mathrm{B}-\mathrm{Y}}$ corrected level of significance is $P=0.027$. Parameter estimates for these models are located in Appendix 3, Table A3.2 .............................. 122

Table 6.1. Mean and standard deviation (SD) values for mate attraction signal parameters of the sample population used in creating artificial calls 150 
Table 6.2. Effects tests for the models examining factors influencing female preference function traits. Significant model effects and parameters are bolded. The FDR $\mathrm{B}_{\mathrm{Y}}$ corrected level of significance is $P=0.017$. Parameter estimates for these models are located in Appendix 4, Table A4.1..........................................161

Table 6.3. Effects tests for the models examining factors influencing preference function shape across chirp rate and carrier frequency call treatments. Significant model effects and parameters are bolded. The FDR $\mathrm{B}_{\mathrm{Y}}$ corrected level of significance is $P=0.015$. Parameter estimates for these models are located in Appendix 4, Table A4.2......... 165 


\section{List of Figures}

Figure 2.1. Example of a waveform of a male G. veletis long-distance acoustic mate attraction signal showing a subset of the parameters measured by the EARS II software. Pulse duration (PD), inter-pulse duration (IPD), chirp duration (CD), inter-chirp duration (ICD), pulses per chirp (PPC), and amplitude ................................... 16

Figure 3.1. Response surfaces illustrating the effects of dietary protein and carbohydrate intake on fitness traits in male and female G. veletis. Dotted lines represent nutritional rails defined by the five protein:carbohydrate ratios available in experimental foods, and the colour scale depicts the magnitude of the dependent response variable

Figure 3.2. Fine-scale temporal signalling response surfaces illustrating the effects of dietary protein and carbohydrate on fitness traits in male G. veletis. Dashed lines represent nutritional rails defined by the five protein:carbohydrate ratios available in diets, and the colour scale depicts the magnitude of the dependent response variable.....36

Figure 3.3. Mean ( \pm SE) cumulative intakes across the first 21 days of adulthood for A) phosphorus relative to protein and carbohydrate $(\mathrm{P}+\mathrm{C})$, and $\mathrm{B})$ protein relative to carbohydrate. Black dotted lines represent nutritional rails defined by A) the three phosphorus levels, and B) the five different protein:carbohydrate ratios available in

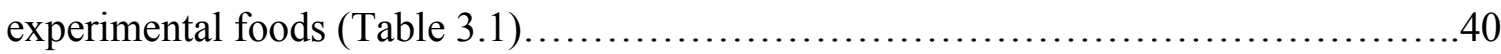


Figure 3.4. Mean $( \pm \mathrm{SE})$ total food consumption within each of the treatment pairs for $\mathrm{A})$ females and B) males for foods differing in phosphorus content (Experiment 2). Light grey bars represent the control, medium gray bars the foods lower in phosphorus, and black bars the foods higher in phosphorus.

Figure 3.5. Cumulative intakes over 72 -h intervals for A-C) phosphorus relative to protein + carbohydrate $(\mathrm{P}+\mathrm{C})$ intake in Experiment 2, and $\mathrm{D}-\mathrm{G})$ protein relative to carbohydrate intake in males (blue) and females (red). Black dotted lines indicate the intake ratio expected if crickets were eating foods indiscriminately. Black dashed, black solid, and grey solid lines indicate the intake ratios in Experiment 1 that maximized male lifespan and signalling, female lifespan, and female egg production, respectively 43

Figure 3.6. Mean $( \pm \mathrm{SE})$ total food consumption within each of the treatment pairs for $\mathrm{A}$ ) females and B) males for foods differing in protein:carbohydrate ratio (Experiment 3). Light grey bars represent the control, medium gray bars the pure protein foods, and black bars the pure carbohydrate foods. 45

Figure 4.1. Marginal effects plots with 95\% confidence intervals showing how dietary phosphorus, body size (sizePC1), and aggression (aggPC1) influence pre-fight signalling: A) males consuming low-phosphorus $(0.45 \% \mathrm{PH})$ diets have higher predicted signalling 
factor 1 scores (shorter inter-pulse and inter-chirp durations; higher pulse and chirp rates) compared to males consuming high-phosphorus (1.45\% higher predicted signalling factor 2 scores (longer time spent signalling; greater pulses per chirp, chirp durations and amplitudes); C) larger and D) more aggressive males had lower predicted signalling factor 3 scores (longer pulse durations; lower carrier

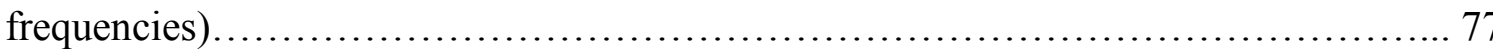

Figure 4.2. Marginal effects plots with $95 \%$ confidence intervals showing how dietary protein:carbohydrate ratio, and an interaction between aggression (aggPC1) and phosphorus level, influence changes in signalling following aggression trials: A) males consuming high-carbohydrate $\left(1_{\mathrm{p}}: 3_{\mathrm{C}}\right)$ diets had higher predicted signalling change factor 2 scores (increased time spent signalling and pulse rate; decreased inter-pulse duration) compared to males consuming high-protein $\left(3_{\mathrm{P}}: 1_{\mathrm{C}}\right)$ and equal protein:carbohydrate $\left(1_{\mathrm{P}}: 1_{\mathrm{C}}\right)$ diets; $\left.\mathrm{B}\right)$ Males consuming high-carbohydrate $\left(1_{\mathrm{P}}: 3_{\mathrm{C}}\right)$ and equal protein:carbohydrate $\left(1_{\mathrm{P}}: 1_{\mathrm{C}}\right)$ diets had higher predicted signalling change factor 3 scores (increased pulse duration, pulses per chirp and chirp duration) compared to males consuming high-protein $\left(3_{\mathrm{P}}: 1_{\mathrm{C}}\right)$ diets; $\left.\mathrm{C}\right)$ predicted signalling change factor 3 scores increase (increased pulse duration, pulses per chirp and chirp duration) with aggressiveness when males consume low-phosphorus $(0.45 \% \mathrm{pH})$ diets, but decrease with aggressiveness when males consume high-phosphorus $(1.45 \% \mathrm{pH})$ diets.................81 
Figure 5.1. Marginal effects plots with $95 \%$ confidence intervals showing how fitted values of A) probability of survival to adulthood, B) development time, and C) adult eclosion weight were influenced by dietary protein:carbohydrate ratio.

Figure 5.2. Marginal effects plots with $95 \%$ confidence intervals showing how fitted values of A-B) probability of having deformed forewings at adulthood, and C) probability of having long hindwings at adulthood were influenced by diet and/or initial weight. ....

Figure 5.3. Marginal effects plots with $95 \%$ confidence intervals showing how fitted values of number of eggs in ovaries was influenced by $A)$ wing-muscle morph $\left(\mathrm{SW}_{\mathrm{W}}-\right.$ short hindwing with white muscle; $\mathrm{LW}_{\mathrm{W}}$ - long hindwing with white muscle; $\mathrm{LW}_{\mathrm{P}}-$ long hindwing with pink muscle; $\mathrm{LW}_{\mathrm{Y}}$ - long hindwing with yellow muscle), and B) dietary protein:carbohydrate ratio 120

Figure 5.4. Marginal effects plots with $95 \%$ confidence intervals showing how fitted values of amount of high-protein (diet $\mathrm{B} ; 3_{\mathrm{P}}: 1_{\mathrm{C}}, 1.45 \% \mathrm{PH}$ ) or high-carbohydrate (diet F; $\left.1_{\mathrm{P}}: 3_{\mathrm{C}}, 1.45 \% \mathrm{PH}\right)$ diet eaten changes with initial body weight.

Figure 6.1. Average preference functions (solid lines) with standard error bands for females within each diet treatment (protein:carbohydrate ratio (A \& B) and phosphorus 
level (C \& D)) and call treatment (chirp rate (A \& C) and carrier frequency (B \& D)),

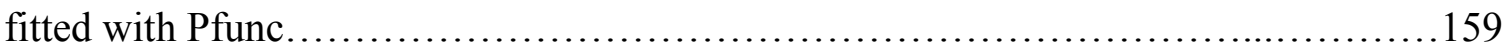

Figure 6.2. Marginal effects plots with 95\% confidence intervals showing how A-B) adult eclosion weight and protein:carbohydrate ratio influence responsiveness, and C) residual eggs influence tolerance............................................ 162

Figure 6.3. Marginal effects plots with $95 \%$ confidence intervals showing how preference in the chirp rate call treatment was influenced by A) an interaction between standard deviation of the artificial call and adult eclosion weight (grey line - large females, black line - small females), and how preference in the carrier frequency call treatment was influenced by B) standard deviation of the artificial call, and C) dietary protein:carbohydrate ratio................................................ 166 


\section{List of Appendices}

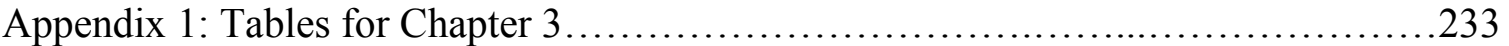

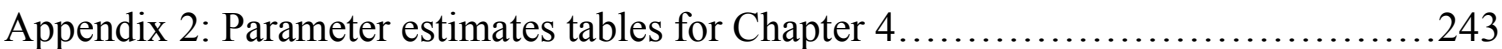

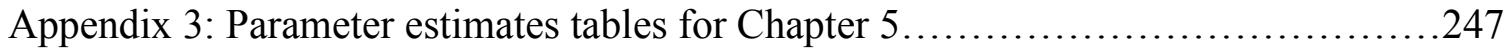

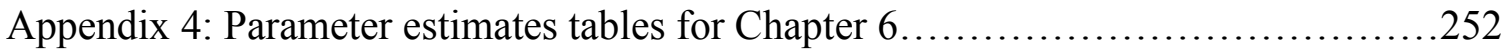




\section{Chapter 1}

\section{General Introduction}




\subsection{Why nutrition matters}

One of the most important environmental challenges faced by animals is finding quality nutritional resources in sufficient quantities. This is evidenced by large differences between the stoichiometric composition of consumers and their food sources, which suggests that animals often struggle to meet their nutritional needs (Elser et al., 2000; Mattson, 1980; Woods, Fagan, Elser, \& Harrison, 2004). This has important consequences for life history and fitness, as the nutrients acquired by individuals collectively constitute a pool of resources that can be allocated to support the expression of various phenotypic traits (Rowe \& Houle, 1996). The quality and quantity of this resource pool influences somatic state, a primary determinant of an individual's body condition (Hill, 2011; Rowe \& Houle, 1996). When food supplies are inadequate, a priority allocation of nutrients to support some fitness traits may negatively affect the expression of others that compete for the same nutrients (Rowe \& Houle, 1996; Tomkins, Radwan, Kotiaho, \& Tregenza, 2004), potentially resulting in life-history trade-offs. Furthermore, nutritional needs are likely to differ between the sexes due to their contrasting reproductive strategies (Kodric-Brown \& Brown, 1987; Morehouse, Nakazawa, Booher, Jeyasingh, \& Hall, 2010; Wheeler, 1996), and are likely to change over an individual's life due to the differing nutritional demands of each ontogenetic stage of development. Therefore, the ability of animals to obtain adequate nutritional resources is likely to be an important proximate cause of variation in individual fitness within populations, through their influence on life-history traits such as growth, survival, 
gamete production, and costly behavioural traits related to inter- and intra-sexual selection.

\subsection{Nutrition and life history}

Extensive research in nutritional ecology has revealed that both diet quality and quantity strongly influence fitness-related life-history traits in a variety of vertebrate and invertebrate taxa. Such studies have found, for example, that consuming a diet with low overall nutrient levels is associated with slower juvenile growth rates and smaller adult body sizes (e.g. Searcy, Peters, \& Nowicki, 2004; Whattam \& Bertram, 2011), and reduced female egg production (e.g. Chippindale, Leroi, Kim, \& Rose, 1993; Magwere, Chapman, \& Partridge, 2004; Wilder \& Rypstra, 2008). High-protein diets are also positively associated with faster juvenile growth rates and larger adult body size (e.g. Hunt et al., 2004; Kpundeh, Qiang, He, Yang, \& Xu, 2015; Shariatmadari \& Forbes, 1993; Venesky et al., 2012), better immune function (e.g. Kiron et al., 1995; Venesky et al., 2012), and increased female egg production (e.g. Carey, 1998; Joern \& Behmer, 1997), whereas high-carbohydrate diets are typically associated with longer lifespans (e.g. Joern \& Behmer, 1997; Lee et al., 2008; Maklakov et al., 2008). Similarly, higher dietary phosphorus results in higher growth rates (e.g. Perkins, Woods, Harrison, \& Elser, 2004; Urabe \& Sterner, 2001; Visanuvimol \& Bertram, 2011) and greater female egg production (e.g. Urabe \& Sterner, 2001; Visanuvimol \& Bertram, 2010). Collectively, these studies demonstrate that diet may explain variation in life-history traits, but the 
similarity of findings across different nutrients in these studies suggests that our understanding of this topic is far from complete.

\subsection{Nutrition and sexual selection}

Nutrition may also be an important influence on male and female life-history traits and behaviours that are involved in inter- and intra-sexual selection. In many sexually reproducing species, the quality of male advertisement signals and the ability to dominate in agonistic contests between rivals are important aspects of male fitness (Andersson, 1994). Dominant males may increase their mating success by guarding females and driving away competitors (e.g. LeBoeuf, 1974; Schuett, 1997), and females may actively choose to mate with dominant males (e.g. Alatalo, Lundberg, \& Glynn, 1986; Candolin, 1999a; Kortet \& Hedrick, 2005). Similarly, male chemical, ornamental, and acoustic advertisement signals may act to deter rival males from entering their mating territories, or may be used by females to select mates (e.g. Alexander, 1961; Hoi \& Griggio, 2008; Martín \& López, 2015). Indicator models of sexual selection predict that these elaborate male sexual traits should honestly reflect male condition, where only high-condition individuals should be able to bear the high costs associated with their expression (Berglund, Bisazza, \& Pilastro, 1996; Grafen, 1990; Kodric-Brown \& Brown, 1984; Maynard Smith, 1985; Pomiankowski, 1987a; Zahavi, 1975, 1977). Thus, females may be able to use male secondary sexual traits as honest indicators of a male's condition or nutritional status, which may convey information about potential direct (e.g. nutritional resources) or indirect (e.g. good genes for acquiring or assimilating nutritional resources) 
mating benefits (Andersson, 1994; Kirkpatrick \& Ryan, 1991; Reynolds \& Gross, 1990). However, individual females can vary considerably in their mate preferences, and this variability may also be explained by variation in female condition (Jennions \& Petrie, 1997; Pomiankowski, 1987b; Widemo \& Sæther, 1999). This condition dependence may arise due to the high costs, in terms of time and energy expenditure, and increased risks of predation and parasitism, associated with searching for and assessing potential mates (Jennions \& Petrie, 1997; Pomiankowski, 1987b; Widemo \& Sæther, 1999). Thus, similar to indicator model predictions for males, the strength of female mating preferences is expected to reflect the cost-to-benefit ratio associated with being choosy, where high-condition females are better able to afford the costs, or benefit the most, from the expression of stronger mate preferences (Cotton, Small, \& Pomiankowski, 2006; Pomiankowski, 1987b).

In support of indicator model predictions, higher overall nutrient availability is often correlated with more elaborate ornaments or higher-effort sexual signals in males (e.g. David et al., 1998; Frischknecht, 1993; Hill, 2000; Holzer, Jacot, \& Brinkhof, 2003; McGraw, Mackillop, Dale, \& Hauber, 2002; Scheuber, Jacot, \& Brinkhof, 2003; Wagner \& Hoback, 1999). Similarly, individual nutrients, such as vitamins (e.g. Kopena, Martín, López, \& Herczeg, 2011), carotenoids (e.g. Karino \& Haijima, 2004), phosphorus (e.g. Bertram, Schade, \& Elser, 2006; Bertram, Whattam, Visanuvimol, Bennett, \& Lauzon, 2009), proteins (e.g. Ferkin, Sorokin, Johnston, \& Lee, 1997; Hunt et al., 2004) and carbohydrates (e.g. Maklakov et al., 2008; South, House, Moore, Simpson, \& Hunt, 2011), have all been implicated in driving variation in the chemical, ornamental, and 
acoustic advertisement signals of males. Compared to male sexual signalling, the influence of nutrition on male intra-sexual competitive abilities has received far less attention, and what little work that has been done has shown no influence of diet on male dominance status (e.g. Han \& Dingemanse, 2017; South et al., 2011). However, various aspects of diet quality and quantity are known to influence individual aggression levels in non-sexual contexts (e.g. Adamo \& Hoy, 1995; Andersson \& Åhlund, 1991; DeMar et al., 2006; DeNapoli, Dodman, Shuster, Rand, \& Gross, 2000; Kaplan, Manuck, \& Shively, 1991; Lemel \& Wallin, 1993; Thurmond, Lasley, Conkin, \& Brown, 1977). Finally, female mate choice is also influenced by diet. Females experiencing food stress are typically less likely to search for mates or copulate (e.g. Clark, DeBano, \& Moore, 1997; Eraly, Hendrickx, \& Lens, 2009; Hunt, Brooks, \& Jennions, 2005; Ortigosa \& Rowe, 2002; Syriatowicz \& Brooks, 2004; Toomey \& McGraw, 2012; Wilgers \& Hebets, 2012; Woodgate, Bennett, Leitner, Catchpole, \& Buchanan, 2010) and often show weakened preferences for male phenotypes (e.g. Brown, 1997; Hebets, Wesson, \& Shamble, 2008; Hingle, Fowler, \& Pomiankowski, 2001b; Hunt et al., 2005; Lerch, RatFischer, Gratier, \& Nagle, 2011). Together these findings suggest that the availability of nutritional resources in the diet may exert strong influences on both male sexual signals and female preferences for such signals.

\subsection{A more nutritionally explicit framework for studying nutrition}

The classical approach used to study the influence of nutrition on the life history and fitness of organisms assumes a priori that either (i) the intake of a single dietary 
component (e.g. energy, carbohydrates, proteins, phosphorus) or (ii) total intake of a uniform food source is of primary importance to understanding the complexities of organism-nutrition interactions. However, this approach ignores the complex chemical nature of foods, and thereby fails to identify which particular combinations (or ratios) of nutrients enhance fitness. Additionally, while the main effects of a single nutrient on lifehistory traits are commonly examined, the interactive effects of different nutrients in the diet are often ignored. Foods have fixed nutrient compositions resulting in interactions among different nutrients, where the costs or benefits of consuming some nutrients may be dependent on the levels of other nutrients in the diet (Raubenheimer \& Simpson, 1993; Simpson \& Raubenheimer, 2012). Both over- and under-ingestion of nutrients from eating imbalanced foods (i.e. diets that do not contain the optimal ratio of nutrients) can result in fitness costs, including reduced reproductive output, obesity, malnutrition and toxicity (Raubenheimer \& Simpson, 2006). Thus, many traditional studies suffer from a lack of nutritional explicitness necessary to fully comprehend the influence of nutrition on life-history traits.

Two recently developed nutritionally-explicit paradigms in nutritional ecology, Ecological Stoichiometry and Nutritional Geometry, have made appreciable contributions to our understanding of the multidimensional interactions between nutrition, life-history traits, and individual fitness (e.g. Bertram et al., 2006; Elser et al., 2000; Lee et al., 2008; Maklakov et al., 2008; Schade, Kyle, Hobbie, Fagan, \& Elser, 2003; South et al., 2011). Central to both frameworks is the idea that, when studying dietary influences on organismal traits, foods should be explicitly characterized by the ratio of nutrients they 
contain (Raubenheimer \& Simpson, 1997; Sterner \& Elser, 2002). However, the two frameworks differ in that nutritional geometry has identified energy-rich macronutrients (proteins, lipids, and carbohydrates) as central to individual fitness, whereas ecological stoichiometry has identified the elements carbon, nitrogen and phosphorus as pivotal to explaining nutritional-related biological variation. These two perspectives partially converge, as nitrogen represents an elemental proxy for amino acids and carbon a proxy for lipids and carbohydrates (Sterner \& Elser, 2002). However, the importance of dietary phosphorus, an important constituent in many biomolecules (e.g. phospholipids, RNA, DNA, ATP), relative to energetic macromolecules has not yet been established.

\subsection{Thesis rationale and objectives}

The aforementioned studies indicate that fitness and life-history traits, such as lifespan, growth, egg production and acoustic mate signalling in invertebrates, are likely to be dependent on the availability of nutritional resources in the environment, particularly with respect to the availability of dietary phosphorus, carbohydrate and protein (Bertram et al., 2009; Holzer et al., 2003; Hunt et al., 2004; Joern \& Behmer, 1997; Maklakov et al., 2008; Visanuvimol \& Bertram, 2010). Furthermore, there is evidence to suggest that in insects, diet quality and quantity may influence male behaviours important in aggressive contests with rivals (e.g. Adamo \& Hoy, 1995; Lemel \& Wallin, 1993) as well as female mate choice decisions, including responsiveness to mates (e.g. Clark et al., 1997; Eraly et al., 2009; Hunt et al., 2005; Ortigosa \& Rowe, 2002; Wilgers \& Hebets, 
2012) and preferences for certain mate phenotypes (e.g. Brown 1997; Hingle et al. 2001; Hebets et al. 2008; Hunt et al. 2005).

Unfortunately, most of these studies have focused on diet manipulations involving only a single nutrient or total diet quantity, ignoring the interactive effects of multiple dietary nutrients on individual fitness. To better understand the role of diet in generating and maintaining intra-population variation in condition-dependent traits, one needs to experimentally investigate both the main and interactive effects of important nutrients in individual diets on such traits. The handful of studies that have incorporated the nutritionally explicit geometric framework have primarily focused on examining the response of fitness traits to protein to carbohydrate (macronutrient) ratios (Chambers, Simpson, \& Raubenheimer, 1995; Lee et al., 2008; Maklakov et al., 2008; Raubenheimer \& Simpson, 1993; Simpson \& Abisgold, 1985; South et al., 2011). Despite the apparent importance of phosphorus to various fitness traits in invertebrates (Bertram et al., 2009; Perkins et al., 2004; Schade et al., 2003; Urabe \& Sterner, 2001; Visanuvimol \& Bertram, 2010, 2011), no study to date has considered the importance of this essential element relative to the ratio of macronutrients in the diet.

For my Doctoral thesis research, I experimentally manipulated the nutrient composition of diets (see Chapter 2, section 2.3 for details of diet preparation) to investigate the potential influence of dietary nutrient balance between carbohydrates, protein, and phosphorus on life-history traits and sexual selection in the field cricket, Gryllus veletis. To do so, I addressed the following interrelated questions: 
1. How does dietary nutrient balance influence adult cricket life-history traits, such as lifespan, weight gain, and proxies of reproductive success (i.e. male sexual signalling and female egg production), and is the influence of diet on these traits sex-specific? (Chapter 3)

2. When given a choice between multiple diets containing varying dietary nutrient ratios, do crickets eat randomly or do they regulate their intake of specific nutrients, and does diet choice differ between the sexes or across stages of development? (Chapters $3 \& 5$ )

3. How does dietary nutrient balance influence male cricket behavioural traits that are important in intra-sexual selection, such as acoustic mate attraction signalling and aggressive behaviour? (Chapters $3 \& 4$ )

4. How does dietary nutrient balance influence juvenile female growth and development, survival to adulthood, adult morphology, and egg production (Chapter 5)

5. How does dietary nutrient balance influence female reproductive behaviours that are important in inter-sexual selection, such as sexual responsiveness and preferences for male mate attraction signals? (Chapter 6) 
Chapter 2

General Methods 
The methodology described below is common to the research described in Chapters 3-6.

\subsection{Choice of model organism}

I used the local Northern spring field cricket, Gryllus veletis, as my study species. Gryllus veletis is a burrow-inhabiting species that is widely distributed across north-eastern North America (Alexander \& Bigelow, 1960). This species is univoltine in the wild; adults are active from May to late July and late instar juveniles overwinter and become sexually mature in the spring (Alexander \& Bigelow, 1960; Alexander \& Meral, 1967; Harrison, 1979). They are easily reared under laboratory conditions since eggs do not require a diapause period in order to develop. As with all field crickets, G. veletis is a generalist omnivore, feeding on plants, fungi, and insects (Carmona, Menalled, \& Landis, 1999; Criddle, 1925; Gangwere, 1961), all of which have varying ratios of protein, carbohydrates and phosphorus in their tissues (Elser et al., 2000; Woods et al., 2004). Crickets are therefore ideal model organisms to use in studies involving manipulations of dietary protein, carbohydrate and phosphorus balance because artificial diets are likely to be ecologically relevant by mimicking the variety of nutrient balances that crickets may encounter in natural food sources. Furthermore, field crickets have complex reproductive behaviours: males compete with rivals in agonistic contests for access to prime mating territories, from which they acoustically signal to attract mates by rubbing their forewings together, and females exhibit phonotaxis towards male signals that they find attractive (Alexander, 1961). This complexity in cricket mating systems provides an opportunity to study the interactions between diet and reproductive behaviours in an effort to more fully understand the influence of diet on sexual selection processes. 


\subsection{Cricket colony and rearing conditions}

I established a laboratory population of $G$. veletis field crickets from approximately 100 wild adults hand-captured at two locations near Ottawa, Ontario, Canada $\left(45^{\circ} 15^{\prime} 53^{\prime \prime} \mathrm{N}\right.$, $76^{\circ} 08^{\prime} 43^{\prime \prime} \mathrm{W}$ and $45^{\circ} 24^{\prime} 33^{\prime \prime} \mathrm{N}, 75^{\circ} 32^{\prime} 51^{\prime \prime} \mathrm{W}$, respectively) in June 2010 . The colony has since been supplemented annually with $\sim 30$ wild-caught individuals to prevent domestication and maintain genetic diversity. I housed the colony in communal plastic bins (68-litre; $49 \mathrm{~cm}$ length x $35 \mathrm{~cm}$ width x $40 \mathrm{~cm}$ height) with screened lids, cardboard egg carton shelters, and ad libitum water and food (Harlan Teklad Rodent diet 8604, Madison, WI, U.S.A.; $24.3 \%$ protein, $40.2 \%$ carbohydrate, $1.1 \%$ phosphorus, $12.4 \%$ fibre). Adult colony bins also contained moist sand for oviposition, which was renewed every 14 days. The colony was kept within a greenhouse at Carleton University on a $14 \mathrm{~h}$ $\mathrm{L}: 10 \mathrm{~h} \mathrm{D}$ illumination regime at $28 \pm 2{ }^{\circ} \mathrm{C}$.

\subsection{Experimental diets}

Experimental diets for the research described in Chapters 3-6 were created following established protocols (Simpson \& Abisgold, 1985). All experimental diets were created using powdered and liquid ingredients. The protein source consisted of a 3:1:1 mixture of vitamin-free casein, bacteriological peptone, and egg albumen, whereas carbohydrates consisted of a 1:1 mixture of powdered sucrose and dextrin. The source of phosphorus was primarily dibasic calcium phosphate $\left(\mathrm{CaHPO}_{4}\right)$, with a small proportion originating from casein $(0.8 \%)$ and albumen $(0.12 \%)$ protein sources. Calcium carbonate $\left(\mathrm{CaCO}_{3}\right)$ was used to balance calcium levels $(2.36 \%$ - Chapter $3 ; 0.85 \%$ - Chapters 4 -6) across 
diets. All diets contained 0.053\% vitamin mix (Harlan Teklad TD.10963; carbohydrate and choline chloride deficient), $0.127 \%$ choline chloride, $1.4 \%$ mineral mix (Harlan Teklad TD.10964; phosphorus and calcium deficient), $0.55 \%$ cholesterol, $0.55 \%$ linoleic acid, and $0.275 \%$ ascorbic acid.

\subsection{Electronic acoustic recording system (EARS II)}

The long-distance acoustic mate attraction signals of male $G$. veletis were recorded in Chapters 3, 4, and 6. This was accomplished with the use of a custom-made Electronic Acoustic Recording System (EARS II; Cambridge Electronic Design, Cambridge, UK), comprised of Styrofoam boxes (for housing individual male crickets) lined with acoustically-isolating foam and containing a suspended microphone and a LED light bulb on a $14 \mathrm{~h} \mathrm{~L}: 10 \mathrm{~h}$ D illumination regime. The EARS II system enabled the simultaneous recording of up to 96 males (see Whattam \& Bertram, 2011 for further details). The EARS II CricketSong software (Cambridge Electronic Design, Cambridge, UK) filters out background noise and records the following 10 mean daily signalling parameters (depicted in Figure 2.1):

- Pulse Duration (PD) - mean duration (ms) of a pulse of sound, created by engaging signalling structures on the wings during a closing wing stroke.

- Inter-Pulse Duration (IPD) - mean duration (ms) of the quiet period in between consecutive pulses within a chirp, created by unengaging signalling structures on the wings during an opening wing stroke. 
- Chirp Duration (CD) - mean duration (ms) of a series of pulses that have been concatenated into a chirp.

- Inter-Chirp Duration (ICD) - mean duration (ms) of the quiet period in between consecutive chirps.

- Pulses per Chirp (PPC) - mean number of pulses within a chirp.

- Amplitude (Figure 2.1) - mean sound pressure level (loudness) of an acoustic signal, measured in Pascals $(\mathrm{Pa})$ and converted to decibels $(\mathrm{dB})$

- Carrier Frequency (not shown) - mean pitch (Hz) of an acoustic signal, controlled by the mechanical resonance of the harp structure on the forewings.

- Pulse Rate - mean number of pulses per second within a chirp (\# pulses/s).

- Chirp Rate - mean number of chirps per minute (\# chirps/min).

- Time Spent Signalling (not shown) - mean time (min) spent producing longdistance acoustic mate attraction signals. 


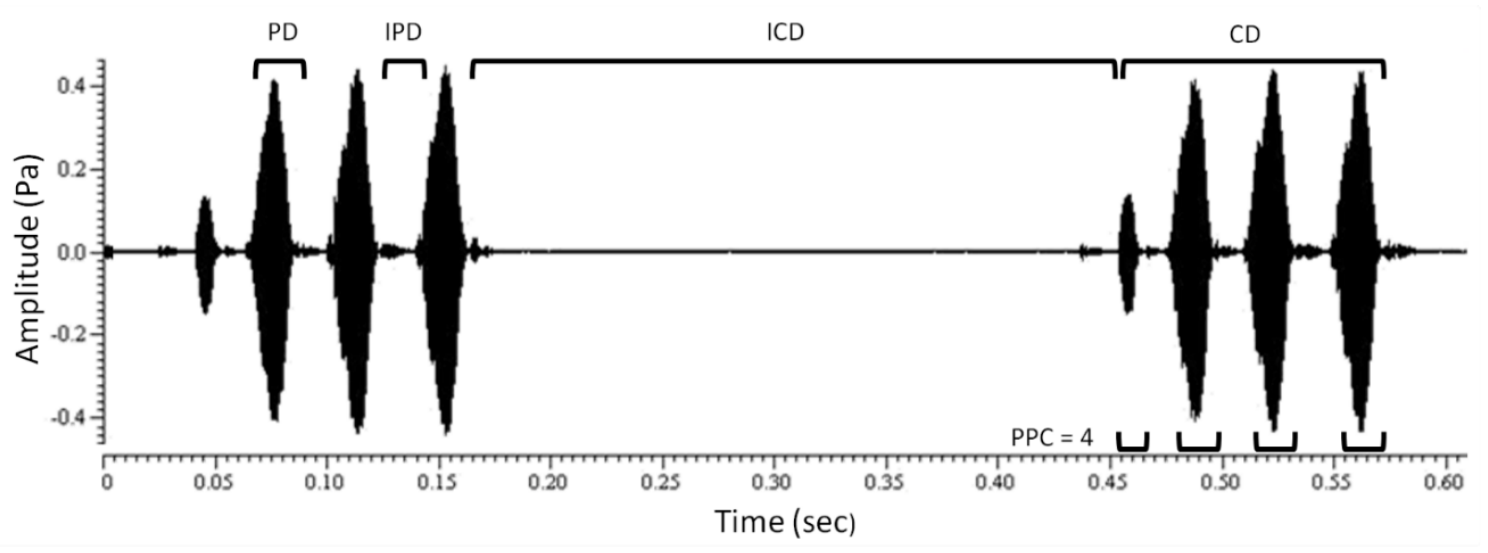

Figure 2.1. Example of a waveform of a male G. veletis long-distance acoustic mate attraction signal, showing a subset of the parameters measured by the EARS II software. Pulse duration (PD), inter-pulse duration (IPD), chirp duration (CD), inter-chirp duration (ICD), pulses per chirp (PPC), and amplitude. 


\section{Chapter 3}

\section{Influence of dietary nutrient balance on male and female lifespan, growth, egg production and acoustic mate attraction signals}

This chapter is published as: Harrison, S. J., Raubenheimer, D., Simpson, S. J., Godin, J.G. J., \& Bertram, S. M. (2014). Towards a synthesis of frameworks in nutritional ecology: interacting effects of protein, carbohydrate and phosphorus on field cricket fitness. Proceedings of the Royal Society B: Biological Sciences, 281, 20140539. It is reproduced here with permission from Royal Society Publishing. 


\subsection{Abstract}

Phosphorus has been identified as an important determinant of nutrition-related biological variation. The macronutrients protein and carbohydrates, both alone and interactively, are known to affect animal performance. No study, however, has investigated the importance of phosphorus relative to dietary protein or carbohydrates, or the interactive effects of phosphorus with these macronutrients, on fitness-related traits in animals. I used a nutritional geometry framework to address this question in adult field crickets (Gryllus veletis). My results showed that lifespan, weight gain, acoustic mate signalling and egg production were maximized on diets with different protein:carbohydrate ratios, that phosphorus intake did not affect any of these fitness traits, and that males and females had different optimal macronutrient intake ratios for reproductive performance. When given a choice, crickets selected diets that maximized both lifespan and reproductive performance by preferentially eating diets with low protein:carbohydrate ratios, and females selected diets with a higher protein:carbohydrate ratio than males. Conversely, phosphorus intake was not regulated. Overall, my findings highlight the importance of disentangling the influences of different nutrients, and of quantifying both their individual and interactive effects, on animal fitness traits, so as to gain a more integrative understanding of their nutritional ecology.

\subsection{Introduction}

Variation in dietary quality and quantity are pervasive and powerful determinants of animal fitness (Simpson \& Raubenheimer, 2012; Sterner \& Elser, 2002). The question of 
how diet influences fitness, and the study of the countervailing adaptations that animals have evolved to buffer variation in fitness against dietary variation, are important and active research areas with implications that reverberate across the biological sciences. Critical to these questions is the realisation that food components interact in their influence on animals. Such interactions are ubiquitous and powerful mediators of the relationship between diet and fitness. For example, nutritional inter-dependency is implicit in the foundational concept of nutrient balance, which is predicated on the realisation that the benefits of nutrients are usually not independent but contingent on the levels in the diet of other nutrients. Likewise, nutrients are forced into relationships of inter-dependency by virtue of their co-occurrence as complex mixtures in foods, and thus can usually not be eaten independently. These concepts have long been considered important in nutritional research (House, 1965; Painter, 1936).

The limiting step in developing this perspective, however, has been the lack of frameworks for investigating interactive effects of food components on animals. A minimal requirement is that any framework should be multi-dimensional to provide a basis for conceptualising nutrition with respect to multiple diet components and their interactions (Raubenheimer, Simpson, \& Mayntz, 2009). In recent years, two such frameworks have become established, namely, ecological stoichiometry (ES: Elser, 2006; Sterner \& Elser, 2002) and nutritional geometry (NG: Raubenheimer \& Simpson, 1993; Simpson \& Raubenheimer, 1993). These frameworks are both centred on the concept of nutritional balance, but they differ in several respects. For the present purposes, the most pertinent difference is that NG is centred on organismal traits, whereas ES is primarily 
centered on ecological processes (Morehouse et al., 2010; Raubenheimer et al., 2009). Similarly, the nutritional variables that are modelled in NG are selected according to their relevance to organismal traits (e.g. nutritional regulatory systems, fitness-relevant responses) whether they are macromolecular nutrients, such as proteins, carbohydrates and lipids, or elements, such as calcium or mineral salts (Lee et al., 2008; Maklakov et al., 2008; Mayntz et al., 2009; Raubenheimer \& Simpson, 2006; South et al., 2011). In contrast, ES models the relationships among chemical elements, since these are general to all levels of biological organisation and can be tracked stoichiometrically in their flow through biological systems (Elser et al., 2000, 2003), although macromolecules have occasionally been investigated (Anderson \& Pond, 2000).

Both NG and ES have made appreciable contributions to the understanding of how nutritional interactions influence biological systems. There are, however, differences in the specific nutritional relationships that have been identified as primary in explaining nutrition-related biological variation. Notably, NG has identified the energetic macronutrients proteins, lipids, and carbohydrates as powerful drivers in most systems. Conversely, ES has identified the elements carbon, nitrogen and phosphorus as pivotal. These perspectives converge to some extent, because nitrogen represents an elementlevel proxy for amino acids and carbon is usually regarded as a metric for the energyproviding macronutrients, principally lipids and carbohydrates (Sterner \& Elser, 2002). A point where continuity has not been established, however, is in relation to the third element, phosphorus. Phosphorus has been identified as a fundamental limiting factor in many stoichiometric studies (Bertram et al., 2006; Elser et al., 2000; Schade et al., 2003), 
yet has been the subject of no studies within the NG paradigm. This is an important omission, because despite their respective organismal and ecological foci, both NG and ES aim to establish continuity across the full range of biological organisation (Elser, 2006; Raubenheimer et al., 2009). To achieve this, we need to learn how behavioural and physiological regulatory mechanisms and animal performance respond to orthogonal variation in dietary phosphorus, protein, and carbohydrates.

To examine this question, I used NG to perform experiments in which protein, carbohydrate and phosphorus were varied systematically in the diets of field crickets (Gryllus veletis). Wild field crickets are omnivorous, feeding on diverse plants and insects (Carmona et al., 1999; Criddle, 1925; Gangwere, 1961) that vary considerably in nutrient content (Bertram, Bowen, Kyle, \& Schade, 2008; Elser et al., 2000; Joern \& Behmer, 1997; Woods et al., 2004). Such dietary breadth suggests that crickets have evolved homeostatic regulatory systems for buffering performance against variation in nutrient intake (Raubenheimer \& Jones, 2006), and in this respect they provide a good model system for investigating complex nutritional regulatory challenges. Field crickets are also ideal for investigating how diet influences sexually selected traits. Males produce acoustic mate attraction signals by rubbing their forewings together (Alexander, 1961). Overall signalling effort is influenced by diet (Bertram et al., 2009; Holzer et al., 2003; Maklakov et al., 2008) and females typically phonolocate towards higher-effort signallers (Holzer et al., 2003; Wagner \& Reiser, 2000).

Using no-choice diet trials, I first examined (i) how dietary nutrient balance during adulthood influences adult fitness traits, (ii) whether diet during adulthood 
influences trade-offs between fitness traits within each sex, and (iii) whether any influence of diet on these traits is sex-specific (Experiment 1). Since females allocate more nutrients to gametes and males allocate more nutrients and energy to sexual displays (Kodric-Brown \& Brown, 1987; Morehouse et al., 2010; Wheeler, 1996), I predicted that reproductive proxies (egg production and signalling) would be optimized in different regions of the nutritional landscape for the sexes. Conversely, I predicted that lifespan and weight gain would be optimized in similar regions of the nutritional landscape, as the metabolic processes maintaining these fitness traits are unlikely to differ between the sexes. Within each sex, I further predicted that diet would influence tradeoffs between fitness traits.

I then investigated adult diet choice by providing crickets with multiple foods containing varying nutrient ratios to ascertain sex-specific regulation of phosphorus intake (Experiment 2) and protein and carbohydrate intakes (Experiment 3). I predicted that the sexes would differ in their diet preference as a consequence of their different reproductive strategies. Based on previous studies of insect diet choice (Maklakov et al., 2008; Raubenheimer \& Jones, 2006; South et al., 2011), I expected that protein and carbohydrate intake would be tightly regulated. By contrast, the observation that bodily phosphorus content often co-varies with dietary phosphorus levels in terrestrial insects implies that neither the intake, nor post-ingestive retention of phosphorus, should be strongly regulated, if at all (Perkins et al., 2004; Schade et al., 2003). 


\subsection{Methods}

\subsubsection{Subjects and rearing}

Gryllus veletis crickets were reared following the conditions outlined in Chapter 2, section 2.2. Juveniles were separated by sex at the penultimate instar and monitored daily for adult eclosion. Upon eclosion, adults were transferred into separate $520 \mathrm{~mL}$ clear plastic containers with a screened lid and provided with shelter, ad libitum water and experimental food(s). All dietary trials were performed in the greenhouse under the same temperature and lighting conditions as experienced by the original colony.

\subsubsection{Measuring initial body size}

I measured two proxies of initial body size: body weight $(\mathrm{mg})$ and pronotum length (mm). Crickets were weighed prior to diet trials using a Denver Instruments analytical balance (Pinnacle Series model PI-114; precision $\pm 0.1 \mathrm{mg}$ ), and then photographed in a dorsal position using a Zeiss Discovery V12 stereo dissecting microscope, from which pronotum length was measured (AxioVision v4.8, Carl Zeiss; magnification $\sim 5 \mathrm{X}$, resolution $\sim 1.60 \mu \mathrm{m})$. Because weight and height were significantly positively correlated (Males: $\mathrm{F}_{1,423}=674.791, P<0.001 ;$ Females: $\mathrm{F}_{1,355}=667.108, P<0.001$ ), they were reduced to a single composite measure of initial body size using Principal Component Analysis (PCA) in JMP (v.10; SAS Institute Inc., Cary, NC, USA). 


\subsubsection{Experiment 1: Influence of dietary nutrient ratio on fitness traits}

\subsubsection{Experimental foods}

Experimental foods were created following established protocols (Simpson \& Abisgold, 1985; Chapter 2, section 2.3). Foods consisted of five different protein (P) to carbohydrate $(C)$ ratios $\left(3_{\mathrm{P}}: 1_{\mathrm{C}}, 1_{\mathrm{P}}: 1_{\mathrm{C}}, 1_{\mathrm{P}}: 3_{\mathrm{C}}, 1_{\mathrm{P}}: 5_{\mathrm{C}}, 1_{\mathrm{P}}: 8_{\mathrm{C}}\right)$, each varying at three phosphorus $(\mathrm{PH})$ levels $(0.45 \% \mathrm{PH}, 1.45 \% \mathrm{PH}$, and $2.45 \%$ PH by mass $)$. The resulting 15 nutrient mixtures were each diluted to three cellulose levels (14, 45, 76\% cellulose), for a total of 45 unique foods (Table 3.1). Dilution with non-nutritional cellulose spreads out nutrient intake along 'nutritional rails' (sensu Raubenheimer \& Simpson, 1993), which allows for a trait-response surface to be produced. After accounting for dilution with nonnutritional cellulose, the absolute percentage phosphorus (by mass) in the 45 experimental foods ranged from $0.07 \%$ to $1.87 \%$ (Table 3.1 ). This range was chosen to reflect natural variation in the diets of crickets in the wild (Carmona et al., 1999; Criddle, 1925; Elser et al., 2000; Gangwere, 1961), including insect matter (0.4\% - 1.4\% phosphorus: Woods et al., 2004) and plant matter (0.02\% - 1.04\% phosphorus: Elser et al., 2000). The range of dietary protein:carbohydrate ratios was chosen based on a previous study in which life-history and fitness traits were mapped across a wide range of protein:carbohydrate ratios and concentrations (Maklakov et al., 2008).

Crickets were provided weekly with fresh food. Weekly protein, carbohydrate, and phosphorus intakes were calculated from total food intake (difference in weight of food dish before and after consumption) and known food compositions (Table 3.1). Food dishes (50 x $9 \mathrm{~mm}$ Petri dishes with upturned $15 \times 15 \mathrm{~mm}$ plastic lids glued in the centre) 
containing food were dried in a drying oven for $48 \mathrm{~h}$ at $30^{\circ} \mathrm{C}$ prior to weighing, and were weighed using a Denver Instruments analytical balance after removing faeces with fine forceps. Control food containers without crickets were housed in $520 \mathrm{~mL}$ plastic containers with water, and were dried with experimental food containers. If control food containers increased in weight, experimental food containers were dried for an additional $24 h$. 
Table 3.1. Composition of foods used in Experiment 1. All values are calculated as a percentage of total mass unless otherwise stated.

\begin{tabular}{cccccccc}
\hline Diet ID & P:C & $\begin{array}{c}\text { \% } \\
\text { Cellulose }\end{array}$ & $\begin{array}{c}\text { \% Total } \\
\text { Nutrients } \\
\text { (P+C+PH) }\end{array}$ & \% P & \% C & \% PH & $\begin{array}{c}\text { \% PH in Total } \\
\text { Nutrients } \\
\text { (PH/(P+C+PH)) }\end{array}$ \\
\hline 1 & $3: 1$ & 76.54 & 14.58 & 10.88 & 3.63 & 0.07 & 0.45 \\
2 & $3: 1$ & 76.52 & 14.58 & 10.77 & 3.59 & 0.21 & 1.45 \\
3 & $3: 1$ & 76.50 & 14.57 & 10.66 & 3.55 & 0.36 & 2.45 \\
4 & $3: 1$ & 45.56 & 45.56 & 34.01 & 11.34 & 0.21 & 0.45 \\
5 & $3: 1$ & 45.52 & 45.52 & 33.65 & 11.22 & 0.66 & 1.45 \\
6 & $3: 1$ & 45.49 & 45.49 & 33.28 & 11.09 & 1.11 & 2.45 \\
7 & $3: 1$ & 14.58 & 76.53 & 57.14 & 19.05 & 0.34 & 0.45 \\
8 & $3: 1$ & 14.56 & 76.44 & 56.50 & 18.83 & 1.11 & 1.45 \\
9 & $3: 1$ & 14.54 & 76.34 & 55.85 & 18.62 & 1.87 & 2.45 \\
\hline 10 & $1: 1$ & 76.54 & 14.58 & 7.26 & 7.26 & 0.07 & 0.45 \\
11 & $1: 1$ & 76.52 & 14.57 & 7.18 & 7.18 & 0.21 & 1.45 \\
12 & $1: 1$ & 76.50 & 14.57 & 7.11 & 7.11 & 0.36 & 2.45 \\
13 & $1: 1$ & 45.55 & 45.55 & 22.67 & 22.67 & 0.20 & 0.45 \\
14 & $1: 1$ & 45.52 & 45.52 & 22.43 & 22.43 & 0.66 & 1.45 \\
15 & $1: 1$ & 45.49 & 45.48 & 22.18 & 22.18 & 1.11 & 2.45 \\
16 & $1: 1$ & 14.58 & 76.52 & 38.09 & 38.09 & 0.34 & 0.45 \\
17 & $1: 1$ & 14.56 & 76.42 & 37.66 & 37.66 & 1.11 & 1.45 \\
18 & $1: 1$ & 14.54 & 76.33 & 37.23 & 37.23 & 1.87 & 2.45 \\
\hline
\end{tabular}


Table 3.1. Continued

\begin{tabular}{|c|c|c|c|c|c|c|c|}
\hline 19 & $1: 3$ & 76.54 & 14.58 & 3.63 & 10.88 & 0.07 & 0.45 \\
\hline 20 & $1: 3$ & 76.52 & 14.57 & 3.59 & 10.77 & 0.21 & 1.45 \\
\hline 21 & $1: 3$ & 76.50 & 14.57 & 3.55 & 10.66 & 0.36 & 2.45 \\
\hline 22 & $1: 3$ & 45.55 & 45.55 & 11.34 & 34.01 & 0.20 & 0.45 \\
\hline 23 & $1: 3$ & 45.52 & 45.51 & 11.21 & 33.64 & 0.66 & 1.45 \\
\hline 24 & $1: 3$ & 45.48 & 45.48 & 11.09 & 33.27 & 1.11 & 2.45 \\
\hline 25 & $1: 3$ & 14.57 & 76.51 & 19.04 & 57.12 & 0.34 & 0.45 \\
\hline 26 & $1: 3$ & 14.55 & 76.41 & 18.83 & 56.48 & 1.11 & 1.45 \\
\hline 27 & $1: 3$ & 14.54 & 76.32 & 18.61 & 55.83 & 1.87 & 2.45 \\
\hline 28 & $1: 5$ & 76.54 & 14.58 & 2.42 & 12.09 & 0.07 & 0.45 \\
\hline 29 & $1: 5$ & 76.52 & 14.57 & 2.39 & 11.97 & 0.21 & 1.45 \\
\hline 30 & $1: 5$ & 76.50 & 14.57 & 2.37 & 11.84 & 0.36 & 2.45 \\
\hline 31 & $1: 5$ & 45.55 & 45.55 & 7.56 & 37.79 & 0.20 & 0.45 \\
\hline 32 & $1: 5$ & 45.51 & 45.51 & 7.48 & 37.38 & 0.66 & 1.45 \\
\hline 33 & $1: 5$ & 45.48 & 45.48 & 7.39 & 36.97 & 1.11 & 2.45 \\
\hline 34 & $1: 5$ & 14.57 & 76.51 & 12.69 & 63.47 & 0.34 & 0.45 \\
\hline 35 & $1: 5$ & 14.55 & 76.41 & 12.55 & 62.75 & 1.11 & 1.45 \\
\hline 36 & $1: 5$ & 14.54 & 76.31 & 12.41 & 62.04 & 1.87 & 2.45 \\
\hline 37 & $1: 8$ & 76.53 & 14.58 & 1.61 & 12.90 & 0.07 & 0.45 \\
\hline 38 & $1: 8$ & 76.52 & 14.57 & 1.60 & 12.77 & 0.21 & 1.45 \\
\hline 39 & $1: 8$ & 76.50 & 14.57 & 1.58 & 12.63 & 0.36 & 2.45 \\
\hline 40 & $1: 8$ & 45.55 & 45.55 & 5.04 & 40.30 & 0.20 & 0.45 \\
\hline 41 & $1: 8$ & 45.51 & 45.51 & 4.98 & 39.87 & 0.66 & 1.45 \\
\hline 42 & $1: 8$ & 45.48 & 45.48 & 4.93 & 39.43 & 1.11 & 2.45 \\
\hline 43 & $1: 8$ & 14.57 & 76.50 & 8.46 & 67.70 & 0.34 & 0.45 \\
\hline 44 & $1: 8$ & 14.55 & 76.41 & 8.37 & 66.93 & 1.11 & 1.45 \\
\hline 45 & $1: 8$ & 14.54 & 76.31 & 8.27 & 66.17 & 1.87 & 2.45 \\
\hline
\end{tabular}




\subsubsection{Measuring male and female fitness traits}

Crickets were weighed weekly and checked every $48 \mathrm{~h}$ to determine date of death. Since female G. veletis begin producing eggs (S.J. Harrison, personal observation) and males begin producing sexual signals (Fitzsimmons \& Bertram, 2011) at approximately one week post-adult eclosion, reproduction proxy measurements began during the second week of adulthood. Females were given the opportunity to mate with a randomly-selected stock male once weekly for $6 \mathrm{~h}$, from day 7-28 of adulthood. Fresh sand for oviposition was provided, and weekly egg production was counted after sifting the sand through a $300 \mu \mathrm{m}$ sieve.

Male acoustic signalling was monitored for $48 \mathrm{~h}$ bouts, beginning on day 7 of adulthood and continuing weekly thereafter until day 29 of adulthood. Signalling was monitored using the Electronic Acoustic Recording System II (EARS II; see Chapter 2, section 2.4). The following average daily signalling parameters were statistically analysed: pulse duration (ms), interpulse duration (ms), chirp duration (ms), interchirp duration (ms), number of pulses per chirp, pulse rate (\# pulses/sec), chirp rate (\# chirps/min), carrier frequency $(\mathrm{Hz})$, amplitude $(\mathrm{dB})$, and time spent signalling (min/day).

Since G. veletis has approximately a 2 -month breeding season in the wild (S.J. Harrison, personal observation), I terminated Experiment 1 nine weeks post-adult eclosion; crickets still alive at this time ( $12 \%$ of males and $32 \%$ of females) were euthanized via freezing. I tested 425 males and 357 females, with 7-10 individuals per experimental food treatment for each sex. 


\subsubsection{Statistical analyses}

To determine how nutrient intake influences adult weight gain, lifespan, egg production, and acoustic mating signals, I used a multivariate surface-response approach to estimate and visualize the linear, quadratic, and correlational effects of protein, carbohydrates, and phosphorus on these fitness traits (Lande \& Arnold, 1983). Response surfaces were fitted using General Linear Models (LMs) in SPSS (v.20; SPSS Inc., Chicago, IL, USA) and visualized using nonparametric thin-plate splines using R (v.2.15.2; http://www.rproject.org/). All LMs included lifetime fitness traits as response variables, and the linear, quadratic and correlational terms for protein, carbohydrate, and phosphorus intake over the first three weeks of adulthood as covariates. Additionally, initial body size PC1 scores were included as covariates to control for differences in intake due to size variation. The PC1 axes explained $89.2 \%($ Eigenvalue $=1.78)$ and $90.4 \%($ Eigenvalue $=1.81)$ of the observed variation in the body size of males and females, respectively. I corrected for multiple hypotheses tests using false discovery rate FDR $_{\mathrm{B}-\mathrm{Y}}($ Benjamini \& Yekutieli, 2001).

Following South et al., (2011), I used a sequential model-building approach (ANCOVA) in SPSS to compare response surfaces within and between sexes to determine if the linear, quadratic, and correlational effects of protein, carbohydrates, and phosphorus intake differed between response variables within a sex, or differed for the same response variables between the sexes. I Z-transformed each response variable before comparison. 


\subsubsection{Experiments 2 and 3: Influence of dietary nutrient ratio on diet selection}

\subsubsection{Experimental foods}

Using methods outlined in Chapter 2, section 2.3, three foods were created for Experiment 2 (Table 3.2) containing different phosphorus contents $(0.45,1.45$ or $2.45 \% \mathrm{PH}$ in total nutrients), but identical protein:carbohydrate $\operatorname{ratios}($ Food $\mathrm{A}=$ $\left.23_{\mathrm{P}}: 23_{\mathrm{C}}: 0.21_{\mathrm{PH}} ; \mathrm{B}=23_{\mathrm{P}}: 23_{\mathrm{C}}: 0.68_{\mathrm{PH}} ; \mathrm{C}=23_{\mathrm{P}}: 23_{\mathrm{C}}: 1.14_{\mathrm{PH}}\right)$. Approximately 10 crickets of each sex were individually provided simultaneously with either two foods that differed only in phosphorus content (Food Pair 1 = A \& B; Pair 2= B \& C; Pair 3= A \& C) or two identical foods as a control (Pair $4=$ B \& B). Diet trials lasted 12 days, with fresh food provided every $72 \mathrm{~h}$. To minimize the influence of spatial and temporal variation in greenhouse environmental conditions on my results, I used a randomized block design to determine treatment (food pair) distribution order, and I alternated the position of paired food types within each container every $72 \mathrm{~h}$.

For Experiment 3, five foods were created (Table 3.3) containing identical phosphorus contents (all with $1.45 \% \mathrm{PH}$ in total nutrients): two pure protein (Food D = $\left.46_{\mathrm{P}}: 0_{\mathrm{C}}: 0.68_{\mathrm{PH}} ; \mathrm{E}=76_{\mathrm{P}}: 0_{\mathrm{C}}: 1.12_{\mathrm{PH}}\right)$, two pure carbohydrate $\left(\mathrm{F}=0_{\mathrm{P}}: 46_{\mathrm{C}}: 0.68_{\mathrm{PH}} ; \mathrm{G}=\right.$ $\left.0_{\mathrm{P}}: 76_{\mathrm{C}}: 1.12_{\mathrm{PH}}\right)$, and one control with equal protein and carbohydrate $(\mathrm{H}=$ $\left.23_{\mathrm{P}}: 23_{\mathrm{C}}: 0.68_{\mathrm{PH}}\right)$. Approximately 10 crickets of each sex were individually provided simultaneously with either one pure protein and one pure carbohydrate food (Food Pair 5 =D \& F; Pair 6=E \& G; Pair 7= D \& G; Pair 8=E \& F) or two identical foods as a control (Pair $9=\mathrm{H} \& \mathrm{H}$ ). Diet trials were performed in the same manner as described for Experiment 2. 
Table 3.2. Composition of foods used in Experiment 2. All values are calculated as a percentage of total mass unless otherwise stated.

\begin{tabular}{|c|c|c|c|c|c|c|c|}
\hline Diet ID & P:C & $\begin{array}{c}\text { \% } \\
\text { Cellulose }\end{array}$ & $\begin{array}{c}\text { \% Total } \\
\text { Nutrients } \\
(\mathrm{P}+\mathrm{C}+\mathrm{PH})\end{array}$ & $\% \mathrm{P}$ & $\% \mathrm{C}$ & $\% \mathrm{PH}$ & $\begin{array}{c}\% \text { PH in Total } \\
\text { Nutrients } \\
(\mathrm{PH} /(\mathrm{P}+\mathrm{C}+\mathrm{PH}))\end{array}$ \\
\hline A & $1: 1$ & 46.70 & 46.70 & 23.24 & 23.24 & 0.21 & 0.45 \\
\hline B & $1: 1$ & 46.66 & 46.66 & 22.99 & 22.99 & 0.68 & 1.45 \\
\hline $\mathrm{C}$ & $1: 1$ & 46.63 & 46.63 & 22.74 & 22.74 & 1.14 & 2.45 \\
\hline
\end{tabular}


Table 3.3. Composition of foods used in Experiment 3. All values are calculated as a percentage of total mass unless otherwise stated.

\begin{tabular}{cccccccc}
\hline Diet ID & P:C & $\begin{array}{c}\% \\
\text { Cellulose }\end{array}$ & $\begin{array}{c}\text { \% Total } \\
\text { Nutrients } \\
\text { (P+C+PH) }\end{array}$ & \% P & \% C & \% PH & $\begin{array}{c}\text { \% PH in Total } \\
\text { Nutrients } \\
\text { (PH/(P+C+PH)) }\end{array}$ \\
\hline D & $46: 0$ & 46.67 & 46.67 & 45.99 & 0.00 & 0.68 & 1.45 \\
E & $76: 0$ & 15.86 & 77.44 & 76.31 & 0.00 & 1.12 & 1.45 \\
F & $0: 46$ & 46.65 & 46.65 & 0.00 & 45.98 & 0.68 & 1.45 \\
G & $0: 76$ & 15.85 & 77.39 & 0.00 & 76.27 & 1.12 & 1.45 \\
H & $1: 1$ & 46.66 & 46.66 & 22.99 & 22.99 & 0.68 & 1.45 \\
\hline
\end{tabular}




\subsubsection{Statistical analyses}

To determine whether crickets preferentially consumed more of one food type within each treatment pair and whether the consumption of each food type differed between the sexes, I used general linear mixed models (LMMs) in SPSS. I included total intake of each food as the dependent variable, individual identity and block as random effects, initial body size PC1 as a covariate, and food, sex, and the interaction term sex*food as fixed effects. The PC1 axes explained 75.5\% (Eigenvalue $=1.51)$ and $78.7 \%$ (Eigenvalue $=1.57)$ of the observed size variation of males and females, respectively, in Experiment 2. Similarly, $\mathrm{PC} 1$ axes for Experiment 3 explained $83.6 \%$ (Eigenvalue $=1.67)$ and $72.7 \%$ (Eigenvalue $=1.45)$ of the observed variation in size of males and females, respectively.

To examine the strength of nutrient intake regulation across treatment pairs differing in total nutrient concentration, I compared the total intake of phosphorus across treatment pairs 1-3 using an analysis of variance (ANOVA) and pairwise Tukey's HSD contrasts, and compared the total intake of carbohydrate and protein across food pairs 5-8 using a multivariate analysis of variance (MANOVA) and pairwise Tukey's HSD contrasts. Significant differences in nutrient intake across food pairs would indicate weak or no regulation of nutrient intake, whereas no significant differences would indicate strong nutrient intake regulation.

The average dietary phosphorus consumed was found by calculating mean percent phosphorus intake (as a percentage of total nutrients) across treatment pairs 1-3. Similarly, average protein:carbohydrate consumed was found by calculating mean ratio consumed across diet pairs 5-8. Controls were not used in mean calculations as these 
pairs did not allow the expression of diet choice. ANCOVAs were used to determine whether the average dietary phosphorus or protein:carbohydrate ratio consumed differed between the sexes.

\subsection{Results}

\subsubsection{Experiment 1: Influence of dietary nutrient ratio on fitness traits}

\subsubsection{Male response surfaces}

Protein and carbohydrate intake influenced male weight gain, lifespan, and mate signalling (Appendix 1, Table A1.1; Figure 3.1A-C; Figure 3.2), whereas phosphorus intake did not significantly influence any male fitness trait (Table A1.1). Smaller males gained more weight relative to body size than larger males (Table A1.1, $\beta=-6.904 \pm$ $1.657, P<0.001)$, and weight gain increased linearly with protein intake $(\beta=0.266 \pm$ $0.047, P<0.001$ ). Lifespan was positively influenced by the intake of both protein (Table A1.1, $\beta=0.038 \pm 0.014, P=0.005)$ and carbohydrate $(\beta=0.158 \pm 0.014, P<0.001)$. A significant negative non-linear slope (Table A1.1, $\beta=-0.001 \pm 0.000, P<0.001$ ) for carbohydrate intake $\left(\mathrm{C}^{*} \mathrm{C}\right)$ indicates that lifespan increased with moderate carbohydrate intake, but declined at higher carbohydrate intakes. Time spent signalling was positively influenced by the intake of both protein (Table A1.1, $\beta=0.570 \pm 0.091, P<0.001$ ) and carbohydrate $(\beta=0.754 \pm 0.094 ; P<0.001)$. All other male sexual signalling parameters were primarily influenced by initial body size and carbohydrate and protein intakes (Table A1.1; Figure 3.2). Phosphorus intake did not influence any male fitness trait (Table A1.1, all $P>0.010$; non- significant after $\mathrm{FDR}_{\mathrm{B}-\mathrm{Y}}$ correction of $P<0.009$ ). 

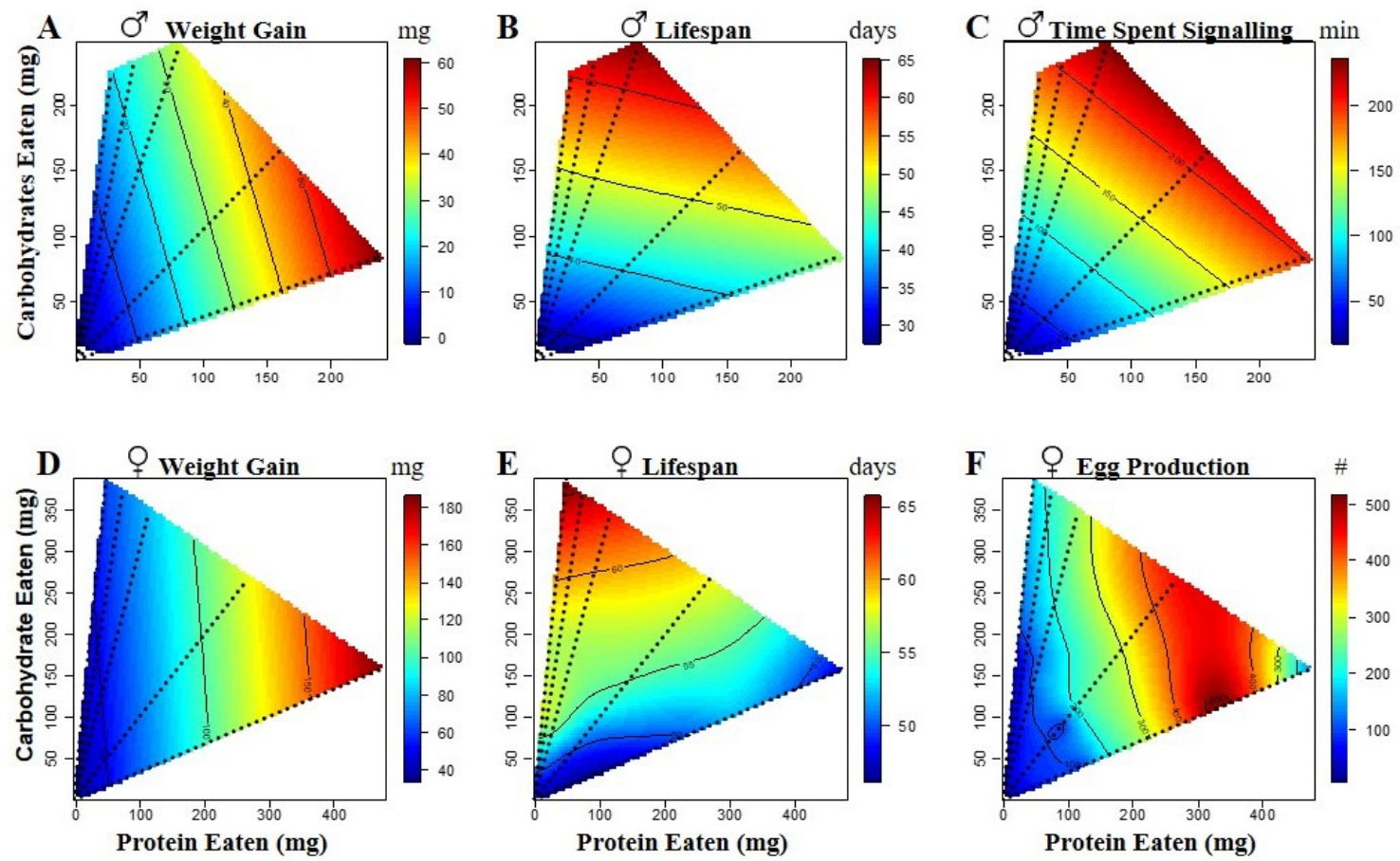

Figure 3.1. Response surfaces illustrating the effects of dietary protein and carbohydrate intake on fitness traits in male and female G. veletis. Dotted lines represent nutritional rails defined by the five protein:carbohydrate ratios available in experimental foods, and the colour scale depicts the magnitude of the dependent response variable. 

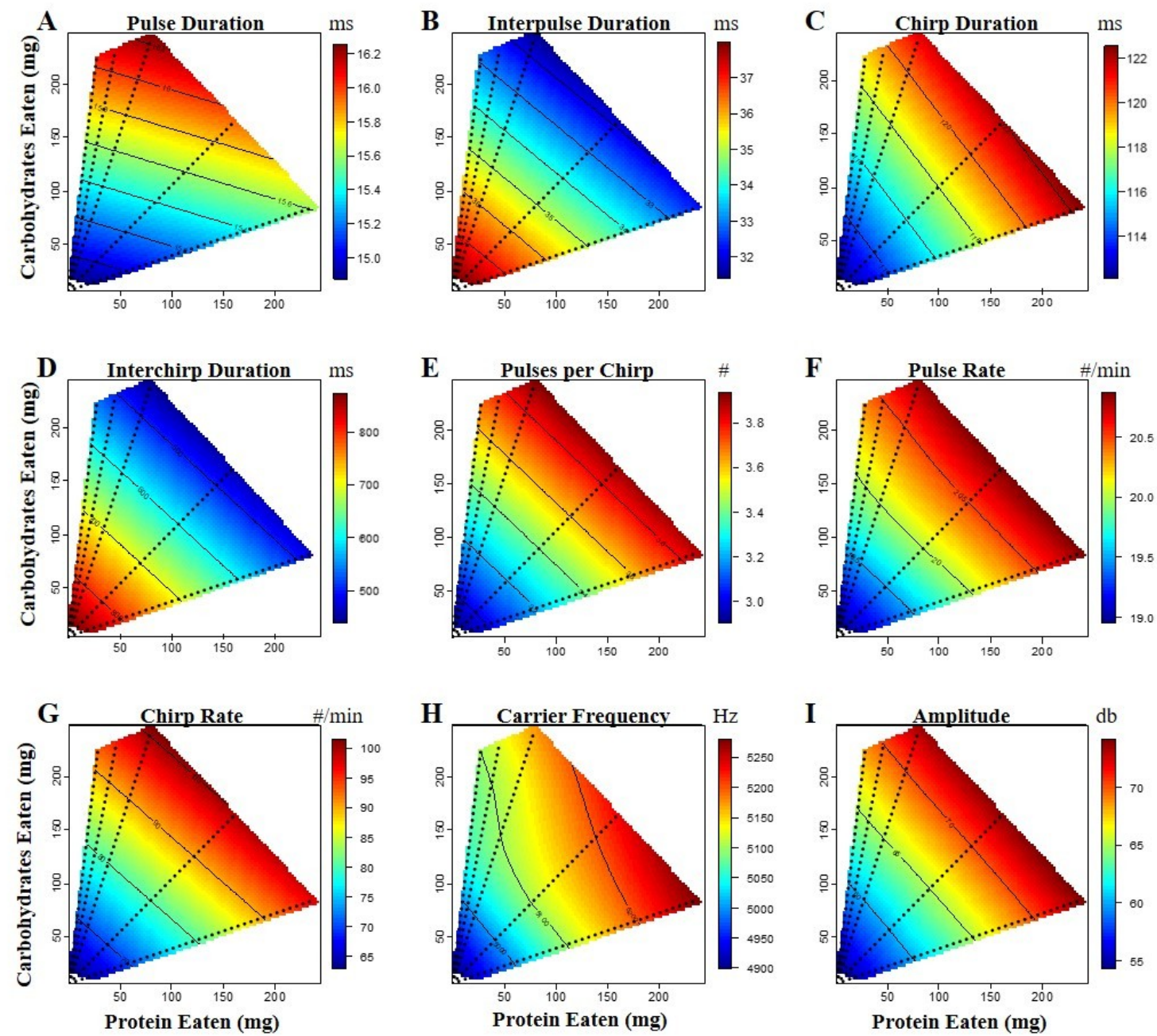

Figure 3.2. Fine-scale temporal signalling response surfaces illustrating the effects of dietary protein and carbohydrate on fitness traits in male G. veletis. Dashed lines represent nutritional rails defined by the five protein:carbohydrate ratios available in diets, and the colour scale depicts the magnitude of the dependent response variable. 
Diet influenced trade-offs between male fitness traits (Figure 3.1A-C; Figure 3.2; Appendix 1, Table A1.2). Weight gain was maximized on approximately a $3_{\mathrm{P}}: 1_{\mathrm{C}}$ nutrient ratio and lifespan on approximately a $1_{\mathrm{P}}: 3_{\mathrm{C}}$ nutrient ratio. In contrast, most acoustic mate signalling parameters increased with increasing total protein and carbohydrate intake, regardless of nutrient ratio, and could therefore be maximized on both low protein:carbohydrate diets that maximize lifespan, or high protein:carbohydrate diets that maximize weight gain.

\subsubsection{Female response surfaces}

Protein and carbohydrate intake influenced female weight gain, lifespan, and egg production (Table A1.1; Figure 3.1D-F), whereas phosphorus did not significantly influence any female fitness trait (Table A1.1). Smaller females gained more weight relative to body size than larger females (Table A1.1, $\beta=-8.268 \pm 2.338, P<0.001$ ), and weight gain increased linearly with protein intake (Table A1.1, $\beta=0.311 \pm 0.044, P<$ 0.001). Lifespan was significantly positively correlated with increasing carbohydrate intake (Table A1.1, $\beta=0.061 \pm 0.016, P<0.001$ ), with a significant negative non-linear slope (Table A1.1, $\beta=-0.001 \pm 0.000, P=0.002)$ associated with carbohydrate intake $\left(\mathrm{C}^{*} \mathrm{C}\right)$ indicating that lifespan increased with moderate carbohydrate intake but declined at higher carbohydrate intakes. Egg production increased linearly with the intake of both protein (Table A1.1, $\beta=1.135 \pm 0.078, P<0.001)$ and carbohydrate $(\beta=0.384 \pm 0.118$, $P=0.001$ ), with a significant negative non-linear slope (Table A1.1, $\beta=-0.002 \pm 0.001$, $P=0.004)$ for protein intake $(\mathrm{P} * \mathrm{P})$ indicating that egg production increased with 
moderate protein intake and declined with higher protein intakes. Diet influenced tradeoffs between female fitness traits (Figure 3.1D-F; Table A1.2). Weight gain and egg production were maximized on a $3 \mathrm{P}: 1_{\mathrm{C}}$ nutrient ratio, whereas lifespan was maximized on a $1_{\mathrm{P}}: 8_{\mathrm{C}}$ nutrient ratio.

\subsubsection{Between-sex comparison of response surfaces}

The influence of nutrient intake on fitness traits was sex-specific (Appendix 1, Table A1.3). Although both males and females gained weight on protein-rich diets, their respective weight gain (Figures 3.1A \& 3.1D) significantly differed in the correlational effects of nutrient intake (Table A1.3), with female but not male weight gain increasing with $\mathrm{P}^{*} \mathrm{C}$ intake (Table A1.1). Male and female lifespan (Figures 3.1B \& 3.1E) significantly differed in the linear effects of nutrient intake (Table A1.3); although both male and female lifespan increased with carbohydrate intake, only male lifespan increased with protein intake (Table A1.1). Male and female reproductive proxies (Figures 3.1C \& 3.1F) significantly differed in the linear effects of nutrient intake (Table A1.3); both time spent signalling and egg production increased linearly with protein and carbohydrate intake, with time spent signalling being more strongly influenced by carbohydrates and egg production more strongly influenced by protein intake (Table A1.1). All statistics are presented in Appendix 1, Tables A1.1 and A1.3. 


\subsubsection{Intake regulation}

Male and female cumulative intake of phosphorus was plotted against macronutrient $(\mathrm{P}+\mathrm{C})$ intake over the first 21 days of adulthood to examine nutrient intake regulation when given no-choice of foods (Figure 3.3A). Phosphorus intake increased proportionately with its concentration relative to macronutrients $(\mathrm{P}+\mathrm{C})$, indicating complete priority of macronutrient intake regulation over phosphorus, and providing no evidence for regulation of phosphorus intake. When the cumulative intake of protein was plotted against carbohydrate intake over the first 21 days of adulthood (Figure 3.3B), the resulting intake array indicated that both protein and carbohydrates contributed to regulation of food intake, with evidence for a decrease in intake when crickets were provided with the most extreme high carbohydrate diets (Figure 3.3B). 

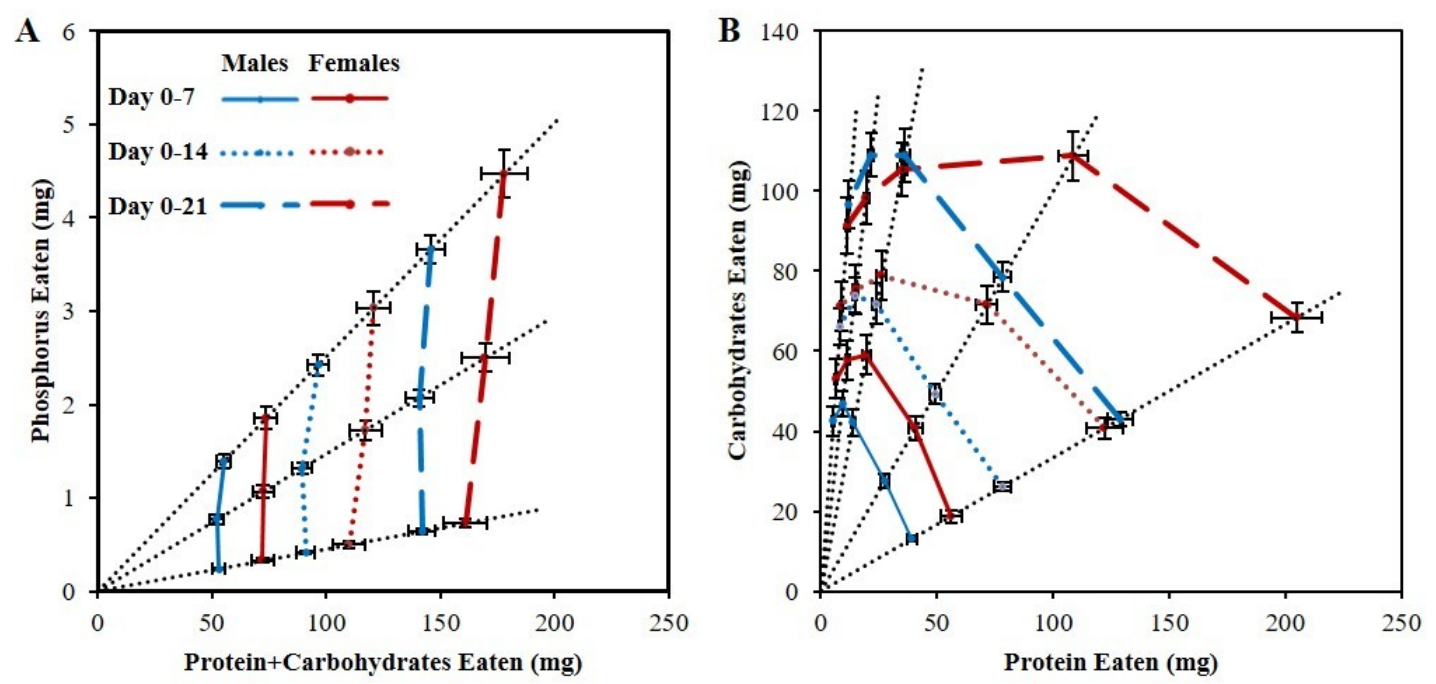

Figure 3.3. Mean ( \pm SE) cumulative intakes across the first 21 days of adulthood for $A$ ) phosphorus relative to protein and carbohydrate $(\mathrm{P}+\mathrm{C})$, and $\mathrm{B})$ protein relative to carbohydrate. Black dotted lines represent nutritional rails defined by A) the three phosphorus levels, and B) the five different protein:carbohydrate ratios available in experimental foods (Table 3.1). 


\subsubsection{Experiment 2: Influence of dietary phosphorus on diet selection}

When given a choice, crickets did not preferentially consume high phosphorus over low phosphorus diets. There was no difference in total intake between foods in any of the treatment pairs (Figure 3.4; Appendix 1, Table A1.4; Pairs 1-4, all $P \geq 0.076$ ). Equal consumption of both foods resulted in the amount of phosphorus eaten closely matching the expected phosphorus intake if crickets were eating randomly between diets (Figure 3.5A-C). Initial body size had no effect on total intake of foods (Table A1.4; Pairs 1-4, all $P \geq 0.205)$. In two of the four treatment pairs, females consumed significantly more than males irrespective of food or body size (Table A1.4; Pair 1, $P=0.007$; Pair 4, $P=0.004$ ). There was no significant sex*food interaction, indicating that males and females did not differ in total intake of each food within treatment pairs (Table A1.4; Pairs 1-4, all $P \geq$ 0.263). Total phosphorus intake significantly differed across treatment pairs 1-3 (ANOVA: $\mathrm{F}_{2,127}=12.514, P<0.001$ ), with significant pairwise Tukey's HSD contrasts for all comparisons $(P \leq 0.007)$ except for treatment pairs 2 and $3(P=0.138)$, indicating weak or no regulation of phosphorus intake. Adjusted mean $( \pm \mathrm{SE})$ percent phosphorus consumed for males and females was $1.45 \pm 0.08$ and $1.47 \pm 0.08$, respectively, and did not differ between the sexes after controlling for initial body size (ANCOVA: $\mathrm{F}_{1,62}=$ $0.020, P=0.888)$ 


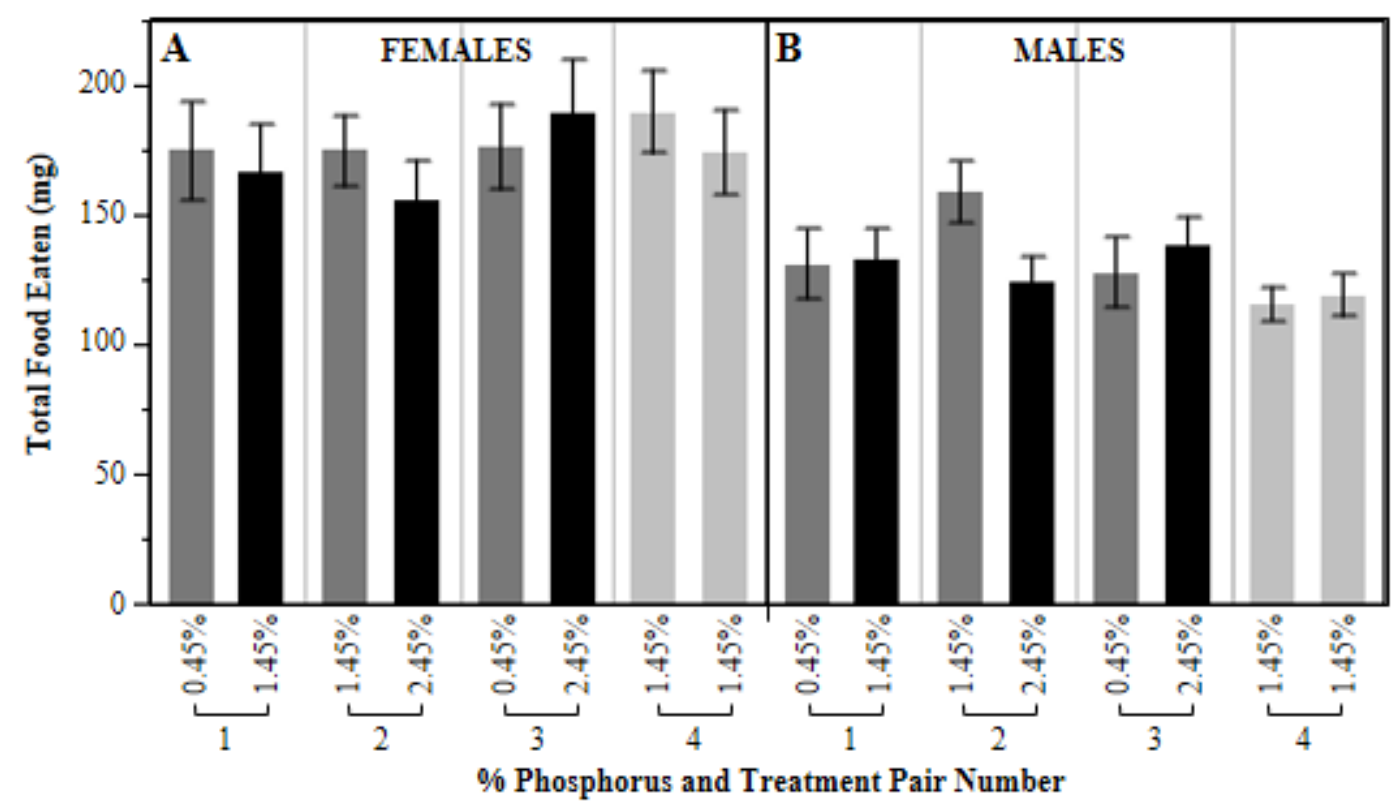

Figure 3.4. Mean $( \pm \mathrm{SE})$ total food consumption within each of the treatment pairs for $A)$ females and B) males for foods differing in phosphorus content (Experiment 2). Light grey bars represent the control, medium gray bars the foods lower in phosphorus, and black bars the foods higher in phosphorus. 

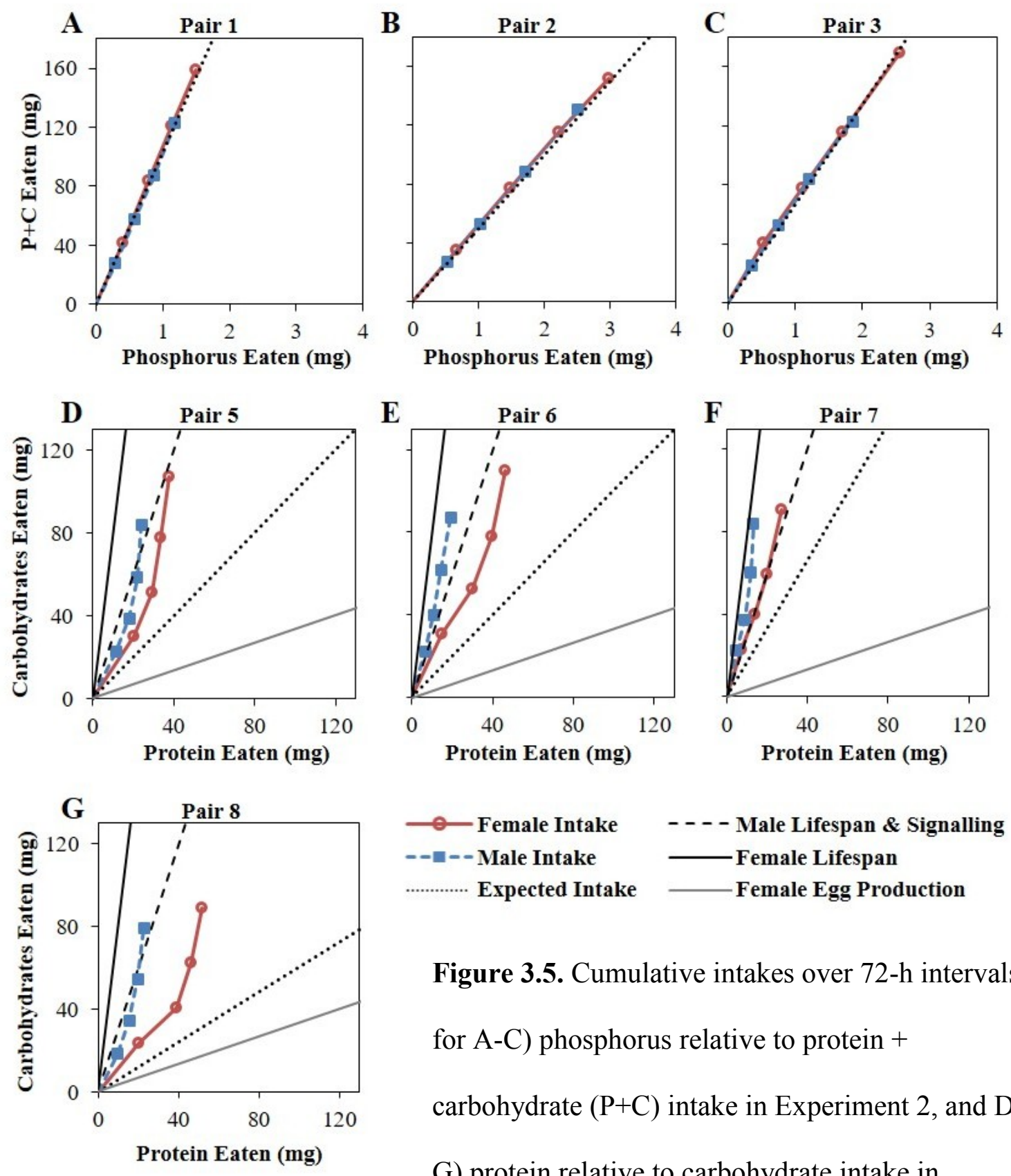

Figure 3.5. Cumulative intakes over 72 -h intervals for A-C) phosphorus relative to protein + carbohydrate $(\mathrm{P}+\mathrm{C})$ intake in Experiment 2, and DG) protein relative to carbohydrate intake in males (blue) and females (red). Black dotted lines indicate the intake ratio expected if crickets were eating foods indiscriminately. Black dashed, black solid, and grey solid lines indicate the intake ratios in Experiment 1 that maximized male lifespan and signalling, female lifespan, and female egg production, respectively. 


\subsubsection{Experiment 3: Influence of dietary protein:carbohydrate ratio on diet selection}

When given a choice, crickets consumed more of the pure carbohydrate food in all treatment pairs (Figure 3.6; Figures 3.5D-G; Table A1.4; Pairs 5-9, all $P \leq 0.001$ ) resulting in an ingested protein:carbohydrate ratio $<1$. Unequal consumption of foods differing in $\mathrm{P}$ and $\mathrm{C}$ content resulted in divergence from the protein:carbohydrate intake expected if crickets were eating randomly between diets (Figures 3.5D-G). Initial body size was significantly positively correlated with total consumption in two of the five treatment pairs (Table A1.4; Pair 6, $P=0.006$; Pair $8, P=0.007$ ). There was a strong trend for females to consume more than males regardless of food or body size (Table A1.4; Pairs 5-9, all $P \leq 0.031$ ), but there was no significant sex*food interaction indicating that females did not significantly differ in total consumption of each food within treatment pairs (Table A1.4; all $P \geq 0.128$ ). Total intake of protein and carbohydrate did not significantly differ across treatment pairs 5-8 (MANOVA: Pillai's trace $=0.040, \mathrm{~F}_{6,336}=1.134$ ), indicating strong regulation of protein:carbohydrate intake. Females consumed higher protein:carbohydrate ratios than males (ANCOVA: $F_{1,83}=$ $6.401, P=0.013)$; the adjusted mean $( \pm \mathrm{SE})$ protein to carbohydrate ratio across treatment pairs $5-8$ was $0.44 \pm 0.06\left(1.3_{\mathrm{p}}: 3_{\mathrm{C}}\right)$ for females and $0.24 \pm 0.06\left(1_{\mathrm{p}}: 4.1_{\mathrm{C}}\right)$ for males. 


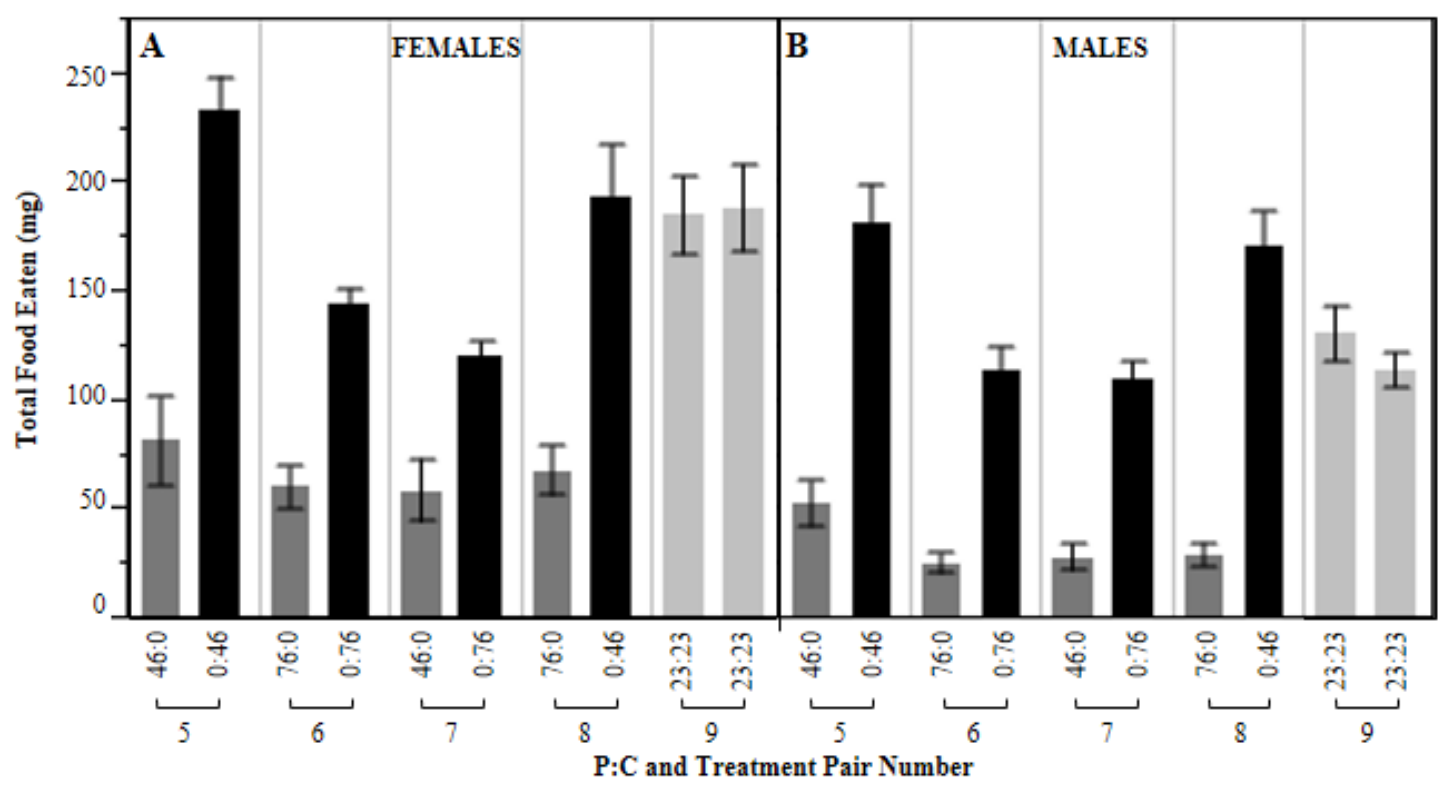

Figure 3.6. Mean ( \pm SE) total food consumption within each of the treatment pairs for $A$ ) females and B) males for foods differing in protein:carbohydrate ratio (Experiment 3). Light grey bars represent the control, medium gray bars the pure protein foods, and black bars the pure carbohydrate foods. 


\subsection{Discussion}

\subsubsection{Experiment 1: Influence of dietary nutrient ratio on fitness traits}

Animals often experience a mismatch between their nutrient requirements and the composition of available foods in nature, where diet quality and quantity affect the pool of resources available for allocation towards different fitness traits (Urabe \& Sterner, 2001). Many ecological stoichiometry (ES) studies suggest that the key to fitness is phosphorus availability (Bertram et al., 2006; Elser et al., 2000; Schade et al., 2003). In contrast, many nutritional geometry $(\mathrm{NG})$ studies suggest that the availability of carbohydrates, lipids, and proteins are key to fitness (Raubenheimer \& Simpson, 1993; Simpson \& Raubenheimer, 1993, 2012). Given that food components interact in their influence, and such interactions are powerful mediators of the relationship between diet and fitness, I investigated (using the NG framework) how fitness trait expression was constrained by concomitant variation in phosphorus, protein and carbohydrates. My results revealed that weight gain, reproductive performance, and lifespan in adult field crickets (Gryllus veletis) were maximized on diets with different protein:carbohydrate ratios, and that the optimal nutrient intake ratio for reproductive performance was sexspecific. Surprisingly, phosphorus intake did not affect any of these fitness traits, nor was there any evidence that phosphorus intake was regulated. When not provided with a choice of foods, both sexes prioritized protein and carbohydrate intake over phosphorus intake, whereas protein and carbohydrate intake were both regulated relatively equally (Figure 3.3B, convex arc intake array; sensu Raubenheimer \& Simpson, 1993), with a decrease in intake evident with the lowest protein:carbohydrate foods. 
Similar to previous studies (Hunt et al., 2004; Joern \& Behmer, 1997; Maklakov et al., 2008), I demonstrated that G. veletis cannot simultaneously maximize all fitness traits, and thus experienced trade-offs between fitness traits depending on the nutritional composition of available foods. Adult weight gain and egg production were maximized on high protein diets $\left(3_{\mathrm{p}}: 1_{\mathrm{C}}\right)$, whereas adult lifespan was maximized on high carbohydrate diets (males: $1_{\mathrm{p}}: 3_{\mathrm{C}}$; females: $1_{\mathrm{p}}: 8_{\mathrm{C}}$ ), and acoustic mate signalling was maximized with increased food intake regardless of nutrient ratio.

Males and females are expected to differ in their nutrient requirements as a result of contrasting reproductive strategies; females allocate more resources towards gamete production, whereas males allocate more resources towards attracting mates (KodricBrown \& Brown, 1987; Morehouse et al., 2010; Wheeler, 1996). The effects of nutrient intake on proxies of reproductive success significantly differed between the sexes; egg production was maximized on a $3 \mathrm{p}: 1_{\mathrm{C}}$ nutrient ratio, whereas most parameters of male sexual signalling were maximized by increasing total carbohydrate or protein intake regardless of dietary nutrient ratio. These results support my prediction that male and female crickets maximize reproductive success in different areas of the nutritional landscape, consistent with most previous studies. For example, $1_{\mathrm{P}}: 1_{\mathrm{C}}$ diets are necessary for maximal egg production and high carbohydrate diets are necessary for maximal signalling effort in T. commodus (Maklakov et al., 2008), whereas high protein diets result in maximal signalling effort in male G. campestris crickets (Hunt et al., 2004). Gryllus veletis males in the current study maximized mate signalling with either high protein or carbohydrate intake, suggesting that signalling is a function of caloric intake 
rather than intake of carbohydrates or protein alone. Dependence on caloric intake reflects the high energetic costs of acoustic signalling (Hoback \& Wagner, 1997; Prestwich \& Walker, 1981).

Dietary trade-offs between lifespan, weight gain, and acoustic signalling effort have important implications for cricket fitness, as older and/or larger males attract more females and have higher mating success (Bateman, Gilson, \& Ferguson, 2001; Zuk, 1988). Furthermore, females typically prefer males displaying higher-energy signals (Hoback \& Wagner, 1997; Popov \& Shuvalov, 1977). Given that higher-energy signals are more costly to produce (Hoback \& Wagner, 1997; Prestwich \& Walker, 1981) and are influenced by nutritional status (Bertram et al., 2009; Holzer et al., 2003; Maklakov et al., 2008; Scheuber et al., 2003), these signals may provide females with reliable information on indirect fitness benefits of mate choice (e.g. good genes for foraging in offspring). However, my assumption that increasing body mass signifies a fitness gain may be invalid, as increasing weight was associated with lethargy and reduced longevity in my study, possibly resulting from urate crystal formation inside fat body cells. For instance, similar to my findings, cockroaches consuming higher protein diets have shorter lifespans, increased weight gain, and develop distended abdomens resulting from extensive urate crystals throughout the fat body (Haydak, 1953). While insects typically excrete nitrogenous waste from protein as uric acid, some orthopteran species including locusts, cockroaches, and cave crickets possess specialized urocyte cells in the fat body which store excess nitrogen as urate crystals (Arrese \& Soulages, 2010; Lipovšek, Novak, Janžekovič, \& Pabst, 2011; Park, Park, \& Takeda, 2013). This store provides a 
source of nitrogen for amino acid synthesis when dietary protein levels are low (Park et al., 2013), but sufficiently large surpluses in nutrient intake may overwhelm postingestive regulatory mechanisms and excess nutrients may become detrimental to the fitness of the organism (Raubenheimer, Lee, \& Simpson, 2005). To my knowledge, urocyte cells have not been identified in field crickets (Gryllinae). Nonetheless, my results suggest that $G$. veletis adults may be storing excess nitrogenous wastes in the body, resulting in weight gain and reduced overall fitness. This supports recent criticisms that the use of residual mass as an estimate of body condition (i.e. pool of nutritional resources, sensu Rowe \& Houle, 1996) may not be appropriate without considering the underlying contributing factors to increasing body mass (Cotton, Fowler, \& Pomiankowski, 2004b). It also supports findings in insect species showing obesity negatively impacting fitness (Skorupa, Dervisefendic, Zwiener, \& Pletcher, 2008; Warbrick-Smith, Behmer, Lee, Raubenheimer, \& Simpson, 2006).

My finding that phosphorus intake did not influence any fitness trait in adult $G$. veletis was unexpected given previous dietary studies. For instance, increasing the phosphorus intake of juvenile invertebrates influences growth, survival, and later reproduction (Perkins et al., 2004; Urabe \& Sterner, 2001). Similar to my current study, Bertram et al., (2009) and Visanuvimol and Bertram (2010) examined the influence of adult dietary phosphorus content on cricket fitness traits. However, in contrast to my current study, these studies found that increasing phosphorus in the diets of adult crickets promoted egg production (Visanuvimol \& Bertram, 2010) and mate signalling effort (Bertram et al., 2009). I did not detect an influence of dietary phosphorus intake on any 
adult fitness trait even though the range of total dietary phosphorus content used in the current study $(0.07 \%-1.87 \%)$ encompasses the range used in the aforementioned studies (0.2\% - 1\%; Bertram et al., 2009; Visanuvimol \& Bertram, 2010). A plausible explanation for the discrepancy between this and similar studies is that the lifetime phosphorus requirements of my study crickets may have been fulfilled during development, as my juvenile crickets were reared on phosphorus-rich $(1.1 \%$ total phosphorus) diets, whereas the diets of juvenile crickets in previous studies were unknown for the first 4-5 instars following hatching (Bertram et al., 2009; Visanuvimol \& Bertram, 2010). However, I also reared juveniles on protein- and carbohydrateadequate diets, suggesting that there might be fundamental differences in the critical ontogenetic periods and timescales over which macronutrients and phosphorus are required, with macronutrients dictating the biological responses at a finer temporal resolution than phosphorus. This would have important implications for ecological models of nutrient limitation, and warrants further attention.

Since phosphorus is a component of various dietary biomolecules (e.g. protein: casein $=0.8 \%$ and albumen $=0.12 \%$ phosphorus $)$, previous findings that phosphorus influences fitness may have been confounded by correlations between levels of dietary phosphorus and protein. My study carefully accounted for the phosphorus contained within all nutrient sources, such that phosphorus was varied independently of carbohydrates and protein. It is also unlikely that my findings resulted from using a metabolically un-digestible phosphorus source since my $\mathrm{CaHPO}_{4}$ source has been used in 
studies wherein cricket fitness was significantly influenced by phosphorus (Bertram et al., 2009; Visanuvimol \& Bertram, 2010).

\subsubsection{Experiments 2 and 3: Influence of dietary nutrient ratio on diet selection}

When faced with nutritional imbalances, organisms may compensate behaviourally by altering the amount they eat or selecting alternative food sources (Simpson \& Abisgold, 1985). I predicted that $G$. veletis would behaviourally regulate the intakes of protein and carbohydrate (Jones \& Raubenheimer, 2001; Maklakov et al., 2008; South et al., 2011), but not phosphorus, because previous insect studies have shown that bodily phosphorus content co-varies with dietary phosphorus levels (Perkins et al., 2004; Schade et al., 2003). My results support these predictions: crickets consumed significantly more carbohydrate than protein when given the choice. Further, crickets did not differ in their total carbohydrate or protein intake across food treatment pairs, suggesting tight regulation of nutrient intake. Carbohydrate and protein regulation is facilitated by receptors in mouthparts and tarsi, which become more sensitive when certain blood metabolite levels are low, stimulating feeding (Raubenheimer \& Simpson, 1993; Simpson \& Raubenheimer, 1993). Conversely, crickets indiscriminately fed on different phosphorus diets and total phosphorus intake differed across food treatment pairs, indicating that phosphorus intake is not regulated.

Since males and females have contrasting reproductive strategies (Kodric-Brown \& Brown, 1987; Morehouse et al., 2010; Wheeler, 1996), and male and female reproductive proxies were maximized in different areas on the nutritional landscape in the 
current study, I predicted that the sexes would differ in their diet choice. As predicted, males and females ate significantly different protein to carbohydrate ratios (females: $1.3_{\mathrm{P}}: 3_{\mathrm{C}}$; males: $1_{\mathrm{P}}: 4.1_{\mathrm{C}}$ ), but did not significantly differ in the percentage of phosphorus consumed. Female preference for higher protein diets likely reflects a higher protein requirement for egg production (Wheeler, 1996). The self-selected protein:carbohydrate ratio ingested presumably reflects the ratio of nutrients required for optimal somatic and metabolic functioning in adult G. veletis ('intake target', sensu Raubenheimer \& Simpson, 1993). The $1_{\mathrm{P}}: 4.1_{\mathrm{C}}$ nutrient ratio self-selected by males in Experiment 3 is similar to the $1_{\mathrm{P}}: 3_{\mathrm{C}}$ ratio that would simultaneously maximize lifespan and signalling in Experiment 1 (Figure 3.5D-G). Conversely, the $1.3 \mathrm{P}: 3_{\mathrm{C}}$ nutrient ratio selected by females in Experiment 3 lies between the $1_{\mathrm{P}}: 8_{\mathrm{C}}$ and $3_{\mathrm{P}}: 1_{\mathrm{C}}$ ratios that maximized lifespan and egg production, respectively (Figure 3.5D-G). Similar to previous findings (Maklakov et al., 2008), my results suggest that females select a protein:carbohydrate ratio that represents a compromise between the different nutritional requirements of egg production and lifespan, whereas male lifespan and mate attraction signalling can be maximized without such compromising.

\subsubsection{Conclusions}

My study is the first to use the NG framework to examine the relative contributions of dietary phosphorus and macronutrients (protein and carbohydrates) to intake regulation and fitness traits. Although other studies have shown that phosphorus influences invertebrate fitness (Bertram et al., 2009; Perkins et al., 2004; Schade et al., 2003; Urabe 
\& Sterner, 2001; Visanuvimol \& Bertram, 2010), these studies were not designed to vary phosphorus orthogonally to protein and carbohydrates and did not quantify the relative individual and interactive contributions of each nutrient to the animals' responses. By varying nutrients independently, I was able to measure the individual as well as interactive effects of phosphorus, protein and carbohydrate on a suite of fitness traits in male and female crickets. My findings reveal that variation in phosphorus in the diets of adult field crickets is unimportant in influencing fitness traits when it is constrained by concomitant variation in dietary protein and carbohydrates, as would be the case for the foods available to adult crickets in the wild. In contrast, adult cricket fitness traits were strongly influenced by protein and carbohydrate intake, irrespective of dietary phosphorus levels. Importantly, dietary macronutrient content influenced trade-offs between fitness traits, such that not all traits could be simultaneously maximized with any given diet. The response of fitness traits to dietary nutrient intake was also sex-specific: while both lifespan and weight gain were maximized in similar regions of the nutritional landscape, the sexes optimized reproductive traits in different regions of the nutritional landscape. Given these strong effects of macronutrients relative to phosphorus on performance, it is not surprising that adult crickets regulated the intake of protein and carbohydrate but not phosphorus. Overall, my findings highlight the importance of disentangling the influences of different nutrients, and quantifying both their individual and interactive effects, on animal fitness traits, so as to gain a more integrative understanding of their nutritional ecology. Important priorities for future research are to investigate the effects of protein, carbohydrate and phosphorus on G. veletis over the 
entire life cycle, and establish the generality of my results across a taxonomically and ecologically diverse range of organisms.

\subsection{Acknowledgements}

I thank Sandra South for her advice on creating experimental diets, Owen Hovey and Jiagie liu for their assistance with data entry, and Louis Gagnon, Ashley Millar, Josh Boudreau, Chris Gillen, Andrew Mikhail, and Robert Watkins for their assistance with animal care and data entry. 


\section{Chapter 4}

\section{The influence of dietary nutrient balance on male aggression and signalling}

This chapter is published as: Harrison, S. J., Godin, J.-G. J., \& Bertram, S. M. (2017). Influence of dietary nutrient balance on aggression and signalling in male field crickets. Animal Behaviour, 134, 123-134. It is reproduced here with permission from Elsevier Publishing. 


\subsection{Abstract}

Indicator models of sexual selection predict that sexually-selected trait elaboration should covary positively with condition. However, nutrition might influence the expression of multiple traits, where high-quality diets may result in positive trait correlations and lowquality diets in trade-offs. Although previous studies have examined how diet quantity or single nutrients, such as protein, carbohydrate and phosphorus, influence sexual traits, few have examined how dietary nutrient balance affects sexual trait expression. I therefore investigated how dietary protein:carbohydrate ratio and phosphorus content influence the relationship between investment in mate attraction signalling and aggression. I fought groups of six adult male Gryllus veletis crickets, each consuming a unique diet, while recording their pre- and post-fight signalling parameters. I found no evidence that diet influenced aggression or pre-fight signalling, with the exception that high-phosphorus diets had a negative influence on several signalling effort parameters. Body size was an important predictor of aggressive behaviour and most signalling parameters, suggesting that developmental diet may have a greater influence on these sexual traits. Several pre-fight signalling parameters were weakly related to aggression, suggesting that signalling may advertise competitive abilities. Males consuming highcarbohydrate and equal protein:carbohydrate diets experienced changes in signalling parameters that represented an overall increase in signalling effort following aggressive contests compared to males consuming high-protein diets, suggesting that dietary effects on signalling may only become apparent following periods of highly energetic activity. Changes in signalling following aggressive contests were also related to aggression levels 
modulated by dietary phosphorus content, such that only males consuming lowphosphorus diets were able to invest heavily in signalling after investing heavily in aggression. My findings highlight the importance of research on the interplay between multiple sexually selected traits, and how dietary nutrient balance influences these relationships.

\subsection{Introduction}

Sexual selection is a major driving force in the evolution of elaborate male secondary sexual traits (Andersson, 1994; Darwin, 1871). Indicator models of sexual selection predict that the expression of elaborate male traits involved in mate attraction and malemale competition should covary positively with individual condition (Grafen, 1990; Kodric-Brown \& Brown, 1984; Maynard Smith, 1985; Pomiankowski, 1987a; Zahavi, 1975, 1977). Furthermore, when males possess multiple elaborate sexually selected traits (e.g. field crickets: Alexander, 1961; guppies: Kodric-Brown \& Nicoletto, 2001; birds: McGraw et al., 2002), they can be correlated if their production depends on similar aspects of condition, or uncorrelated if they reflect different aspects of condition or the same aspect over different time scales (Candolin, 2003; Johnstone, 1996; Møller \& Pomiankowski, 1993). Thus, male sexual traits are expected to serve as honest indicators of condition to potential mates and rival male competitors (Berglund et al., 1996; Johnstone, 1995; Lailvaux \& Irschick, 2006; Maynard Smith \& Harper, 2003).

Nutrition is an important source of variability in an individual's somatic state, which in combination with epigenetic and genetic components, make up the primary 
determinants of individual condition (Hill, 2011). The nutrients acquired by an organism may collectively constitute a pool of resources that are allocated to various physiological processes that support somatic maintenance, growth, development, reproduction, and elaborate sexually selected trait expression (Hill, 2011; Rowe \& Houle, 1996; Tomkins et al., 2004). There is abundant evidence that mate attraction signalling is influenced by diet (reviewed by Cotton et al., 2004b; Johnstone, 1995), but much of this research has focussed on simplistic measures of nutrition, such as overall diet quantity or the importance of single nutrients (Cotton et al., 2004b; Hill, 2011). For example, consuming greater amounts of food or more nutrient-dense food is often associated with increased ornamentation or sexual signalling (e.g. stalk-eyed flies: Cotton, Fowler, \& Pomiankowski, 2004a; crickets: Holzer et al., 2003; Whattam \& Bertram, 2011; wolf spiders: Kotiaho, 2000; cowbirds: McGraw et al., 2002). Similarly, individual nutrients such as protein (crickets: Hunt et al., 2004; fruit flies: Yuval, Kaspi, Shloush, \& Warburg, 1998), and phosphorus (crickets: Bertram et al., 2006, 2009) also influence sexual signalling. Unfortunately, dietary manipulation of total food quantity or the amount of a single nutrient does not take into account the nutritional complexity of natural foods.

The balance of multiple dietary nutrients is an important component of an individual's resource pool, as the functioning of vital physiological processes and the expression of different phenotypic traits may depend on different optimal ratios of nutrients (“intake target”, sensu Raubenheimer \& Simpson, 1993). Dietary nutrient ratio could therefore potentially influence relationships between multiple male sexual traits if, for example, their expression depends on differing optimal nutrient ratios, or if a priority 
allocation of a limiting nutrient towards one trait negatively affects the expression of another (Rowe \& Houle, 1996; Tomkins et al., 2004). Additionally, both surpluses and deficits of nutrients from eating imbalanced foods can result in fitness costs, including reduced reproductive output, obesity, malnutrition, or toxicity (Huggins, Navara, Mendonça, \& Hill, 2010; Raubenheimer et al., 2005; Raubenheimer \& Simpson, 2006). Thus, researchers are shifting towards nutritionally-explicit approaches to understand the influence of diet on mate attraction signalling and other sexual traits (e.g. amphipods: Goos, Cothran, \& Jeyasingh, 2016; crickets: Harrison, Raubenheimer, Simpson, Godin, \& Bertram, 2014; Maklakov et al., 2008; flies: Sentinella, Crean, \& Bonduriansky, 2013; cockroaches: South et al., 2011).

Comparatively fewer studies have examined the influence of nutrition on aggressive behaviours related to male-male competition, with most studies using crude measures of individual energy reserves, such as body weight or weight corrected for size (e.g. Bertram \& Rook, 2012; Brown, Smith, Moskalik, \& Gabriel, 2006; Fitzsimmons \& Bertram, 2012; Wilson et al., 2010). Only two studies to date have used a nutritionallyexplicit approach that considers how dietary nutrient ratio influences aggression or dominance (crickets: Han \& Dingemanse, 2017; cockroaches: South et al., 2011). Collectively, these studies have provided mixed support for an influence of nutrition on aggressive behaviour in the context intra-sexual competition. However, in non-sexual contexts, dietary composition and overall hunger levels have been found to influence aggression (e.g. crickets: Adamo \& Hoy, 1995; house sparrows; Andersson \& Åhlund, 1991; redback spiders: Andrade, 1998; Argentine ants: Grover, Kay, Monson, Marsh, \& 
Holway, 2007). Clearly, further work is needed on the extent to which dietary nutrient balance influences aggression in the context of male-male competition.

In field crickets (Grillidae), both acoustic mate attraction signalling and malemale aggression influence male reproductive success (Alexander, 1961). Male field crickets compete in aggressive (agonistic) contests with rivals for access to mating territories, from which they signal acoustically to attract mates from a distance (Alexander, 1961). Female field crickets prefer to mate with males that produce higher effort acoustic mate attraction signals (Hirtenlehner \& Römer, 2014; Holzer et al., 2003; Scheuber, Jacot, \& Brinkhof, 2004; Wagner, 1996), and males that are successful at winning fights (Nelson \& Nolen, 1997; Savage, Hunt, Jennions, \& Brooks, 2005). While field crickets are frequently used as model organisms in studies of animal aggression (e.g. Adamo \& Hoy, 1995; Bertram, Rook, Fitzsimmons, \& Fitzsimmons, 2011; Judge \& Bonanno, 2008) and acoustic signalling (e.g. Chapter 3; Harrison et al., 2014; Maklakov et al., 2008), little research has been done on examining relationships between these sexually selected behaviours. There is evidence that higher aggression levels are related to more 'proactive' behavioural profiles that include greater motility, exploration, and general activity (e.g. Rose, Cullen, Simpson, \& Stevenson, 2017), leading to the expectation that aggression may be related to signalling activity. There is some evidence that aggression might be related to fine-scale temporal (e.g. pulse and chirp rates), amplitude, and frequency aspects of cricket acoustic signals (Bertram \& Rook, 2012; Brown et al., 2006). However, previous studies examining correlations between aggression and broad-scale measures of mate attraction signalling effort in field crickets 
have found no relationship (e.g. total signalling time, signalling bout duration, signalling bout rate: Fitzsimmons \& Bertram, 2012; Wilson et al., 2010). Thus, our understanding of how these two components of male field cricket reproductive success are related to one another remains unclear.

Both acoustic signalling and aggression are energetically costly behaviours for male crickets, resulting in a 2- to 13-fold increase in oxygen consumption over resting rates (Hack, 1997; Hoback \& Wagner, 1997; Prestwich, 1994). Additionally, agonistic contests between rivals typically involve a stereotypical escalating sequence of discrete behaviours (Adamo \& Hoy, 1995; Alexander, 1961), with energetic expenditure increasing with both contest duration and level of escalation (Hack, 1997). Carbohydrate metabolism appears to be the main source of energy for fueling increased metabolic activity in muscle tissue associated with acoustic signalling (Thomson, Darveau, \& Bertram, 2014) and agonistic contests (Briffa, 2008), and increasing the ratio of dietary carbohydrate relative to protein content appears to be positively correlated with acoustic signalling effort in crickets (Maklakov et al., 2008). Acoustic signalling effort in crickets is also positively associated with increased phosphorus intake (Bertram et al., 2009), which may be due to phosphorus (an important component of RNA) fuelling the repair and replacement of damaged proteins in muscles and other tissue involved in high metabolic activity (Bertram et al., 2006). Only one study to date has examined the influence of dietary nutrient balance of protein, carbohydrate, and phosphorus on acoustic mate attraction signalling in any species (crickets: Harrison et al., 2014; Chapter 3). To 
my knowledge, the combined influence of these nutrients on other metabolically costly traits, such as aggressive behaviour, has not been examined.

In the current study, I investigated how dietary protein, carbohydrate, and phosphorus composition influence investment in acoustic mate attraction signalling and aggressive behaviour in male spring field crickets (Gryllus veletis). My aim was to answer three questions: (1) How does dietary nutrient composition influence signalling and aggression?, (2) How is signalling related to aggression, and does dietary nutrient composition influence the relationship?, and (3) Do males alter their signalling behaviour following agonistic contests, and are these changes related to their level of aggression or dietary nutrient composition? I predicted that individuals consuming diets high in carbohydrates (i.e. low protein:carbohydrate ratio) and phosphorus would invest more heavily in both signalling and aggression, whereas individuals consuming diets low in both carbohydrates and phosphorus would be unable to afford the costs of both higheffort signalling and aggression, resulting in either reduced investment in both behaviours or a trade-off between them. Similarly, I predicted that when males invest heavily in aggression, only males consuming diets high in both carbohydrates and phosphorus should be able to invest heavily in signalling following the agonistic contest.

By examining the influence of energetic macronutrients (protein and carbohydrates) in tandem with an elemental nutrient (phosphorus), my study links two disparate areas of research in the field of nutritional ecology - ecological stoichiometry and nutritional geometry - which seek to understand how nutrients drive variation in biological systems. Ecological stoichiometry focusses on the importance of elemental 
nutrients like carbon, nitrogen, and phosphorus (e.g. Bertram et al., 2006; Elser et al., 2000; Schade et al., 2003; Sterner \& Elser, 2002), whereas nutritional geometry focusses on energetic macronutrients such as proteins, lipids and carbohydrates (e.g. Chapter 3; Harrison et al., 2014; Lee et al., 2008; Maklakov et al., 2008; Mayntz et al., 2009; Raubenheimer \& Simpson, 1993; Simpson \& Raubenheimer, 1993; South et al., 2011). Furthermore, by studying the condition-dependence of multiple sexually selected male traits and their interactions in unison, I hope to increase our understanding of how diet may influence mechanisms of sexual selection ("total sexual selection", sensu Hunt, Breuker, Sadowski, \& Moore, 2009).

\subsection{Methods}

\subsubsection{Subjects and rearing}

Using the colony rearing conditions outlined in Chapter 2, section 2.2, I raised experimental male $G$. veletis in same-sex communal bins ( $\sim 100$ individuals) from approximately the $5^{\text {th }}$ larval instar until the day they reached adulthood. Adult males were then weighed using a Denver Instruments analytical balance (Pinnacle Series model PI114 ; precision $\pm 0.1 \mathrm{mg}$ ) and assembled into 41 groups of six similar-aged individuals differing in wet mass by no more than $25 \%(15.8 \pm 7.43 \%)$. I then painted the dorsal side of the prothorax of each group member with one of six different colours of enamel paint (Sally Hansen Insta-Dri ${ }^{\circledR}$ nail polish) and assigned each male within a group to one of six experimental diets (described below; diet and paint colours assigned at random, without repetition within group). Experimental adult males were housed individually in 
clear $520 \mathrm{~mL}$ plastic containers with a screened lid, a plastic shelter, ad libitum water and their assigned experimental diet. Thus, group members may have interacted as juveniles, but I ensured no physical interaction between adult males for a minimum of 11 days before their aggressive behavioural trials. Occasionally an experimental adult male died before their aggression trial $(26 / 390=6.7 \%)$, leaving incomplete groups. I replaced these males when possible, resulting in crickets within a group differing in age by up to 7 days.

\subsubsection{Experimental diets}

I created six powdered experimental diets varying in protein $(\mathrm{P})$, carbohydrate $(\mathrm{C})$, and phosphorus $(\mathrm{PH})$ concentration following established protocols (Simpson \& Abisgold, 1985; Chapter 2, section 2.3). All diets were comprised (by mass) of 45\% indigestible cellulose, $50 \%$ total nutrients $(\mathrm{P}+\mathrm{C}+\mathrm{PH})$, and 5\% vitamins, minerals, and lipids (see Chapter 2, section 2.3 for further details on diet composition). Diets consisted of three protein to carbohydrate ratios (high-protein $-3_{\mathrm{P}}: 1_{\mathrm{C}}$; equal protein:carbohydrate $-1_{\mathrm{P}}: 1_{\mathrm{C}}$; high-carbohydrate $1_{\mathrm{P}}: 3_{\mathrm{C}}$ ), each varied at two phosphorus levels (low-phosphorus $0.45 \% \mathrm{PH}$ and high-phosphorus $-1.45 \% \mathrm{PH}$ of total nutrients, corresponding to $0.21 \% \mathrm{PH}$ and $0.66 \%$ pH of total dry food mass).

\subsubsection{Mate attraction signal recording}

On day 7 of adulthood of the youngest individual in the group, I placed males in an Electronic Acoustic Recording System (EARS II; see Chapter 2, section 2.4 for further details) to record their long-distance acoustic mate attraction signalling behaviour 
(hereafter 'signalling'). Males were kept in the EARS II continuously from days 7 to 14 of adulthood of the youngest individual in the group, except for $1 \mathrm{~h}$ on day 11 when aggressive behaviour trials (hereafter 'aggression trials') were performed. Thus, males were acoustically isolated from one another for four days prior to their aggression trial. I recorded the following 10 mean daily signalling parameters: time spent signalling (min), pulse duration (ms), inter-pulse duration (ms), pulse rate (\# pulses/s), chirp duration (ms), inter-chirp duration (ms), number of pulses per chirp, chirp rate (\# chirps/min), carrier frequency (Hz), and amplitude (dB) (see Chapter 2, section 2.4 for further details). Day 7 in the EARS II was used as an acclimatization period, and I partitioned the signalling data from days 8-14 into two time periods - those measured before (pre-fight) and those measured after the aggression trial (post-fight). I performed principal components analysis with varimax factor rotation in JMP v.13. (SAS Institute Inc., Cary, NC) on the 10 pre-fight signalling parameters and identified three factors that collectively explained $75 \%$ of the variation in pre-fight signalling (Table 4.1 ; signalling factor $1=37 \%$, signalling factor $2=24 \%$, signalling factor $3=14 \%$ ). In all further statistical analyses, I used signalling factors 1-3 as my measures of signalling prior to aggression trials.

I then quantified how each of the 10 signalling parameters changed following the aggression trial by subtracting each signalling parameter's pre-fight value from its postfight value (positive changes indicate an increase and negative changes indicate a decrease in the signalling parameter following the aggression trial). I then performed principal components analysis with varimax factor rotation on these 10 signalling difference values and identified three factors that collectively explained $71 \%$ of the 
variation in signalling change between pre- and post-fight time periods (Table 4.1; signalling change factor $1=28 \%$, signalling change factor $2=25 \%$, signalling change factor $3=18 \%$ ). I emphasize here that signalling change factors $1-3$ (i.e. pre- vs. postfight) do not represent a change in signalling factors 1-3 (i.e. only pre-fight), as individual pre-fight signalling parameters that loaded onto a specific signalling factor did not necessarily change in the same manner following the aggression trial (Table 4.1). In all further statistical analyses, I used signalling change factors 1-3 as my measures of change in signalling behaviour following the aggression trials. 
Table 4.1. Rotated factor loadings for individual signalling parameters measured prior to aggression trials (signalling factors 1-3), and changes in signalling parameters following aggression trials (signalling change factors 1-3). Bolded loadings indicate the factor on which each signalling parameter loaded most heavily. Signs (+/-) on loadings indicate that higher levels of a factor are either (i) positively/negatively associated with a signalling parameter prior to aggression trials (signalling factors), or (ii) associated with an increase/decrease in a signalling parameter following aggression trials (signalling change factors).

\section{Signalling Signalling Change}

Signalling Parameter Factor 1 Factor 2 Factor 3 Factor 1 Factor 2 Factor 3

\begin{tabular}{lrrrrrr}
\hline Time Spent Signalling & 0.435 & $\mathbf{0 . 5 4 1}$ & 0.096 & 0.220 & $\mathbf{0 . 6 8 5}$ & -0.034 \\
Pulse Duration & 0.464 & 0.357 & $\mathbf{- 0 . 6 6 5}$ & -0.234 & 0.530 & $\mathbf{0 . 6 4 1}$ \\
Inter-Pulse Duration & $\mathbf{- 0 . 9 4 0}$ & -0.013 & 0.187 & -0.392 & $\mathbf{- 0 . 8 3 3}$ & -0.149 \\
Pulses per Chirp & 0.206 & $\mathbf{0 . 8 6 1}$ & -0.297 & 0.210 & 0.176 & $\mathbf{0 . 8 4 1}$ \\
Chirp Duration & -0.396 & $\mathbf{0 . 8 2 2}$ & -0.161 & -0.020 & -0.431 & $\mathbf{0 . 7 8 2}$ \\
Inter-Chirp Duration & $\mathbf{- 0 . 7 1 3}$ & -0.426 & -0.157 & $\mathbf{- 0 . 7 6 5}$ & -0.315 & -0.159 \\
Carrier Frequency & 0.237 & 0.001 & $\mathbf{0 . 8 2 1}$ & $\mathbf{0 . 6 4 5}$ & 0.230 & -0.227 \\
Amplitude & 0.495 & $\mathbf{0 . 5 5 1}$ & 0.233 & $\mathbf{0 . 7 7 8}$ & 0.056 & 0.087 \\
Pulse Rate & $\mathbf{0 . 9 1 6}$ & -0.133 & 0.030 & 0.494 & $\mathbf{0 . 7 4 8}$ & -0.057 \\
Chirp Rate & $\mathbf{0 . 7 4 4}$ & 0.316 & 0.179 & $\mathbf{0 . 7 8 6}$ & 0.324 & 0.057 \\
\hline
\end{tabular}




\subsubsection{Aggressive behaviour trials and scoring}

I ran each group's aggression trial in a clear plastic cylindrical arena $(20 \mathrm{~cm}$ diameter $\mathrm{x}$ $25 \mathrm{~cm}$ height) with a sand-covered bottom, which was positioned within a large open-top wooden box ( $74 \mathrm{~cm}$ length $\times 36 \mathrm{~cm}$ width $\times 42.5 \mathrm{~cm}$ height) to minimize observer disturbance. Prior to the start of the trial, I inserted a solid, opaque Plexiglas divider that partitioned the arena into six equal sextant $\left(60^{\circ}\right)$ sectors. On day 11 of adulthood of the youngest male in the group, I placed each group member into his own arena sector at random, thereby ensuring he could not see or physically interact with any of the other males in his group. After a 10-min acclimatization period, I removed the divider and allowed the males to physically interact. I recorded their aggressive behaviours from above for $15 \min (900 \mathrm{~s})$ using a Canon Vixia HG10 video camera. Males were returned to the EARS II immediately following the aggression trial to monitor their post-fight signalling behaviour. All aggression trials were run between 09:00 and 14:00 h in a quiet room at $26 \pm 2^{\circ} \mathrm{C}$ under overhead fluorescent lighting. At the end each trial, I wiped down the arena's walls and divider with $99 \%$ ethyl alcohol to prevent pheromones from affecting subsequent trials.

I used JWatcher v.1.0. (http://www.jwatcher.ucla.edu/registerJwatcher.html) to score each male's aggressive behaviour. Aggressive behaviours were scored on a scale from 0 to 5: with $0=$ no aggression/withdrawal; $1=$ unilateral or bilateral antennal fencing; 2 = back leg kick or victory display (body judder or judder combined with an aggressive call); 3 = unilateral mandible spread, chasing, aggressive call and/or biting; 4 = bilateral mandible spread, chasing, aggressive call and/or biting; $5=$ bilateral grapple: 
two males lock mandibles and pull or wrestle (adapted from Adamo \& Hoy, 1995;

Bertram \& Rook, 2012; Jang, Gerhardt, \& Choe, 2008). Males occasionally performed same-sex courtship behaviours (analyzed and reported in Boutin, Harrison, Fitzsimmons, McAuley, \& Bertram, 2016), which I scored as non-aggressive in the current study. I quantified two measures of aggression for each male: maximum aggression score was taken as the highest scoring behaviour recorded $(0-5)$, and overall aggression intensity score, a cumulative measure of how aggressive a male was towards all other group members, was calculated using equation 1 .

$$
\begin{aligned}
& \text { Aggression Intensity Score } \\
& \qquad=\frac{\sum(\text { score of behaviour } \mathrm{x} \text { time spent performing behaviour }(\mathrm{s}))}{4500 \mathrm{~s}}
\end{aligned}
$$

The denominator in equation (1) is equivalent to the maximum possible behaviour score multiplied by the trial duration in seconds (i.e. $5 \times 900 \mathrm{~s}=4500 \mathrm{~s}$ ). Thus, individuals performing the most aggressive behaviour (i.e. $5=$ bilateral grapple) for the entire aggression trial would receive an aggression intensity score of 1 , whereas an individual performing the least aggressive behaviour for the entire trial (i.e. $0=$ no aggression/withdrawal) would receive an aggression intensity score of 0 .

Using principal components analysis in JMP v.13, I identified a single principal component (aggPC1) that explained $71 \%$ of the variation in the two measures of 
aggression (eigenvalue $=1.42$; eigenvector loadings $=0.71$ for both). In all further statistical analyses, I used aggPC1 as my measure of aggression.

\subsubsection{Body size measurements}

I removed each group of males from the EARS II and humanely euthanized them (by freezing) on day 14 of adulthood of the youngest male in the group. I photographed each male dorsal side up beside a ruler using a Sony Nex 7 camera (30mm, F3.5 macro lens) and then used ImageJ software (http:// imagej.nih.gov/ij/) to obtain three body size measures: maximum pronotum length along the anterior-posterior axis, maximum pronotum width, and maximum distance between the outer edges of the eyes. Using principal components analysis in JMP v.13, I identified a single principal component (sizePC1) that explained $93 \%$ of the variation in the three body size measures (eigenvalue $=2.80$; eigenvector loadings: 0.57 for all three), and used sizePC1 as my measure of body size in all statistical analyses.

\subsubsection{Data analyses}

To examine how dietary nutrient composition influences aggression, I fitted a linear mixed model (LMM) using the maximum likelihood (ML) method using the 'lme4' package (Bates, Mächler, Bolker, \& Walker, 2015) in R v.3.3.2 (R Development Core Team, Vienna, Austria; http://www.R-project.org). I included aggression score (aggPC1) as the dependent variable, group ID as a random effect, and age, body size (sizePC1), protein:carbohydrate ratio, phosphorus level, and the interaction between 
protein:carbohydrate ratio and phosphorus level as explanatory variables. I included group ID as a random effect to control for variance in the dependent variable explained by shared experiences during recording in the EARS II (even though they were housed individually and in acoustic isolation of each other) and/or aggression trials, and I included both age and body size as covariates in order to statistically remove (control for) their effects since they are known to influence signalling and aggression in crickets (Bertram \& Rook, 2012; Brown et al., 2006; Fitzsimmons \& Bertram, 2011; Judge \& Bonanno, 2008). Model simplification (see below) resulted in the removal of the interaction between protein:carbohydrate ratio and phosphorus level from the aggression model.

To examine how signalling is related to dietary nutrient composition, aggressive behaviour, and their interaction, I fitted three LMMs using the ML method in R using signalling factors 1-3 (calculated using a PCA on pre-fight signalling parameters) as the dependent variables. I used only pre-fight signalling data rather than all signalling data in these models to avoid the confounding effects that exposure to rival males and energy expenditure during aggressive trials may have had on signalling behaviour (e.g. winner/loser effects: Adamo \& Hoy, 1995; victory displays: Rook, Fitzsimmons, \& Bertram, 2010). Thus, my pre-fight signalling models ask how mate attraction signalling (unaltered by aggressive experience or activity levels) relates to aggression. Models included group ID as a random effect, and explanatory variables were age, body size (sizePC1), aggression score (aggPC1), protein:carbohydrate ratio, phosphorus level, and all 2- and 3- way interactions between aggPC1, protein:carbohydrate ratio, and 
phosphorus level. Males that did not signal prior to the aggression trial $(18 / 246=7.3 \%)$ were omitted from all signalling analyses. Model simplification resulted in the removal of all interactions between aggPC1, protein:carbohydrate ratio and phosphorus level from all signalling models.

To quantify how males change their signalling behaviour after aggression trials, I first estimated the repeatability of long-distance signalling parameters between pre- and post-fight time periods by estimating intraclass correlation coefficients (ICC) and $95 \%$ confidence intervals using the 'ICC' package (Wolak, Fairbairn, \& Paulsen, 2012) in R 3.3.2. I considered a signalling parameter to have a high degree of repeatability if its ICC estimate was $>0.60$ (Cicchetti, 1994) and the $95 \%$ confidence interval did not include zero (Wolak et al., 2012).

I then fitted three LMMs using the ML method in R using signalling change factors 1-3 (calculated using a PCA on the differences between pre-and post-fight signalling parameters) as the dependent variables. Models included group ID as a random effect, and explanatory variables were age, body size (sizePC1), aggression score (aggPC1), protein:carbohydrate ratio, phosphorus level, and all 2- and 3- way interactions between aggPC1, protein:carbohydrate ratio and phosphorus level. Model simplification resulted in the removal of all interactions between aggPC1, protein:carbohydrate ratio, and phosphorus level from signalling change models, with the exception of aggPC $1 *$ Phosphorus in the signalling change factor 3 model. Males that did not signal during either one or both 3 -day time periods $(27 / 246=11 \%)$ were omitted from all signalling change analyses. I used signalling change factors 1-3 as dependant variables 
rather than running a single repeatability model with all signalling data from pre- and post-fight time periods because the later models required the addition of a time variable (i.e. pre- and post-fight signalling) plus all interactions with other predictors. The resultant full models would therefore have had 17 predictor variables ( 25 parameter estimates), which would have severely reduced the statistical power and the ability to detect the effects of diet and aggression on signalling behaviour.

I used a normal error structure and identity link function in all LMMs as residual diagnostic plots (residuals vs. fitted values and Q-Q plots) indicated residuals followed normal distributions. LMMs were simplified by removing non-significant interaction terms by comparing the residual sums of squares of progressively reduced nested models using the 'anova()' function in R. To estimate overall model fits, I calculated two pseudoR-squared terms following Nakagawa \& Schielzeth (2013) using the 'r.squaredGLMM()' function in R's 'MuMIn' package: (i) marginal R-squared $\left(\mathrm{R}_{\mathrm{m}}^{2}\right)$, representing the variance explained by the fixed factors alone, and (ii) conditional R-squared $\left(\mathrm{R}^{2}\right)$, representing the variance explained by both fixed and random factors (i.e. whole model). P-values and denominator degrees of freedom were calculated based on Satterthwaite's approximation (type II sums of squares) using R's 'lmerTest' package. Marginal effects plots with 95\% confidence intervals were created using R's sjPlot and ggplot2 packages. For models with significant protein:carbohydrate ratio diet effects, I examined how the dependent variable changed across diet treatment using pairwise Tukey's HSD contrasts using the 'multcomp' package in R (Hothorn, Bretz, \& Westfall, 2008). I corrected for 
multiple hypotheses tests using the false discovery rate FDR $_{\mathrm{B}-\mathrm{Y}}$ method (Benjamini \& Yekutieli, 2001).

\subsection{Results}

Aggressive behaviour (aggPC1) was not influenced by diet, but there was a nonsignificant trend for larger males (sizePC1) to be more aggressive than smaller males (Table 4.2; Appendix 2, Table A2.1). Pre-fight acoustic mate attraction signalling was influenced by both diet and body size (Figure 4.1A-C; Table 4.3; Appendix 2, Table A2.2). Males consuming low-phosphorus $(0.45 \% \mathrm{pH})$ diets had higher signalling factor 1 scores (shorter inter-pulse and inter-chirp durations; higher pulse and chirp rates; Figure 4.1A; Tables 4.1, 4.3, \& A2.2) compared to males consuming high-phosphorus $(1.45 \% \mathrm{PH})$ diets. Larger males (sizePC1) had significantly higher signalling factor 2 scores (longer time spent signalling; greater pulses per chirp, chirp durations and amplitudes; Figure 4.1B; Tables 4.1, 4.3, \& A2.2) and lower signalling factor 3 scores (longer pulse durations; lower carrier frequencies; Figure 4.1C; Tables 4.1, 4.3, \& A2.2). There was also a near-significant trend for more aggressive males to have lower signalling factor 3 scores (Figure 4.1D; Tables 4.1, 4.3, \& A2.2).

All signalling parameters were highly repeatable between the pre- and post-fight signalling periods (Table 4.4; all ICC >0.62; all CI $\nsupseteq 0$ ). Neither diet, aggression, nor their interaction predicted changes in inter-chirp duration, carrier frequency, amplitude, or chirp rate signalling parameters represented by signalling change factor 1 (Tables 4.1 \& 4.5; Appendix 2, Table A2.3). There was, however, a non-significant trend for males 
consuming high-carbohydrate $\left(1_{\mathrm{P}}: 3_{\mathrm{C}}\right)$ diets to have higher signalling change factor 2 scores (increased time spent signalling and pulse rate; decreased inter-pulse duration) compared to males consuming equal protein:carbohydrate $\left(1_{\mathrm{P}}: 1_{\mathrm{C}}\right)$ and high-protein $\left(3_{\mathrm{P}}: 1_{\mathrm{C}}\right)$ diets (Figure 4.2A; Tables 4.1, 4.5, \& A2.3). Dietary protein:carbohydrate ratio also significantly influenced signalling change factor 3 (Figure 4.2B; Tables 4.1, 4.5, \& A2.3). Pairwise Tukey's HSD contrasts indicated that males consuming high-protein $\left(3_{\mathrm{P}}: 1_{\mathrm{C}}\right)$ diets had significantly lower signalling change factor 3 scores (lower pulse duration, pulses per chirp, and chirp duration) compared to males consuming both highcarbohydrate $\left(1_{\mathrm{P}}: 3_{\mathrm{C}} ; P=0.041\right)$ and equal protein:carbohydrate $\left(1_{\mathrm{P}}: 1_{\mathrm{C}} ; P=0.033\right)$ diets, whereas high-carbohydrate and equal protein:carbohydrate treatments did not significantly differ $(P=0.999)$. Aggressive behaviour (aggPC1) also influenced signalling change factor 3 , but that effect was dependent on dietary phosphorus level (Figure 4.2C; Tables 4.5 \& A2.3). Investment in aggressive behaviour was positively correlated with signalling change factor 3 (increased pulse duration, pulses per chirp and chirp duration) when males consumed low-phosphorus $(0.45 \% \mathrm{pH})$ diets (Figure $4.2 \mathrm{C}$; Tables 4.1, 4.5, \& A2.3). However, a trade-off occurred between investment in aggressive behaviour and signalling post-aggression trial when males consumed highphosphorus (1.45\% $\mathrm{PH}$ ) diets (Figure 4.2C; Tables $4.5 \& \mathrm{~A} 2.3$ ). 
Table 4.2. Model effects tests for the linear mixed model examining factors influencing aggression (aggPC1). FDR $\mathrm{B}_{\mathrm{Y}}$ corrected level of significance is $P=0.024$. Significant terms are bolded. Parameter estimates for this model can be found in Appendix 2, Table A2.1.

\begin{tabular}{|c|c|c|c|c|c|c|}
\hline Model & $\mathbf{R}_{\mathrm{m}}^{2}$ & $\mathbf{R}_{\mathrm{c}}^{2}$ & Model Effect & $F$ & df & $P$ \\
\hline \multirow[t]{4}{*}{ AggPC1 } & 0.038 & 0.101 & Age & 1.813 & $1,101.58$ & 0.181 \\
\hline & & & SizePC1 & 0.041 & $1,97.37$ & 0.042 \\
\hline & & & Protein:Carbohydrate & 0.797 & $2,203.75$ & 0.797 \\
\hline & & & Phosphorus & 0.750 & $1,202.57$ & 0.750 \\
\hline
\end{tabular}



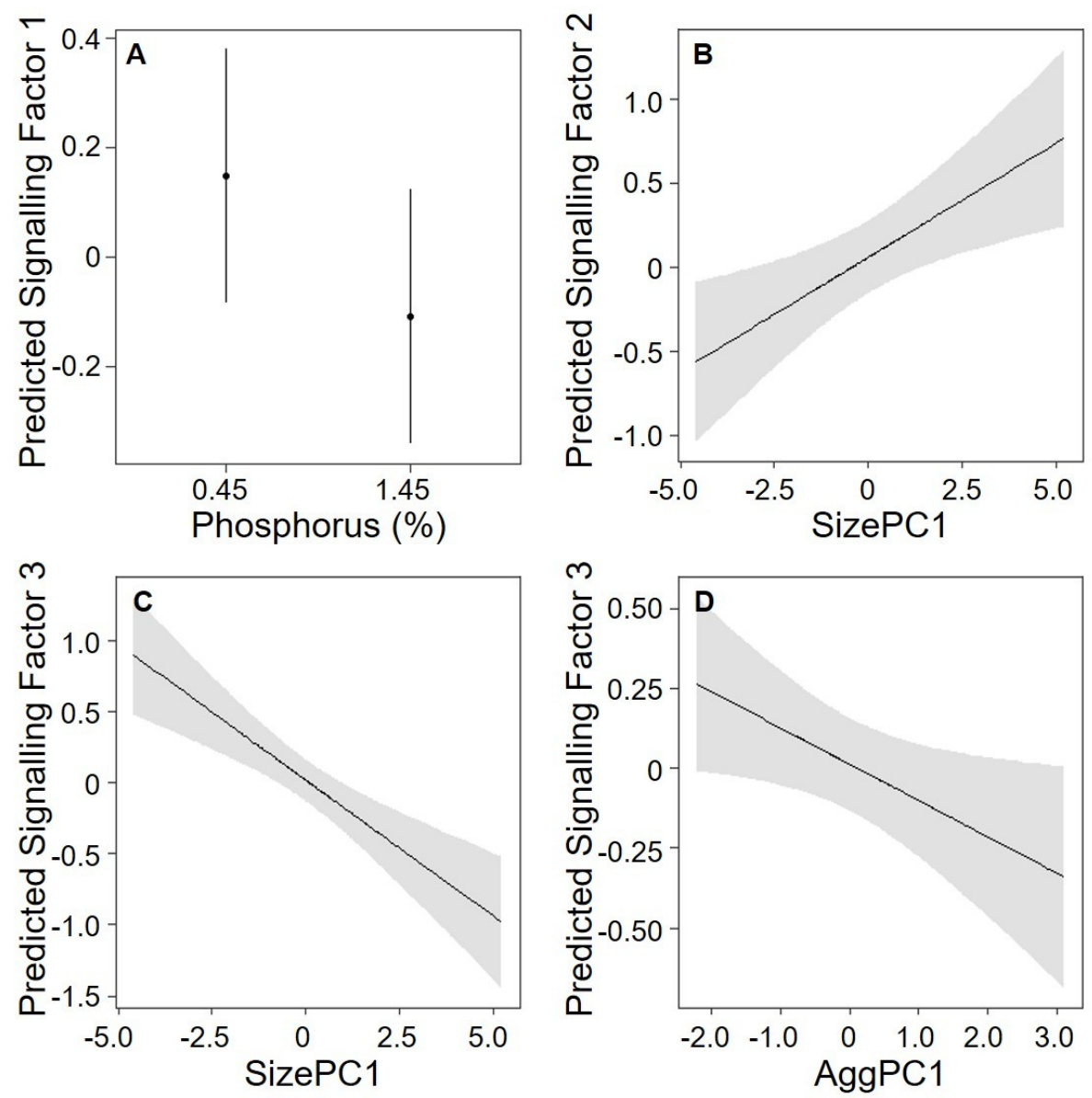

Figure 4.1. Marginal effects plots with $95 \%$ confidence intervals showing how dietary phosphorus, body size (sizePC1), and aggression (aggPC1) influence pre-fight signalling: A) males consuming low-phosphorus $(0.45 \% \mathrm{PH})$ diets have higher predicted signalling factor 1 scores (shorter inter-pulse and inter-chirp durations; higher pulse and chirp rates) compared to males consuming high-phosphorus (1.45\% higher predicted signalling factor 2 scores (longer time spent signalling; greater pulses per chirp, chirp durations and amplitudes); C) larger and D) more aggressive males had lower predicted signalling factor 3 scores (longer pulse durations; lower carrier frequencies). 
Table 4.3. Model effects tests for linear mixed models examining factors influencing prefight signalling (signalling factors 1-3). FDR $\mathrm{B}_{\mathrm{B}-\mathrm{Y}}$ corrected level of significance is $P=$ 0.022. Significant terms are bolded. Parameter estimates for these models can be found in Appendix 2, Table A2.2.

\begin{tabular}{|c|c|c|c|c|c|c|}
\hline Model & $\mathbf{R}_{m}^{2}$ & $\mathbf{R}_{c}^{2}$ & Model Effect & $F$ & $d f$ & $P$ \\
\hline \multirow{5}{*}{$\begin{array}{l}\text { Signalling } \\
\text { Factor } 1\end{array}$} & 0.051 & 0.412 & Age & 0.363 & $1,193.32$ & 0.548 \\
\hline & & & SizePC1 & 3.590 & $1,184.46$ & 0.060 \\
\hline & & & AggPC1 & 2.007 & $1,208.82$ & 0.158 \\
\hline & & & Protein:Carbohydrate & 0.730 & $2,187.03$ & 0.483 \\
\hline & & & Phosphorus & 6.476 & $1,184.64$ & 0.012 \\
\hline \multirow{5}{*}{$\begin{array}{l}\text { Signalling } \\
\text { Factor } 2\end{array}$} & 0.062 & 0.455 & Age & 0.115 & $1,204.52$ & 0.735 \\
\hline & & & SizePC1 & 8.495 & $1,196.56$ & 0.004 \\
\hline & & & AggPC1 & 0.555 & $1,208.06$ & 0.457 \\
\hline & & & Protein:Carbohydrate & 2.185 & $2,189.37$ & 0.115 \\
\hline & & & Phosphorus & 1.890 & $1,187.20$ & 0.171 \\
\hline \multirow{5}{*}{$\begin{array}{l}\text { Signalling } \\
\text { Factor } 3\end{array}$} & 0.139 & 0.221 & Age & 0.448 & $1,104.03$ & 0.505 \\
\hline & & & SizePC1 & 19.871 & $1,104.92$ & $<0.001$ \\
\hline & & & AggPC1 & 4.803 & $1,227.01$ & 0.029 \\
\hline & & & Protein:Carbohydrate & 0.100 & $2,188.37$ & 0.905 \\
\hline & & & Phosphorus & 0.806 & $1,185.45$ & 0.370 \\
\hline
\end{tabular}


Table 4.4. Repeatability estimates for the signalling parameters of 219 males measured before and after their aggressive behaviour trial (i.e. $\mathrm{k}=2$ measurements per individual). $\mathrm{ICC}=$ intraclass correlation coefficient, $\mathrm{CI}=$ confidence interval.

\begin{tabular}{lcc}
\hline Signalling Parameter & ICC & $\mathbf{9 5 \%}$ CI \\
\hline Time Spent Signalling (min) & 0.62 & $0.53-0.70$ \\
Pulse Duration (ms) & 0.89 & $0.86-0.92$ \\
Inter Pulse Duration (ms) & 0.86 & $0.82-0.89$ \\
Pulses Per Chirp & 0.93 & $0.91-0.94$ \\
Chirp Duration (ms) & 0.92 & $0.90-0.94$ \\
Inter Chirp Duration (ms) & 0.80 & $0.75-0.84$ \\
Carrier Frequency (Hz) & 0.91 & $0.89-0.93$ \\
Amplitude (dB) & 0.84 & $0.79-0.87$ \\
Pulse Rate (\# pulses/s) & 0.85 & $0.81-0.88$ \\
Chirp Rate (\# chirps/min) & 0.77 & $0.71-0.82$ \\
\hline
\end{tabular}


Table 4.5. Model effects tests for linear mixed models examining factors influencing signalling change following aggressive behaviour trials (signalling change factors 1-3). $\mathrm{FDR}_{\mathrm{B}-\mathrm{Y}}$ corrected level of significance is $P=0.022$ for signalling change factors $1 \& 2$, and $P=0.020$ for signalling change factor 3 . Significant terms are bolded. Parameter estimates for these models can be found in Appendix 2, Table A2.3.

\begin{tabular}{|c|c|c|c|c|c|c|}
\hline Model & $\mathbf{R}_{\mathrm{m}}^{2}$ & $\mathbf{R}_{\mathrm{c}}^{2}$ & Model Effect & $F$ & df & $P$ \\
\hline \multirow{5}{*}{$\begin{array}{l}\text { Signalling } \\
\text { Change } \\
\text { Factor } 1\end{array}$} & 0.025 & 0.188 & Age & 0.868 & $1,127.49$ & 0.353 \\
\hline & & & SizePC1 & 1.035 & $1,130.15$ & 0.311 \\
\hline & & & AggPC1 & 0.206 & $1,213.78$ & 0.650 \\
\hline & & & Protein:Carbohydrate & 0.942 & $2,182.75$ & 0.392 \\
\hline & & & Phosphorus & 2.230 & $1,180.92$ & 0.137 \\
\hline \multirow{5}{*}{$\begin{array}{l}\text { Signalling } \\
\text { Change } \\
\text { Factor } 2\end{array}$} & 0.052 & 0.241 & Age & 2.093 & $1,133.52$ & 0.150 \\
\hline & & & SizePC1 & 1.792 & $1,134.85$ & 0.183 \\
\hline & & & AggPC1 & 0.191 & $1,211.28$ & 0.663 \\
\hline & & & Protein:Carbohydrate & 3.099 & $2,180.49$ & 0.048 \\
\hline & & & Phosphorus & 0.009 & $1,178.57$ & 0.926 \\
\hline \multirow{6}{*}{$\begin{array}{l}\text { Signalling } \\
\text { Change } \\
\text { Factor } 3\end{array}$} & 0.109 & 0.139 & Age & 1.277 & $1,88.66$ & 0.261 \\
\hline & & & SizePC1 & 1.955 & $1,97.49$ & 0.165 \\
\hline & & & AggPC1 & 1.457 & $1,218.96$ & $<0.001$ \\
\hline & & & Protein:Carbohydrate & 4.047 & $1,184.06$ & 0.019 \\
\hline & & & Phosphorus & 0.554 & $2,182.41$ & 0.458 \\
\hline & & & AggPC1 ${ }^{*}$ Phosphorus & 14.953 & $1,216.21$ & $<0.001$ \\
\hline
\end{tabular}



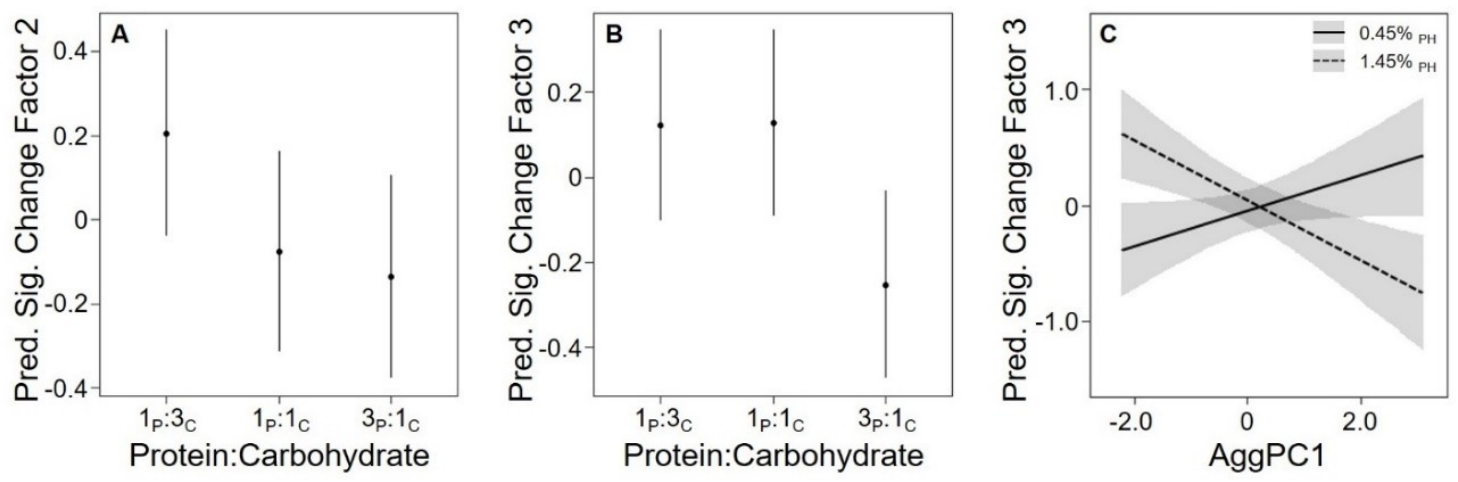

Figure 4.2. Marginal effects plots with $95 \%$ confidence intervals showing how dietary protein:carbohydrate ratio, and an interaction between aggression (aggPC1) and phosphorus level, influence changes in signalling following aggression trials: A) males consuming high-carbohydrate $\left(1_{\mathrm{P}}: 3_{\mathrm{C}}\right)$ diets had higher predicted signalling change factor 2 scores (increased time spent signalling and pulse rate; decreased inter-pulse duration) compared to males consuming high-protein $\left(3_{\mathrm{P}}: 1_{\mathrm{C}}\right)$ and equal protein:carbohydrate $\left(1_{\mathrm{P}}: 1_{\mathrm{C}}\right)$ diets; $\left.\mathrm{B}\right)$ Males consuming high-carbohydrate $\left(1_{\mathrm{P}}: 3_{\mathrm{C}}\right)$ and equal protein:carbohydrate $\left(1_{\mathrm{P}}: 1_{\mathrm{C}}\right)$ diets had higher predicted signalling change factor 3 scores (increased pulse duration, pulses per chirp and chirp duration) compared to males consuming high-protein $\left(3_{\mathrm{P}}: 1_{\mathrm{C}}\right)$ diets; $\left.\mathrm{C}\right)$ predicted signalling change factor 3 scores increase (increased pulse duration, pulses per chirp and chirp duration) with aggressiveness when males consume low-phosphorus $(0.45 \% \mathrm{PH})$ diets, but decrease with aggressiveness when males consume high-phosphorus $(1.45 \% \mathrm{PH})$ diets. 


\subsection{Discussion}

Elaborate sexually selected traits are expected to serve as honest indicators of condition (Grafen, 1990; Iwasa \& Pomiankowski, 1994; Pomiankowski, 1987a; Zahavi, 1975, 1977). When males use multiple sexual traits to attract mates or compete with rivals, the relative expression of such traits may be influenced by diet (Rowe \& Houle, 1996). In support of the indicator model prediction that multiple elaborate male sexual traits should be correlated (Kodric-Brown \& Brown, 1984; Zahavi, 1975, 1977), I found evidence that several male $G$. veletis pre-fight signalling parameters were related to aggressive behaviour. Adult body size was the strongest predictor of aggressive behaviour and many pre-fight signalling parameters, whereas adult diet had little to no effect, suggesting that the condition-dependence of these traits may lie in developmental resources rather than in adult diet. Interestingly, an influence of adult diet on signalling behaviour became apparent after males experienced an aggressive contest. Male G. veletis altered several signalling parameters following aggressive interactions, and these changes were related to both adult diet and aggressive behaviour, suggesting that socio-sexual experience and nutrition may play an important role in individual plasticity in reproductive strategies.

\subsubsection{Aggressive behaviour}

My results revealed that the aggressive behaviour of male G. veletis is not influenced by adult dietary protein:carbohydrate ratio or phosphorus level, corroborating previous studies demonstrating that aggression and/or dominance in insects is not influenced by adult dietary protein:carbohydrate ratio (Han \& Dingemanse, 2017; South et al., 2011). 
This finding is somewhat surprising given that aggression is energetically costly in crickets (Hack, 1997), and would presumably result in an increased demand for nutrients important for fueling metabolic activity (e.g. carbohydrates: Briffa, 2008) and aiding in the repair of damaged tissues involved in high metabolic activity (e.g. phosphorus: Bertram et al., 2006). It is possible that I did not observe any effect of adult diet on aggression because (i) my low-carbohydrate $\left(3_{\mathrm{p}}: 1_{\mathrm{C}}\right)$ and low-phosphorus $(0.45 \% \mathrm{PH})$ treatments were not dramatic enough to negatively influence aggression, and/or (ii) dietary effects may only become apparent over longer time scales after males deplete their nutrient or energy reserves following multiple aggressive interactions. Furthermore, nutrients important in neuronal tissue growth may be related to performance in successive aggressive interactions, as achieving a high dominance status during an aggressive encounter appears to stimulate neurogenesis in adult crickets (Ghosal, Gupta, \& Killian, 2009). Therefore, it is possible that a relationship between adult diet and aggression may be revealed by using a wider range of diet treatments over longer time scales and/or multiple aggressive interactions.

While I found no evidence that aggressive behaviour honestly reflects condition in terms of adult diet composition, I did find a weak trend for larger males to be more aggressive. This finding corroborates previous studies demonstrating the importance of a large body size, and associated larger weaponry, to cricket competitive abilities (Brown et al., 2006; Jang et al., 2008; Judge \& Bonanno, 2008; Savage et al., 2005). This suggests that aggression may depend on the availability of nutritional resources during development (e.g. Han \& Dingemanse, 2017), as adult body size is a trait that is strongly 
influenced by juvenile diet in crickets (protein: Han \& Dingemanse, 2017; Hunt et al., 2004; phosphorus: Visanuvimol \& Bertram, 2011; total food quantity: Whattam \& Bertram, 2011).

\subsubsection{Pre-aggression trial signalling behaviour}

Several pre-fight signalling parameters were related to body size, aggressive behaviour, and dietary phosphorus level, but pre-fight signalling was not related to any interaction between aggressive behaviour and diet. In support of previous findings that body size influences cricket mate attraction signalling (Chapter 3; Bertram \& Rook, 2012; Harrison et al., 2014; Simmons, 1988; Thomson et al., 2014), I found that larger males signalled with higher amplitude (louder) and more often, with more pulses per chirp, lower carrier frequencies, and longer chirp and pulse durations (signalling factors $2 \& 3$ ). Since adult body size is a function of juvenile diet in field crickets (Hunt et al., 2004; Visanuvimol \& Bertram, 2011; Whattam \& Bertram, 2011), females may use these signalling parameters as indicators of mate quality (e.g. good genes for juvenile resource acquisition and assimilation) and/or mating benefits (e.g. indicating that a male's territory contains ample food that can be temporarily exploited by mating females) (Reviewed by Andersson, 1994).

I additionally found a non-significant trend for males that signal with longer pulse durations and lower carrier frequencies (signalling factor 3) to be more aggressive, corroborating previous findings that aggressive behaviour is related to acoustic signalling in several taxa (e.g. frogs: Wagner, 1992; birds: Ballentine, Searcy, \& Nowicki, 2008). 
Additionally, my results support previous findings that fine-scale temporal and frequency aspects of cricket acoustic signals are related to aggressive behaviour (e.g. Gryllus assimilis pulse and chirp durations, amplitude, and carrier frequency: Bertram \& Rook, 2012; Acheta domesticus pulse duration, pulse and chirp rates: Brown et al., 2006), whereas broad-scale measures of cricket mate attraction signalling effort are not (e.g. $G$. veletis signalling time: Fitzsimmons \& Bertram, 2012; A. domesticus signalling time, signalling bout duration, and bout rate: Wilson et al., 2010). Since I found no significant aggression-by-diet interaction on pre-fight signalling, aggression may be related to signal pulse rate and carrier frequency due to their mutual dependence on some other aspect of male condition not measured in the present study, such as genetic quality, immune function, or developmental resources. However, this relationship is not due to variation in body size, as my models statistically controlled for it. Therefore, in support of the dual utility model (sensu Berglund et al., 1996), my findings suggest that mate attraction signals may contain additional information about an individual's aggressive behaviour, potentially signalling their ability to outcompete rivals for mates, food, territory, and other resources ("resource holding potential", sensu Parker, 1974).

Contrary to my prediction, I found no influence of dietary protein:carbohydrate treatment on pre-fight signalling behaviour. While a high carbohydrate diet positively influences signalling effort in one cricket species (Teleogryllus commodus: Maklakov et al., 2008), my results are more in line with my previous findings for G. veletis that overall amount of nutrients consumed ( $\mathrm{P}$ or $\mathrm{C})$, rather than dietary protein:carbohydrate ratio, is a major driving factor in individual differences in signalling in this species (Chapter 3; 
Harrison et al., 2014). This result also lends support to previous evidence that cricket species may differ in their nutrient requirements necessary for optimal sexual signalling (e.g. Thomson et al., 2014)). However, future work examining the effect of diet on signalling should use a wider range of protein:carbohydrate ratio treatments, as it is possible that my low-carbohydrate diet was not low enough to negatively influence prefight signalling.

I also found no evidence to support my prediction that increased dietary phosphorus results in increased signalling effort, as males consuming high-phosphorus diets had higher inter-chirp and inter-pulse durations and lower pulse and chirp rates (i.e. lower signalling effort; signalling factor 1) compared to males consuming lowphosphorus diets. Therefore, the signals of high-phosphorus males would presumably be less sexually attractive than low-phosphorus males, as female crickets tend to prefer higheffort acoustic signals with higher species-specific pulse rates (Gryllus bimaculatus: Simmons, 1988) and chirp rates (G. bimaculatus: Hirtenlehner \& Römer, 2014; Gryllus campestris: Scheuber et al., 2004; Gryllus lineaticeps: Wagner, 1996). In contrast, previous work using similar dietary phosphorus levels as in the present study has shown that phosphorus positively influences field cricket signalling effort (Bertram et al., 2009). A possible explanation for this discrepancy is that early juvenile diet composition in the latter study was unknown and may have been phosphorus-deficient, resulting in a positive influence of high-phosphorus adult diets on signalling effort. In contrast, my juveniles were fed a diet rich in phosphorus (1.1\% of total dry food mass), which may have reduced phosphorus requirements during adulthood. In support of this proposition, 
juvenile grasshopper growth rates generally increase with increasing dietary phosphorus, but decline when phosphorus surpasses $1.0 \%$ (dry food mass), and their phosphorus requirements also decline as they approach adulthood (Cease, Fay, Elser, \& Harrison, 2016). This suggests that my high-phosphorus diet $(1.45 \%$ PH in total nutrients; $0.66 \% \mathrm{PH}$ total dry food mass) may have contained phosphorus in excess of adult G. veletis requirements. While terrestrial insects are able to compensate for excessive dietary phosphorus by decreasing absorption and/or increasing excretion (Cease et al., 2016; Woods, Perkins, Elser, \& Harrison, 2002; Zhang et al., 2014), the extra energetic costs of excreting excess phosphorus may explain why my high-phosphorus diet negatively influenced signalling.

\subsubsection{Changes in signalling behaviour following aggression trial}

While most individual signalling parameters were highly repeatable between pre- and post-fight time periods, the signalling parameters represented by signalling change factors $2 \& 3$ experienced protein:carbohydrate-dependent changes following aggression trials. I found a weak trend for males consuming high-carbohydrate $\left(1_{\mathrm{p}}: 3_{\mathrm{C}}\right)$ diets to have higher signalling change factor 2 scores (increased time spent signalling and pulse rate; decreased inter-pulse duration) compared to males consuming equal protein:carbohydrate $\left(1_{\mathrm{P}}: 1_{\mathrm{C}}\right)$ and high-protein diets $\left(3_{\mathrm{P}}: 1_{\mathrm{C}}\right)$. Similarly, males consuming both highcarbohydrate and equal protein:carbohydrate diets had significantly higher signalling change factor 3 scores (higher pulse duration, pulses per chirp, and chirp duration) compared to males consuming high-protein diets. Therefore, signalling parameter 
changes in high-carbohydrate and equal protein:carbohydrate diet treatments generally represented an increase in signalling effort following aggression trials, whereas signalling parameter changes in the high-protein treatment generally represented a decrease in signalling effort. I do not believe that these changes in signalling are age-related, particularly for males eating high-carbohydrate and equal protein:carbohydrate diets, as signalling effort in G. veletis males decreases rather than increases with age (Fitzsimmons \& Bertram, 2011), and age at aggression trial was not a significant predictor of signalling behaviour in the current study. However, since eating high-protein (i.e. high protein:carbohydrate) diets decreases lifespan in G. veletis and other crickets (Chapter 3; Harrison et al., 2014; Maklakov et al., 2008), it is possible that consuming high-protein diets in my study may have accelerated the onset of age-related declines in signalling effort.

Positive changes in signalling effort (i.e. higher signalling change factors $2 \& 3$ ), representing an increase in acoustic sound energy per unit time, would necessitate higher levels of metabolic energy (Prestwich, 1994), suggesting that males eating diets that contained higher or equal levels of carbohydrates relative to protein were able to afford the costs of increased signalling effort following aggression trials. In contrast to my prefight signalling results, this finding lends support to previous evidence that cricket signalling effort is maximized on high-carbohydrate (i.e. low protein:carbohydrate) diets (T. commodus: Maklakov et al., 2008). Thus, my findings are in agreement with the indicator-model prediction that mate attraction signalling should covary positively with condition (Grafen, 1990; Kodric-Brown \& Brown, 1984; Maynard Smith, 1985; 
Pomiankowski, 1987a; Zahavi, 1975, 1977). However, condition-dependence of sexual signals may only become apparent after an energetically demanding event, such as an aggressive interaction with rivals, as I found no influence of dietary protein:carbohydrate ratio on pre-fight signalling behaviour.

Similar to my pre-fight signalling findings, investment in signalling following aggression trials was also negatively influenced by a high-phosphorus diet. Highly aggressive males that consumed low-phosphorus diets increased their effort in post-fight signalling by increasing their pulse duration, pulses per chirp and chirp duration parameters (signalling change factor 3). In contrast, males consuming high-phosphorus diets experienced a trade-off between investment in aggressive behaviour and post-fight signalling. Thus, males that invest heavily in aggressive behaviour were also able to invest heavily in post-fight signalling as long as they consume low-phosphorus diets, whereas males consuming high-phosphorus diets were unable to invest in both aggressive behaviour and increase their effort in post-fight signalling, possibly due to the increased cost of excreting excess phosphorus or associated cations (Cease et al., 2016). As my results contradict previous findings that high-phosphorus adult diets benefit cricket acoustic signalling (Bertram et al., 2009), clearly more research is needed on how different levels of dietary phosphorus throughout development and adulthood influences sexual signalling.

Exposure to rivals can result in significant changes to a variety of male reproductive behaviours (reviewed by Bretman, Gage, \& Chapman, 2011). Short term winner- and loser-effects, in which fight winners become more aggressive and losers 
become more docile (e.g. crickets: Adamo \& Hoy, 1995; jumping spiders: Kasumovic, Elias, Sivalinghem, Mason, \& Andrade, 2010), may influence other reproductive behaviours. These winner- and loser- effects are mediated by changes to hormonal and chemical signalling pathways in crickets (Rillich \& Stevenson, 2011; Stevenson \& Rillich, 2015, 2016). While my study design was unable to account for the identity of fight winners and losers, more aggressive male crickets typically win more fights (Bertram \& Rook, 2012; Bertram et al., 2011). Thus, the changes I observed in several signalling parameters following aggression trials, represented by signalling change factors 2 and 3, may act to inform potential mates and rival males of the dominance status achieved during previous fights, and their motivation to continue fighting (Brown et al., 2006). This potentially provides further support that cricket acoustic signals may serve a dual purpose in mate attraction and male-male competition (Berglund et al., 1996).

Alternatively, my finding that the relationship between post-fight signalling changes and aggressive behaviour is phosphorus-dependent may result from individual plasticity in reproductive strategies, where males adjust their investment in different sexual traits depending on their diet and social/sexual experience (Bretman et al., 2011; Fricke, Adler, Brooks, \& Bonduriansky, 2015). For example, males of several taxa increase sperm production and change ejaculate composition in response to increased risk of sperm competition (Bretman et al., 2011; Wedell, Gage, \& Parker, 2002; Wigby et al., 2009). Diet may influence this plasticity, as spermatogenesis is energetically and nutritionally costly (Wedell et al., 2002), and males are expected to experience a resource trade-off between expenditure in ejaculates and other reproductive traits (Parker, 1998; 
Wedell et al., 2002), particularly those involved in current versus future reproduction (Bretman et al., 2011; Candolin, 1999b). Dietary phosphorus may mediate this trade-off, not only due to its importance in nucleic acid production for spermatogenesis (Zittle \& O’Dell, 1941), but also because males could be transferring phosphorus directly to females via their ejaculates for use in egg production (e.g. Drosophila: Markow, Coppola, \& Watts, 2001), which could explain why female crickets experience lifespan and fertility benefits from the ejaculates of preferred males (e.g. G. lineaticeps: Wagner $\&$ Harper, 2003). Therefore, in the present study, highly aggressive males consuming high-phosphorus diets, potentially having achieved a high dominance status resulting in good future mating prospects, may be investing in ejaculate quality over post-fight signalling effort. Conversely, aggressive males consuming low-phosphorus diets may lack the necessary phosphorus required for improving ejaculate quality, and may instead invest in post-fight signalling in an effort to quickly secure a mate. Future studies should examine how dietary phosphorus influences fertility in field crickets, including the role of phosphorus in sperm production and fertility-boosting seminal compounds, as well as individual plasticity in reproductive strategies.

\subsubsection{Conclusions}

My findings lend partial support to indicator models of sexual selection, as I found weak evidence that several male G. veletis mate attraction signalling parameters were related to levels of aggressiveness in competitive interactions, but this relationship was not due to condition-dependence in terms of adult diet. Furthermore, while I found little evidence 
that signalling or aggressive behaviour is related to adult diet, adult body size, a proxy of nutritional resources during development, influenced these traits. Both adult diet and aggression levels did, however, influence changes in signalling following exposure to rival males. While I found only weak evidence that diet influences relationships between multiple sexually selected male traits, this under-studied topic deserves further investigation due to the known physiological changes initiated by social experiences in insects, such as changes to hormonal and chemical signalling pathways following aggressive contests in crickets (Rillich \& Stevenson, 2011; Stevenson \& Rillich, 2015, 2016). Furthermore, behavioural traits, such as aggression and signalling, have the potential to more flexibly reflect current nutritional condition than static traits, such as body size, that are fixed during development (Fricke et al., 2015). Continued research is, therefore, needed on the influence of a wider range of diet treatments on other aspects of male-male competitive abilities, such as the ability to win fights and achieve a high dominance status, and how these behaviours are related to mate attraction signalling. My findings highlight the importance of continuing research on the interplay between multiple male behavioural traits important in sexual selection, and how dietary nutrient balance throughout an individual's life may influence these relationships.

\subsection{Acknowledgements}

I thank Zachary Cronk, Francis Wong, and Dana Kolenich for their assistance with animal care and data entry. 


\section{Chapter 5}

The influence of dietary nutrient balance on female life-history traits throughout development and adulthood 


\subsection{Abstract}

It has long been recognized that the abundance and quality of nutritional resources in the environment is a major source of variation in the fitness of animals. Recently, research on this topic has shifted away from focussing on the importance of overall food quantity or single nutrients to more nutritionally-explicit approaches which consider the importance of the relative amounts (i.e. ratio) of multiple dietary nutrients. Such studies have demonstrated that the ratios of dietary macronutrients (e.g. protein, carbohydrate, lipids) or elemental nutrients (e.g. nitrogen, carbon, phosphorus) have important consequences for animal fitness, but few studies have examined the importance of dietary nutrient balance between elemental and macronutrients simultaneously. Furthermore, studies of dietary nutrient balance on animal fitness commonly focus on adult life stages, resulting in a lack of information on nutrition during development. Here, I raised juvenile female Gryllus veletis field crickets on one of six unique diets differing in protein, carbohydrate, and phosphorus content (no choice of diet), and monitored their development rate, growth, and survival to adulthood. At adulthood, I further examined how dietary nutrient balance influences female fecundity and morphological characteristics - forewing deformities, hindwing length, and flight muscle histolysis - that would influence flight and dispersal capabilities. Additionally, in a second experiment, I provided juvenile females with pairs of diets with complementary nutrient ratios to measure their intake regulation (diet choice). I found that diet influenced trade-offs between life-history traits such that not all fitness traits could be maximized on the same diet. While juvenile growth, development rate, and adult egg production were maximized on higher protein 
diets, juveniles had a greater chance of surviving to adulthood on an equal protein:carbohydrate ratio diet, and were more likely to develop long hindwings, potentially allowing for flight capability, on high-carbohydrate diets. In contrast, dietary phosphorus had little influence on fitness traits. Furthermore, female fecundity was related to the degree of flight muscle histolysis, supporting previous evidence for a reproduction-dispersal trade-off common to wing-polymorphic crickets and other insects. However, dietary nutrient ratio did not influence the relationship between female fecundity and flight muscle histolysis. Lastly, when given a choice between diets differing in nutrient composition, juvenile females self-selected a carbohydrate-biased diet relative to protein, but did not regulate their intake of phosphorus. These findings help provide a greater understanding of how the availability of nutrients in the environment during development and early adulthood influences the expression of lifehistory traits, and ultimately, animal fitness.

\subsection{Introduction}

It is well recognized that the abundance and quality of nutritional resources in the environment is a major source of variation in the fitness of animals (Simpson \& Raubenheimer, 2012; Sterner \& Elser, 2002). Nutrition has important implications for an individual's somatic state, which in combination with epigenetic and genetic components, make up the primary determinants of individual body condition and the ability to overcome environmental challenges (Hill, 2011). The nutrients acquired by an organism collectively constitute a pool of resources that are allocated to various physiological and 
metabolic processes that support somatic maintenance, growth, development, and reproduction (Hill, 2011; Rowe \& Houle, 1996; Tomkins et al., 2004). The quality, quantity, and relative amounts of different nutrients that organisms are able to acquire and assimilate may result in life-history trade-offs if nutrition is inadequate and a priority allocation of nutrients to support some physiological processes negatively affects allocation towards others (Rowe \& Houle, 1996; Tomkins et al., 2004). Thus, mismatches between an individual's ingested food and its nutritional requirements may constrain its ability to achieve high fitness.

Traditionally, studies on the influence of nutrition on life-history traits have involved crude manipulations of total dietary nutrient levels, or have focused on the importance of a single nutrient such as protein, carbohydrate, lipid, or salts (Simpson \& Raubenheimer, 2012). Such studies have found, for example, that consuming a diet with low overall nutrient levels is associated with slower juvenile growth rates and smaller adult body sizes (e.g. Searcy et al., 2004; Whattam \& Bertram, 2011), lower quality sexual ornaments or lower effort sexual signalling in males at adulthood (e.g. David et al., 1998; Frischknecht, 1993; Hill, 2000; Holzer, Jacot, \& Brinkhof, 2003; McGraw, Mackillop, Dale, \& Hauber, 2002; Wagner \& Hoback, 1999), and reduced female egg production (e.g. Chippindale et al., 1993; Magwere et al., 2004; Wilder \& Rypstra, 2008). Similarly, dietary protein is positively linked with such traits as juvenile growth rates and immune function, adult pheromonal and acoustic sexual signals, and female egg production (e.g. Carey, 1998; Ferkin et al., 1997; Hunt et al., 2004; Joern \& Behmer, 1997; Kiron et al., 1995; Kpundeh et al., 2015; Shariatmadari \& Forbes, 1993; Venesky 
et al., 2012). While informative, these approaches ignore the chemical complexity of foods, as well as the interactive nature of nutrient consumption, as the benefits of consuming some nutrients are often dependent on levels of other nutrients in the diet (Simpson and Raubenheimer 2012).

In recent years, there has been a shift towards using more nutrient-specific frameworks to study how nutrients influence biological systems, namely, nutritional geometry (NG; Raubenheimer \& Simpson, 1993; Simpson \& Raubenheimer, 1993, 2012) and ecological stoichiometry (ES; Elser, 2006; Sterner \& Elser, 2002). Although both NG and ES frameworks consider the importance of multiple dietary nutrients and their interactions in driving biological variation, the two frameworks differ in that NG typically focuses on organismal fitness traits, whereas ES more commonly focuses on ecological processes (Morehouse et al., 2010). Additionally, NG studies primarily investigate the importance of macromolecule nutrients (e.g. proteins, carbohydrates, and lipids: Jensen, Mcclure, Priest, \& Hunt, 2015; Maklakov et al., 2008; Mayntz et al., 2009; Raubenheimer \& Simpson, 1993; South et al., 2011), whereas ES studies primarily focus on elemental nutrients (e.g. carbon, nitrogen, and phosphorus: Bertram et al., 2006; Elser et al., 2000, 2003; Schade et al., 2003).

Both NG and ES have made substantial contributions to our understanding of how dietary nutrient balance influences biological systems. For example, NG studies have demonstrated that low protein:carbohydrate ratios (high carbohydrate) in the diets of adult insects is linked with longer lifespans (e.g. Chapter 3; Harrison et al., 2014; Jensen et al., 2015; Lee et al., 2008; Maklakov et al., 2008), and increased pheremonal and 
acoustic sexual signalling in males (e.g. Maklakov et al., 2008; South et al., 2011), whereas the optimal protein:carbohydrate ratio for egg production in females appears to vary across taxa (e.g. Chapter 3; Harrison et al., 2014; Lee et al., 2008; Maklakov et al., 2008). In contrast, ES studies have shown, for example, that lower carbon:phosphorus or nitrogen:phosphorus ratios (higher phosphorus) in either the diet or body tissues of various invertebrates appears to correlate positively with juvenile growth, survival, and female egg production (e.g. Perkins et al., 2004; Urabe \& Sterner, 2001; Visanuvimol \& Bertram, 2010, 2011), and acoustic sexual signalling in males (e.g. Bertram et al., 2009), but sometimes with negative effects of high phosphorus diets on growth, development rate, survival (e.g. Cease et al., 2016; Loaiza, Jonas, \& Joern, 2008), and sexual signalling (e.g. Chapter 3; Harrison et al., 2014).

The dietary nutrient ratio of available foods may also influence life-history tradeoffs when an organism's fitness traits have varying nutritional requirements for optimal functioning and, consequently, not all fitness traits may be maximized simultaneously on a single food source. For example, females in several insect taxa experience a trade-off between adult lifespan and reproduction because longevity is maximized on high carbohydrate diets and egg production is maximized on high protein diets (e.g. Chapter 3; Harrison et al., 2014; Maklakov et al., 2008; Sentinella et al., 2013). Similarly, diet may also influence a physiological or resource allocation trade-off between dispersal and reproduction in insect taxa such as Coleoptera, Orthoptera, and Heteroptera that commonly display wing length and flight muscle polymorphisms (Harrison, 1980). In these species, only long-winged individuals with well-developed flight musculature are 
flight-capable, whereas short-winged individuals are typically more fecund (Harrison, 1980; Tanaka, 1993, 1994; Zera \& Rankin, 1989), likely due to long winged individuals having increased resource costs associated with developing and maintaining the flight musculature necessary for dispersal (Roff \& Fairbairn, 1991). Furthermore, there is evidence that adult dietary protein:carbohydrate ratio influences wing-morph specific allocation of nutrients to reproductive tissues versus somatic energy stores used to fuel flight (Clark, Zera, \& Behmer, 2015).

Together NG and ES studies have demonstrated that variation in an organism's consumption of specific nutrients, such as elemental phosphorus, carbohydrates and proteins, is an important proximate cause of variation in life-history traits. Parallels between ES and NG studies can often easily be made since carbon is regarded as an elemental-level proxy for energetic macronutrients such as carbohydrates and lipids, whereas nitrogen is similarly considered to be a good proxy for the amino acids that make up proteins (Sterner \& Elser, 2002). However, the importance of phosphorus relative to dietary macromolecule nutrients such as proteins, carbohydrates, and lipids remains unclear. Phosphorus is an essential nutrient to all organisms, as it is a component of many biological molecules involved in vital physiological processes, including synthesis of RNA, DNA, ATP, proteins, and cellular membranes (Sterner \& Elser, 2002). To my knowledge, only two studies to date have examined the relative importance of phosphorus in relation to macromolecule nutrients, such as proteins and carbohydrates, on animal fitness (Chapters $3 \&$ 4; Harrison, Godin, \& Bertram, 2017; Harrison et al., 2014). Additionally, many of the previous studies examining the influence of dietary 
nutrient ratio on organism fitness have largely focussed on adult life stages (but see Reifer, Harrison, \& Bertram, 2018; Sentinella et al., 2013). Consequentially, there is a need to examine the importance of dietary nutrient balance during developmental life stages.

Here, in a first experiment, I investigated how nutrient balance between protein, carbohydrate and phosphorus in artificial diets influenced developmental, morphological, and reproductive fitness traits in female Gryllus veletis field crickets. Specifically, I provided juvenile females with one of six diets differing in protein:carbohydrate ratio and phosphorus concentration and examined the influence of diet on juvenile growth, development rate, and survival to adulthood. I predicted that higher dietary protein and phosphorus would result in faster development and greater growth in juveniles due to the importance of these nutrients in building new tissues. However, since higher carbohydrate diets can importantly influence adult insect lifespan (e.g. Chapter 3; Harrison et al., 2014; Jensen et al., 2015; Lee et al., 2008; Maklakov et al., 2008), I predicted that survival to adulthood would similarly be maximized on higher carbohydrate diets compared to juvenile growth and development time. Therefore, I predicted that juvenile diet would influence trade-offs between survival, development and growth.

Once juvenile females reached adulthood, I continued providing adults with the diet that they experienced during development and examined the impact of diet on their fecundity. Previously, dietary phosphorus and protein have been identified as important nutrients for egg production in field crickets (e.g. Chapter 3; Harrison et al., 2014; 
Maklakov et al., 2008; Visanuvimol \& Bertram, 2010). Therefore, I predicted that higher dietary protein and phosphorus would be associated with greater fecundity. I also quantified how diet impacted wing morphology and flight capability by measuring the prevalence of wing deformities, hindwing length and flight muscle development. Gryllus veletis is a wing-dimorphic cricket species, with the prevalence of the long-hindwing morph being greater in laboratory reared (94\%; Bégin \& Roff, 2002) than in wild populations ( $<5 \%$; Alexander, 1968; Bégin \& Roff, 2002). Both long hindwings and functional flight muscles are a requirement for flight capability in field crickets, where flight muscle colour can be used to indicate the degree of histolysis and muscle functionality (Tanaka 1994). Given that hindwing development in juvenile crickets appears to be maximized on low to intermediate protein levels (Mcfarlane, 1964), and metabolically active flight muscles are fueled by carbohydrates stored as lipids (Zera \& Mole 1994; Zera \& Rankin 1989; Zera, Sall, \& Grudzinski, 1997), I predicted that greater proportions of flight-capable, long-hindwing morphs would be found on highcarbohydrate diets. As such, I expected that adult diet would influence a trade-off between adult female flight capability and fecundity.

As the ratio of nutrients in the diet has important implications for organism fitness, it is unsurprising that a variety of species are capable of behaviourally regulating their nutrient intake by selecting between multiple foods with differing nutrient compositions, resulting in the ingestion of a nutrient mixture that provides maximal fitness (Behmer, 2009; Simpson \& Raubenheimer, 2012). Therefore, in a second experiment, I quantified diet choice in juvenile female G. veletis by providing them with 
pairs of foods differing in protein:carbohydrate ratio or phosphorus composition in order to estimate their intake targets for these nutrients (Simpson \& Raubenheimer, 1993). Previously, I found that adult female G. veletis self-selected a dietary protein:carbohydrate ratio of 1.3:3, but appeared incapable of regulating their intake of phosphorus (Chapter 3; Harrison et al., 2014). However, I predicted that juvenile females would regulate their intake of phosphorus due to the important role that this nutrient plays in rRNA and protein synthesis necessary for tissue growth during development (Elser et al., 2000). Similarly, based on previous studies of insect diet choice (Lee et al., 2008; Maklakov et al., 2008; South et al., 2011), I further predicted that juveniles would strongly regulate their intake of protein and carbohydrates, and would self-select diets higher in protein than previously found for adult G. veletis females (1.3:3; Chapter 3; Harrison et al., 2014), due to the importance of protein and amino acids for juvenile growth.

By studying the influence of protein, carbohydrate and phosphorus nutrient balance on both juvenile and adult life-history traits, I hope to advance our knowledge of how environmental heterogeneity in the availability of dietary macronutrients and elemental nutrients impact fitness during different ontogenic life stages, and influences life-history trade-offs. 


\subsection{Methods}

\subsubsection{Subjects and rearing}

Using the colony rearing conditions outlined in Chapter 2, section 2.2, I raised experimental juvenile female G. veletis in same-sex communal bins ( 25-50 individuals) from approximately the fifth nymphal instar until they reached their final nymphal instar, as evidenced by a long ovipositor (5-10 mm in length) and large wing buds. Within $24 \mathrm{~h}$ of reaching the final nymphal instar, females were removed from colony bins and assigned at random to one of two experiments: Experiment 1 (no choice of diet) and Experiment 2 (diet choice). All experimental females were housed individually in clear $520 \mathrm{~mL}$ plastic containers equipped with a screened lid, a cardboard shelter, ad libitum water and their assigned experimental $\operatorname{diet}(\mathrm{s})($ described below). Experimental females experienced the same greenhouse illumination regime and temperature as the colony.

\subsubsection{Experiment 1 - No choice of diet}

\subsubsection{Diet treatments}

Juvenile females $(\mathrm{N}=638)$ were assigned at random to one of six powdered experimental diets varying in protein $(\mathrm{P})$, carbohydrate $(\mathrm{C})$, and phosphorus $(\mathrm{PH})$ concentration, created following established protocols (Simpson \& Abisgold, 1985). All diets were comprised (by mass) of $45 \%$ indigestible cellulose, $50 \%$ total nutrients $(\mathrm{P}+\mathrm{C}+\mathrm{PH})$, and $5 \%$ vitamins, minerals, and lipids (see Chapter 2, section 2.3 for further details on diet composition). Diets consisted of three protein to carbohydrate ratios $\left(3_{\mathrm{P}}: 1_{\mathrm{C}} ; 1_{\mathrm{P}}: 1_{\mathrm{C}} ; 1_{\mathrm{P}}: 3_{\mathrm{C}}\right)$, each varied at two phosphorus levels $(0.45 \% \mathrm{PH}$ and $1.45 \% \mathrm{PH}$ in total nutrients, 
corresponding to $0.21 \% \mathrm{PH}$ and $0.66 \% \mathrm{pH}$ of total dry food mass) (Table 5.1). Diets were supplied ad libitum and replaced with fresh once weekly. 
Table 5.1. Dietary protein to carbohydrate ratio and phosphorus concentration of artificial diets.

\begin{tabular}{ccc}
\hline Diet ID & Protein:Carbohydrate & Phosphorus Level (\%) \\
\hline A & $3: 1$ & 0.45 \\
B & $3: 1$ & 1.45 \\
C & $1: 1$ & 0.45 \\
D & $1: 1$ & 1.45 \\
E & $1: 3$ & 0.45 \\
F & $1: 3$ & 1.45 \\
\hline
\end{tabular}




\subsubsection{Life-history and morphological traits}

For each individual, I recorded their initial weight prior to being given experimental diets using an analytical balance (Ohaus Pioneer Series; model PA214; precision $\pm 0.1 \mathrm{mg}$ ). Thereafter, I monitored crickets daily to check for adult eclosion and/or death. A few females $(\mathrm{N}=4$ out of $638=<1 \%)$ underwent an additional nymphal moult after being given their experimental diet. These females were discarded from the experiment, as their final nymphal instar had been misidentified. I weighed all crickets a second time within $24 \mathrm{~h}$ of eclosing as adults. Since most crickets at least partially consumed their exuvia prior to weighing, I ensured that all new adult crickets were weighed with their exuvia (eaten or not). Additionally, following sclerotization of the cuticle, I classified each cricket's wing morphology as long or short hindwings, and deformed or normal forewings. Deformed wings were classified as those not reaching full inflation before sclerotization, resulting in a crumpled appearance, and all females with deformed forewings also possessed deformed hindwings. Additionally, long-hindwing females that underwent natural de-elation (i.e. a loss of hindwings; $\mathrm{N}=2$ out of $638=<1 \%$ ) at any point in the experiment were omitted from all statistical analysis due to the potential influence on flight muscle histolyzation and egg production (Tanaka \& Suzuki, 1998).

On the 16th day $( \pm 2)$ of adulthood, all females were humanely euthanized via freezing. I then estimated body size, fecundity, and level of histolysis in flight muscles for a subset of females $(\mathrm{N}=326$ out of 638). I photographed each female's dorsal side next to a ruler and then used ImageJ software (http:// imagej.nih.gov/ij/) to obtain three body size measures: maximum pronotum length along the anterior-posterior axis, 
maximum pronotum width, and maximum distance between the outer edges of the eyes. Using principal components analysis in JMP v.13, I identified a single principal component (sizePC1) that explained $94.2 \%$ of the variation in these three body size measures (eigenvalue $=2.83$; eigenvector loadings: 58 for all three size variables). Following photography, I then dissected females ventrally to remove their ovaries and manually counted the number of mature eggs within them using a dissecting microscope, identifying mature eggs as those large in size and possessing a durable outer cuticle. Additionally, I classified flight muscle colour as either pink (well developed), yellow (partially histolyzed), or white (histolyzed) (Tanaka, 1994; Tanaka \& Suzuki, 1998). I categorized females as having one of the following hindwing length and flight muscle colour morphs, hereafter 'wing-muscle morph': short hindwings with white flight muscles $\left(\mathrm{SW}_{\mathrm{w}}\right)$, long hindwings with white flight muscles $\left(\mathrm{LW}_{\mathrm{w}}\right)$, long hindwings with yellow flight muscles $\left(\mathrm{LW}_{\mathrm{y}}\right)$, long hindwings with pink flight muscles $\left(\mathrm{LW}_{\mathrm{p}}\right)$.

\subsubsection{Statistical analyses}

All data analyses were performed in R v.3.3.2 (R Development Core Team, Vienna, Austria; http://www.R-project.org). I used a generalized linear model (GLM) with binomial error and logit link to examine how initial weight and juvenile diet influenced survival to adulthood for 632 juvenile females. For all individuals surviving to adulthood $(\mathrm{N}=593)$, I used the following models to examine how initial weight and juvenile diet influenced life-history traits: (i) a GLM with quasi-poisson error for number of days to reach adult eclosion (= development time); (ii) a linear model (LM) with normal error 
and identity link for adult eclosion weight; (iii) a GLM with binomial error and complementary log-log (cloglog) link for the probability of eclosing as a long hindwing morph at adulthood; and (iv) a GLM with binomial error and a probit link for the probability of eclosing as an adult with deformed forewings. Link functions were chosen to minimize residual deviance, and the quasi-poisson error family was used when models were overdispersed. Predictor variables for all full models above included each individual's weight at the start of the experiment (initial weight) as a covariate, protein:carbohydrate ratio and phosphorus level as fixed factors, and all 2- and 3-way interactions. When either protein:carbohydrate ratio or phosphorus level predictor variables were found to be significant in these models, Tukey's Honest Significant Difference (HSD) post-hoc tests were used to compare means across diet treatments using the 'multcomp' package (Hothorn et al., 2008). Model simplification (described below) resulted in the removal of all 2- and 3-way interactions for the above models, with the exception of the initial weight * protein:carbohydrate interaction in both the hindwing morph and forewing deformity models, and the protein:carbohydrate * phosphorus level interaction in the forewing deformity model. Additionally, I used an ordinary least squares regression to determine how adult eclosion weight is related to adult body size (sizePC1).

For a subset of long-hindwing (LW) morphs surviving to adulthood (N = 61), I used a multinomial logistic regression to examine factors influencing the log odds of long hindwing individuals having yellow $\left(\mathrm{LW}_{\mathrm{y}}\right)$ or white $\left(\mathrm{LW}_{\mathrm{w}}\right)$ flight muscles over pink $\left(\mathrm{LW}_{\mathrm{p}}\right.$; baseline category of comparison) using the 'nnet' package in $\mathrm{R}$ (Venables \& 
Ripley, 2002). Short-hindwing (SW) morphs were omitted from this analysis, as all SW morphs had white (histolized) flight muscles. The predictor variables for this full model included age at euthanization (age) and adult body size (sizePC1) as covariates, protein:carbohydrate ratio and phosphorus level as fixed factors, and all 2- and 3- way interactions between age, protein:carbohydrate ratio and phosphorus level. Model simplification (described below) resulted in the removal of all 2- and 3-way interactions in the wing-muscle morph model.

For a subset of all individuals surviving to adulthood $(\mathrm{N}=322)$, I used a GLM with quasi-poisson error to examine factors influencing the number of eggs in ovaries at the time of euthanization. The predictor variables for this full model included age at euthanization (age) and adult body size (sizePC1) as covariates, wing-muscle morph, protein:carbohydrate ratio and phosphorus level as fixed factors, and all 2- to 4- way interactions between age, wing-muscle morph, protein:carbohydrate ratio and phosphorus level. Tukey's HSD post hoc tests were used to compare across means for significant protein:carbohydrate ratio and wing-muscle morph predictor variables. Model simplification (described below) resulted in the removal of all interactions for the egg model.

As AIC values are unavailable for quasi-poisson models, I performed model simplification for these models by progressively removing the highest-order nonsignificant interaction term and using a deletion test with the 'anova()' function in R to determine if removal of the term significantly improved the model fit. For all other models, I performed model simplification using backwards stepwise AIC using R's 
'MASS' package to select the model with the lowest AIC value (Venables and Ripley 2002). However, the main effects of all covariates (e.g. initial weight, body size, age), and the two diet variables (protein:carbohydrate ratio and phosphorus level) were retained in all simplified models as they were the primary factors of interest. Based on the number of overall effects in the saturated models, I corrected for multiple hypotheses tests using the false discovery rate FDR $_{\mathrm{B}-\mathrm{Y}}$ method (Benjamini \& Yekutieli, 2001).

\subsubsection{Experiment 2 - Diet choice}

\subsubsection{Diet treatments}

Using a subset of diets from Experiment 1 (Table 5.1), females $(\mathrm{N}=90)$ were assigned at random to one of two pairs of diets: (i) diets B and F (differing only in protein:carbohydrate ratio) and (ii) diets $\mathrm{C}$ and $\mathrm{D}$ (differing only in phosphorus content). I provided females simultaneously with two food dishes containing their assigned diets ad libitum for one week. The positions of each food dish within crickets' enclosures was alternated daily to prevent a potential side bias from influencing the consumption of each diet. Pairs of food dishes $(50 \times 9 \mathrm{~mm}$ Petri dishes with upturned $15 \times 15 \mathrm{~mm}$ plastic lids glued at the centre) containing diets were dried in a $30{ }^{\circ} \mathrm{C}$ drying oven (Fisher Isotemp 200 Series; model 230G) for $48 \mathrm{~h}$ and weighed both before and after being given to females. Each female's intakes of protein, carbohydrate, and phosphorus were calculated using known diet composition and total food intake (difference in weight of food dish before and after consumption). 


\subsubsection{Statistical analysis}

I used two linear mixed models (LMM) using R's lme4 package (Bates et al., 2015) to examine factors influencing the amount of food eaten when simultaneously provided with pairs of diets differing in either (i) protein:carbohydrate ratio (diet $\mathrm{B} ; 3_{\mathrm{P}}: 1_{\mathrm{C}}, 1.45 \% \mathrm{PH}$ and

$\operatorname{diet} \mathrm{F} ; 1_{\mathrm{P}}: 3_{\mathrm{C}}, 1.45 \%{ }_{\mathrm{PH}}$; Table 5.1 ), or (ii) phosphorus content (diet $\mathrm{C} ; 1_{\mathrm{P}}: 1_{\mathrm{C}}, 0.45 \% \mathrm{PH}$ and diet $\mathrm{D} ; 1_{\mathrm{P}}: 1_{\mathrm{C}}, 1.45 \% \mathrm{PH}$; Table 5.1 ). Both models included individual ID as a random effect, initial weight as a covariate, diet, and the interaction between initial weight and diet. The non-significant diet * initial weight interaction term was removed from the phosphorus model using model simplification, as outlined above.

\subsection{Results}

\subsubsection{Experiment 1 - No choice of diet}

\subsubsection{Survival to adulthood}

Of the 632 juveniles used in Experiment 1, 593 individuals (93.8\%) survived to adulthood. Initial weight and protein:carbohydrate ratio were significant predictors of the probability of survival to adulthood (Table 5.2). Females with higher initial weights were significantly more likely to successfully reach adulthood (Table 5.2; Appendix 3, Table A3.1). Survival to adulthood was also influenced by protein:carbohydrate ratio, but not phosphorus level (Tables 5.2 \& A3.1; Figure 5.1A). Pairwise Tukey’s HSD contrasts indicated that females consuming equal protein:carbohydrate ratio $\left(1_{\mathrm{P}}: 1_{\mathrm{C}}\right)$ diets had a greater chance of surviving to adulthood compared to females consuming both highcarbohydrate $\left(1_{\mathrm{P}}: 3_{\mathrm{C}} ; P=0.036\right)$ and high-protein $\left(3_{\mathrm{P}}: 1_{\mathrm{C}} ; P=0.042\right)$ diets, whereas 
survival on high-protein and high-carbohydrate treatments did not significantly differ from one another $(P=0.999)$ (Figure 5.1A). 
Table 5.2. Effects tests for the models examining factors influencing juvenile and adult female life-history traits. Significant model effects and parameters are bolded. The FDR $\mathrm{B}_{-}$ y corrected level of significance is $P=0.018$ for the wing-muscle morph model, $P=$ 0.015 for the egg model, and $P=0.019$ for all remaining models. Parameter estimates for these models are located in Appendix 3, Table A3.1.

\begin{tabular}{llrrr}
\hline & & \multicolumn{3}{c}{ Effects Tests } \\
Model & Model Term & $\boldsymbol{\chi}^{2} / \boldsymbol{F}$ & df & $\boldsymbol{P}$ \\
\hline Probability of & Initial Weight & $\mathbf{1 8 . 5 3 4}$ & $\mathbf{1}$ & $<\mathbf{0 . 0 0 1}$ \\
Survival to & Protein:Carbohydrate & $\mathbf{8 . 6 3 2}$ & $\mathbf{2}$ & $\mathbf{0 . 0 1 3}$ \\
Adulthood & Phosphorus & 0.055 & 1 & 0.815 \\
\hline Development & Initial Weight & $\mathbf{2 4 . 7 8 3}$ & $\mathbf{1}$ & $<\mathbf{0 . 0 0 1}$ \\
Time & $\mathbf{3 3 . 1 2}$ & $\mathbf{2}$ & $<\mathbf{0 . 0 0 1}$ \\
& Protein:Carbohydrate & 0.76 & 1 & 0.383 \\
\hline Adult Eclosion & Phosphorus & $\mathbf{3 0 9 . 4 3 1}$ & $\mathbf{1 , 5 8 8}$ & $<\mathbf{0 . 0 0 1}$ \\
Weight & Pritial Weight & $\mathbf{3 4 . 9 9 8}$ & $\mathbf{2 , 5 8 8}$ & $<\mathbf{0 . 0 0 1}$ \\
& Phosphorus & 0.283 & 1,588 & 0.595 \\
\hline Probability of & Initial Weight & 0.958 & 1 & 0.328 \\
Forewing & Protein:Carbohydrate & $\mathbf{3 5 . 1 0 2}$ & $\mathbf{2}$ & $<\mathbf{0 . 0 0 1}$ \\
Deformity & Phosphorus & 3.055 & 1 & 0.080 \\
& Protein:Carbohydrate * Phosphorus & 7.564 & 2 & 0.023 \\
& Initial Weight * Protein:Carbohydrate & 6.422 & 2 & 0.040 \\
\hline Probability of & Initial Weight & $\mathbf{1 1 . 2 2 1}$ & $\mathbf{1}$ & $<\mathbf{0 . 0 0 1}$ \\
Long Hindwing & Protein:Carbohydrate & $\mathbf{1 5 . 3 5 3}$ & $\mathbf{2}$ & $<\mathbf{0 . 0 0 1}$ \\
Morph & Phosphorus & 0.303 & 1 & 0.582 \\
& Initial Weight * Protein:Carbohydrate & $\mathbf{8 . 7 9 7}$ & $\mathbf{2}$ & $\mathbf{0 . 0 1 2}$ \\
\hline Wing-Muscle & SizePC1 & 1.726 & 2 & 0.422 \\
Morph & Age & 0.794 & 2 & 0.673 \\
& Protein:Carbohydrate & 4.992 & 4 & 0.288 \\
& Phosphorus & 0.23 & 2 & 0.891 \\
\hline Number of Eggs & SizePC1 & $\mathbf{6 6 . 0 9 3}$ & $\mathbf{1}$ & $<\mathbf{0 . 0 0 1}$ \\
& Age & 4.517 & 1 & 0.034 \\
& Wing-Muscle Morph & $\mathbf{4 1 . 5 2 3}$ & $\mathbf{3}$ & $<\mathbf{0 . 0 0 1}$ \\
& Protein:Carbohydrate & $\mathbf{3 1 6 . 5 5 3}$ & $\mathbf{2}$ & $<\mathbf{0 . 0 0 1}$ \\
& Phosphorus & 2.032 & 1 & 0.154 \\
\hline & & & &
\end{tabular}



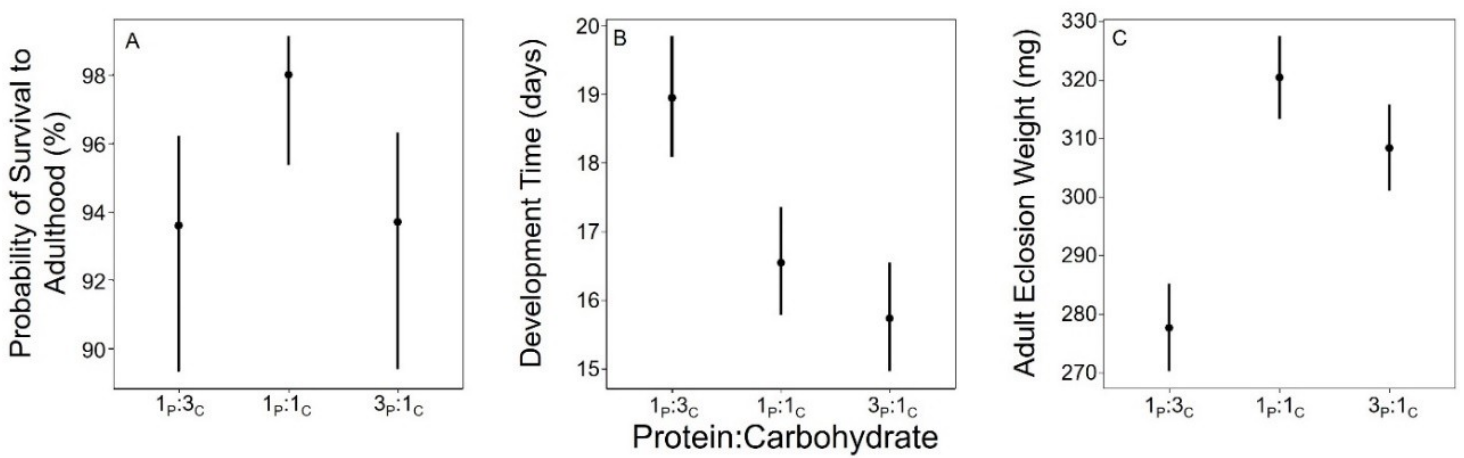

Figure 5.1. Marginal effects plots with $95 \%$ confidence intervals showing how fitted values of A) probability of survival to adulthood, B) development time, and C) adult eclosion weight were influenced by dietary protein:carbohydrate ratio. 


\subsubsection{Development time}

Initial weight and protein:carbohydrate ratio were significant predictors of how quickly juveniles reached adulthood (Table 5.2). Females with higher initial weights had significantly shorter development times (Tables 5.2 \& A3.1). Development time was also influenced by protein:carbohydrate ratio, but not phosphorus level (Tables 5.2 \& A3.1; Figure 5.1B). Pairwise Tukey's HSD contrasts revealed that females consuming highcarbohydrate $\left(1_{\mathrm{P}}: 3_{\mathrm{C}}\right)$ diets developed more slowly (i.e. had longer development times) than females consuming either equal protein:carbohydrate ratio $\left(1_{\mathrm{P}}: 1_{\mathrm{C}} ; P=0.003\right)$ or high-protein $\left(3_{\mathrm{P}}: 1_{\mathrm{C}} ; P=0.002\right)$ diets, whereas development time on equal protein:carbohydrate ratio and high-protein diets did not significantly differ from one another $(P=0.959)$ (Figure 5.1B).

\subsubsection{Growth}

Initial weight and protein:carbohydrate ratio were significant predictors of adult eclosion weight (Table 5.2). Females with higher initial weights had significantly greater adult eclosion weights (Tables 5.2 \& A3.1). Adult eclosion weight was also influenced by protein:carbohydrate ratio, but not phosphorus level (Tables 5.2 \& A3.1; Figure 5.1C). Pairwise Tukey's HSD contrasts revealed that females consuming high-carbohydrate $\left(1_{\mathrm{P}}: 3_{\mathrm{C}}\right)$ diets had significantly lower adult eclosion weights after accounting for initial body size compared to females consuming either equal protein:carbohydrate $\left(1_{\mathrm{P}}: 1_{\mathrm{C}} ; P<\right.$ $0.001)$ or high-protein $\left(3_{\mathrm{P}}: 1_{\mathrm{C}} ; P<0.001\right)$ diets (Figure $\left.5.1 \mathrm{C}\right)$. There was also a nonsignificant trend for females consuming equal protein:carbohydrate diets to have higher 
adult eclosion weights than those consuming high-protein diets $(P=0.055)$ (Figure 5.1C). For the subset of females that were measured for body size (head and pronotum measures), adult eclosion weight was strongly positively correlated with sizePC1 $\left(\mathrm{R}^{2} \mathrm{ADJ}\right.$ $\left.=0.72, F_{1,320}=835.38, P<0.001\right)$, indicating that heavier adults had overall larger body sizes.

\subsubsection{Forewing deformity}

Of the 593 juveniles that survived to adulthood in Experiment 1, 77 (13.0\%) eclosed as adults with deformed forewings. There was a non-significant trend for a protein:carbohydrate ratio by phosphorus interaction to influence the probability of having deformed forewings (Tables $5.2 \&$ A3.1; Figure 5.2A). For individuals consuming either the equal protein:carbohydrate ratio $\left(1_{\mathrm{P}}: 1_{\mathrm{C}}\right)$ or high-carbohydrate $\left(1_{\mathrm{P}}: 3_{\mathrm{C}}\right)$ diets, having a high-phosphorus level $(1.45 \% \mathrm{pH})$ in the diet increased the probability of eclosing with deformed forewings over individuals consuming the low-phosphorus $(0.45 \% \mathrm{PH})$ diets. There was also a non-significant trend for a protein:carbohydrate ratio by initial weight interaction to influence the probability of having deformed forewings (Tables 5.2 \& A3.1; Figure 5.2B). The probability of eclosing with deformed forewings was highest when females consumed high-carbohydrate diets, but only when initial weight was low (Figure 5.2B). 

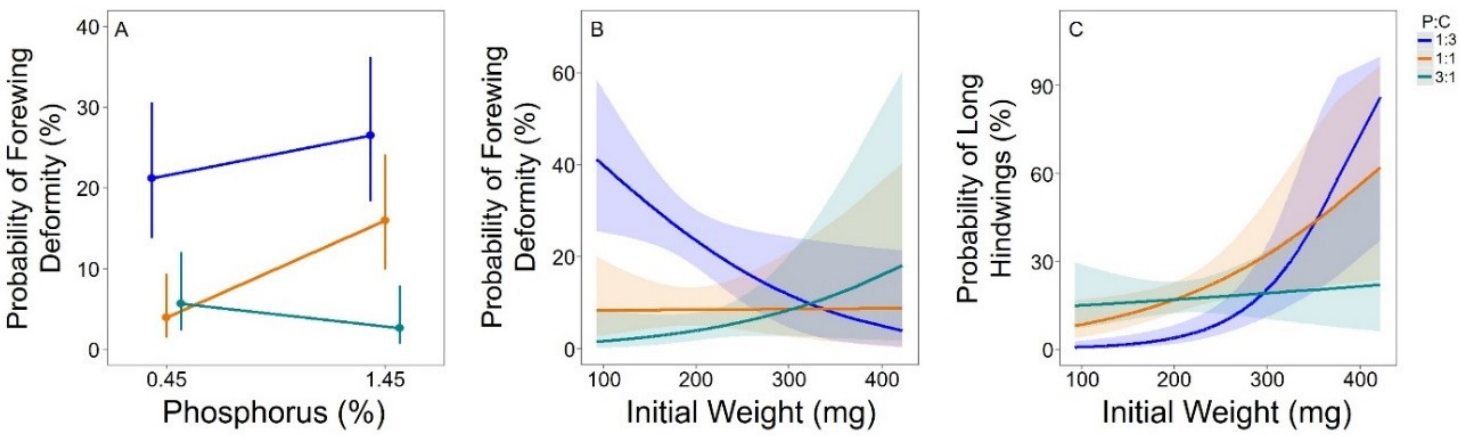

Figure 5.2. Marginal effects plots with $95 \%$ confidence intervals showing how fitted values of A-B) probability of having deformed forewings at adulthood, and C) probability of having long hindwings at adulthood were influenced by diet and/or initial weight. 


\subsubsection{Hindwing morph}

Of the 593 juveniles that survived to adulthood in Experiment 1, 80 individuals (13.5\%) eclosed as adults with long hindwings. A significant interaction between initial weight and protein:carbohydrate ratio influenced the probability of having long hindwings at adult eclosion (Tables 5.2 \& A3.1; Figure 5.2C). When females had low initial weights, the probability of eclosing as a long-hindwing morph was similar for all diet treatments (Figure 5.2C). However, while the probability of eclosing as a long-hindwing morph on a high-protein diet remained similar across all initial weights, the probability having long hindwings significantly increased on high-carbohydrate $\left(1_{\mathrm{P}}: 3_{\mathrm{C}}\right)$ and equal protein:carbohydrate $\left(1_{\mathrm{P}}: 1_{\mathrm{C}}\right)$ diets as initial weight increased (Figure $\left.2 \mathrm{C}\right)$. Dietary phosphorus level had no significant effect on the probability of having long hindwings at adulthood (Tables $5.2 \&$ A3.1).

\subsubsection{Wing-muscle morph}

Of the 322 individuals examined for flight muscle colour, $261(81.1 \%)$ had short hindwings (SW) and 61 (18.9\%) had long hindwings (LW). All short-hindwing individuals had fully histolyzed flight muscles (white; $\mathrm{SW}_{\mathrm{W}}$ ), 14 long-hindwing individuals had fully developed muscles (pink; $\mathrm{LW}_{\mathrm{P}}$ ), 32 long-hindwing individuals had partially histolyzed muscles (yellow; $\mathrm{LW}_{\mathrm{Y}}$ ), and 15 long-hindwing individuals had fully histolyzed muscles (white; $\mathrm{LW}_{\mathrm{W}}$ ). Neither adult body size, age at time of euthanization, dietary protein:carbohydrate ratio or phosphorus level influenced the log odds of long- 
hindwing individuals having either white $\left(\mathrm{LW}_{\mathrm{W}}\right)$ or yellow $\left(\mathrm{LW}_{\mathrm{Y}}\right)$ forewings muscles over pink $\left(\mathrm{LW}_{\mathrm{P}}\right)($ Tables $5.2 \& \mathrm{~A} 3.1)$.

\subsubsection{Number of eggs}

Adult body size, protein:carbohydrate ratio and wing-muscle morph were significant predictors of number of eggs contained within adult female ovaries (Tables 5.2 \& A3.1; Figure 5.3). Larger females had significantly more eggs in their ovaries, and there was also a non-significant trend for older females to have more eggs (Tables 5.2 \& A3.1). Pairwise Tukey's HSD contrasts indicated that short-hindwing females with white flight muscles $\left(\mathrm{SW}_{\mathrm{W}}\right)$ had significantly more eggs in their ovaries than long-hindwing females with either white muscles $\left(\mathrm{LW}_{\mathrm{W}} ; P=0.035\right)$ or pink muscles $\left(\mathrm{LW}_{\mathrm{P}} ; P=0.001\right)$, but did not significantly differ from long-hindwing females with yellow flight muscles $\left(\mathrm{LW}_{\mathrm{Y}} ; P\right.$ $=0.474)$ (Figure $5.3 \mathrm{~A}) . \mathrm{LW}_{\mathrm{Y}}$ females had significantly more eggs in their ovaries compared to $\mathrm{LW}_{\mathrm{W}}(P=0.008)$ and $\mathrm{LW}_{\mathrm{P}}(P=0.001)$ females, but $\mathrm{LW}_{\mathrm{W}}$ and $\mathrm{LW}_{\mathrm{P}}$ did not significantly differ in the number of eggs $(P=0.068)$ (Figure 5.3A). Pairwise Tukey's HSD contrasts also revealed that females consuming high-carbohydrate $\left(1_{\mathrm{p}}: 3_{\mathrm{C}}\right)$ diets had significantly fewer eggs than females consuming either high-protein $\left(3_{\mathrm{P}}: 1_{\mathrm{C}} ; P<0.001\right)$ or equal protein:carbohydrate ratio $\left(1_{\mathrm{P}}: 1_{\mathrm{C}} ; P<0.001\right)$ diets, whereas high-protein and equal protein:carbohydrate ratio treatments did not significantly differ from one another $(P=$ 0.060) (Figure 5.3B). Dietary phosphorus had no significant influence on number of eggs in ovaries (Tables $5.2 \& \mathrm{~A} 3.1$ ). 

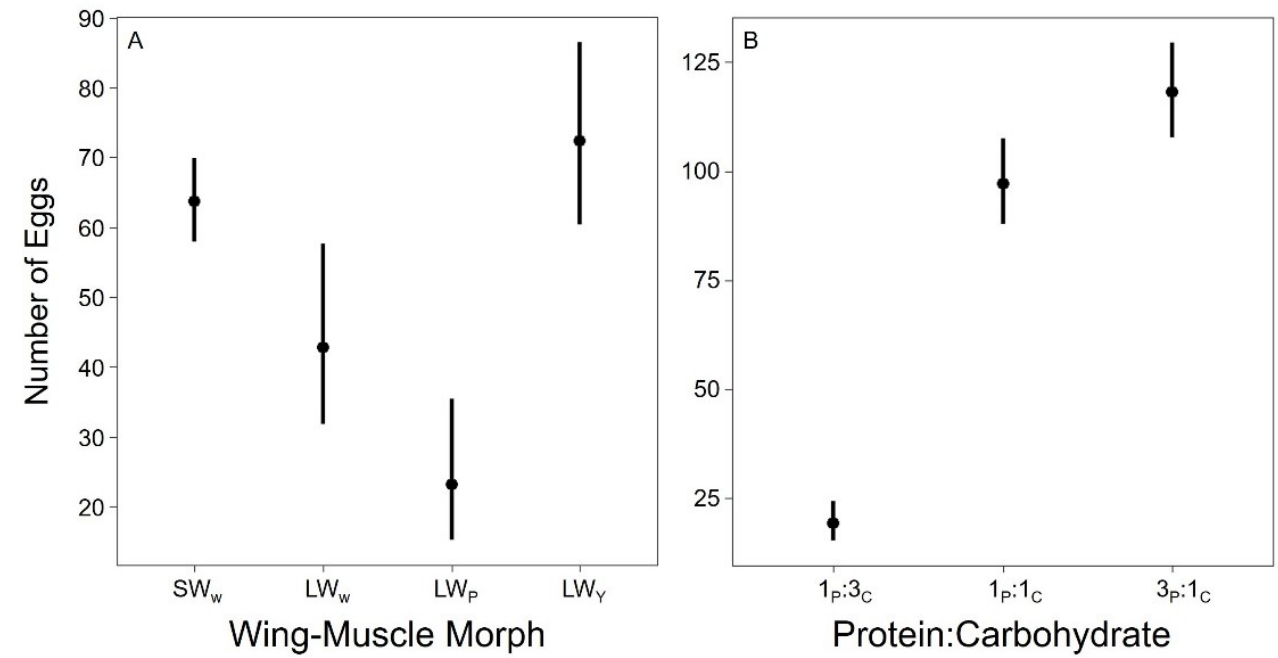

Figure 5.3. Marginal effects plots with $95 \%$ confidence intervals showing how fitted values of number of eggs in ovaries was influenced by $\mathrm{A})$ wing-muscle morph $\left(\mathrm{SW}_{\mathrm{W}}-\right.$ short hindwing with white muscle; $\mathrm{LW}_{\mathrm{W}}$ - long hindwing with white muscle; $\mathrm{LW}_{\mathrm{P}}$ - long hindwing with pink muscle; $\mathrm{LW}_{\mathrm{Y}}$ - long hindwing with yellow muscle), and B) dietary protein:carbohydrate ratio. 


\subsubsection{Experiment 2 - Diet choice}

\subsubsection{Intake regulation of protein and carbohydrates}

When given a choice between two diets differing in protein:carbohydrate ratio but identical in phosphorus content, juvenile female crickets preferentially consumed more of the high-carbohydrate $\operatorname{diet}\left(\operatorname{diet} \mathrm{F} ; 1_{\mathrm{P}}: 3_{\mathrm{C}}, 1.45 \% \mathrm{PH}\right)$ than the high-protein $\operatorname{diet}(\operatorname{diet} \mathrm{B}$; $\left.3_{\mathrm{P}}: 1_{\mathrm{C}}, 1.45 \% \mathrm{PH}\right)$ (Table 5.3; Appendix 3, Table A3.2). There was also a significant protein:carbohydrate ratio by initial weight interaction on diet preference (Tables $5.3 \&$ A3.2; Figure 5.4). Juvenile females consumed progressively more of the highcarbohydrate diet with increasing initial body weight, whereas consumption of the highprotein diet remained relatively similar across all initial weights (Figure 5.4). A preferential consumption of the high-carbohydrate diet resulted in juvenile female crickets self-selecting a mean dietary protein:carbohydrate ratio of $0.479 \pm 0.028$ S.E. (approximately $1.44_{\mathrm{P}}: 3_{\mathrm{C}}$ ). This self-selected protein:carbohydrate ratio was a significant divergence from the expected protein:carbohydrate ratio intake (i.e. $\left.1_{\mathrm{P}}: 1_{\mathrm{C}}\right)$ if crickets had eaten the diets at random (one-sample t-test: $t_{29}=-18.429, P<0.001$ ). 
Table 5.3. Effects tests for the models examining factors influencing the amount of food juvenile females ate when given pairs of diets differing in either protein:carbohydrate ratio (diet $\mathrm{B} ; 3_{\mathrm{P}}: 1_{\mathrm{C}}, 1.45 \% \mathrm{pH}$ and $\operatorname{diet} \mathrm{F} ; 1_{\mathrm{P}}: 3_{\mathrm{C}}, 1.45 \% \mathrm{opH}$ ) or phosphorus level (diet $\mathrm{C}$; $1_{\mathrm{P}}: 1_{\mathrm{C}}, 0.45 \%{ }_{\mathrm{PH}}$ and diet $\left.\mathrm{D} ; 1_{\mathrm{P}}: 1_{\mathrm{C}}, 1.45 \% \mathrm{pH}\right)$. Significant model effects and parameters are bolded. The FDR $\mathrm{B}_{\mathrm{B}-\mathrm{Y}}$ corrected level of significance is $P=0.027$. Parameter estimates for these models are located in Appendix 3, Table A3.2.

\begin{tabular}{llrrr}
\hline & & \multicolumn{3}{c}{ Effects Tests } \\
Model & Model Term & $\boldsymbol{F}$ & df & $\boldsymbol{P}$ \\
\hline Amount Eaten (Diets B \& F) & Initial Weight & 2.292 & 1,28 & 0.141 \\
& Diet & $\mathbf{1 0 5 . 0 7 2}$ & $\mathbf{1 , 2 8}$ & $<\mathbf{0 . 0 0 1}$ \\
& Initial Weight * Diet & $\mathbf{6 . 7 8 7}$ & $\mathbf{1 , 2 8}$ & $\mathbf{0 . 0 1 5}$ \\
\hline Amount Eaten (Diets C \& D) & Initial Weight & 3.853 & 1,28 & 0.060 \\
& Diet & 0.004 & 1,29 & 0.951 \\
\hline
\end{tabular}




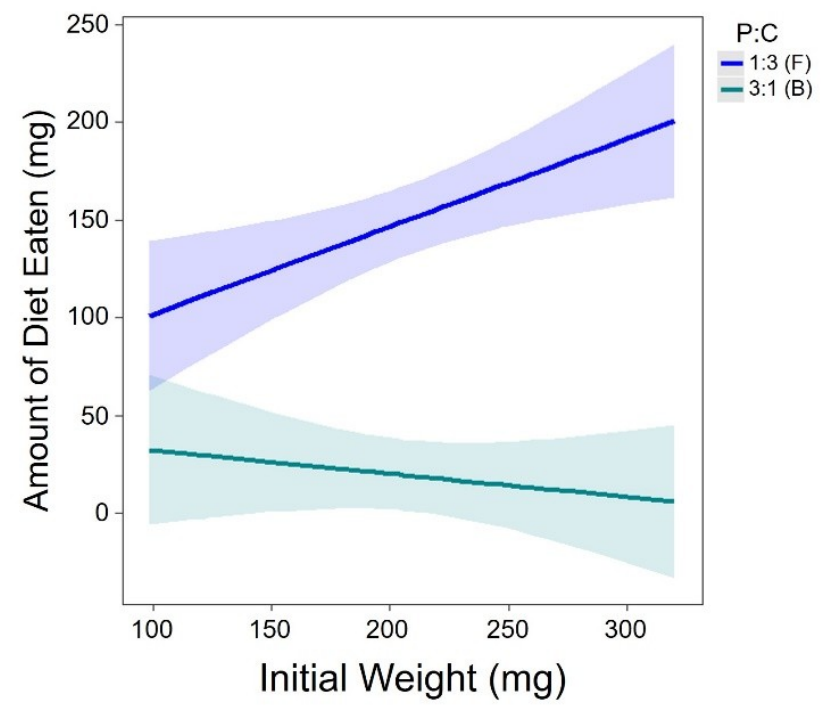

Figure 5.4. Marginal effects plots with $95 \%$ confidence intervals showing how fitted values of amount of high-protein (diet $\mathrm{B} ; 3_{\mathrm{P}}: 1_{\mathrm{C}}, 1.45 \% \mathrm{pH}$ ) or high-carbohydrate (diet F; $\left.1_{\mathrm{P}}: 3_{\mathrm{C}}, 1.45 \% \mathrm{pH}\right)$ diet eaten changes with initial body weight. 


\subsubsection{Intake regulation of phosphorus}

When given a choice between two diets differing in phosphorus content but identical in protein:carbohydrate ratio, juvenile female crickets did not preferentially consume either the low-phosphorus $\operatorname{diet}\left(\operatorname{diet} \mathrm{C} ; 1_{\mathrm{P}}: 1_{\mathrm{C}}, 0.45 \%{ }_{\mathrm{PH}}\right)$ or the high-phosphorus $\operatorname{diet}(\operatorname{diet} \mathrm{D}$; $\left.1_{\mathrm{P}}: 1_{\mathrm{C}}, 1.45 \% \mathrm{pH}\right)($ Tables $5.3 \& \mathrm{~A} 3.2)$. As a result, the mean concentration of phosphorus consumed $(0.941 \pm 0.034 \% \mathrm{PH})$ did not significantly differ from the expected phosphorus consumption $(0.950 \% \mathrm{PH})$ if crickets were eating between the two diets at random (one sample t-test: $\left.t_{29}=-0.251, P=0.804\right)$.

\subsection{Discussion}

Nutrition has the potential to profoundly influence the fitness and life history of individuals during development and throughout adulthood. Due to differences in the underlying physiological and metabolic processes that support such traits as growth, survival, fecundity and dispersal capability, an organism's fitness traits may require differing optimal nutrient mixtures for maximal expression. Thus, when the diversity of food items and associated nutrient ratios is limiting, diet may constrain fitness maximization by influencing trade-offs between various fitness traits (e.g. Chapter 3; Harrison et al., 2014; Hunt et al., 2004; Maklakov et al., 2008; Sentinella et al., 2013). However, when organisms are faced with a diversity of foods with variable and complementary nutrient ratios, they are often capable of behaviourally compensating and selecting between multiple foods to obtain a diet with a more favourable nutrient balance (Behmer, 2009; Simpson \& Raubenheimer, 2012). 


\subsubsection{Juvenile growth, development, and survival}

Growth, development rate, and survival to adulthood were influenced by dietary protein to carbohydrate ratio. As predicted, juvenile females consuming intermediate to high levels of dietary protein $\left(1_{\mathrm{P}}: 1_{\mathrm{C}}\right.$ or $\left.3_{\mathrm{P}}: 1_{\mathrm{C}}\right)$ developed faster and were significantly heavier at adult eclosion compared to females consuming high-carbohydrate $\left(1_{\mathrm{P}}: 3_{\mathrm{C}}\right)$ diets. This finding supports many previous studies demonstrating that development rates and growth in a variety of taxa are positively influenced by the amount of protein in the juvenile diet (Hunt et al., 2004; Shariatmadari \& Forbes, 1993; Venesky et al., 2012). There was, however, a non-significant trend for juvenile growth to be higher on the equal protein:carbohydrate ratio diet compared to the high-protein diet, likely reflecting an increased metabolic requirement for carbohydrates in order to process protein into new body tissues (Clark et al., 2015).

Juvenile growth and development rate are important to adult female cricket fitness, as faster development rates would reduce juvenile predation risk, larger adult females are typically more fecund (e.g. Chapter 3; Bertram et al., 2016; Bertram \& Rook, 2012; Harrison et al., 2014; Visanuvimol \& Bertram, 2010), and male field crickets may preferentially court larger females (Bateman \& Fleming, 2006). Furthermore, given that G. veletis is a univoltine species whose offspring over-winter in the nymphal stage (Alexander \& Bigelow, 1960; Alexander \& Meral, 1967; Harrison, 1979), faster juvenile development rates may increase female fitness by allowing earlier reproduction and greater lifetime fecundity, and may provide their offspring with a longer duration to grow and accumulate bodily nutrient stores prior to experiencing cold diapause. Juvenile diet, 
therefore, has the potential to not only influence juvenile life-history traits, but may also influence fitness into adulthood.

Juvenile survival to adulthood was also significantly higher on a diet with equal protein:carbohydrate ratio $\left(1_{\mathrm{P}}: 1_{\mathrm{C}}\right)$, but declined slightly on both extreme diets $\left(3_{\mathrm{P}}: 1_{\mathrm{C}}\right.$ and $1_{\mathrm{P}}: 3_{\mathrm{C}}$ ). Similar findings have been demonstrated for adult survival in black field crickets (Maklakov et al., 2008), and in juvenile nerrid flies where egg to adult survival decreases with at high dietary protein levels, and adult body size peaks at intermediate protein to carbohydrate ratios and declines on diets with extreme protein or carbohydrate bias (Sentinella et al., 2013). Therefore, juvenile survival requires greater amounts of carbohydrates compared to growth and development rate. This suggests that juvenile diet may influence a trade-off between fitness traits, as the availability of only high protein foods may allow for optimal development rates and relatively high growth rates, but would not allow for optimal juvenile to adult survival. Furthermore, my survival results suggest that the optimal nutrient ratio for survival differs between life stages in G. veletis, as I previously found that adult females live longer on diets higher in carbohydrate $\left(1_{\mathrm{P}}: 8_{\mathrm{C}}\right.$; Chapter 3 ; Harrison et al., 2014) compared to the juvenile females in the present study. Thus, my results support many previous studies demonstrating the importance of dietary protein during early life stages on development rate and growth, and also highlights the need to assess the effects of protein relative to the amounts other dietary nutrients. 


\subsubsection{Wings and flight muscles}

I found that juveniles with low initial body weights consuming high-carbohydrate $\left(1_{\mathrm{P}}: 3_{\mathrm{C}}\right)$ diets had a greater probability of eclosing as adults with deformed forewings compared to individuals with high initial weights, or those consuming either the equal protein:carbohydrate $\left(1_{\mathrm{P}}: 1_{\mathrm{C}}\right)$ or high-protein $\left(3_{\mathrm{P}}: 1_{\mathrm{C}}\right)$ diets. Furthermore, compared to the low-phosphorus $(0.45 \% \mathrm{PH})$ diets, consuming a high-phosphorus $(1.45 \% \mathrm{PH})$ diet resulted in an increased probability of eclosing with deformed forewings in individuals consuming the two highest carbohydrate diets $\left(1_{\mathrm{P}}: 1_{\mathrm{C}}\right.$ and $\left.1_{\mathrm{P}}: 3_{\mathrm{C}}\right)$. Similar to previous studies showing that protein is important for juvenile cricket growth (Hunt et al., 2004) and wing development (Mcfarlane, 1964), these results suggests that juveniles require sufficient amounts of protein in order to properly develop wing tissues. Furthermore, my results support recent findings that high levels of dietary phosphorus in developmental diets may have negative consequences on juvenile growth and fitness (Cease et al., 2016; Loaiza et al., 2008). Thus, juvenile diet has important consequences on the flightcapability of adults, as forewings in crickets are an important structure used in steering and providing lift during flight (May \& Hoy, 1990; Taylor, 2001).

In contrast, juvenile females with high initial body weights at the start of the experiment were more likely to develop into adults with long hindwings when consuming the two highest carbohydrate diets $\left(1_{\mathrm{P}}: 1_{\mathrm{C}}\right.$ and $\left.1_{\mathrm{P}}: 3_{\mathrm{C}}\right)$ compared to juveniles with low initial weights, or those consuming the high-protein $\operatorname{diet}\left(3_{\mathrm{P}}: 1_{\mathrm{C}}\right)$. This supports previous findings in Gryllodes sigillatus crickets where juveniles are more likely to eclose with long hindwings if they consume low to intermediate levels of dietary protein $(<20 \%$ 
protein by mass) during development (Mcfarlane, 1964). It is possible that this results from low protein diets having negative consequences for the biosynthesis of juvenile hormone, as this hormone has been identified as a controlling factor in wing development, where lower levels result in a greater proportion of long hindwing individuals in G. rubens (Zera, Strambi, Tiebel, Strambi, \& Rankin, 1989; Zera \& Tiebel, 1989). Alternatively, this may reflect a physiological response to unfavourable environmental conditions, as wing dimorphism in insects is thought to be an adaptation for coping with environmental heterogeneity that allows some individuals experiencing harsh conditions during development to disperse and locate more favourable environments (Alexander, 1961; Bégin \& Roff, 2002; Roff, 1986; Walker \& Sivinski, 1986). Thus, juveniles with high initial weights, likely having already completed the majority of their growth prior to the start of the experiment and likely possessing sufficient somatic protein stores, responded to higher carbohydrate diets by developing long hindwings. This physiological response would potentially allow these females to disperse and find protein-rich resources needed for their own reproduction and the development of their offspring. In contrast, juveniles with low initial weights who were fed a higher carbohydrate diet were not able to physiologically respond to this presumably unfavourable environment and did not develop long hindwings for dispersal, and instead often developed wing deformities, perhaps due to a lack of somatic protein stores. Thus, a protein-limitation in the developmental environment, coupled with a sufficient level of prior development and/or somatic nutrient stores, may stimulate 
physiological changes that result in long hindwing individuals with the ability to escape that environment to find one with better nutritional resources.

Given that possessing functional flight muscles is a necessary requirement for flight capability in long-hindwing individuals (Tanaka, 1994), I investigated the influence of diet on flight muscle histolysis in long-hindwing females. I expected that high carbohydrate diets would result in a greater proportion of long-hindwing individuals with functional flight muscles. However, I did not find any influence of diet on level of flight muscle histolysis, as indicated by muscle colour, in long-hindwing females. This result is surprising given that, in comparison to white (inactive) flight muscles, active (pink) flight muscles have higher respiration rates and metabolic activity (Zera et al., 1997), and other Gryllus species store carbohydrates as lipids to use as a primary flight fuel (Zera \& Mole, 1994; Zera \& Rankin, 1989; Zera et al., 1997). Thus, a likely explanation for my result is that many long-hindwing females may have had already began or completed histolyzation of their flight muscles by day $16 \pm 2$ of adulthood, resulting in few females retaining active flight muscles at this time $(14 / 61=23 \%)$. For instance, in G. firmus, long-hindwing females begin histolizing their flight muscles after the fifth day of adulthood (Zera et al., 1997). However, Clark et al., (2015) found no influence of dietary protein to carbohydrate ratio on the probability of flight muscle histolysis in five-day-old long-hindwing G. firmus females. Further research is thus needed on the impact of dietary nutrient ratio on the timing of flight muscle histolyzation in long-hindwing females. 


\subsubsection{Reproduction - dispersal trade-off}

My results support previous findings that differences in fecundity are explained more so by differences in flight muscle development and level of histolysis than by hindwing length (Tanaka, 1993; Zera et al., 1997). Similar to these previous findings, shorthindwing females in the current study, all of which possessed inactive (white; $\mathrm{SW}_{\mathrm{W}}$ ) flight muscles, had more eggs in their ovaries compared to most long-hindwing females, including those with both inactive (white; $\mathrm{LW}_{\mathrm{W}}$ ) and active (pink; $\mathrm{LW}_{\mathrm{W}}$ ) flight muscles. However, long-hindwing females that were in the process of histolizing their muscles (yellow; $\mathrm{LW}_{\mathrm{Y}}$ ) had similar, if not greater, numbers of eggs in their ovaries compared to short-hindwing females, likely resulting from their re-allocation of nutrients from flight muscle maintenance to egg production (Tanaka, 1993; Zera \& Rankin, 1989). In contrast, long-hindwing females with inactive flight muscles $\left(\mathrm{LW}_{\mathrm{W}}\right)$ may not have developed active flight muscles at adult emergence, resulting in them not possessing the resources in their flight muscles to re-allocate to eggs. My findings support the existence of a reproduction-dispersal life-history trade-off in wing polymorphic crickets such that flight-capable females suffer fecundity costs, likely as a result of developing and maintaining flight muscles. I did not, however, find any evidence that diet influenced the relationship between fecundity and wing-muscle morph, which again may be due to my measurement of flight muscle histolysis occurring late in adulthood.

Fecundity was also influenced by diet. Females consuming diets with equal protein:carbohydrate $\left(1_{\mathrm{P}}: 1_{\mathrm{C}}\right)$ or high-protein $\left(3_{\mathrm{P}}: 1_{\mathrm{C}}\right)$ diets had higher numbers of eggs in their ovaries, supporting previous findings that diets with equal or higher amounts of 
protein relative to carbohydrates result in increased egg production in adult insects (e.g. Chapter 3; Carey, 1998; Harrison et al., 2014; Joern \& Behmer, 1997; Maklakov et al., 2008). More specifically, this result is consistent with my previous finding that the number of eggs laid by adult female G. veletis could be maximized on diets with intermediate to high protein levels (Chapter 3; Harrison et al., 2014). Increased dietary protein may be resulting in increased egg production not only through direct allocation of protein to eggs, but also indirectly through its influence on juvenile hormone production in insects (Schal, Chiang, Burns, Gadot, \& Cooper, 1993), since juvenile hormone induces yolk production by insect fat bodies and uptake by oocytes (Wheeler 1996). Additionally, I found that larger adult females had significantly more eggs in their ovaries, supporting numerous studies on the importance of body size on fecundity in crickets and other Orthopterans (e.g. Chapter 3; Bertram et al., 2016; Bertram \& Rook, 2012; Harrison et al., 2014; Visanuvimol \& Bertram, 2010; Whitman, 2008). Further, as adult body size is fixed at adulthood in crickets, this result highlights the positive impact that a developmental diet which maximizes juvenile growth (i.e. $1_{\mathrm{P}}: 1_{\mathrm{C}}$ to $3_{\mathrm{P}}: 1_{\mathrm{C}}$ in the present study) may have on fecundity.

\subsubsection{Phosphorus}

Contrary to my a priori predictions, I found no significant influence of dietary phosphorus on juvenile female growth, development time, survival to adulthood, adult wing morphology, or flight muscles. Recently, Cease et al., (2016) demonstrated a nonlinear relationship between dietary phosphorus levels and the growth, survival, and 
development of juvenile Schistocerca americana grasshoppers, such that these fitness traits peaked at $\sim 0.5 \%$ PH but were reduced on low $(<0.10 \%)$ and high $(>1.0 \%)$ phosphorus diets. Similar negative effects of high-phosphorus diets on juvenile growth, development, and survival have been observed in other orthopterans (Loaiza et al., 2008; Smith, 1960). Thus, my finding of a lack of an effect of phosphorus on life-history traits in juvenile female G. veletis may imply that my choice of phosphorus levels $(0.21 \% \mathrm{PH}$ and $0.66 \%$ PH in total food mass) were not sufficiently extreme and/or did not encompass a wide enough range to have any observable effects. It is also possible that my use of final instar juveniles in the current study may have limited my ability to detect an influence of dietary phosphorus on fitness traits. In support of this possibility, Cease et al., (2016) found that third-instar grasshopper nymphs consume and assimilate relatively more phosphorus relative to final instar nymphs, likely as a consequence of the higher specific growth rates of younger nymphs.

I also surprisingly found no effect of dietary phosphorus on the number of eggs in adult ovaries. This result is in line with my previous finding that the phosphorus content of adult diets does not influence the number of eggs laid by G. veletis females (range tested: $0.07-1.87 \%$ phosphorus in total food mass; Chapter 3). However, a similar study on female house crickets (Acheta domesticus), which tracked life-history traits from the fourth larval instar until death and used similar dietary phosphorus levels $(0.2-1.0 \%$ phosphorus in total food mass) as the current study, found a positive effect of higher phosphorus diets on egg laying (Visanuvimol \& Bertram, 2010). However, the latter study did not simultaneously vary dietary protein and carbohydrate levels as I did here. 
Thus, my results likely indicate that variation in dietary phosphorus is less important to fecundity and other fitness traits when it covaries with dietary macronutrients such as protein and carbohydrates. Alternatively, these conflicting results could reflect differing phosphorus requirements among field cricket species, or perhaps a difference in phosphorus levels in the rearing diet provided to hatchlings prior to initiation of the experiments (see Chapter 4 for further discussion). It is also possible that this result may be due to females in the current study not being mated and allowed to lay eggs, where the lowest phosphorus diet in the current study may have been sufficient to fill ovaries with eggs, but may not have sustained egg development over a female's lifetime. As evidence for this, female G. veletis on average lay $115 \pm 5.64 \mathrm{SE}$ eggs over their lifetime (S.J. Harrison, unpublished data) compared to the $84.5 \pm 5.94$ SE un-laid eggs observed in ovaries in the current study. Thus, future studies should examine the influence of a broader range of dietary phosphorus over an individual's entire lifespan (hatching until death), or at least over multiple juvenile instars.

\subsubsection{Diet choice}

My diet choice experiment revealed that juvenile female G. veletis regulate their intakes of both carbohydrates and protein. When given a choice between two diets differing in protein:carbohydrate ratio, juvenile females preferentially consumed more of the highcarbohydrate $\left(1_{\mathrm{P}}: 3_{\mathrm{C}}\right)$ diet compared to the high-protein $\left(3_{\mathrm{P}}: 1_{\mathrm{C}}\right)$ diet. This diet preference resulted in juvenile females self-selecting an average dietary nutrient ratio of $1.44_{\mathrm{P}}: 3_{\mathrm{C}}$. Previously, I found that adult female G. veletis also preferentially consume high- 
carbohydrate over high-protein foods, but self-selected a dietary nutrient ratio slightly higher in carbohydrates than the juveniles in the current study $\left(1.3_{\mathrm{P}}: 3_{\mathrm{C}}\right.$; Chapter 3$)$. Thus, juvenile G. veletis females preferentially consumed greater amounts of carbohydrates relative to protein, but with a slightly greater protein intake compared to adult females, likely owing to their greater need for protein to sustain physiological and metabolic processes supporting growth and development.

Furthermore, juvenile females with higher initial weights preferentially ate greater amounts of carbohydrates relative to protein compared to those with lower initial weights. This likely reflects a reduced need for protein in larger juveniles, who presumably had already completed the majority of their growth prior to the start of the experiment. However, irrespective of developmental stage and how much growth an individual has yet to complete, larger individuals may simply differ from smaller individuals in their diet preference. For example, larger adult male crickets consume greater amounts of carbohydrates relative to protein compared to smaller individuals (Gryllus bimaculatus: Han, Jäger, \& Dingemanse, 2016), and morphological similarity in threespine sticklebacks (Gasterosteus aculeatus) is related to similarity in dietary prey composition (Bolnick \& Paull, 2009). Thus, body size and morphology may explain inter-individual differences in dietary preferences. As I did not compare the diet preferences of juveniles who subsequently became long- vs. short-hindwing adults in the current study, further work is needed to address how female wing morphology and flight muscle histolysis influences diet choice (e.g. Clark, McConnell, Zera, \& Behmer, 2013). 
Contrary to my a priori prediction, I found no evidence that juvenile female crickets regulate their intake of phosphorus. When given a choice between two diets differing in phosphorus content, the amount of phosphorus females consumed did not differ from the expected intake if crickets were eating at random between the two diets. While this result is in line with my previous finding that adult $G$. veletis females do not behaviourally regulate their intake of phosphorus (Chapter 3; Harrison et al., 2014), it is surprising given the numerous previous studies demonstrating the importance of phosphorus for juvenile invertebrate growth (e.g. Clancy \& King, 1993; Elser, Hayakawa, \& Urabe, 2001; Perkins et al., 2004; Visanuvimol \& Bertram, 2010), coupled with the finding that other juvenile orthopterans are capable of regulating their phosphorus intake (S. americana: Cease et al., 2016). My findings may suggest that crickets lack taste receptors for phosphorus, or that both diets had sufficient phosphorus and therefore did not warrant regulation of intake. Alternatively, it is possible that, in the current study, juvenile females' intake target for phosphorus lies exactly half way between my low- and high-phosphorus diets, thereby obscuring my ability to detect a deviation of the observed phosphorus intake from that would be expected if crickets were eating between the two diets at random. For example, an intake target lying half way between my low- and high-phosphorus diets would amount to $0.95 \%$ pH in total nutrients ( $0.435 \%_{\mathrm{PH}}$ in total dry food mass), which is similar to the $0.60 \%$ PH (total dry food mass) that juvenile S. americana grasshoppers self-select (Cease et al., 2016). A greater breadth of dietary phosphorus in diet choice treatments is necessary to conclusively determine whether or not juvenile crickets regulate their intake of phosphorus. 


\subsubsection{Conclusions}

In conclusion, my findings suggest that when juvenile female crickets are limited to consuming a single diet with a fixed nutrient ratio, diet influenced trade-offs between life-history traits such that not all fitness traits could be maximized on the same diet. While juvenile growth, development rate, and adult egg production were maximized on higher protein:carbohydrate ratio (equal protein:carbohydrate or high-protein) diets, juveniles had a greater chance of surviving to adulthood on an equal protein:carbohydrate ratio diet, and were more likely to develop long hindwings, potentially allowing for flight and dispersal capability, on low protein:carbohydrate ratio (high-carbohydrate) diets. In contrast, dietary phosphorus had little influence on fitness traits. Furthermore, I found evidence supporting a reproduction-dispersal trade-off common to wing-polymorphic crickets and other insects (e.g. Clark et al., 2015; Tanaka, 1993), as female fecundity was related to their hindwing morphology and level of histolysis in flight muscles (wingmuscle morph). However, I found no evidence that dietary nutrient ratio influenced this life-history trade-off. Lastly, when given a choice between diets differing in nutrient composition, juvenile females self-selected a carbohydrate-biased diet relative to protein, but did not regulate their intake of phosphorus. When coupled with my previous findings (Chapter 3; Harrison et al., 2014), this suggests that juvenile female crickets self-select a diet with slightly more protein than do adults, which likely reflects the greater need for protein during development. Together, these findings demonstrate that an individual's ability to acquire dietary proteins and carbohydrates in the appropriate ratio during 
development may have consequences not only for their ability grow and survive to adulthood, but also their adult morphology, dispersal capabilities and fecundity.

However, I nonetheless urge caution when relating my current results obtained from a laboratory-reared cricket population to wild populations for at least a couple of reasons. First, I suspect the high prevalence (13.5\%) of long-hindwing morphs in my current study is related to $(i)$ an artifact of rearing in a laboratory environment $(<5 \% \mathrm{LW}$ in wild populations: Alexander, 1968; Bégin \& Roff, 2002), and (ii) being reared individually for the final juvenile stage, as this has previously been found to increase the prevalence of long-hindwing morphs in G. rubens (Walker, 1987). Second, while I have supplemented the laboratory colony of $G$. veletis annually with wild individuals to maintain genetic diversity, I do not cold diapause this laboratory colony, likely resulting in artificial selection for direct-developers that do not require a cold diapause. As direct development is strongly genetically correlated with long hindwings (Bégin \& Roff, 2002), my results likely reflect the influence of diet on the fitness and life-history traits of

primarily direct-developing individuals, and these results may differ in diapause-obligate G. veletis individuals in wild populations.

\subsection{Acknowledgements}

I thank Deepro Chowdhury, Alexa Derkson, MaryAnn Wu, Natasha Osborne, Dana Kolenich, Zach Cronk, and Alicia Cable for their assistance with animal care and data entry. 


\section{Chapter 6}

The influence of dietary nutrient balance on female sexual

responsiveness and mate preferences 


\subsection{Abstract}

In sexually reproducing species, females generally prefer to mate with males displaying more elaborate sexual ornaments or higher effort mate attraction signals, which has important consequences for the evolution of male sexual traits. However, females also show a great deal of intra-specific variation in their mate choice decisions. This variation may be due to female condition, as mate searching and assessment activities are costly, such that only high condition females should be able to express strong mate preferences. Female fecundity may also influence variation in mate preferences, as only females with reproductive capabilities stand to benefit from being choosy. While previous research has demonstrated that nutritional stress does indeed influence female sexual responsiveness and mate preferences in a variety of taxa, research on this topic has traditionally suffered from a lack of nutritionally explicit methodologies. Here I raised female Gryllus veletis field crickets on one of six unique diets differing in protein, carbohydrate and phosphorus composition, and after reaching adulthood, measured their sexual responsiveness and preference functions for artificial male acoustic mate attraction signals using a series of no-choice phonotaxis trials in an open-arena apparatus. Additionally, I examined how female body size and fecundity alter female mate preferences, as these traits themselves are influenced by dietary nutrient balance. Females that consumed high-protein diets during development were larger as adults, and these larger females were subsequently more sexually responsive and had steeper preference functions for male acoustic signals, suggesting that female mate preferences may depend on resources accumulated during development. In contrast, females that consumed high-carbohydrate diets as adults were 
also more sexually responsive to artificial male acoustic signals, suggesting that females' willingness to search for mates and copulate may be constrained by carbohydrate-derived energy stores. Neither dietary phosphorus nor fecundity significantly influenced female responsiveness or preference functions. Together, these findings support theoretical predictions that female mate preferences are condition dependent and suggest that dietary nutrient balance during both developmental and adult life stages may have important consequences for the strength and direction of sexual selection on male acoustic mate attraction signals.

\subsection{Introduction}

In sexually reproducing species, female mate choice decisions have important consequences for the evolution of male phenotypes (Andersson, 1994; Darwin, 1871). Inter-sexual selection occurs when males possessing certain traits, such as increased ornamentation or sexual signalling, have greater mating success arising from female mate choice (Andersson, 1994; Johnstone, 1995; Ryan \& Keddy-hector, 1992). However, within a species, females can vary in their individual mate preferences (Jennions \& Petrie, 1997; Widemo \& Sæther, 1999). Sexual selection theory predicts coevolution between male sexually selected traits and female preferences (Fisher, 1930). Despite this prediction, much of sexual selection research to date has focused primarily on factors influencing variation in male sexual traits (Andersson, 1994; Cotton et al., 2004b), with comparatively less attention being given to causes of variation in female mate choice decisions (Cotton et al., 2006). Understanding the proximate causes of variation in female 
mate choice decisions at the individual level is important, as it has consequences for the intensity, rate, and direction of sexual selection on male traits (Jennions \& Petrie, 1997; Widemo \& Sæther, 1999).

Variation between females in their mate choice decisions may arise, in part, due to individual condition, which is broadly determined by the combined effects of an individual's somatic, genetic, and epigenetic states (Hill, 2011). For instance, there is evidence that variation in female mating preferences may be related to inter-individual variation in genetics (e.g. Bakker \& Pomiankowski, 1995; Bakker, 1999; Delcourt, Blows, \& Rundle, 2010; Godin \& Dugatkin, 1995), age (e.g. Gray, 1999; Pacheco, Dawson, Jutting, \& Bertram, 2013; Wilgers \& Hebets, 2012), body morphology (e.g. Bakker, Kunzler, \& Mazzi, 1999; Hingle, Fowler, \& Pomiankowski, 2001a; Jennions, Backwell, \& Passmore, 1995), and levels of parasite infection (e.g. López, 1999; Pfennig \& Tinsley, 2002). This condition-dependence may arise due to the time and energy expenditure, and increased risk of predation and parasitism, associated with searching for and sampling between potential mates (Jennions \& Petrie, 1997; Pomiankowski, 1987b; Widemo \& Sæther, 1999). For example, searching for mates results in a loss of time that could be devoted to other fitness-enhancing activities (e.g. Alatalo, Carlson, \& Lundberg, 1988; Slagsvold, Lifjeld, Stenmark, \& Breiehagen, 1988), and there is evidence that females may more readily accept a less attractive mates when there is increased predation risk (e.g. Godin \& Briggs, 1996; Hedrick \& Dill, 1993; Johnson \& Basolo, 2003), or increased energetic costs (e.g. López, 1999; Milinski \& Bakker, 1992), associated with searching for a more attractive mate. Thus, the costly nature of female mate choice is 
expected to result in condition-dependence (Cotton et al., 2006; Jennions \& Petrie, 1997) comparable to the handicap principle's prediction of condition-dependence for costly male sexually selected traits (Andersson, 1994; Cotton et al., 2004b; Zahavi, 1975, 1977).

Given the costs of female mate choice, the strength of female preferences are expected to reflect the cost-to-benefit ratio associated with being choosy, where highcondition females may be better able to afford the costs, or may benefit the most, from the expression of stronger mate preferences (Cotton et al., 2006). High-condition females are therefore expected to exhibit stronger preferences, either through increased responsiveness (willingness to search for or copulate with a mate) or more discriminatory preference functions (overall ranking of male sexual trait values) (Cotton et al., 2006; Jennions \& Petrie, 1997). This prediction is supported by evidence that variability in nutritional resources, an important aspect of condition, influences mating preferences. Females experiencing food stress are typically less likely to search for mates or copulate (e.g. Clark et al., 1997; Eraly et al., 2009; Hunt et al., 2005; Ortigosa \& Rowe, 2002; Syriatowicz \& Brooks, 2004; Wilgers \& Hebets, 2012) and often show weakened preferences for certain male phenotypes (e.g. Brown, 1997; Hebets et al., 2008; Hingle et al., 2001b; Hunt et al., 2005). These effects of inadequate nutritional resources on female sexual responsiveness and mate preferences may arise due to a lack of energetic nutrients required to fuel searching for a more preferred mate (e.g. Milinski \& Bakker, 1992), or malnourished females may have underdeveloped sensory structures that hinder their ability to detect differences between male sexual signals (e.g. David et al., 1998; Hingle et al., 2001a). Females may also be less willing to invest time and energy in mate 
searching and sampling activities if they are unlikely to benefit from being choosy as a result of reduced fecundity from malnourishment (Hingle et al., 2001b; Hunt et al., 2005).

Despite promising evidence that dietary nutrient availability may influence mating preferences, the majority of previous studies on this topic have tested for the effects of a single nutrient or the total amount of diet available to females, an approach that ignores the chemical complexities of natural foods. In contrast, research on the condition-dependence of male sexual signals and other life-history traits in recent years has experienced a shift towards more nutritionally-explicit approaches that consider the importance of multiple dietary macromolecule nutrients, such as protein, carbohydrates, and lipids (Raubenheimer \& Simpson, 1993; Simpson \& Raubenheimer, 1993, 2012), and elemental nutrients such as carbon, nitrogen, and phosphorus (Elser, 2006; Sterner \& Elser, 2002). These studies have demonstrated an importance of dietary nutrient ratio on male sexual signalling traits (e.g. Bertram et al., 2009; Maklakov et al., 2008; Reifer et al., 2018; South et al., 2011), adult lifespan (e.g. Jensen et al., 2015; Lee et al., 2008; Maklakov et al., 2008), female fecundity (e.g. Lee et al., 2008; Maklakov et al., 2008; Visanuvimol \& Bertram, 2010), and juvenile growth rates (e.g. Cease et al., 2016; Loaiza et al., 2008; Perkins et al., 2004; Reifer et al., 2018; Urabe \& Sterner, 2001; Visanuvimol \& Bertram, 2011). However, to my knowledge, no study to date has considered the potential influence of the nutritional composition of diets, in terms of the ratio of multiple dietary nutrients, on the expression of female mate choice decisions.

Here, I examined how varying dietary nutrient composition influences the expression of female mate choice decisions in the field cricket, Gryllus veletis. In field 
crickets, males broadcast acoustic mate attraction signals to attract females from long distances, and females exhibit phonotaxis towards male signals that they find attractive (Alexander, 1961). Within the range of male signal variability for a given species, female crickets often show preferences for male signals with intermediate carrier frequencies (Bentsen, Hunt, Jennions, \& Brooks, 2006; Brooks et al., 2005; Hunt et al., 2005) and with faster temporal structures that indicate higher effort, such as higher chirp rates (Simmons, 1988; Wagner, 1996; Wagner \& Reiser, 2000), longer chirp durations (Wagner, 1996), more frequent calling (Cade \& Cade, 1992; Holzer et al., 2003), and longer calling bout durations (Hedrick, 1986). Furthermore, individual female mate preferences in field crickets show moderate levels of repeatability (e.g. Bailey, 2011; Wagner, Murray, \& Cade, 1995). Field crickets are therefore ideal organisms to use to study female mate choice decisions.

Theory suggests that high-condition females should be better able to afford the costs of strong mate preferences, and mate preferences are expected to be expressed primarily by females that can benefit from being choosy (Cotton et al., 2006). As such, female fecundity may influence mate choice decisions given that infertile females stand to benefit little from mating or being choosy, and morphological characteristics such as adult body size may be related to female mate preferences since they commonly reflect developmental condition. In Chapter 5, I reported my findings for a study in which juvenile female $G$. veletis field crickets were raised on one of six diets differing in protein, carbohydrate, and phosphorus content in order to assess the effects of dietary nutrient balance on juvenile growth, development, and survival, as well as subsequent 
body morphology and fecundity at adulthood. In insects, both protein and phosphorus are important nutrients used in the production of eggs (e.g. Joern \& Behmer, 1997;

Visanuvimol \& Bertram, 2010), and in juvenile growth (e.g. Cease et al., 2016; David et al., 1998; Hunt et al., 2004; Perkins et al., 2004; Reifer et al., 2018; Visanuvimol \& Bertram, 2011), whereas high-carbohydrate diets often reduce egg production in insects (Hingle et al., 2001b; Maklakov et al., 2008). Therefore, I expected that both phosphorus and protein:carbohydrate ratio in developmental diets would influence adult body size and fecundity. However, I found that only protein:carbohydrate ratio significantly influenced these condition-dependent traits, with higher fecundity and adult body size on intermediate- to high-protein diets $\left(1_{\mathrm{P}}: 1_{\mathrm{C}}\right.$ and $3_{\mathrm{P}}: 1_{\mathrm{C}}$; Chapter 5$)$. However, phosphorus did not have a significant effect on adult female body size or fecundity (Chapter 5).

As an extension of my previous study presented in Chapter 5, I examined in the current study the mate choice decisions of adult female G. veletis who had previously been reared on one of six unique diets differing in protein, carbohydrate, and phosphorus content. Female response to artificial male mate attraction signals, differing in either chirp rate or carrier frequency, was measured using a series of no-choice phonotaxis trials in an open-arena apparatus. This allowed me to estimate female preference functions and overall sexual responsiveness, both of which are important components in the decision making process that ultimately determines mate choice outcome (Cotton et al., 2006; Jennions \& Petrie, 1997; Wagner, 1998; Widemo \& Sæther, 1999). I hypothesized that diet would mediate female mate choice decisions primarily through its influence on female body size and fecundity. Prior to obtaining the results presented in Chapter 5, I 
made the a priori prediction that diets containing higher levels of protein and phosphorus would result in larger females with higher fecundity, and consequently, these females would have increased sexual responsiveness and stronger mate preferences relative to females on diets that are poorer in protein and phosphorus content.

Variation in female mate choice decisions has important consequences for the intensity, rate, and direction of sexual selection on male traits (Jennions \& Petrie, 1997; Widemo \& Sæther, 1999). Increased variability in female preferences may result in frequency-dependent selection on male traits (Wagner et al., 1995). Changes to the population mean preference may result in a decrease in the intensity of directional selection on male traits (Jennions \& Petrie, 1997), or even disruptive selection leading to speciation (Turner \& Burrows, 1995). Understanding how dietary nutrient composition influences variation in female mate choice decisions at the individual level is thus important to understanding sexual selection processes that result in the evolution of elaborate male signals and ornaments.

\subsection{Methods}

\subsubsection{Subjects and rearing}

Using the colony rearing conditions outlined in Chapter 2, section 2.2, I raised experimental juvenile female $G$. veletis in same-sex communal bins ( $25-50$ individuals) from approximately the fifth nymphal instar until they reached their final nymphal instar, as evidenced by a long ovipositor (5-10 mm in length) and large wing buds. Within $24 \mathrm{~h}$ of reaching the final nymphal instar, experimental females were moved individually into 
$520 \mathrm{~mL}$ plastic containers equipped with a cardboard shelter, a screened lid for ventilation, water, and one of six experimental diets (see below).

\subsubsection{Diet treatments}

Juvenile females were assigned at random to one of six powdered experimental diets varying in protein $(\mathrm{P})$, carbohydrate $(\mathrm{C})$, and phosphorus $(\mathrm{PH})$ concentration, created following established protocols (Simpson \& Abisgold, 1985). All diets were roughly comprised (by mass) of $45 \%$ indigestible cellulose, $50 \%$ total nutrients $(\mathrm{P}+\mathrm{C}+\mathrm{PH})$, and $5 \%$ vitamins, minerals, and lipids (see Chapter 2, section 2.3 for further details on diet composition). Diets consisted of three protein:carbohydrate ratios (high-protein - $3_{\mathrm{P}}: 1_{\mathrm{C}}$; equal protein:carbohydrate $-1_{\mathrm{P}}: 1_{\mathrm{C}} ;$ high-carbohydrate $-1_{\mathrm{P}}: 3_{\mathrm{C}}$ ), each varied at two phosphorus levels $(0.45 \% \mathrm{PH}$ and $1.45 \% \mathrm{PH}$ of total nutrients, corresponding to $0.21 \% \mathrm{PH}$ and $0.66 \%$ PH of total dry food mass). Diets were supplied ad libitum and replaced with fresh once weekly.

\subsubsection{Adult weight and fecundity}

Experimental females were weighed within $24 \mathrm{~h}$ of emerging as adults using an analytical balance (Ohaus Pioneer Series; model PA214; precision $\pm 0.1 \mathrm{mg}$ ) to obtain their adult eclosion weights. I used adult eclosion weight as a measure of overall adult body size, as it is strongly correlated with female head and pronotum measurements $\left(\mathrm{R}^{2}{ }_{\mathrm{ADJ}}=0.72, F_{1}\right.$, $320=835.38, P<0.001$; Chapter 5). Following the completion of phonotaxis trials, females were humanely euthanized by freezing and then dissected ventrally to remove 
their ovaries using a dissecting microscope. The number of mature eggs within ovaries were counted manually, identifying mature eggs as those large in size and possessing a durable outer cuticle. I used the residual number of eggs on adult eclosion weight, calculated from an ordinary least squares regression of number of eggs against adult eclosion weight, as a measure of female fecundity.

\subsubsection{Artificial calls}

I created two sets of artificial male long-distance acoustic mate attraction signals (hereafter "artificial calls"), one set varying in chirp rate and the other in carrier frequency, but otherwise identical in structure in all other signal parameters and mimicking natural mate attraction signals. To estimate natural male signalling parameters, I used a sample population of thirty 10-day old virgin adult male G. veletis from the laboratory colony. Individually housed males were placed into an Electronic Acoustic Recording System (EARS II; see Chapter 2, section 2.4 for details) wherein their long-distance mate attraction signalling was continually monitored for four days. I recorded males at $25 \pm 2{ }^{\circ} \mathrm{C}$, as this is the temperature at which female phonotaxis trials would be conducted, and ambient temperature may influence both male signals and female response to those signals (Martin, Gray, \& Cade, 2000; Pires \& Hoy, 1992). Sample population mean values for the following signalling parameters were then calculated using Spike2 v 6.09 (Cambridge Electronic Design, Cambridge, U.K.): pulse duration (ms), inter-pulse duration (ms), chirp duration (ms), inter-chirp duration (ms), number of pulses per chirp, carrier frequency $(\mathrm{Hz})$, amplitude $(\mathrm{dB})$, pulse rate (\# 
pulses/s), and chirp rate (\# chirps/min) (Table 6.1; see Chapter 2, section 2.4 for further details). Furthermore, I examined a sample of these recorded signals by hand using Spike2 in order to quantify within-chirp variation in signal parameters, such as pulse and inter-pulse durations and pulse amplitude so as to mimic this variation in the artificial calls. 
Table 6.1. Mean and standard deviation (SD) values for mate attraction signal parameters of the sample population used in creating artificial calls.

\begin{tabular}{lrr}
\hline Parameter & Mean & SD \\
\hline Pulse Duration (ms) & 15.00 & 1.09 \\
Inter-pulse Duration (ms) & 18.08 & 2.55 \\
Pulses Per Chirp & 3.56 & 0.49 \\
Chirp Duration (ms) & 111.01 & 11.02 \\
Inter-chirp Duration (ms) & 504.41 & 108.35 \\
Amplitude (dB) & 62.72 & 7.60 \\
Carrier Frequency (Hz) & 5374.76 & 240.21 \\
Pulse Rate (\# pulses/s) & 30.37 & 2.15 \\
Chirp Rate (\# chirps/min) & 100.22 & 16.74 \\
\hline
\end{tabular}


To create artificial calls, I first downloaded pulses of sound of the desired frequency and duration from Wavtones online function generator (http://www.wavtones.com). I then used Adobe Audition CC 2014 (Adobe Systems; San Jose, CA, USA) to manipulate the relative amplitudes of these pulses, string together pulses to create chirps with the desired inter-pulse durations, and finally join together chirps with the desired inter-chirp durations to create the final artificial calls. I created a total of 21 artificial calls: (i) one standard call with parameters matching the sample population mean signal parameters (Table 6.1), (ii) 10 calls differing from the standard call in carrier frequency by $-2.5,-2,-1.5,-1,-0.5,+0.5,+1,+1.5,+2$, or +2.5 standard deviations from the sample population mean, and (iii) 10 calls differing from the standard call in chirp rate by $-2.5,-2,-1.5,-1,-0.5,+0.5,+1,+1.5,+2$, or +2.5 standard deviations from the sample population mean. Thus, for each call treatment (carrier frequency or chirp rate), female preference was tested for 11 artificial calls: the standard call, and 10 calls differing from the standard call in either chirp rate or carrier frequency.

\subsubsection{Phonotaxis trials}

Phonotaxis trials were conducted within a rectangular arena $(100 \mathrm{~cm}$ length $\mathrm{x} 50 \mathrm{~cm}$ width $x 30 \mathrm{~cm}$ height) made of corrugated white plastic, with the upper $15 \mathrm{~cm}$ of the inner walls covered in $3.5 \mathrm{~cm}$ egg crate foam to reduce echoes. Speakers (Insignia NSPCS40; Richfield, MN, USA) were embedded in the walls at either end of the long axis of the arena, positioned $3 \mathrm{~cm}$ higher than the arena floor to prevent females from climbing the speakers. Two 30-cm diameter semi-circular choice zones centered around 
on each speaker and a 12-cm diameter circular acclimatization zone at the centre of the arena were demarcated on the arena floor. Artificial calls were broadcasted during phonotaxis trials using Adobe Audition CC software on a computer connected to the two speakers, and each call-speaker combination was calibrated to play at $60 \mathrm{~dB}$ (mimicking the sample population mean amplitude, Table 6.1) when measured 3-cm away from the active speaker at the centre of the choice zone, and $52 \mathrm{~dB}$ at the centre of the arena's acclimatization zone. Amplitude calibration measurements were taken at the level of the arena floor using a sound pressure level metre (Extech Instruments Model 407750; Nashua, NH, USA) with the microphone pointed directly at the speaker. I also ensured that the intended carrier frequency of all artificial calls was correctly being reproduced by the computer speakers by recording broadcasted signals and measuring their frequency with Audacity v. 2.1 .0 (http://www.audacityteam.org/).

To reduce the likelihood of environmental noise disturbing phonotaxis trials, the arena was placed within an acoustic isolation chamber $(142 \mathrm{~cm}$ length $\mathrm{x} 79 \mathrm{~cm}$ width $\mathrm{x}$ $97 \mathrm{~cm}$ height) that was constructed of a wooden frame with a hinged door and lined with a layer of $2.5 \mathrm{~cm}$ wedge foam (outer layer) and a layer of $4 \mathrm{~cm}$ egg crate foam (inner layer). The arena was uniformly lit with two 6W LED lamps suspended inside the acoustic isolation chamber. Each lamp was fitted with a red light filter (Roscolux R27 medium red; Rosco, Sydenham, London, UK) which filtered out most light wavelengths that Orthopteran visual receptor cells are sensitive to $(<600 \mathrm{~nm}$; Briscoe \& Chittka, 2001), thereby simulating dim natural lighting conditions. An upturned $520 \mathrm{~mL}$ clear plastic cup was suspended inside the acoustic isolation chamber by a string and 
positioned directly over the centre of the arena to enclose females during the acclimatization period of the phonotaxis trial. The upper two thirds of the cup's walls were replaced with aluminium window screening to allow females to hear the signals during acclimatization, and the cup could be lifted silently by pulling on the portion of the string lying outside the acoustic isolation chamber. A video camera (GoPro Hero 4; San Mateo, CA, USA) suspended within the acoustic isolation chamber was used to record all phonotaxis trials, and enabled real time monitoring of trials on a tablet (GoPro Android application).

I conducted phonotaxis trials with $15 \pm 1$ day-old adult females at $25 \pm 1^{\circ} \mathrm{C}$ between 08:00 - 14:00 hrs. A total of 326 females $(N=26$ to 28 per diet-by-call treatment combination) were tested, with each female only participating in one set of 11 phonotaxis trials associated with either the chirp rate or carrier frequency call treatment. Each female's 11 phonotaxis trials were run consecutively over 25-60 min, and the order of presentation for artificial calls was randomized for each female. During each phonotaxis trial, only one speaker played the artificial call (active speaker) while the other speaker remained silent. The designated active speaker was chosen at random for each female's first phonotaxis trial, and alternated thereafter for her 10 remaining trials. At the beginning of each phonotaxis trial, the female was allowed a $60 \mathrm{~s}$ acclimatization period in silence under the acclimatization cup at the centre of the arena. Artificial call broadcast was then started, but females remained under the acclimatization cup for the first $30 \mathrm{~s}$ of broadcast, after which the cup was silently lifted. Females then had a maximum of $180 \mathrm{~s}$ remaining in the artificial call broadcast to demonstrate their 
preference. Phonotaxis trials were terminated once females entered the active speaker choice zone, or at the maximum trial duration, whichever came first. Between phonotaxis trials, females were handled minimally by gently sliding a clean piece of paper under them, covering them with the acclimatization cup, and sliding them back to the acclimatization zone. Before starting phonotaxis trials for a new female, the arena was wiped down with $95 \%$ ethyl alcohol to remove any residual pheromonal or chemical signals from the previous female.

I used phonotaxis trial video recordings to determine response latency: the amount of time females took to enter the choice zone around the active speaker. Females who failed to enter this choice zone, representing a low preference for the artificial call, were assigned a response latency of $180 \mathrm{~s}$ (equal to the maximum phonotaxis trial duration). However, since it is more intuitive when high female preferences are associated with high numerical values, I used the amount of time remaining in the phonotaxis trial after females entered the choice zone (180 seconds - response latency) as the measure of preference. Thus, females who entered the choice zone around the active speaker more quickly received higher preference scores, whereas females who entered the choice zone more slowly received lower preference scores. A small number of females $(6 / 326=1.8 \%)$ did not respond to the artificial call in any of their 11 phonotaxis trials and consequently were omitted from all statistical analyses. 


\subsubsection{Statistical analysis}

I plotted preference functions across the range of artificial call chirp rate and carrier frequency standard deviation values for each individual using the computer program PFunc, which uses generalized additive models to fit non-parametric curves (Kilmer et al., 2017). I also used PFunc to extract four traits from each female's preference function which generally describe height and shape metrics: (i) peak stimulus - the artificial call with the highest preference; (ii) strength - the degree to which preference drops with deviation from the peak stimulus; (iii) responsiveness - the average preference across all artificial calls; (iv) tolerance - the range of artificial call stimulus values over which preference remains relatively high (i.e. within $1 / 3$ of the peak height).

I performed all statistical analyses using R v 3.4.3 (R Development Core Team, Vienna, Austria; http://www.R-project.org). I first analyzed how diet, weight, and fecundity influence individual female preference function traits across call treatments (chirp rate and carrier frequency). I fitted general linear models for responsiveness and tolerance, and a generalized linear model (family = gamma, link = log) for strength using R's "stats" package. As peak stimulus followed a bimodal distribution, I transformed it into a 3-category nominal variable with females either preferring the lowest (-2.5 SD), highest (+2.5 SD), or any intermediate stimulus value, with approximately equal numbers of females in each peak stimulus category. I then fitted a multinomial log-linear model to this categorical peak stimulus variable to examine factors influencing the log odds of females preferring an intermediate or high stimulus value over a low (baseline category of comparison) stimulus value using the "nnet" package (Venables \& Ripley, 2002). All 
preference function trait models were fitted using type II sums of squares and included call treatment (chirp rate or carrier frequency), adult eclosion weight, residual number of eggs, protein:carbohydrate ratio, phosphorus level, the protein:carbohydrate ratio * phosphorus level interaction, and all 2-way interactions between call treatment and main effects. Model simplification (outlined below) resulted in the removal of all interaction terms from preference function trait models.

I then analyzed how diet, weight, and fecundity influence preference function shape across call treatments. For each call treatment, I fitted a linear mixed model with R's "lme4" package (Bates et al., 2015) with female preference as the dependent variable. Both models were fitted using maximum likelihood parameter estimation with type II sums of squares, and included female identity as a random effect to account for pseudo replication across multiple phonotaxis trials. The independent variables in both models included adult eclosion weight, residual number of eggs, protein:carbohydrate ratio, phosphorus level, and the linear and quadratic terms for the standard deviation of the artificial call. The standard deviation terms tested for preference function shape, where a significant linear or quadratic term would indicate a linear or curvilinear function, respectively. I additionally included the 2-way interactions between each standard deviation variable (linear or quadratic term) and adult eclosion weight, residual number of eggs, protein:carbohydrate ratio, and phosphorus level in order to test how these variables influence preference function shape. Lastly, I included the linear and quadratic terms for phonotaxis trial number to control for any changes in female preference that might occur over the course of successive phonotaxis trials. Model simplification 
(outlined below) resulted in the removal of all quadratic and interaction terms from carrier frequency and chirp rate preference models, except for a significant adult eclosion weight $*$ standard deviation interaction (chirp rate model), a significant quadratic trial number term (chirp rate model), and a significant quadratic standard deviation term (carrier frequency model).

I selected error families and link functions for all statistical models on the basis of minimizing residual deviance, and visual examination of quantile-quantile and residual plots using R's “DHARMa” package (Hartig, 2017). For all models, I checked for multicolinearity between main effects using the "usdm" package (Naimi, Hamm, Groen, Skidmore, \& Toxopeus, 2014), and found minimal multicolinearity in all models (all variance inflation factors $<1.5$, where values $>10$ indicate multicolinearity). For all models, model simplification was performed by removing non-significant interaction terms, beginning with the highest-order interactions, and using deletion tests with the anova() function in $\mathrm{R}$ to determine if the removal of the term significantly improved the model fit. Based on the number of overall effects in the saturated models, I corrected for multiple hypotheses tests using the false discovery rate $\mathrm{FDR}_{\mathrm{B}-\mathrm{Y}}$ method (Benjamini \& Yekutieli, 2001).

\subsection{Results}

\subsubsection{Preference functions}

A visual examination of the mean preference functions fitted for each protein:carbohydrate and phosphorus diet treatment revealed several general trends 
(Figure 6.1 A-D). Females consuming high-protein $\left(3_{\mathrm{p}}: 1_{\mathrm{C}}\right)$ diets generally had reduced preference for all artificial calls compared to those consuming high-carbohydrate $\left(1_{\mathrm{P}}: 3_{\mathrm{C}}\right)$ or equal protein:carbohydrate $\left(1_{\mathrm{P}}: 1_{\mathrm{C}}\right)$ diets (Figure $\left.6.1 \mathrm{~A}-\mathrm{B}\right)$, but this trend is more prominent in the carrier frequency call treatment. Dietary phosphorus appeared to have little effect on preference in the chirp rate treatment (Figure 6.1C), but females consuming low-phosphorus $(0.45 \% \mathrm{PH})$ diets had reduced overall preference function height compared to those consuming high-phosphorus (1.45\% Regardless of diet treatment, chirp rate preference functions tend to linearly increase with higher stimulus values, whereas carrier frequency preference functions tended to be curvilinear and peak at intermediate stimulus values. The significance of these visual trends in preference functions were tested below. 


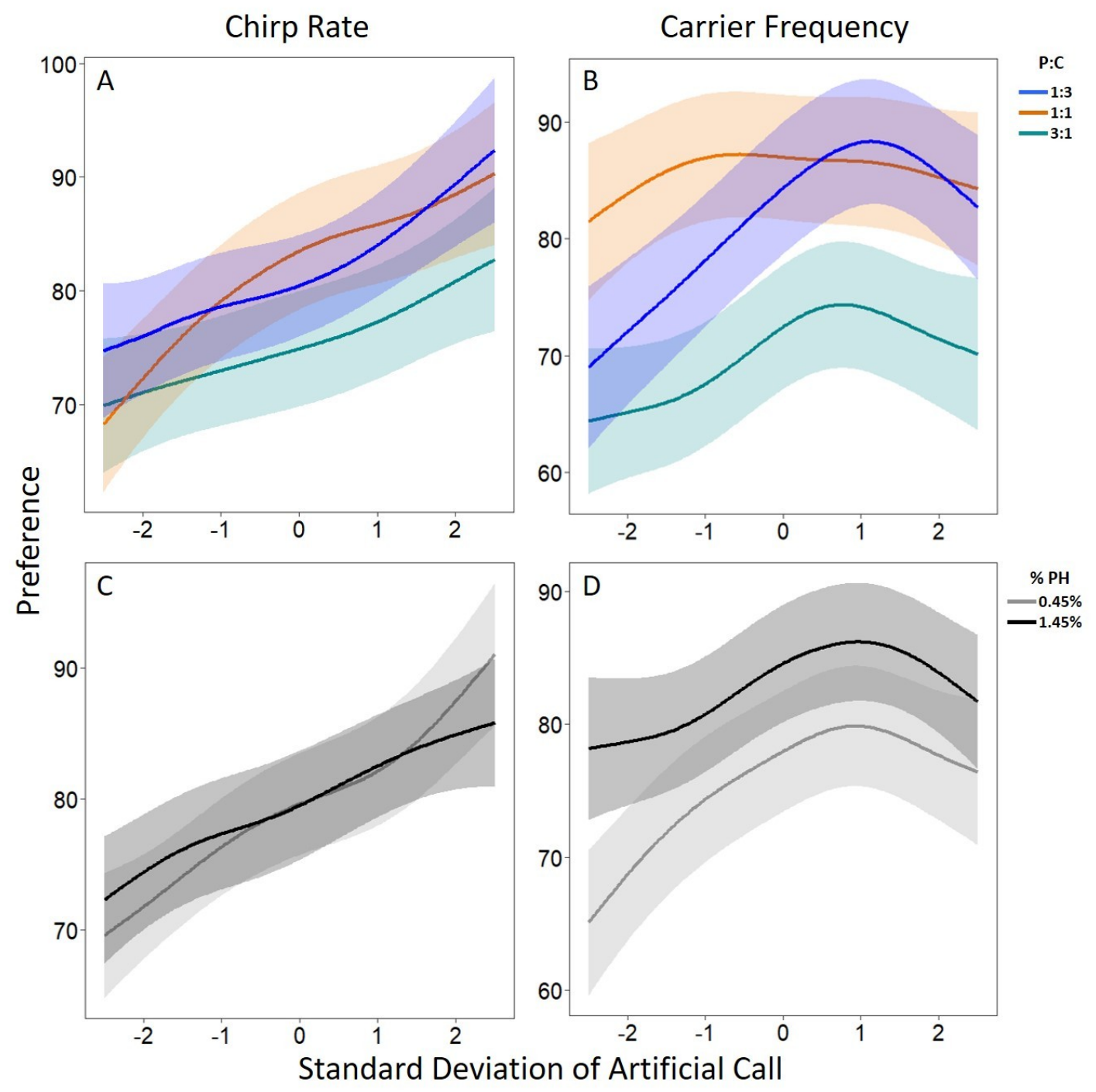

Figure 6.1. Average preference functions (solid lines) with standard error bands for females within each diet treatment (protein:carbohydrate ratio (A \& B) and phosphorus level (C \& D)) and call treatment (chirp rate (A \& C) and carrier frequency (B \& D)), fitted with Pfunc. 


\subsubsection{Preference function traits}

Neither call treatment (chirp rate or carrier frequency), residual number of eggs, nor dietary phosphorus level had any significant main or interaction effects on any of the female preference function traits (Table 6.2). However, females with higher adult eclosion weights had significantly higher responsiveness (Table 6.2; Appendix 4, Table A4.1; Figure 6.2A). Protein:carbohydrate ratio also significantly influenced responsiveness (Tables 6.2 \& A4.1; Figure 6.2B). Pairwise Tukey’s HSD contrasts revealed that females consuming high-protein diets $\left(3_{\mathrm{P}}: 1_{\mathrm{C}}\right)$ had significantly lower responsiveness compared to those consuming equal protein:carbohydrate $\left(1_{\mathrm{P}}: 1_{\mathrm{C}} ; P=\right.$ $0.034)$ or high-carbohydrate diets $\left(1_{\mathrm{P}}: 3_{\mathrm{C}} ; P=0.005\right)$, but with no significant difference in responsiveness between equal protein:carbohydrate and high-carbohydrate diets $(P=$ 0.395). There was also a weak trend for females with greater residual number of eggs to have higher tolerance (Tables 6.2 \& A4.1; Figure 6.2C). Neither the peak stimulus nor the strength of female preference functions were influenced by any main or interaction effects of female weight, fecundity, diet, or call treatment (Table 6.2). 
Table 6.2. Effects tests for the models examining factors influencing female preference function traits. Significant model effects and parameters are bolded. The FDR $\mathrm{B}_{\mathrm{B}-\mathrm{Y}}$ corrected level of significance is $P=0.017$. Parameter estimates for these models are located in Appendix 4, Table A4.1.

\begin{tabular}{llrrr}
\hline \multirow{3}{*}{ Model } & & \multicolumn{3}{c}{ Effects Tests } \\
\hline Peak Stimulus & Codel Term & $\chi^{2} / \boldsymbol{F}$ & df & $\boldsymbol{P}$ \\
& Adult Treatment & 4.042 & 2 & 0.133 \\
& Residual Eggs & 0.271 & 2 & 0.873 \\
& Protein:Carbohydrate & 1.191 & 2 & 0.551 \\
& Phosphorus & 5.342 & 4 & 0.729 \\
Strength & Call Treatment & 0.049 & 1 & 0.069 \\
& Adult Eclosion Weight & 0.488 & 1 & 0.825 \\
& Residual Eggs & 0.228 & 1 & 0.633 \\
& Protein:Carbohydrate & 2.201 & 2 & 0.333 \\
& Phosphorus & 0.259 & 1 & 0.610 \\
\hline Tolerance & Call Treatment & 2.245 & 1,313 & 0.135 \\
& Adult Eclosion Weight & 3.557 & 1,313 & 0.060 \\
& Residual Eggs & 4.678 & 1,313 & 0.031 \\
& Protein:Carbohydrate & 2.483 & 2,313 & 0.085 \\
& Phosphorus & 0.924 & 1,313 & 0.337 \\
\hline Responsiveness & Call Treatment & 0.016 & 1,313 & 0.898 \\
& Adult Eclosion Weight & $\mathbf{1 3 . 5 7 4}$ & $\mathbf{1 , 3 1 3}$ & $<\mathbf{0 . 0 0 1}$ \\
& Residual Eggs & 2.522 & 1,313 & 0.113 \\
& Protein:Carbohydrate & $\mathbf{5 . 5 9 4}$ & $\mathbf{2 , 3 1 3}$ & $\mathbf{0 . 0 0 4}$ \\
& Phosphorus & 0.889 & 1,313 & 0.347 \\
\hline
\end{tabular}



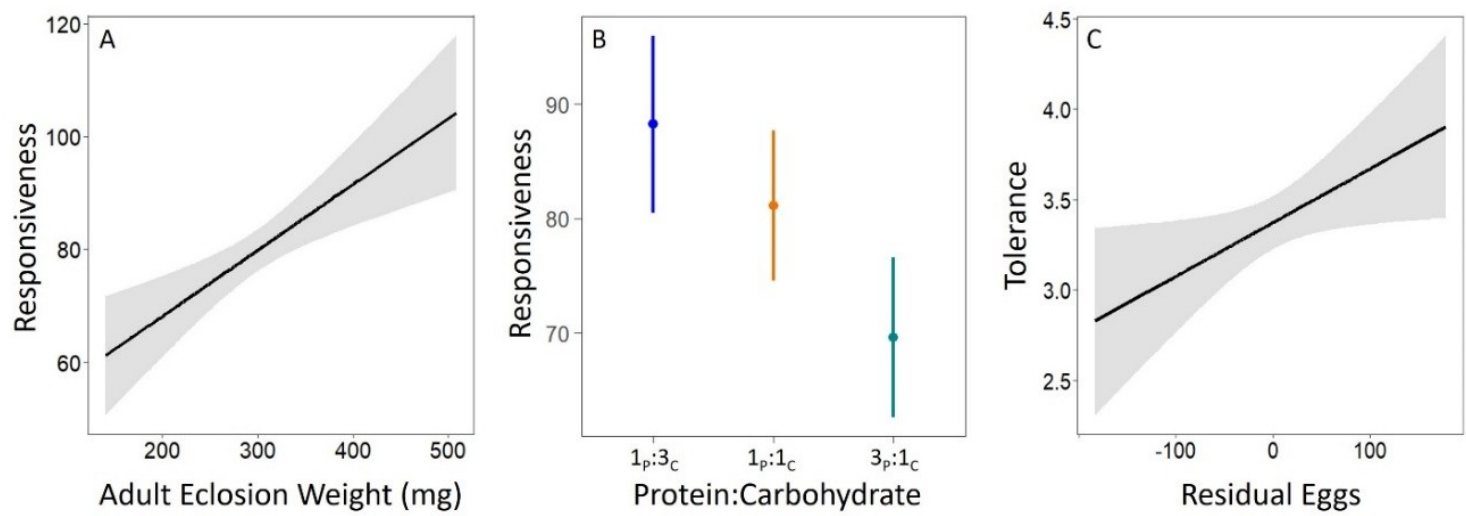

Figure 6.2. Marginal effects plots with $95 \%$ confidence intervals showing how A-B) adult eclosion weight and protein:carbohydrate ratio influence responsiveness, and C) residual eggs influence tolerance. 


\subsubsection{Preference function shape}

As would be expected from the shape of the preference functions fitted with PFunc (Figure 6.1), the preference models indicated that chirp rate and carrier frequency preference functions differ in shape (Table 6.3). For the chirp rate preference model, there was a significant interaction between the linear term for standard deviation of the artificial call and adult eclosion weight. This indicates that, compared to lighter females, heavier females have steeper preference functions that increase linearly with standard deviation of the artificial call (Table 6.3; Appendix 4, Table A4.2; Figure 6.3A). In contrast, in the carrier frequency preference model, a significant quadratic term for standard deviation of the artificial call indicated that females had a higher preference for intermediate carrier frequencies and decreased preference for extreme carrier frequencies (Tables 6.3 \& A4.2; Figure 6.3B).

There was also a significant effect of protein:carbohydrate ratio on female preference, but only in the carrier frequency preference model (Tables 6.3 \& A4.2; Figure 6.3C). Pairwise Tukey's HSD contrasts revealed that females consuming high-protein $\left(3_{\mathrm{P}}: 1_{\mathrm{C}}\right)$ diets had a significantly lower preference for carrier frequency artificial calls compared to those consuming equal protein:carbohydrate $\left(1_{\mathrm{P}}: 1_{\mathrm{C}} ; P=0.035\right)$ or highcarbohydrate diets $\left(1_{\mathrm{P}}: 3_{\mathrm{C}} ; P=0.019\right)$, but with no significant difference in preference between equal protein:carbohydrate and high-carbohydrate diets $(P=0.675)$. Neither dietary phosphorus level nor residual number of eggs significantly influenced preference in either the chirp rate or carrier frequency preference models. Aside from the significant interaction between standard deviation and adult eclosion weight, there were no 
significant interaction effects between the linear or quadratic standard deviation terms and diet variables, adult eclosion weight, or residual number of eggs in either model, indicating no influence of these variables on preference function shape.

Lastly, phonotaxis trial number significantly influenced female preference for chirp rate, with the quadratic term indicating that female preference is lowest during the beginning and end of the sequence of phonotaxis trials, and highest during intermediate trials (Tables 6.3 \& A4.2). A similar trend for preference decreasing with phonotaxis trial number was seen for the carrier frequency treatment, but this was not significant (Tables $6.3 \& \mathrm{~A} 4.2)$. 
Table 6.3. Effects tests for the models examining factors influencing preference function shape across chirp rate and carrier frequency call treatments. Significant model effects and parameters are bolded. The $\mathrm{FDR}_{\mathrm{B}-\mathrm{Y}}$ corrected level of significance is $P=0.015$. Parameter estimates for these models are located in Appendix 4, Table A4.2.

\begin{tabular}{llrrr}
\hline & & \multicolumn{3}{c}{ Effects Tests } \\
Model & Model Term & $\boldsymbol{\chi}^{\mathbf{2}}$ & $\mathbf{d f}$ & $\boldsymbol{P}$ \\
\hline Chirp Rate & Trial Number & 5.604 & 1 & 0.018 \\
Preference & Trial Number $^{2}$ & $\mathbf{9 . 1 9 7}$ & $\mathbf{1}$ & $\mathbf{0 . 0 0 2}$ \\
& Adult Eclosion Weight & $\mathbf{1 1 . 2 5 8}$ & $\mathbf{1}$ & $\mathbf{0 . 0 0 1}$ \\
& Residual Eggs & 0.306 & 1 & 0.580 \\
& Protein:Carbohydrate & 2.756 & 2 & 0.252 \\
& Phosphorus & 0.001 & 1 & 0.977 \\
& Standard Deviation & $\mathbf{1 5 . 9 1 9}$ & $\mathbf{1}$ & $<\mathbf{0 . 0 0 1}$ \\
& Adult Eclosion Weight*Standard Deviation & $\mathbf{6 . 1 2 7}$ & $\mathbf{1}$ & $\mathbf{0 . 0 1 3}$ \\
\hline Carrier & Trial Number & 2.831 & 1 & 0.092 \\
Frequency & Adult Eclosion Weight & 3.415 & 1 & 0.065 \\
Preference & Residual Eggs & 2.797 & 1 & 0.094 \\
& Protein:Carbohydrate & $\mathbf{8 . 9 6 9}$ & $\mathbf{1}$ & $\mathbf{0 . 0 1 1}$ \\
& Phosphorus & 1.477 & 2 & 0.224 \\
& Standard Deviation & 4.963 & 1 & 0.026 \\
& Standard Deviation & $\mathbf{9 . 5 1 7}$ & $\mathbf{1}$ & $\mathbf{0 . 0 0 2}$ \\
\hline
\end{tabular}



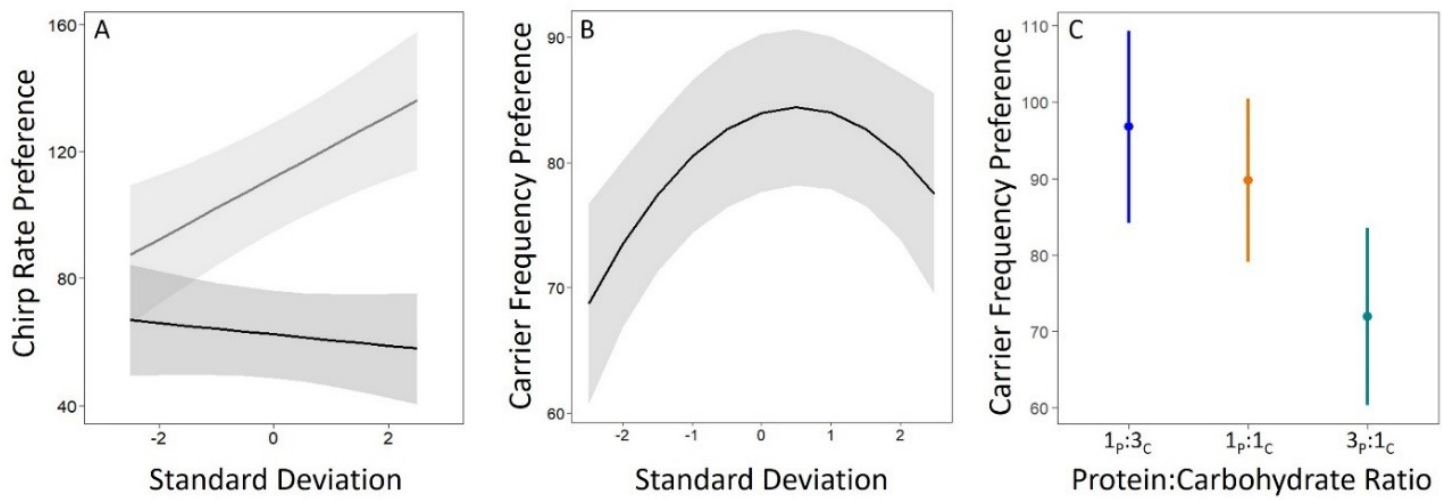

Figure 6.3. Marginal effects plots with $95 \%$ confidence intervals showing how preference in the chirp rate call treatment was influenced by A) an interaction between standard deviation of the artificial call and adult eclosion weight (grey line - large females, black line - small females), and how preference in the carrier frequency call treatment was influenced by B) standard deviation of the artificial call, and C) dietary protein:carbohydrate ratio. 


\subsection{Discussion}

Here, I tested the hypothesis that female G. veletis field crickets express conditiondependent mate preferences. Specifically, I asked whether and how female sexual responsiveness and preference functions relate to condition-dependent traits like adult body size and fecundity, as well as the protein, carbohydrate, and phosphorus content of their diet. High-condition females are expected to be better able to afford the costs of mate searching and assessment activities (Cotton et al., 2006; Jennions \& Petrie, 1997), and more fecund females may stand to benefit more from being choosy than infertile females (Eraly et al., 2009; Hingle et al., 2001b; Hunt et al., 2005; Syriatowicz \& Brooks, 2004). I therefore predicted that high-protein diets that maximize adult female body size and fecundity (Chapter 5) would result in increased sexual responsiveness and stronger mate preferences. My findings support theoretical predictions that female mate choice decisions are condition-dependent in $G$. veletis, as both female body size and dietary protein:carbohydrate ratio influenced the strength of mate preferences and/or sexual responsiveness, but with no influence of dietary phosphorus content or fecundity.

Overall, female preference functions for chirp rate were linear, with increasing preference for artificial calls with higher chirp rates. These findings support previous evidence that female field crickets tend to prefer higher effort acoustic mate attraction signals (e.g. Brooks et al., 2005; Cade \& Cade, 1992; Hunt et al., 2005; Judge, Ting, \& Gwynne, 2014), including signals with higher chirp rates (e.g. Simmons, 1988; Wagner, 1996; Wagner \& Reiser, 2000). In contrast, female preference functions for carrier frequency were curvilinear, with higher preferences for intermediate values slightly 
higher than the sample population mean, and lower preferences for extreme values. Similarly, stabalizing selection on the carrier frequency of male cricket signals has been found in other species of field crickets (e.g. Bentsen et al., 2006; Brooks et al., 2005; Hunt et al., 2005). Thus, regardless of body size, fecundity, or diet treatments, my experimental females' preference functions for chirp rate and carrier frequency were consistent with those of other field crickets, suggesting my choice of experimental design was appropriate.

\subsubsection{Body size}

As predicted, larger females (i.e. higher adult eclosion weight) had higher levels of sexual responsiveness and stronger preferences compared to lighter females. When considering each female's preference function as the trait of interest, heavier females had preference functions with significantly higher responsiveness measures, reflecting a higher overall preference function elevation compared to lighter females. Likewise, when considering preference function shape, heavier females had chirp rate preference functions with steeper slopes resulting from an increased preference for higher chirp rates, whereas the preferences of lighter females did not appear to change with chirp rate. These findings support evidence that various indices of female body size are positively correlated with stronger preferences for certain male phenotypes (e.g. Bakker et al., 1999; Beeler, Rauter, \& Moore, 2002; Hingle et al., 2001b; Hunt et al., 2005; Jennions et al., 1995). For example, female Teleogryllus commodus crickets reared on high-protein diets are heavier at adulthood and have stronger mate preferences for the frequency of male signals 
compared to low-protein females (Hunt et al. 2005), larger female African painted reed frogs (Hyperolius marmoratus) more often prefer attractive male acoustic signals with lower carrier frequencies than do smaller females (Jennions et al., 1995), and female three-spined sticklebacks (Gasterosteus aculeatus) with higher body weight to length ratios more frequently prefer more colourful male sexual ornaments than females with lower ratios (Bakker et al., 1999). Since I found that juvenile female growth was higher on the two highest protein diets $\left(1_{\mathrm{P}}: 1_{\mathrm{C}}\right.$ and $3_{\mathrm{P}}: 1_{\mathrm{C}}$; Chapter 5$)$, access to sufficient dietary protein during development may be driving this relationship between female body size and mate preferences. Therefore, my findings suggest that variation in adult female body size, as a consequence of access to protein in the developmental diet, may influence the strength and direction of selection on the chirp rate component of male acoustic mate attraction signals.

There are several non-mutually exclusive physiological explanations for the link between female body size, sexual responsiveness, and the strength of mate preferences. Because body size often reflects bodily energy stores accumulated during development (Whitman, 2008), smaller or lighter females may have less energy to devote to mate searching or sampling activities, and so may be less choosy in their mate preferences. Furthermore, due to allometric scaling relationships between individual body size and aspects of physiology and morphology, larger individuals are typically stronger, have longer limbs, faster walking speeds, and greater metabolic efficiencies compared to smaller females (Whitman, 2008). Given that the preference measure used in the present study was essentially a measure of response speed, heavier females may simply be faster 
at responding to artificial calls due to having longer legs, and/or potentially reduced locomotion costs due to higher metabolic efficiencies compared to lighter females. It is also possible that female size may be related to the sensitivity of sensory structures, allowing larger females to sense directionality of the active speaker more accurately. For example, female stalk eyed flies (Cyrtodiopsis dalmanni) with wider eye-spans can discriminate between males more accurately than females with shorter eye-spans (Hingle et al., 2001a). Similarly, hearing in female field crickets (Gryllinae) is accomplished partly from auditory input via spiracles located on their thoraces (Michelsen \& Larsen, 2014), where auditory spiracle size scales with body size, and larger spiracle openings confer greater hearing sensitivity (Bailey, 1998; Gwynne \& Bailey, 1999). Regardless of the underlying physiological mechanism, my findings suggest that females who have small body size resulting from inadequate protein in their diet during development may consequently have reduced sexual responsiveness and preference strength for male acoustic signals, particularly those that vary in chirp rate. Therefore, variation in female body size may contribute to maintaining genetic variation in male acoustic mate attraction signals.

\subsubsection{Fecundity}

I found no support for my prediction that more fecund females would express greater sexual responsiveness and stronger mate preferences than less fecund ones. While females that consumed high-protein $\left(3_{\mathrm{p}}: 1_{\mathrm{C}}\right)$ diets during development had greater numbers of eggs in their ovaries (Chapter 5), fecundity did not significantly influence 
preference function traits or overall preference function shape. However, I found a weak trend for more fecund females to have preference functions with higher tolerance measures, indicating that their preferences remained relatively high over a broader range of artificial call stimuli and suggesting that more fecund females may have more indiscriminate mate preferences compared to females with lower fecundity. It is possible that my use of virgin females may explain the lack of effect of fecundity on female responsiveness and preference functions, because virgin female crickets tend to mate more quickly and indiscriminately than mated females (Judge, Tran, \& Gwynne, 2010), likely due to the fitness costs if females were to remain unmated. Additionally, fecundity may have less of an effect on cricket mate preferences compared to other taxa because female crickets possess spermatheca organs which are capable of storing sperm from multiple males (Zuk \& Simmons, 1997). Female crickets with low fecundity might still be receptive to mating and display strong mate preferences because they can store sperm that can be used in the future if their fecundity improves due to finding more nutritious foods. Given these points, I suggest that the influence of fecundity on mate preferences may be more prominent in female crickets that have mated, or in other taxa that are incapable of long-term sperm storage.

\subsubsection{Protein:Carbohydrate ratio}

After statistically controlling for the influences of female body size and fecundity, dietary protein:carbohydrate ratio had additional influence on female preference, but in the opposite direction than predicted. Preference function responsiveness measures were 
significantly higher for females that consumed diets containing equal protein:carbohydrate ratios or high-carbohydrate compared to the high-protein diet treatment. However, the preference function shape models indicated that this effect was only significant in the carrier frequency call treatment. This result may reflect the energetic demands of adult locomotion needed for mate searching and assessment activities (e.g. López, 1999; Milinski \& Bakker, 1992), since carbohydrates stored as glycogen or triglycerides in cricket fat bodies are their primary source of metabolic fuel (Arrese \& Soulages, 2010; Woodring, Clifford, \& Beckman, 1979). Furthermore, although my diet treatments likely had similar caloric contents due to protein and carbohydrates having similar energy densities ( $\sim 4$ calories per gram), the use of protein to supply metabolic energy through the process of gluconeogenesis is itself energetically expensive (van Milgen, 2002) and produces toxic nitrogenous waste products that must be removed from the body (Hamilton \& Schal, 1988; Zanotto, Simpson, \& Raubenheimer, 1993), suggesting that my high-protein females may be more energetically constrained than the high-carbohydrate females. Although high dietary protein during development may positively influence sexual responsiveness through its effects on body size, my findings suggest that sexual responsiveness is also dependent on females being able to acquire greater amounts of carbohydrates at adulthood.

My findings support growing evidence that female mate preferences are related to nutrition (e.g. Hingle et al., 2001b; Hunt et al., 2005; Judge et al., 2014; Ortigosa \& Rowe, 2002; Syriatowicz \& Brooks, 2004). For instance, similar to my results, Judge et al. (2014) reared female Gryllus pennsylvanicus crickets on low and high nutrient diets, 
and found that the high nutrient diet treatment produced larger females that responded more slowly to artificial male calls in simultaneous choice tests for male signals, with increasing latency to respond over successive phonotaxis trials. While Judge et al., (2014) concluded that this was evidence of increased choosiness in high-condition females, I suggest that their high nutrient diet (9:1, rabbit food to bran ratio) was lower in digestible carbohydrates compared to their low-nutrient $\operatorname{diet}(1: 9$, rabbit food to bran ratio) and may have resulted in energetic constraints resulting in higher response latencies. In contrast, Hunt et al. (2005) reared female T. commodus crickets on high and low protein diets created by altering the ratio of fish food to oatmeal, and found that adult females reared on the high-protein diet had stronger mate preferences and reduced response latencies. As neither Hunt et al. (2005) nor Judge et al. (2014) controlled for dietary macronutrient ratio or levels of vitamins, salts, and other nutrients across diets, it is difficult to compare results across studies, and demonstrates the importance of using more nutrient-specific approaches to studying nutrition (e.g. Elser, 2006; Raubenheimer \& Simpson, 1993; Simpson \& Raubenheimer, 2012; Sterner \& Elser, 2002) in favour of crude dietary manipulations.

\subsubsection{Phosphorus}

As I found no evidence that dietary phosphorus levels influenced female fecundity or body size (Chapter 5), it is unsurprising that dietary phosphorus also did not influence female mate preferences. While my high- and low-phosphorus diets $(0.45 \% \mathrm{pH}$ and $1.45 \% \mathrm{PH}$; corresponding to $0.21 \% \mathrm{PH}$ and $0.66 \% \mathrm{pH}$ of total dry food mass) were chosen to 
reflect the low-to-mid range of phosphorus found in the omnivorous diets of field crickets, including insect matter (0.4-1.4\%; Woods et al., 2004) and plant matter (0.021.04\%; Elser et al., 2000), it is possible that the lowest phosphorus diet was not low enough to affect body size, fecundity, or mate preferences. However, several interesting lines of research suggest that phosphorus could be playing an important role in female cricket mate choice decisions that has yet to be investigated. First, previous research has found that phosphorus is related to mate attraction signalling in crickets, with high-effort signallers having greater elemental phosphorus in their bodies (Bertram et al., 2006) and high-phosphorus diets resulting in greater signalling effort (Bertram et al., 2009). Although my previous findings suggest male G. veletis mate attraction signalling is influenced very little by manipulating the phosphorus content of adult diets (Chapters 3 \& 4; Harrison et al., 2017, 2014), it is likely that phosphorus limitation during development may have a greater impact on male signalling at adulthood. Second, female crickets also appear to receive lifespan and fertility benefits from mating with preferred males with higher effort signals, suggesting males may be transferring some substance directly to females through their ejaculates (Wagner \& Harper, 2003). It is possible that this substance is phosphorus, as is seen in Drosophila, where males transfer large quantities of phosphorus to females via their ejaculates, which then gets incorporated directly into eggs (Markow et al., 2001). Therefore, female crickets that previously have had access to limited dietary phosphorus could potentially use male acoustic mate attraction signals to indicate which males' territories contain ample phosphorus-rich foods that could be exploited, or which males may be capable of transferring larger 
amounts of phosphorus during mating. To my knowledge, the possibility that female crickets may be receiving direct benefits by mating with males on the basis of acoustic signals that honestly reflect males' bodily phosphorus content has yet to be investigated.

\subsubsection{Order of artificial call presentation}

Given that female preference was related to the order of presentation of artificial calls, my experimental design may have resulted in females habituating to artificial stimuli or becoming exhausted energetically with successive testing. Thus, I advise that future studies examining mate preferences in field crickets should (i) allow females longer acclimatization period within the phonotaxis arena prior to beginning testing, and (ii) minimize the length of time over which female's preferences are tested to prevent females from tiring and/or habituating to the signals. These issues may be easily addressed with the implementation of a spherical treadmill (trackball) (e.g. Pacheco et al., 2013) which would allow female phonotaxis measures for successive artificial calls to occur more quickly and accurately than in an open arena design.

\subsubsection{Conclusions}

In conclusion, my findings suggest that female mate choice decisions are conditiondependent in $G$. veletis field crickets. Heavier females exhibited greater sexual responsiveness and stronger preferences, with an increasing preference for higher chirp rates, whereas lighter females were less discriminatory. After controlling for variation in body size (juvenile diet), diets limited in carbohydrates relative to protein produced less 
sexually responsive females, particularly in the carrier frequency treatment. I suspect that differences in the influence of body size and diet across the carrier frequency and chirp rate call treatments may be explained by aspects of female body condition having variable influences on female neurophysiology and sensory structures. For instance, current nutritional state might be influencing the sensitivities of auditory neurons that are responsible for sensing signal carrier frequency, whereas sensory organs that scale according to body size might play a larger role in detecting differences in signal temporal properties like chirp rate.

My findings also suggest attaining high condition, and the associated expression of strong mate preferences and increased sexual responsiveness, may depend on females altering their relative intakes of protein and carbohydrates between developmental and adult life stages. In support of this proposition, male field crickets require a similar dietary switch between juvenile and adult stages to maximize their growth and mate attraction signalling effort (Reifer et al., 2018), and my previous work did indeed show that adult female $G$. veletis preferentially consume a diet higher in carbohydrates than do juvenile females (Chapters $3 \& 5$; Harrison et al., 2014).

Phosphorus had no influence on female fecundity or mate preferences, but I suspect this may be due to the low-phosphorus diet not being limiting enough. Further work is needed on this topic, as it is possible that phosphorus-limited female crickets could potentially use male signals to lead them to locations with phosphorus-rich foods (Bertram et al., 2006, 2009), or to indicate that males could transfer phosphorus directly to females during mating (Markow et al., 2001; Wagner \& Harper, 2003). I also found 
little evidence that fecundity influences female cricket mate choice decisions, but believe this may be due to the mating status of my experimental females, or to the reproductive physiology of field crickets in general.

Overall, my results support theoretical predictions that sexual responsiveness and preference functions are condition dependent (Cotton et al., 2006; Jennions \& Petrie, 1997; Widemo \& Sæther, 1999), and suggest that dietary nutrient balance during both developmental and adult life stages may have important consequences for the strength and direction of sexual selection on male acoustic mate attraction signals.

\subsection{Acknowledgements}

I thank Alicia Cable, Rebekah Vice, Synclair Calder, Sarah Fawzy-Esmaiel, and Karla Martinez-Silva for their assistance with animal care and data entry. 


\section{Chapter 7}

\section{General Conclusions}




\subsection{The influence of dietary protein to carbohydrate ratio on life-history traits}

In this thesis, I have shown that the ratio of protein and carbohydrate in the diet importantly influences variation in life-history traits and reproductive behaviours in both male and female Gryllus veletis field crickets. As juveniles, females were more likely to survive to adulthood if they consumed diets containing equal amounts of protein and carbohydrates, but had faster development times, reduced chances of having wing deformities, and attained larger adult body sizes when they consumed high-protein diets (Chapter 5). Furthermore, adult females were more likely to have long (i.e. flightcapable) hindwings when they were reared on high-carbohydrate diets, suggesting that environments lacking in nutrients important for development (i.e. protein) may drive adult dispersal capability. Some life-history traits responded to diet in similar ways in adult males and females, as I found that both sexes had longer adult lifespans when they consumed high-carbohydrate diets, but gained more weight when consuming high-protein diets (Chapter 3). However, the influence of diet on reproductive life-history traits differed across the sexes. Male mate attraction signalling effort was maximized by consuming greater amounts of food regardless of protein to carbohydrate ratio (Chapter 3), but males required higher carbohydrate diets to maximize their signalling effort after experiencing an energetically strenuous activity (Chapter 4). In contrast, females required high-protein diets to maximize their egg production (Chapters $3 \& 5$ ), but were more sexually responsive when they consumed high-carbohydrate diets (Chapter 6). Therefore, similar to previous studies (Hunt et al., 2004; Joern \& Behmer, 1997; Maklakov et al., 2008), my findings demonstrated that male and female $G$. veletis cannot simultaneously 
maximize all life-history traits and achieve maximal fitness when confined to eating a single diet, and thus experienced trade-offs between traits depending on the nutritional composition of available foods.

\subsection{The influence of dietary phosphorus on life-history traits}

My findings revealed that, compared to variation in dietary protein to carbohydrate ratio, variation in dietary phosphorus was far less important in influencing cricket life-history traits (Chapters 3 - 6). In contrast to previous findings that higher levels of dietary phosphorus positively influence acoustic mate attraction signalling in crickets (Bertram et al., 2006; 2009), I found that high-phosphorus diets had a negative impact on the pulse and chirp rates of male mate attraction signals (Chapters $3 \& 4$ ), representing a decrease in signalling effort. Furthermore, high dietary phosphorus levels influenced a trade-off between male aggression levels and their subsequent mate attraction signalling effort: males that invested heavily in aggressive behaviour were also able to invest heavily in post-fight signalling as long as they consumed low-phosphorus diets, whereas males consuming high-phosphorus diets were unable to invest in both aggressive behaviour and increase their effort in post-fight signalling, possibly due to the increased cost of excreting excess phosphorus (Cease et al., 2016). Since female crickets tend to prefer high-effort acoustic signals with higher species-specific pulse rates (e.g. Simmons, 1988) and chirp rates (e.g. Chapter 6; Hirtenlehner \& Römer, 2014; Scheuber et al., 2004; Wagner, 1996), females would presumably be less attracted to the mate attraction signals of males consuming a high-phosphorus diet compared to low-phosphorus diets. High- 
phosphorus diets, therefore, likely reduce male G. veletis fitness. Additionally, I found no support for previous evidence that both juvenile growth and egg production are influenced by dietary phosphorus (e.g. Cease et al., 2016; Perkins et al., 2004; Urabe \& Sterner, 2001; Visanuvimol \& Bertram, 2010, 2011). Overall, my findings that dietary phosphorus had either negative (Chapters $3 \& 4$ ), or no influence on G. veletis life-history traits (Chapters $5 \& 6$ ), may possibly reflect limitations of my experimental design related to the range of phosphorus concentrations used, or the life stage at which dietary phosphorus was varied (see section 7.6 below). Regardless, my results indicate that high levels of phosphorus entering natural environments through the use of fertilizers in agriculture could have a negative impact on the sexual behaviours of plant-eating insects such as crickets, which may have implications for insect abundance and biodiversity.

\subsection{Nutritional requirements change across development and contexts}

Several of my findings indicate that nutritional requirements may be context dependent, and may change with an individual's experiences with their environment. When males were isolated in small enclosures for their entire adult lives, they were able to produce high-effort mate attraction signals as long as they ate large amounts of food, regardless of the protein to carbohydrate ratio (Chapter 3). However, when males experienced an agonistic contest with rival males, only males that consumed high-carbohydrate diets showed an increase in mate attraction signalling effort following the contest (Chapter 4). Given that acoustic signalling and agonistic contests are energetically costly behaviours in field crickets (Hack, 1997; Hoback \& Wagner, 1997; Prestwich, 1994), my findings 
suggest that the nutritional requirements needed to maximize sexual signalling may change following an energetically demanding event, such as an aggressive interaction with rivals. While I found no evidence that male aggression levels were influenced by diet, I suspect that had I subjected males to multiple or longer agonistic contests, dietary carbohydrates would have become increasingly important as males depleted their energy reserves. Thus, nutrient requirements appear to depend on an individual's experiences. My findings also indicate that the optimal dietary nutrient ratio that maximizes fitness differs across life stages. For instance, in support of previous findings in insects (e.g. Maklakov et al., 2008; Sentinella et al., 2013), juvenile female crickets had a greater chance of surviving to adulthood if they were consuming a diet with equal amounts of protein and carbohydrates (Chapter 5), whereas adult females on high-carbohydrate diets had the greatest longevity (Chapter 3). This likely reflects a greater need for protein during development, as I found that juvenile females consuming high-protein diets had higher development rates, achieved larger adult body sizes, and had lower rates of wing deformation (Chapter 5). While I did not examine the influence of dietary nutrient ratio on juvenile males, the positive influence that dietary protein has on juvenile male cricket growth has been demonstrated previously (e.g. Hunt et al., 2004), including in a recent study on male Gryllus assimilis that I co-authored (Reifer et al., 2018). This importance of high levels of protein in developmental diets for maximizing juvenile male and female growth has important implications for the expression of male and female reproductive traits at adulthood, as adult body size (or weight) had a strong influence on male acoustic mate attraction signalling (Chapters $3 \& 4$ ), male aggression (Chapter 4), and female 
sexual responsiveness (Chapter 6). However, several of my findings indicate that it would be advantageous for both males and females to switch to eating a high-carbohydrate diet at adulthood, as this diet maximized male mate attraction signalling under some circumstances (Chapter 4), and female sexual responsiveness to male signals (Chapter 6). Lifetime fitness, therefore, likely depends on individual ability to detect their changing nutritional requirements and to regulate nutrient intakes accordingly.

\subsection{Nutrient intake regulation changes with sex and developmental stage}

Given my results showing that G. veletis require different nutrient intakes depending on their sex, individual experiences, and life stage, the ability to regulate nutrient intake would be advantageous. In insects, detecting the nutrient composition of foods can be accomplished with nutrient receptors located on various appendages (e.g. mouthparts, limbs) which become more sensitive when certain metabolite levels in the haemolymph are low, thereby stimulating a feeding response (Raubenheimer \& Simpson, 1993). As expected, G. veletis regulated their nutrient intakes, and their self-selected dietary nutrient ratio reflected the nutritional needs of their life stage and/or sex. When provided with a choice of foods containing differing (but complementary) nutrient ratios, both adult males and females regulated their protein and carbohydrate intakes such that both sexes preferred to eat more carbohydrate relative to protein (Chapter 3). However, adult females selected a diet that was marginally higher in protein compared to the dietary nutrient ratio selected by adult males (females $-1.3_{\mathrm{P}}: 3_{\mathrm{C}}$; males $-1_{\mathrm{P}}: 4.1_{\mathrm{C}}$; Chapter 3 ). This dietary protein to carbohydrate ratio selected by females reflects a compromise between 
the conflicting nutritional requirements needed to maximize various adult female lifehistory traits: lifespan $\left(1_{\mathrm{P}}: 8_{\mathrm{C}}\right)$, sexual responsiveness $\left(1_{\mathrm{P}}: 1_{\mathrm{C}}\right.$ or $1_{\mathrm{P}}: 3_{\mathrm{C}}$; Chapter 6$)$, and egg production $\left(3_{\mathrm{P}}: 1_{\mathrm{C}}\right.$; Chapters $\left.3 \& 5\right)$. In contrast, the dietary protein to carbohydrate ratio selected by adult males would simultaneously maximize both adult lifespan and mate attraction signalling effort without compromise $\left(1_{\mathrm{p}}: 3_{\mathrm{C}}\right.$; Chapter 3$)$. Juvenile females also differed from adult females from their diet choice by selecting a diet with marginally higher amounts of protein $\left(1.44_{\mathrm{P}}: 3_{\mathrm{C}}\right)$, likely due to the importance of this nutrient for juvenile growth and development (Chapter 5). In contrast to this strong regulation of protein and carbohydrates across the sexes and across life stages, I found no evidence that G. veletis regulate their intake of phosphorus. This either suggests that (i) crickets do not possess the sensory capabilities to detect the phosphorus content of available foods, or (ii) the diets provided did not differ enough, or were not extreme enough, in phosphorus content to elicit behavioural regulation of phosphorus intake.

\subsection{Influence of nutrition on sexual selection}

Several of my findings support the prediction from indicator models of sexual selection that the expression of elaborate male traits involved in mate attraction and male-male competition should covary positively with individual condition (Grafen, 1990; KodricBrown \& Brown, 1984; Maynard Smith, 1985; Pomiankowski, 1987a; Zahavi, 1975, 1977). For instance, my findings show that eating larger amounts of protein and carbohydrates, regardless of nutrient ratio, generally supports the expression of higheffort male mate attraction signals (Chapter 3), but with higher carbohydrate diets 
becoming more important following an energetically strenuous activity such as an agonistic contest with rivals (Chapter 4). Furthermore, high levels of dietary phosphorus negatively impacted several aspects of male mate attraction signalling effort (Chapters 3 \& 4), suggesting that there are costs associated with consuming excess phosphorus. Additionally, several aspects of pre-fight mate attraction signalling behaviour in males were correlated with their subsequent aggression levels (Chapter 4), suggesting that these sexual traits may covary due to their mutual condition-dependence. However, these traits were not influenced by dietary protein to carbohydrate ratio (Chapter 4). Instead, adult body size was the strongest predictor of aggressive behaviour and male signalling behaviour (Chapter 4), suggesting that the condition-dependence of these traits may lie in developmental resources rather than in adult diets. Thus, females may be able to use male sexual traits as honest indicators of a male's condition or nutritional status, which may convey information about potential direct (e.g. nutritional resources) or indirect (e.g. good genes for acquiring or assimilating nutritional resources) mating benefits (Andersson, 1994; Kirkpatrick \& Ryan, 1991; Reynolds \& Gross, 1990).

Similar to my findings for males, I found support for indicator model predictions that the strength of female preferences reflect the cost-to-benefit ratio associated with being choosy, where high-condition females may be better able to afford the costs of expressing stronger mate preferences (Cotton et al., 2006; Pomiankowski, 1987b). For instance, females that consumed high-protein diets as juveniles were larger as adults, and these larger females were subsequently more sexually responsive and had steeper preference functions for male acoustic signals (Chapters $5 \& 6$ ), suggesting that female 
mate preferences may depend on resources accumulated during development, or possibly size-dependent scaling of limbs and sensory structures (Chapter 6). Females that consumed high-carbohydrate diets as adults were also more sexually responsive to artificial male acoustic signals, suggesting that females' willingness to search for mates and copulate may be constrained by carbohydrate-derived energy stores.

Collectively, my findings suggest that diet throughout development and into adulthood may influence the strength and direction of selection pressures on male $G$. veletis acoustic mate attraction signals. For instance, since diet influenced male mate attraction signalling (Chapters $3 \& 4$ ), then the availability of nutrients in the environment may influence the range and diversity of male signal phenotypes in the population on which sexual selection can act. This has implications for the maintenance of variation in male sexually selected traits: if male genetic quality influences their ability to acquire these nutrients in the optimal ratios and then allocate them appropriately between sexual traits and other life-history traits, then this has the potential to explain the unexpectedly high levels of genetic variation that persists in male sexually selected traits despite the expectation that female mate choice should erode such variation (Rowe \& Houle, 1996; Tomkins et al., 2004). However, variation in female mating preferences, driven by variation in dietary nutrient availability, may also contribute to the maintenance of variation in male sexually selected traits in natural populations (Chapter 6). Collectively, my findings indicate that variability in nutritional resources in the environment influences the diversity of male signal phenotypes on which females can exert their preferences, as well as variability in female preferences for these phenotypes. 
Thus, the strength and direction of selection on male sexual signals within a population may depend on the relative frequency of different male phenotypes, and the frequency of females that are attracted to such phenotypes, that arise due to individual ability to acquire nutritional resources in the optimal ratios (i.e. frequency- dependent sexual selection).

\subsection{Study limitations, criticisms, and future directions}

As I outlined in Chapter 3, the strength of using nutritional geometry as a conceptual framework is that it permits researchers to examine the influence of multiple dietary components and their interactions on fitness traits, and allows for the visualization of multi-dimensional fitness trait response surfaces across the nutritional landscape (Raubenheimer \& Simpson, 1999). However, the downside to this methodology is that in order to adequately measure fitness trait responses across the nutritional landscape, a large number of diet treatments covering a wide range of nutrient ratios is required, each varied at several dilution factors, and food intake must be measured for every individual. The data-hungry nature of this methodology, in combination with time constraints on the data collection period for this thesis, led to several compromises in my experimental design. First, the 45 experimental diets in Chapter 3 only used three dietary phosphorus levels. I believe my decision to use only three dietary phosphorus levels restricted the resolution of the phosphorus fitness surfaces and likely hindered the ability to detect a phosphorus intake target for adult G. veletis. Using only three dietary phosphorus levels was necessary, however, because the addition of just one more phosphorus level would 
have required 15 additional diet treatments and thus significantly more time to complete the experiment. Second, based on the findings reported in Chapter 3, I chose to use only six of the original 45 diets in all subsequent experiments, and did not measure each individual's food intake (Chapters 4-6). The choice of using only a subset of diets and not measuring food intake was primarily driven by the time consuming nature of the data collection process for male aggressive behaviour (Chapter 4), and female mate preference behaviour (Chapter 6). While this approach allowed me to collect larger sample sizes for the experiments outlined in Chapters 4-6, the data collected were not conducive to producing fitness response surfaces and thereby did not allow detailed examination of the interactive effects of protein, carbohydrate, and phosphorus on fitness traits. If time had permitted, I would have used nutritional geometry methodologies (Chapter 3) in all subsequent experiments outlined in my thesis (Chapters 4-6), and would have used larger number of dietary phosphorus levels. Future work on animal nutrition should strive to use geometric framework methodologies, as it provides a more accurate picture of how organism fitness responds to nutritional complexity.

Investigating both acquisition and allocation aspects of nutrition are important for understanding resource allocation and the expression of fitness traits (Morehouse, 2014; Van-Noordwijk \& de Jong, 1986). However, in this thesis, I made conclusions about the allocation of protein, carbohydrate and phosphorus to various fitness traits on the basis of positive or negative correlations between these dietary components and the expression of fitness traits. I did not, however, investigate the physiological, metabolic, and biochemical processes that underlie these relationships. For instance, nutrients consumed 
by an organism may be related to fitness trait expression through several different biological processes, such as the breakdown of energetic nutrients for metabolic fuel, the use of nutrients to synthesize biomolecules or body tissues, or the impact certain nutrients may have on signalling pathways or gene expression (Hill, 2011). Furthermore, individuals within a species may vary in their strategies for allocating nutritional resources towards the expression of competing fitness traits, and this has important consequences for understanding the form of life-history trade-offs (Morehouse, 2014). Future studies would benefit from incorporating biochemical analysis techniques to understand the biological processes that result in various dietary components influencing fitness traits. For instance, tracking ingested nutrients and determining how they are incorporated into body tissues and/or excreted as waste could be accomplished with a number of different biochemical analysis techniques, such as (i) radiolabelling nutrients and examining deposition in body tissues or excretion (e.g. Markow et al., 2001), (ii) tracking nutrient excretion in faecal matter (e.g. Cease et al., 2016; Perkins et al., 2004), (iii) post-mortem lipid extraction to estimate bodily lipid reserves (e.g. South et al., 2011), (iv) examining metabolites in various body tissues (e.g. Clark et al., 2015; Thomson et al., 2014), and (v) comparing the elemental stoichiometry of organisms with that of their diets (e.g. Visanuvimol \& Bertram, 2010).

Additionally, extending from my thesis findings, further research is needed on the extent to which dietary nutrient ratio influences male $G$. veletis sexual traits, such as other aspects of males' intra-sexual competitive abilities not addressed in this thesis. For instance, due to my experimental design of having six males simultaneously participating 
in an agonistic contest, and the resultant chaotic interactions between males, I was unable to rank males on their dominance status as I had originally planned (Chapter 4).

Dominant status is likely a greater indicator of male fitness in field crickets since males that win fights (i.e. dominant males) are able retain control of higher quality mating territories (Alexander, 1961). In hindsight, agonistic contests between pairs of males would have been a more appropriate experimental design that would have allowed for more detailed behavioural observations and dominance scoring. Furthermore, research is needed into the extent to which male ejaculate quality is influenced by dietary nutrient ratio since this is an important aspect of post-copulatory intra-sexual selection in polyandrous species such as field crickets (Parker, 1970). Various dietary components have previously been found to influence aspects of male sperm viability and numbers in insects (Gage \& Cook, 1994; Hellriegel \& Blanckenhorn, 2002; Meikle \& Mcfarlane, 1965). Additionally, the possibility exists that male field crickets may be transferring phosphorus directly to females via their ejaculates for use in egg production, as seen in Drosophila fruit flies (Markow, Coppola, \& Watts, 2001), which could explain why female crickets experience lifespan and fertility benefits from the ejaculates of preferred males (Wagner \& Harper, 2003). Thus, higher dietary phosphorus may positively influence males' ejaculate quality, and phosphorus-deprived females may alter their mate preferences to select mates that can transfer more phosphorus. This research would further our understanding of how diet influences selection processes.

In contrast to previous work on crickets which has demonstrated that growth, egg production, and male sexual signalling is positively related to dietary phosphorus content 
(e.g. Bertram et al., 2006, 2009, Visanuvimol \& Bertram, 2010, 2011), I found no influence of dietary phosphorus on G. veletis growth or egg production (Chapters $3 \& 5$ ), and a negative effect of high-phosphorus diets on male signalling effort (Chapters $3 \& 4$ ). While it is possible that this discrepancy between this previous work and my own is due to species-specific differences in dietary phosphorus needs, it is more likely that my choice of phosphorus treatments (percent phosphorus in total food mass: $0.07-1.87 \%$ in Chapter $3 ; 0.21 \%$ and $0.66 \%$ in Chapters 4 - 6) did not encompass a wide enough range. These phosphorus treatments were chosen to reflect the range of phosphorus in natural foods that omnivorous crickets would consume, including insect matter $(0.4-1.4 \%$; Woods et al., 2004) and plant matter (0.02-1.04\%; Elser et al., 2000). However, it is possible that my use of older crickets (late-instar juveniles and adults) rather than hatchlings restricted my ability to detect negative fitness consequences from phosphoruslimitation, since other Orthopterans show a decline in their dietary phosphorus requirements as individuals transition from juveniles to adults (Cease et al., 2016). In contrast, the negative effect of high-phosphorus diets on male signalling that I observed (Chapters $3 \& 4$ ) implies that this diet contained phosphorus in excess of males' requirements. While terrestrial insects are able to compensate for excessive dietary phosphorus by decreasing absorption and/or increasing excretion (Cease et al., 2016; Woods et al., 2002; Zhang et al., 2014), the extra energetic costs of excreting excess phosphorus may have resulted in reduced signalling effort (Chapters $3 \& 4$ ). Thus, it is likely that male signalling effort peaks at intermediate phosphorus levels, but I was unable to detect this due to a lack of a diet treatment with sufficiently low phosphorus 
content. Future work on this topic will greatly benefit from a recently developed technique that allows the creation of artificial diets with lower phosphorus levels than those used in this thesis (Cease et al., 2016). Therefore, our understanding of how phosphorus influences organism fitness is far from complete. Further work is needed to examine the influence of a broader range of dietary phosphorus levels, varied systematically with dietary protein and carbohydrate levels, over an individual's entire lifespan. 


\section{References Cited}

Adamo, S. A., \& Hoy, R. R. (1995). Agonistic behaviour in male and female field crickets, Gryllus bimaculatus, and how behavioural context influences its expression. Animal Behaviour, 49, 1491-1501. http://doi.org/10.1016/00033472(95)90070-5

Alatalo, R. V., Carlson, A., \& Lundberg, A. (1988). The search cost in mate choice of the pied flycatcher. Animal Behaviour, 36, 289-291. http://doi.org/10.1016/S0003$3472(88) 80272-0$

Alatalo, R. V., Lundberg, A., \& Glynn, C. (1986). Female pied flycatchers choose territory quality and not male characteristics. Nature, 323, 152-153.

Alexander, R. D. (1961). Aggressiveness, territoriality, and sexual behavior in field crickets (Orthoptera: Gryllidae). Behaviour, 17, 130-223. http://doi.org/10.1163/156853961X00042

Alexander, R. D. (1968). Life cycle origins, speciation, and related phenomena in crickets. Quarterly Review of Biology, 43, 1-41.

Alexander, R. D., \& Bigelow, R. S. (1960). Allochronic speciation in field crickets, and a new species, Acheta veletis. Evolution, 14(3), 334-346.

Alexander, R. D., \& Meral, G. H. (1967). Seasonal and daily chirping cycles in the northern spring and fall field crickets, Gryllus veletis and G. pennsylvanicus. The Ohio Journal of Science, 67(1960), 200-209.

Anderson, T. R., \& Pond, D. W. (2000). Stoichiometric theory extended to 
micronutrients: comparison of the roles of essential fatty acids, carbon, and nitrogen in the nutrition of marine copepods. Limnology and Oceanography, 45, 1162-1167.

Andersson, M. (1994). Sexual Selection. Princeton University Press, Princeton.

Andersson, S., \& Åhlund, M. (1991). Hunger affects dominance among strangers in house sparrows. Animal Behaviour, 41, 895-897. http://doi.org/10.1016/S0003$3472(05) 80356-2$

Andrade, M. C. B. (1998). Female hunger can explain variation in cannibalistic behavior despite male sacrifice in redback spiders. Behavioral Ecology, 9, 33-42. http://doi.org/10.1093/beheco/9.1.33

Arrese, E. L., \& Soulages, J. L. (2010). Insect fat body: energy, metabolism, and regulation. Annual Review of Entomology, 55, 207-225. http://doi.org/10.1146/annurev-ento-112408-085356

Bailey, W. J. (1998). Do large bushcrickets have more sensitive ears? Natural variation in hearing thresholds within populations of the bushcricket Requena verticalis (Listroscelidinae: Tettigoniidae). Physiological Entomology, 23(2), 105-112. http://doi.org/10.1046/j.1365-3032.1998.232071.x

Bailey, N. W. (2011). Mate choice plasticity in the field cricket Teleogryllus oceanicus: effects of social experience in multiple modalities. Behavioral Ecology and Sociobiology, 65(12), 2269-2278. http://doi.org/10.1007/s00265-011-1237-8

Bakker, T. C. M. (1999). The study of intersexual selection using quantitative genetics. Behaviour, 136(9), 1237-1266. 
Bakker, T. C. M., Kunzler, R., \& Mazzi, D. (1999). Condition-related mate choice in sticklebacks. Nature, 401, 234. http://doi.org/10.1038/45727

Bakker, T. C. M., \& Pomiankowski, A. (1995). The genetic basis of female mate preferences. Journal of Evolutionary Biology, 8, 129-171.

Ballentine, B., Searcy, W. A., \& Nowicki, S. (2008). Reliable aggressive signalling in swamp sparrows. Animal Behaviour, 75, 693-703. http://doi.org/10.1016/j.anbehav.2007.07.025

Bateman, P. W., \& Fleming, P. A. (2006). Males are selective too: mating, but not courtship, with sequential females influences choosiness in male field crickets (Gryllus bimaculatus). Behavioral Ecology and Sociobiology, 59(4), 577-581. http://doi.org/10.1007/s00265-005-0083-y

Bateman, P. W., Gilson, L. N., \& Ferguson, J. W. H. (2001). Male size and sequential mate preference in the cricket Gryllus bimaculatus. Animal Behaviour, 61, 631-637. http://doi.org/10.1006/anbe.2000.1617

Bates, D., Mächler, M., Bolker, B. M., \& Walker, S. . (2015). Fitting linear mixed-effects models using lme4. Journal of Statistical Software, 67(1), 1-48. http://doi.org/10.18637/jss.v067.i01

Beeler, A. E., Rauter, C. M., \& Moore, A. J. (2002). Mate discrimination by females in the burying beetle Nicrophorus orbicollis: the influence of male size on attractiveness to females. Ecological Entomology, 27(1), 1-6. http://doi.org/10.1046/j.1365-2311.2002.0371a.x 
Bégin, M., \& Roff, D. A. (2002). The common quantitative genetic basis of wing morphology and diapause occurrence in the cricket Gryllus veletis. Heredity, 89, 473-479. http://doi.org/10.1038/sj.hdy.6800168

Behmer, S. T. (2009). Insect herbivore nutrient regulation. Annual Review of Entomology, 54(1), 165-187. http://doi.org/10.1146/annurev.ento.54.110807.090537

Benjamini, Y., \& Yekutieli, D. (2001). The control of the false discovery rate in multiple testing under dependency. The Annals of Statistics, 29, 1165-1188.

Bentsen, C. L., Hunt, J., Jennions, M. D., \& Brooks, R. (2006). Complex multivariate sexual selection on male acoustic signaling in a wild population of Teleogryllus commodus. The American Naturalist, 167, E102-E116. http://doi.org/10.1086/501376

Berglund, A., Bisazza, A., \& Pilastro, A. (1996). Armaments and ornaments: an evolutionary exploration of traits of dual utility. Biological Journal of the Linnean Society, 58, 385-399. http://doi.org/10.1006/bijl.1996.0043

Bertram, S. M., Bowen, M., Kyle, M., \& Schade, J. D. (2008). Extensive natural intraspecific variation in stoichiometric $(\mathrm{C}: \mathrm{N}: \mathrm{P})$ composition in two terrestrial insect species. Journal of Insect Science, 8, 1-7. http://doi.org/10.1673/031.008.2601

Bertram, S. M., Loranger, M. J., Thomson, I. R., Harrison, S. J., Ferguson, G. L., Reifer, M. L., ... Gowaty, P. A. (2016). Linking mating preferences to sexually selected traits and offspring viability: good versus complementary genes hypotheses. Animal Behaviour, 119, 75-86. http://doi.org/10.1016/j.anbehav.2016.06.003 
Bertram, S. M., \& Rook, V. L. M. (2012). Relationship between condition, aggression, signaling, courtship, and egg laying in the field cricket, Gryllus assimilis. Ethology, 118, 1-13. http://doi.org/10.1111/j.1439-0310.2011.02019.x

Bertram, S. M., Rook, V. L. M., Fitzsimmons, J. M., \& Fitzsimmons, L. P. (2011). Fineand broad-scale approaches to understanding the evolution of aggression in crickets. Ethology, 117, 1067-1080. http://doi.org/10.1111/j.1439-0310.2011.01970.x

Bertram, S. M., Schade, J. D., \& Elser, J. J. (2006). Signalling and phosphorus: correlations between mate signalling effort and body elemental composition in crickets. Animal Behaviour, 72, 899-907. http://doi.org/10.1016/j.anbehav.2006.02.012

Bertram, S. M., Whattam, E. M., Visanuvimol, L., Bennett, R., \& Lauzon, C. (2009). Phosphorus availability influences cricket mate attraction displays. Animal Behaviour, 77, 525-530. http://doi.org/10.1016/j.anbehav.2008.11.012

Bolnick, D. I., \& Paull, J. S. (2009). Morphological and dietary differences between individuals are weakly but positively correlated within a population of threespine stickleback. Evolutionary Ecology Research, 11(8), 1217-1233.

Boutin, S. R. T., Harrison, S. J., Fitzsimmons, L. P., McAuley, E. M., \& Bertram, S. M. (2016). Same-sex sexual behaviour in crickets: understanding the paradox. Animal Behaviour, 114, 101-110. http://doi.org/10.1016/j.anbehav.2016.01.022

Bretman, A., Gage, M. J. G., \& Chapman, T. (2011). Quick-change artists: male plastic behavioural responses to rivals. Trends in Ecology and Evolution, 26, 467-473. 
http://doi.org/10.1016/j.tree.2011.05.002

Briffa, M. (2008). Decisions during fights in the house cricket, Acheta domesticus: mutual or self assessment of energy, weapons and size? Animal Behaviour, 75(3), 1053-1062. http://doi.org/10.1016/j.anbehav.2007.08.016

Briscoe, A. D., \& Chittka, L. (2001). The evolution of color vision in insects. Annual Review of Entomology, 46, 471-510. http://doi.org/10.1146/annurev.ento.46.1.471

Brooks, R., Hunt, J., Blows, M. W., Smith, M. J., Bussière, L. F., \& Jennions, M. D. (2005). Experimental evidence for multivariate stabilizing sexual selection. Evolution, 59(4), 871-880.

Brown, W. D. (1997). Female remating and the intensity of female choice in blackhorned tree crickets, Oecanthus nigricornis. Behavioral Ecology, 8(1), 66-74.

Brown, W. D., Smith, A. T., Moskalik, B., \& Gabriel, J. (2006). Aggressive contests in house crickets: size, motivation and the information content of aggressive songs. Animal Behaviour, 72, 225-233. http://doi.org/10.1016/j.anbehav.2006.01.012

Cade, W. H., \& Cade, E. S. (1992). Male mating success, calling and searching behaviour at high and low densities in the field cricket, Gryllus integer. Animal Behaviour, 43, 49-56. http://doi.org/10.1016/S0003-3472(05)80070-3

Candolin, U. (1999a). Male-male competition facilitates female choice in sticklebacks. Proceedings of the Royal Society B: Biological Sciences, 266(1421), 785-789.

Candolin, U. (1999b). The relationship between signal quality and physical condition: is sexual signalling honest in the three-spined stickleback? Animal Behaviour, 58, 
1261-1267. http://doi.org/10.1006/anbe.1999.1259

Candolin, U. (2003). The use of multiple cues in mate choice. Biological Reviews, 78, 575-595. http://doi.org/10.1017/S1464793103006158

Carey, J. R. (1998). Dual modes of aging in mediterranean fruit fly females. Science, 281(5379), 996-998. http://doi.org/10.1126/science.281.5379.996

Carmona, D. M., Menalled, F. D., \& Landis, D. A. (1999). Gryllus pennsylvanicus (Orthoptera: Gryllidae): laboratory weed seed predation and within field activitydensity. Journal of Economic Entomology, 92, 825-829.

Cease, A. J., Fay, M., Elser, J. J., \& Harrison, J. F. (2016). Dietary phosphate affects food selection, post-ingestive phosphorus fate, and performance of a polyphagous herbivore. Journal of Experimental Biology, 219, 64-72. http://doi.org/10.1242/jeb.126847

Chambers, P. G., Simpson, S. J., \& Raubenheimer, D. (1995). Behavioural mechanisms of nutrient balancing in Locusta migratoria nymphs. Animal Behaviour, 50(6), 1513-1523. http://doi.org/10.1016/0003-3472(95)80007-7

Chippindale, A. K., Leroi, A. M., Kim, S. B., \& Rose, M. R. (1993). Phenotypic plasticity and selection in Drosophila life-history evolution. I. Nutrition and the cost of reproduction. Journal of Evolutionary Biology, 6(2), 171-193. http://doi.org/10.1046/j.1420-9101.1993.6020171.x

Cicchetti, D. V. (1994). Guidelines, criteria, and rules of thumb for evaluating normed and standardized assessment instruments in psychology. Psychological Assessment, 
6, 284-290. http://doi.org/10.1037/1040-3590.6.4.284

Clancy, K. M., \& King, R. M. (1993). Defining the western spruce budworm's nutritional niche with response surface methodology. Ecology, 74, 442-454.

Clark, D. C., DeBano, S. J., \& Moore, A. J. (1997). The influence of environmental quality on sexual selection in Nauphoeta cinerea (Dictyoptera: Blaberidae). Behavioral Ecology, 8(1), 46-53.

Clark, R. M., McConnell, A., Zera, A. J., \& Behmer, S. T. (2013). Nutrient regulation strategies differ between cricket morphs that trade-off dispersal and reproduction. Functional Ecology, 27(5), 1126-1133. http://doi.org/10.1111/1365-2435.12103

Clark, R. M., Zera, A. J., \& Behmer, S. T. (2015). Nutritional physiology of life-history trade-offs: how food protein-carbohydrate content influences life-history traits in the wing-polymorphic cricket Gryllus firmus. Journal of Experimental Biology, 218(2), 298-308. http://doi.org/10.1242/jeb.112888

Cotton, S., Fowler, K., \& Pomiankowski, A. (2004a). Condition dependence of sexual ornament size and variation in the stalk-eyed fly Cyrtodiopsis dalmanni (Diptera: Diopsidae). Evolution, 58, 1038-1046. http://doi.org/10.1111/j.00143820.2004.tb00437.x

Cotton, S., Fowler, K., \& Pomiankowski, A. (2004b). Do sexual ornaments demonstrate heightened condition-dependent expression as predicted by the handicap hypothesis? Proceedings of the Royal Society B: Biological Sciences, 271, 771-783. http://doi.org/10.1098/rspb.2004.2688 
Cotton, S., Small, J., \& Pomiankowski, A. (2006). Sexual selection and conditiondependent mate preferences. Current Biology, 16(17), R755-R765. http://doi.org/10.1016/j.cub.2006.08.022

Criddle, N. (1925). Field crickets in Manitoba. The Canadian Entomologist, 57, 79-84.

Darwin, C. (1871). The Descent of Man and Selection in Relation to Sex. Penguin, London.

David, P., Hingle, A., Greig, D., Rutherford, A., Pomiankowski, A., \& Fowler, K. (1998). Male sexual ornament size but not asymmetry reflects condition in stalk-eyed flies. Proceedings of the Royal Society B: Biological Sciences, 265, 2211-2216. http://doi.org/10.1098/rspb.1998.0561

Delcourt, M., Blows, M. W., \& Rundle, H. D. (2010). Quantitative genetics of female mate preferences in an ancestral and a novel environment. Evolution, 64(9), 27582766. http://doi.org/10.1111/j.1558-5646.2010.01031.x

DeMar, J. C., Ma, K., Bell, J. M., Igarashi, M., Greenstein, D., \& Rapoport, S. I. (2006). One generation of $\mathrm{n}-3$ polyunsaturated fatty acid deprivation increases depression and aggression test scores in rats. Journal of Lipid Research, 47(1), 172-180. http://doi.org/10.1194/jlr.M500362-JLR200

DeNapoli, J. S., Dodman, N. H., Shuster, L., Rand, W. M., \& Gross, K. L. (2000). Effect of dietary protein content and tryptophan supplementation on dominance aggression, territorial aggression, and hyperactivity in dogs. Journal of the American Veterinary Medical Association, 217(4), 504-508. http://doi.org/10.2460/javma.2000.217.504 
Elser, J. J. (2006). Biological stoichiometry: a chemical bridge between ecosystem ecology and evolutionary biology. The American Naturalist, 168, S25-35. http://doi.org/10.1086/509048

Elser, J. J., Acharya, K., Kyle, M., Cotner, J., Makino, W., Markow, T., ... Sterner, R. W. (2003). Growth rate-stoichiometry couplings in diverse biota. Ecology Letters, 6 , 936-943. http://doi.org/10.1046/j.1461-0248.2003.00518.x

Elser, J. J., Fagan, W. F., Denno, R. F., Dobberfuhl, D. R., Folarin, A., Huberty, A., ... Sterner, R. W. (2000). Nutritional constraints in terrestrial and freshwater food webs. Nature, 408, 578-580. http://doi.org/10.1038/35046058

Elser, J. J., Hayakawa, K., \& Urabe, J. (2001). Nutrient limitation reduces food quality for zooplankton: Daphnia response to seston phosphorus enrichment. Ecology, 82(3), 898-903.

Eraly, D., Hendrickx, F., \& Lens, L. (2009). Condition-dependent mate choice and its implications for population differentiation in the wolf spider Pirata piraticus. Behavioral Ecology, 20(4), 856-863. http://doi.org/10.1093/beheco/arp072

Ferkin, M. H., Sorokin, E. S., Johnston, R. E., \& Lee, C. J. (1997). Attractiveness of scents varies with protein content of the diet in meadow voles. Animal Behaviour, 53, 133-141. http://doi.org/10.1006/anbe.1996.0284

Fisher, R. A. (1930). The Genetical Theory of Natural Selection. Oxford University Press, Oxford.

Fitzsimmons, L. P., \& Bertram, S. M. (2011). The calling songs of male spring field 
crickets (Gryllus veletis) change as males age. Behaviour, 148, 1045-1065. http://doi.org/10.1163/000579511X588812

Fitzsimmons, L. P., \& Bertram, S. M. (2012). Signaling effort does not predict aggressiveness in male spring field crickets. Behavioral Ecology and Sociobiology, 67, 213-220. http://doi.org/10.1007/s00265-012-1441-1

Fricke, C., Adler, M. I., Brooks, R. C., \& Bonduriansky, R. (2015). The complexity of male reproductive success: effects of nutrition, morphology, and experience. Behavioral Ecology, 26, 617-624. http://doi.org/10.1093/beheco/aru240

Frischknecht, M. (1993). The breeding colouration of male three-spined sticklebacks (Gasterosteus aculeatus) as an indicator of energy investment in vigour. Evolutionary Ecology, 7(5), 439-450. http://doi.org/10.1007/BF01237640

Gage, M. J. G., \& Cook, P. A. (1994). Sperm size or numbers? effects of nutritional stress upon eupyrene and apyrene sperm production strategies in the moth Plodia interpunctella (Lepidoptera: Pyralidae). Functional Ecology, 8, 594-599. http://doi.org/10.2307/2389920

Gangwere, S. K. (1961). A monograph on food selection in Orthoptera. Transactions of the American Entomological Society, 87, 67-230.

Ghosal, K., Gupta, M., \& Killian, K. A. (2009). Agonistic behavior enhances adult neurogenesis in male Acheta domesticus crickets. Journal of Experimental Biology, 212, 2045-2056. http://doi.org/10.1242/jeb.026682

Godin, J.-G. J., \& Briggs, S. E. (1996). Female mate choice under predation risk in the 
guppy. Animal Behaviour, 51(1), 117-130.

Godin, J.-G. J., \& Dugatkin, L. A. (1995). Variability and repeatability of female mating preference in the guppy. Animal Behaviour, 49(6), 1427-1433.

Goos, J. M., Cothran, R. D., \& Jeyasingh, P. D. (2016). Sex-specific nutrient use and preferential allocation of resources to a sexually selected trait in Hyalella amphipods. Journal of Experimental Biology, 219(5), 649-657. http://doi.org/10.1242/jeb.132498

Grafen, A. (1990). Biological signals as handicaps. Journal of Theoretical Biology, 144, 517-546. http://doi.org/10.1016/S0022-5193(05)80088-8

Gray, D. A. (1999). Intrinsic factors affecting female choice in house crickets: time cost, female age, nutritional condition, body size, and size-relative reproductive investment. Journal of Insect Behavior, 12(5), 691-700.

Grover, C. D., Kay, A. D., Monson, J. A., Marsh, T. C., \& Holway, D. A. (2007). Linking nutrition and behavioural dominance: carbohydrate scarcity limits aggression and activity in Argentine ants. Proceedings of the Royal Society B:

Biological Sciences, 274, 2951-2957. http://doi.org/10.1098/rspb.2007.1065

Gwynne, D. T., \& Bailey, W. J. (1999). Female-female competition in katydids: sexual selection for increased sensitivity to a male signal? Evolution, 53(2), 546-551.

Hack, M. A. (1997). The energetic costs of fighting in the house cricket, Acheta domesticus L. Behavioral Ecology, 8, 28-36. http://doi.org/10.1093/beheco/8.1.28

Hamilton, R. L., \& Schal, C. (1988). Effects of dietary protein levels on reproduction and 204 
food consumption in the German cockroach (Dictyoptera: Blattellidae). Annals of the Entomological Society of America, 81, 969-976.

Han, C. S., \& Dingemanse, N. J. (2017). You are what you eat: diet shapes body composition, personality and behavioural stability. BMC Evolutionary Biology, 17, 8. http://doi.org/10.1186/s12862-016-0852-4

Han, C. S., Jäger, H. Y., \& Dingemanse, N. J. (2016). Individuality in nutritional preferences: a multi-level approach in field crickets. Scientific Reports, 6, 29071. http://doi.org/10.1038/srep29071

Harrison, R. G. (1979). Speciation in North American field crickets: evidence from electrophoretic comparisons. Evolution, 33(4), 1009-1023.

Harrison, R. G. (1980). Dispersal polymorphisms in insects. Annual Review of Ecology and Systematics, 11, 95-118.

Harrison, S. J., Godin, J.-G. J., \& Bertram, S. M. (2017). Influence of dietary nutrient balance on aggression and signalling in male field crickets. Animal Behaviour, 134, 123-134. http://doi.org/10.1016/j.anbehav.2017.10.006

Harrison, S. J., Raubenheimer, D., Simpson, S. J., Godin, J.-G. J., \& Bertram, S. M. (2014). Towards a synthesis of frameworks in nutritional ecology: interacting effects of protein, carbohydrate and phosphorus on field cricket fitness. Proceedings of the Royal Society B: Biological Sciences, 281, 20140539.

http://doi.org/10.1098/rspb.2014.0539

Hartig, F. (2017). DHARMa: residual diagnostics for hierarchical (multi-level / mixed) 
regression models.

Haydak, M. H. (1953). Influence of the protein level of the diet on the longevity of cockroaches. Annals of the Entomological Society of America, 46, 547-560. http://doi.org/10.1093/aesa/46.4.547

Hebets, E., Wesson, J., \& Shamble, P. S. (2008). Diet influences mate choice selectivity in adult female wolf spiders. Animal Behaviour, 76(2), 355-363. http://doi.org/10.1016/j.anbehav.2007.12.021

Hedrick, A. V. (1986). Female preferences for male calling bout duration in a field cricket. Behavioral Ecology and Sociobiology, 19, 73-77.

Hedrick, A. V., \& Dill, L. M. (1993). Mate choice by female crickets is influence by predation risk. Animal Behaviour, 46, 193-196.

Hellriegel, B., \& Blanckenhorn, W. U. (2002). Environmental influences on the gametic investment of yellow dung fly males. Evolutionary Ecology, 16, 505-522. http://doi.org/10.1023/A:1020875021823

Hill, G. E. (2000). Energetic constraints on expression of carotenoid-based plumage coloration. Journal of Avian Biology, 31(4), 559-566.

Hill, G. E. (2011). Condition-dependent traits as signals of the functionality of vital cellular processes. Ecology Letters, 14, 625-634. http://doi.org/10.1111/j.14610248.2011.01622.x

Hingle, A., Fowler, K., \& Pomiankowski, A. (2001a). Size-dependent mate preference in the stalk-eyed fly Cyrtodiopsis dalmanni. Animal Behaviour, 61(3), 589-595. 
http://doi.org/10.1006/anbe.2000.1613

Hingle, A., Fowler, K., \& Pomiankowski, A. (2001b). The effect of transient food stress on female mate preference in the stalk-eyed fly Cyrtodiopsis dalmanni. Proceedings of the Royal Society B: Biological Sciences, 268(1473), 1239-1244. http://doi.org/10.1098/rspb.2001.1647

Hirtenlehner, S., \& Römer, H. (2014). Selective phonotaxis of female crickets under natural outdoor conditions. Journal of Comparative Physiology A: Neuroethology, Sensory, Neural, and Behavioral Physiology, 200, 239-250.

http://doi.org/10.1007/s00359-014-0881-7

Hoback, W. W., \& Wagner, W. E. (1997). The energetic cost of calling in the variable field cricket, Gryllus lineaticeps. Physiological Entomology, 22, 286-290. http://doi.org/10.1111/j.1365-3032.1997.tb01170.x

Hoi, H., \& Griggio, M. (2008). Dual utility of a melanin-based ornament in bearded tits. Ethology, 114, 1094-1100. http://doi.org/10.1111/j.1439-0310.2008.01566.x

Holzer, B., Jacot, A., \& Brinkhof, M. W. G. (2003). Condition-dependent signaling affects male sexual attractiveness in field crickets, Gryllus campestris. Behavioral Ecology, 14, 353-359. http://doi.org/10.1093/beheco/14.3.353

Hothorn, T., Bretz, F., \& Westfall, P. (2008). Simultaneous inference in general parametric models. Biometrical Journal, 50(3), 346-363. http://doi.org/10.1002/bimj.200810425

House, H. L. (1965). Effects of low levels of the nutrient content of a food and of nutrient 
imbalance on the feeding and the nutrition of a phytophagous larva, Celerio euphorbiae (Linnaeus). The Canadian Entomologist, 97, 62-68.

Huggins, K. A., Navara, K. J., Mendonça, M. T., \& Hill, G. E. (2010). Detrimental effects of carotenoid pigments: the dark side of bright coloration. Naturwissenschaften, 97, 637-644. http://doi.org/10.1007/s00114-010-0679-6

Hunt, J., Breuker, C. J., Sadowski, J. A., \& Moore, A. J. (2009). Male-male competition, female mate choice and their interaction: determining total sexual selection. Journal of Evolutionary Biology, 22, 13-26. http://doi.org/10.1111/j.14209101.2008.01633.x

Hunt, J., Brooks, R., \& Jennions, M. D. (2005). Female mate choice as a conditiondependent life-history trait. The American Naturalist, 166, 79-92. http://doi.org/10.1086/430672

Hunt, J., Brooks, R., Jennions, M. D., Smith, M. J., Bentsen, C. L., \& Bussière, L. F. (2004). High-quality male field crickets invest heavily in sexual display but die young. Nature, 432, 1024-1027. http://doi.org/10.1038/nature03084

Iwasa, Y., \& Pomiankowski, A. (1994). The evolution of mate preferences for multiple sexual ornaments. Evolution, 48, 853-867. http://doi.org/10.2307/2410492

Jang, Y., Gerhardt, H. C., \& Choe, J. C. (2008). A comparative study of aggressiveness in eastern North American field cricket species (genus Gryllus). Behavioral Ecology and Sociobiology, 62, 1397-1407. http://doi.org/10.1007/s00265-008-0568-6

Jennions, M. D., Backwell, P. R. Y., \& Passmore, N. I. (1995). Repeatability of mate 
choice: the effect of size in the African painted reed frog, Hyperolius marmoratus. Animal Behaviour, 49, 181-186. http://doi.org/10.1016/0003-3472(95)80165-0

Jennions, M. D., \& Petrie, M. (1997). Variation in mate choice and mating preferences: a review of causes and consequences. Biological Reviews, 72(2), 283-327.

Jensen, K., Mcclure, C., Priest, N. K., \& Hunt, J. (2015). Sex-specific effects of protein and carbohydrate intake on reproduction but not lifespan in Drosophila melanogaster. Aging Cell, 14(4), 605-615. http://doi.org/10.1111/acel.12333

Joern, A., \& Behmer, S. T. (1997). Importance of dietary nitrogen and carbohydrates to survival, growth, and reproduction in adults of the grasshopper Ageneotettix deorum (Orthoptera: Acrididae). Oecologia, 112, 201-208.

http://doi.org/10.1007/s004420050301

Johnson, J. B., \& Basolo, A. L. (2003). Predator exposure alters female mate choice in the green swordtail. Behavioral Ecology, 14, 619-625. http://doi.org/10.1093/beheco/arg046

Johnstone, R. A. (1995). Sexual selection, honest advertisement and the handicap principle: reviewing the evidence. Biological Reviews, 70(1), 1-65. http://doi.org/10.1111/j.1469-185X.1995.tb01439.x

Johnstone, R. A. (1996). Multiple displays in animal communication: "backup signals" and "multiple messages." Philosophical Transactions of the Royal Society of London B: Biological Sciences, 351, 329-338. http://doi.org/10.1098/rstb.1996.0026

Jones, S. A., \& Raubenheimer, D. (2001). Nutritional regulation in nymphs of the 
German cockroach, Blattella germanica. Journal of Insect Physiology, 47, 11691180.

Judge, K. ., \& Bonanno, V. L. (2008). Male weaponry in a fighting cricket. PLoS ONE, 3, e3980. http://doi.org/10.1371/journal.pone.0003980

Judge, K. A., Ting, J. J., \& Gwynne, D. T. (2014). Condition dependence of female choosiness in a field cricket. Journal of Evolutionary Biology, 27(11), 2529-2540. http://doi.org/10.1111/jeb.12509

Judge, K. A., Tran, K.-C., \& Gwynne, D. T. (2010). The relative effects of mating status and age on the mating behaviour of female field crickets. Canadian Journal of Zoology, 88(2), 219-223. http://doi.org/10.1139/Z09-139

Kaplan, J. R., Manuck, S. B., \& Shively, C. A. (1991). The effects of fat and cholesterol on social behavior in monkeys. Psychosomatic Medicine, 53(6), 634-642.

Karino, K., \& Haijima, Y. (2004). Algal-diet enhances sexual ornament, growth and reproduction in the guppy. Behaviour, 141(5), 585-601.

Kasumovic, M. M., Elias, D. O., Sivalinghem, S., Mason, A. C., \& Andrade, M. C. B. (2010). Examination of prior contest experience and the retention of winner and loser effects. Behavioral Ecology, 21(2), 404-409. http://doi.org/10.1093/beheco/arp204

Kilmer, J. T., Fowler-Finn, K. D., Gray, D. A., Höbel, G., Rebar, D., Reichert, M. S., \& Rodríguez, R. L. (2017). Describing mate preference functions and other functionvalued traits. Journal of Evolutionary Biology, 30(9), 1658-1673. 
http://doi.org/10.1111/jeb.13122

Kirkpatrick, M., \& Ryan, M. J. (1991). The evolution of mating preferences and the paradox of the lek. Nature. http://doi.org/10.1038/350033a0

Kiron, V., Watanabe, T., Fukuda, H., Okamoto, N., Takeuchi, T., \& Watanabe, T. (1995). Protein nutrition and defence mechanisms in rainbow trout Oncorhynchus mykiss. Comparative Biochemistry \& Physiology A: Comparative Physiology, 111(3), 351359. http://doi.org/10.1016/0300-9629(95)00043-7

Kodric-Brown, A., \& Brown, J. H. (1984). Truth in advertising: the kinds of traits favored by sexual selection. The American Naturalist, 124, 309-323. http://doi.org/10.1086/284275

Kodric-Brown, A., \& Brown, J. H. (1987). Anisogamy, sexual selection, and the evolution and maintenance of sex. Evolutionary Ecology, 1, 95-105. http://doi.org/10.1007/BF02067393

Kodric-Brown, A., \& Nicoletto, P. (2001). Female choice in the guppy (Poecilia reticulata): the interaction between male color and display. Behavioral Ecology and Sociobiology, 50, 346-351. http://doi.org/10.1007/s002650100374

Kopena, R., Martín, J., López, P., \& Herczeg, G. (2011). Vitamin E supplementation increases the attractiveness of males' scent for female European green lizards. PLoS ONE, 6(4), e19410. http://doi.org/10.1371/journal.pone.0019410

Kortet, R., \& Hedrick, A. (2005). The scent of dominance: female field crickets use odour to predict the outcome of male competition. Behavioral Ecology and 
Sociobiology, 59, 77-83. http://doi.org/10.1007/s00265-005-0011-1

Kotiaho, J. S. (2000). Testing the assumptions of conditional handicap theory: costs and condition dependence of a sexually selected trait. Behavioral Ecology and Sociobiology, 48, 188-194. http://doi.org/10.1007/s002650000221

Kpundeh, M. D., Qiang, J., He, J., Yang, H., \& Xu, P. (2015). Effects of dietary protein levels on growth performance and haemato-immunological parameters of juvenile genetically improved farmed tilapia (GIFT), Oreochromis niloticus. Aquaculture International, 23(5), 1189-1201. http://doi.org/10.1007/s10499-014-9876-1

Lailvaux, S. P., \& Irschick, D. J. (2006). A functional perspective on sexual selection: insights and future prospects. Animal Behaviour, 72(2), 263-273. http://doi.org/10.1016/j.anbehav.2006.02.003

Lande, R., \& Arnold, S. J. (1983). The measurement of selection on correlated characters. Evolution, 37(6), 1210-1226.

LeBoeuf, B. J. (1974). Male-male competition and reproductive success in elephant seals. The American Zoologist, 14(1), 163-176.

Lee, K. P., Simpson, S. J., Clissold, F. J., Brooks, R., Ballard, J. W. O., Taylor, P. W., ... Raubenheimer, D. (2008). Lifespan and reproduction in Drosophila: new insights from nutritional geometry. Proceedings of the National Academy of Sciences, 105, 2498-2503. http://doi.org/10.1073/pnas.0710787105

Lemel, J., \& Wallin, K. (1993). Status signalling, motivational condition and dominance: an experimental study in the great tit, Parus major L. Animal Behaviour, 45, 549- 
558. http://doi.org/10.1006/anbe.1993.1065

Lerch, A., Rat-Fischer, L., Gratier, M., \& Nagle, L. (2011). Diet quality affects mate choice in domestic female canary Serinus canaria. Ethology, 117(9), 769-776. http://doi.org/10.1111/j.1439-0310.2011.01929.x

Lipovšek, S., Novak, T., Janžekovič, F., \& Pabst, M. A. (2011). Role of the fat body in the cave crickets Troglophilus cavicola and Troglophilus neglectus (Rhaphidophoridae, Saltatoria) during overwintering. Arthropod Structure \& Development, 40, 54-63. http://doi.org/10.1016/j.asd.2010.09.002

Loaiza, V., Jonas, J. L., \& Joern, A. (2008). Does dietary P affect feeding and performance in the mixed-feeding grasshopper (Acrididae) Melanoplus bivitattus? Environmental Entomology, 37, 333-339. http://doi.org/10.1603/0046225X(2008)37[333:DDPAFA]2.0.CO;2

López, S. (1999). Parasitized female guppies do not prefer showy males. Animal Behaviour, 57(5), 1129-1134. http://doi.org/10.1006/anbe.1998.1064

Magwere, T., Chapman, T., \& Partridge, L. (2004). Sex differences in the effect of dietary restriction on life span and mortality rates in female and male Drosophila melanogaster. Journal of Gerontology, 59(1), 3-9.

Maklakov, A. A., Simpson, S. J., Zajitschek, F., Hall, M. D., Dessmann, J., Clissold, F., ... Brooks, R. C. (2008). Sex-specific fitness effects of nutrient intake on reproduction and lifespan. Current Biology, 18, 1062-1066.

http://doi.org/10.1016/j.cub.2008.06.059 
Markow, T. A. A., Coppola, A., \& Watts, T. D. D. (2001). How Drosophila males make eggs: it is elemental. Proceedings of the Royal Society B: Biological Sciences, 268(1475), 1527-1532. http://doi.org/10.1098/rspb.2001.1673

Martín, J., \& López, P. (2015). Condition-dependent chemosignals in reproductive behavior of lizards. Hormones and Behavior, 68, 14-24. http://doi.org/10.1016/j.yhbeh.2014.06.009

Martin, S. D., Gray, D. A., \& Cade, W. H. (2000). Fine-scale temperature effects on cricket calling song. Canadian Journal of Zoology, 78(5), 706-712. http://doi.org/10.1139/cjz-78-5-706

Mattson, W. J. (1980). Herbivory in relation to plant nitrogen content. Annual Review of Ecology and Systematics, 11, 119-161.

May, M. L., \& Hoy, R. R. (1990). Ultrasound-induced yaw movements in the flying Australian field cricket (Teleogryllus oceanicus). Journal of Experimental Biology, 149(1), 177-189.

Maynard Smith, J. (1985). Sexual selection, handicaps and true fitness. Journal of Theoretical Biology, 115(1), 1-8. http://doi.org/10.1016/S0022-5193(85)80003-5

Maynard Smith, J., \& Harper, D. (2003). Animal Signals. Oxford University Press, Oxford.

Mayntz, D., Nielsen, V. H., Sørensen, A., Toft, S., Raubenheimer, D., Hejlesen, C., \& Simpson, S. J. (2009). Balancing of protein and lipid intake by a mammalian carnivore, the mink, Mustela vison. Animal Behaviour, 77, 349-355. 
http://doi.org/10.1016/j.anbehav.2008.09.036

Mcfarlane, J. E. (1964). Factors affecting growth and wing polymorphism in Gryllodes sigillatus (Walk.): dietary protein level and a possible effect of photoperiod. Canadian Journal of Zoology, 42, 767-771.

McGraw, K. J., Mackillop, E. A., Dale, J., \& Hauber, M. E. (2002). Different colors reveal different information: how nutritional stress affects the expression of melanin- and structurally based ornamental plumage. Journal of Experimental Biology, 205, 3747-3755. http://doi.org/10.1007/s00265-010-1135-5

Meikle, J. E. S., \& Mcfarlane, J. E. (1965). The role of lipid in the nutrition of the house cricket, Acheta domesticus L. (Orthoptera: Gryllidae). Canadian Journal of Zoology, 43(1), 87-98. http://doi.org/10.1139/z65-007

Michelsen, A., \& Larsen, O. N. (2014). Directional hearing in insects and other small animals: the physics of pressure-difference receiving ears. (A. N. Popper \& R. R. Fay, Eds.)Perspectives on Auditory Research. Springer, New York. http://doi.org/10.1007/978-1-4614-9102-6

Milinski, M., \& Bakker, T. C. M. (1992). Costs influence sequential mate choice in sticklebacks, Gasterosteus aculeatus. Proceedings of the Royal Society B: Biological Sciences, 250, 229-233.

Møller, A. P., \& Pomiankowski, A. (1993). Why have birds got multiple sexual ornaments? Behavioral Ecology and Sociobiology, 32, 167-176. http://doi.org/10.1007/BF00173774 
Morehouse, N. I. (2014). Condition-dependent ornaments, life histories, and the evolving architecture of resource-use. Integrative and Comparative Biology, 54(4), 591-600. http://doi.org/10.1093/icb/icu103

Morehouse, N. I., Nakazawa, T., Booher, C. M., Jeyasingh, P. D., \& Hall, M. D. (2010). Sex in a material world: why the study of sexual reproduction and sex-specific traits should become more nutritionally-explicit. Oikos, 119, 766-778. http://doi.org/10.1111/j.1600-0706.2009.18569.x

Naimi, B., Hamm, N. A. S., Groen, T. A., Skidmore, A. K., \& Toxopeus, A. G. (2014). Where is positional uncertainty a problem for species distribution modelling? Ecography, 37(2), 191-203. http://doi.org/10.1111/j.1600-0587.2013.00205.x

Nakagawa, S., \& Schielzeth, H. (2013). A general and simple method for obtaining R2 from generalized linear mixed-effects models. Methods in Ecology and Evolution, 4, 133-142. http://doi.org/10.1111/j.2041-210x.2012.00261.x

Nelson, C. M., \& Nolen, T. G. (1997). Courtship song, male agonistic encounters, and female mate choice in the house cricket, Acheta domesticus (Orthoptera: Gryllidae). Journal of Insect Behavior, 10, 557-570. http://doi.org/10.1007/BF02765377

Ortigosa, A., \& Rowe, L. (2002). The effect of hunger on mating behaviour and sexual selection for male body size in Gerris buenoi. Animal Behaviour, 64(3), 369-375. http://doi.org/10.1006/anbe.2002.3065

Pacheco, K., Dawson, J. W., Jutting, M., \& Bertram, S. M. (2013). How age influences phonotaxis in virgin female Jamaican field crickets (Gryllus assimilis). PeerJ, 1, 
e130. http://doi.org/10.7717/peerj.130

Painter, R. H. (1936). The food of insects and its relation to resistance of plants to insect attack. The American Naturalist, 70(731), 547-566. http://doi.org/10.2307/1934961

Park, M. S., Park, P., \& Takeda, M. (2013). Roles of fat body trophocytes, mycetocytes and urocytes in the American cockroach, Periplaneta americana under starvation conditions: an ultrastructural study. Arthropod Structure \& Development, 42, 287295. http://doi.org/10.1016/j.asd.2013.03.004

Parker, G. A. (1970). Sperm competition and its evolutionary consequences in the insects. Biological Reviews, 45(4), 525-567.

Parker, G. A. (1974). Assessment strategy and evolution of fighting behavior. Journal of Theoretical Biology, 47, 223-243. http://doi.org/10.1016/0022-5193(74)90111-8

Parker, G. A. (1998). Sperm competition and the evolution of ejaculates: towards a theory base. In T. R. Birkhead \& A. P. Møller (Eds.), Sperm Competition and Sexual Selection (pp. 3-49). Academic Press, San Diego.

Perkins, M. C., Woods, H. A., Harrison, J. F., \& Elser, J. J. (2004). Dietary phosphorus affects the growth of larval Manduca sexta. Archives of Insect Biochemistry and Physiology, 55, 153-168. http://doi.org/10.1002/arch.10133

Pfennig, K. S., \& Tinsley, R. C. (2002). Different mate preferences by parasitized and unparasitized females potentially reduces sexual selection. Journal of Evolutionary Biology, 15, 399-406.

Pires, A., \& Hoy, R. R. (1992). Temperature coupling in cricket acoustic communication. 
Journal of Comparative Physiology A: Neuroethology, Sensory, Neural, and Behavioral Physiology, 171(1), 79-92. http://doi.org/10.1007/BF00195963

Pomiankowski, A. (1987a). Sexual selection: the handicap principle does work sometimes. Proceedings of the Royal Society B: Biological Sciences, 231, 123-145. http://doi.org/10.1098/rspb.1987.0038

Pomiankowski, A. (1987b). The costs of choice in sexual selection. Journal of Theoretical Biology, 128(2), 195-218. http://doi.org/10.1016/S0022$5193(87) 80169-8$

Popov, A. V., \& Shuvalov, V. F. (1977). Phonotactic behavior of crickets. Journal of Comparative Physiology A: Neuroethology, Sensory, Neural, and Behavioral Physiology, 119, 111-126.

Prestwich, K. N. (1994). The energetics of acoustic signaling in anurans and insects. The American Zoologist, 34, 625-643. http://doi.org/10.1093/icb/34.6.625

Prestwich, K. N., \& Walker, T. J. (1981). Energetics of singing in crickets: effect of temperature in three trilling species (Orthoptera: Gryllidae). Journal of Comparative Physiology B: Biochemical, Systemic, and Environmental Physiology, 143, 199212. http://doi.org/10.1007/BF00797699

Raubenheimer, D., \& Jones, S. A. (2006). Nutritional imbalance in an extreme generalist omnivore: tolerance and recovery through complementary food selection. Animal Behaviour, 71(6), 1253-1262. http://doi.org/10.1016/j.anbehav.2005.07.024

Raubenheimer, D., Lee, K. P., \& Simpson, S. J. (2005). Does Bertrand's rule apply to 
macronutrients? Proceedings of the Royal Society B: Biological Sciences, 272, 2429-2434. http://doi.org/10.1098/rspb.2005.3271

Raubenheimer, D., \& Simpson, S. J. (1993). The geometry of compensatory feeding in the locust. Animal Behaviour, 45, 953-964. http://doi.org/10.1006/anbe.1993.1114

Raubenheimer, D., \& Simpson, S. J. (1997). Integrative models of nutrient balancing: application to insects and vertebrates. Nutrition Research Reviews, 10, 151-179. http://doi.org/10.1079/NRR19970009

Raubenheimer, D., \& Simpson, S. J. (1999). Integrating nutrition: a geometrical approach. Entomologia Experimentalis et Applicata, 91, 67-82. http://doi.org/10.1046/j.1570-7458.1999.00467.x

Raubenheimer, D., \& Simpson, S. J. (2006). The challenge of supplementary feeding: can geometric analysis help save the kakapo? Notornis, 53, 100-111.

Raubenheimer, D., Simpson, S. J., \& Mayntz, D. (2009). Nutrition, ecology and nutritional ecology: toward an integrated framework. Functional Ecology, 23, 4-16. http://doi.org/10.1111/j.1365-2435.2008.01522.x

Reifer, M. L., Harrison, S. J., \& Bertram, S. M. (2018). How dietary protein and carbohydrate influence field cricket development, size, and mate attraction signalling. Animal Behaviour, In Press.

Reynolds, J. D., \& Gross, M. R. (1990). Costs and benefits of female mate choice: is there a lek paradox ? The American Naturalist, 136(2), 230-243.

Rillich, J., \& Stevenson, P. A. (2011). Winning fights induces hyperaggression via the 
action of the biogenic amine octopamine in crickets. PLOS ONE, 6(12), e28891. http://doi.org/10.1371/journal.pone.0028891

Roff, D. A. (1986). The evolution of wing dimorphism in insects. Evolution, 40(5), 10091020.

Roff, D. A., \& Fairbairn, D. J. (1991). Wing dimorphisms and the evolution of migratory polymorphisms among the Insecta. The American Zoologist, 31, 243-251.

Rook, V. L. M., Fitzsimmons, L. P., \& Bertram, S. M. (2010). Strutting their stuff: victory displays in the spring field cricket, Gryllus veletis. Behaviour, 147, 12491266. http://doi.org/10.1163/000579510X514535

Rose, J., Cullen, D. A., Simpson, S. J., \& Stevenson, P. A. (2017). Born to win or bred to lose: aggressive and submissive behavioural profiles in crickets. Animal Behaviour, 123, 441-450. http://doi.org/10.1016/j.anbehav.2016.11.021

Rowe, L., \& Houle, D. (1996). The lek paradox and the capture of genetic variance by condition dependent traits. Proceedings of the Royal Society B: Biological Sciences, 263, 1415-1421. http://doi.org/10.1098/rspb.1996.0207

Ryan, M. J., \& Keddy-hector, A. (1992). Directional patterns of female mate choice and the role of sensory biases. The American Naturalist, 139, S4-S35.

Savage, K. E., Hunt, J., Jennions, M. D., \& Brooks, R. (2005). Male attractiveness covaries with fighting ability but not with prior fight outcome in house crickets. Behavioral Ecology, 16, 196-200. http://doi.org/10.1093/beheco/arh143

Schade, J. D., Kyle, M., Hobbie, S. E., Fagan, W. F., \& Elser, J. J. (2003). Stoichiometric 220 
tracking of soil nutrients by a desert insect herbivore. Ecology Letters, 6, 96-101. http://doi.org/10.1046/j.1461-0248.2003.00409.x

Schal, C., Chiang, A.-S., Burns, E. L., Gadot, M., \& Cooper, R. A. (1993). Role of the brain in juvenile hormone synthesis and oöcyte development: effects of dietary protein in the cockroach Blattella germanica (L.). Journal of Insect Physiology, 39(4), 303-313.

Scheuber, H., Jacot, A., \& Brinkhof, M. W. G. (2003). Condition dependence of a multicomponent sexual signal in the field cricket Gryllus campestris. Animal Behaviour, 65, 721-727. http://doi.org/10.1006/anbe.2003.2083

Scheuber, H., Jacot, A., \& Brinkhof, M. W. G. (2004). Female preference for multiple condition-dependent components of a sexually selected signal. Proceedings of the Royal Society B: Biological Sciences, 271, 2453-2457.

http://doi.org/10.1098/rspb.2004.2907

Schuett, G. W. (1997). Body size and agonistic experience affect dominance and mating success in male copperheads. Animal Behaviour, 54(1), 213-224.

Searcy, W. A., Peters, S., \& Nowicki, S. (2004). Effects of early nutrition on growth rate and adult size in song sparrows Melospiza melodia. Journal of Avian Biology, 35(3), $269-279$.

Sentinella, A. T., Crean, A. J., \& Bonduriansky, R. (2013). Dietary protein mediates a trade-off between larval survival and the development of male secondary sexual traits. Functional Ecology, 27, 1134-1144. http://doi.org/10.1111/1365-2435.12104 
Shariatmadari, F., \& Forbes, J. M. (1993). Growth and food intake responses to diets of different protein contents and a choice between diets containing two concentrations of protein in broiler and layer strains of chicken. British Poultry Science, 1934, 595570.

Simmons, L. W. (1988). The calling song of the field cricket, Gryllus bimaculatus (De Geer): constraints on transmission and its role in intermale competition and female choice. Animal Behaviour, 36, 380-394. http://doi.org/10.1016/S00033472(88)80009-5

Simpson, S. J., \& Abisgold, J. D. (1985). Compensation by locusts for changes in dietary nutrients: behavioural mechanisms. Physiological Entomology, 10, 443-452. http://doi.org/10.1111/j.1365-3032.1985.tb00066.x

Simpson, S. J., \& Raubenheimer, D. (1993). A multi-level analysis of feeding behaviour: the geometry of nutritional decisions. Philosophical Transactions of the Royal Society B: Biological Sciences, 342, 381-402. http://doi.org/10.1098/rstb.1993.0166

Simpson, S. J., \& Raubenheimer, D. (2012). The nature of nutrition: a unifying framework from animal adaptation to human obesity. Princeton: Princeton University Press.

Skorupa, D. A., Dervisefendic, A., Zwiener, J., \& Pletcher, S. D. (2008). Dietary composition specifies consumption, obesity, and lifespan in Drosophila melanogaster. Aging Cell, 7, 478-490. http://doi.org/10.1111/j.14749726.2008.00400.x.Dietary 
Slagsvold, T., Lifjeld, J. T., Stenmark, G., \& Breiehagen, T. (1988). On the cost of searching for a mate in female pied flycatchers Ficedula hypoleuca. Animal Behaviour, 36, 433-442. http://doi.org/10.1016/S0003-3472(88)80013-7

Smith, D. S. (1960). Effects of changing the phosphorus content of the food plant on the migratory grasshopper, Melanoplus bilituratus (Walker) (Orthoptera: Acrididae). The Canadian Entomologist, 92(2), 103-107.

South, S. H., House, C. M., Moore, A. J., Simpson, S. J., \& Hunt, J. (2011). Male cockroaches prefer a high carbohydrate diet that makes them more attractive to females: implications for the study of condition dependence. Evolution, 65, 15941606. http://doi.org/10.1111/j.1558-5646.2011.01233.x

Sterner, R. W., \& Elser, J. J. (2002). Ecological Stoichimetry: The Biology of Elements from Molecules to the Biosphere. Princeton University Press, Princeton, New Jersey, USA.

Stevenson, P. A., \& Rillich, J. (2015). Adding up the odds — nitric oxide signaling underlies the decision to flee and post-conflict depression of aggression. Science Advances, 1 , e1500060. http://doi.org/10.1126/sciadv.1500060

Stevenson, P. A., \& Rillich, J. (2016). Controlling the decision to fight or flee: the roles of biogenic amines and nitric oxide in the cricket. Current Zoology, 62, 265-275. http://doi.org/10.1093/cz/zow028

Syriatowicz, A., \& Brooks, R. (2004). Sexual responsiveness is condition-dependent in female guppies, but preference functions are not. BMC Ecology, 4(1), 5. 
Tanaka, S. (1993). Allocation of resources to egg production and flight muscle development in a wing dimorphic cricket, Modicogryllus confirmatus. Journal of Insect Physiology, 39, 493-498. http://doi.org/10.1016/0022-1910(93)90081-2

Tanaka, S. (1994). Endocrine control of ovarian development and flight-muscle histolysis in a wing dimorphic cricket,Modicogryllus confirmatus. Journal of Insect Physiology, 40(6), 483-490. http://doi.org/Doi 10.1016/0022-1910(94)90121-X

Tanaka, S., \& Suzuki, Y. (1998). Physiological trade-offs between reproduction, flight capability and longevity in a wing-dimorphic cricket, Modicogryllus confirmatus. Journal of Insect Physiology, 44(2), 121-129.

Taylor, G. K. (2001). Mechanics and aerodynamics of insect flight control. Biological Reviews, 76(4), 449-471. http://doi.org/10.1017/S1464793101005759

Thomson, I. R., Darveau, C.-A., \& Bertram, S. M. (2014). Body morphology, energy stores, and muscle enzyme activity explain cricket acoustic mate attraction signaling variation. PLoS ONE, 9, 1-16. http://doi.org/10.1371/journal.pone.0090409

Thurmond, J. B., Lasley, S. M., Conkin, A. L., \& Brown, J. W. (1977). Effects of dietary tyrosine, phenylalaline, and trytophan on aggression in mice. Pharmacology, Biochemistry and Behavior, 6, 475-478.

Tomkins, J. L., Radwan, J., Kotiaho, J. S., \& Tregenza, T. (2004). Genic capture and resolving the lek paradox. Trends in Ecology \& Evolution, 19, 323-328. http://doi.org/10.1016/j.tree.2004.03.029

Toomey, M. B., \& McGraw, K. J. (2012). Mate choice for a male carotenoid-based 
ornament is linked to female dietary carotenoid intake and accumulation. $B M C$ Evolutionary Biology, 12, 3. http://doi.org/10.1186/1471-2148-12-3

Turner, G. F., \& Burrows, M. T. (1995). A model of sympatric speciation by sexual selection. Proceedings of the Royal Society B: Biological Sciences, 260, 287-292.

Urabe, J., \& Sterner, R. W. (2001). Contrasting effects of different types of resource depletion on life-history traits in Daphnia. Functional Ecology, 15, 165-174.

Van-Noordwijk, A. J., \& de Jong, G. (1986). Acquisition and allocation of resources: their influence on variation in life history tactics. The American Naturalist, 128, $137-142$

van Milgen, J. (2002). Modeling biochemical aspects of energy metabolism in mammals. Journal of Nutrition, 132(10), 3195-3202.

Venables, W. N., \& Ripley, B. D. (2002). Modern Applied Statistics with S (Fourth Edi). Springer, New York.

Venesky, M. D., Wilcoxen, T. E., Rensel, M. A., Rollins-Smith, L., Kerby, J. L., \& Parris, M. J. (2012). Dietary protein restriction impairs growth, immunity, and disease resistance in southern leopard frog tadpoles. Oecologia, 169(1), 23-31. http://doi.org/10.1007/s00442-011-2171-1

Visanuvimol, L., \& Bertram, S. M. (2010). Dietary phosphorus availability influences female cricket lifetime reproductive effort. Ecological Entomology, 35(3), 386-395. http://doi.org/10.1111/j.1365-2311.2010.01195.x

Visanuvimol, L., \& Bertram, S. M. (2011). How dietary phosphorus availability during 
development influences condition and life history traits of the cricket, Acheta domesticus. Journal of Insect Science, 11, 1-17.

http://doi.org/10.1673/031.011.6301

Wagner, W. E. (1992). Deceptive or honest signalling of fighting ability? A test of alternative hypotheses for the function of changes in call dominant frequency by male cricket frogs. Animal Behaviour, 44, 449-462. http://doi.org/10.1016/00033472(92)90055-E

Wagner, W. E. (1996). Convergent song preferences between female field crickets and acoustically orienting parasitoid flies. Behavioral Ecology, 7, 279-285. http://doi.org/10.1093/beheco/7.3.279

Wagner, W. E. (1998). Measuring female mating preferences. Animal Behaviour, 55(4), 1029-1042. http://doi.org/10.1006/anbe.1997.0635

Wagner, W. E., \& Harper, C. J. (2003). Female life span and fertility are increased by the ejaculates of preferred males. Evolution, 57, 2054-2066. http://doi.org/10.1554/02548

Wagner, W. E., \& Hoback, W. W. (1999). Nutritional effects on male calling behaviour in the variable field cricket. Animal Behaviour, 57, 89-95. http://doi.org/10.1006/anbe.1998.0964

Wagner, W. E., Murray, A.-M., \& Cade, W. H. (1995). Phenotypic variation in the mating preferences of female field crickets, Gryllus integer. Animal Behaviour, 49, $1269-1281$. 
Wagner, W. E., \& Reiser, M. G. (2000). The importance of calling song and courtship song in female mate choice in the variable field cricket. Animal Behaviour, 59, 1219-1226. http://doi.org/10.1006/anbe.1999.1428

Walker, T. J. (1987). Wing dimorphism in $</ \mathrm{i}>$ Gryllus rubens $<\mathrm{i}>$. Annals of the Entomological Society of America, 80(5), 547-560.

Walker, T. J., \& Sivinski, J. M. (1986). Wing dimorphism in field crickets (Orthoptera: Grillidae: Gryllus). Annals of the Entomological Society of America.

Warbrick-Smith, J., Behmer, S. T., Lee, K. P., Raubenheimer, D., \& Simpson, S. J. (2006). Evolving resistance to obesity in an insect. Proceedings of the National Academy, 103, 14045-14049. http://doi.org/10.1073/pnas.0605225103

Wedell, N., Gage, M. J. G., \& Parker, G. A. (2002). Sperm competition, male prudence, and sperm-limited females. Trends in Ecology and Evolution, 17, 313-320. http://doi.org/10.1007/978-0-387-28039-4_3

Whattam, E. M., \& Bertram, S. M. (2011). Effects of juvenile and adult condition on long-distance call components in the Jamaican field cricket, Gryllus assimilis. Animal Behaviour, 81, 135-144. http://doi.org/10.1016/j.anbehav.2010.09.024

Wheeler, D. (1996). The role of nourishment in oogenesis. Annual Review of Entomology, 41, 407-431. http://doi.org/10.1146/annurev.en.41.010196.002203

Whitman, D. W. (2008). The significance of body size in the Orthoptera: a review. Journal of Orthoptera Research, 17(2), 117-134.

Widemo, F., \& Sæther, S. A. (1999). Beauty is in the eye of the beholder: causes and 
consequences of variation in mating preferences. Trends in Ecology \& Evolution, 14(1), 26-31.

Wigby, S., Sirot, L. K., Linklater, J. R., Buehner, N., Calboli, F. C. F., Bretman, A., ...

Chapman, T. (2009). Seminal fluid protein allocation and male reproductive success. Current Biology, 19, 751-757. http://doi.org/10.1016/j.cub.2009.03.036

Wilder, S. M., \& Rypstra, A. L. (2008). Diet quality affects mating behaviour and egg production in a wolf spider. Animal Behaviour, 76(2), 439-445.

http://doi.org/10.1016/j.anbehav.2008.01.023

Wilgers, D. J., \& Hebets, E. A. (2012). Age-related female mating decisions are condition dependent in wolf spiders. Behavioral Ecology and Sociobiology, 66, 2938. http://doi.org/10.1007/s00265-011-1248-5

Wilson, A. D. M., Whattam, E. M., Bennett, R., Visanuvimol, L., Lauzon, C., \& Bertram, S. M. (2010). Behavioral correlations across activity, mating, exploration, aggression, and antipredator contexts in the European house cricket, Acheta domesticus. Behavioral Ecology and Sociobiology, 64, 703-715. http://doi.org/10.1007/s00265-009-0888-1

Wolak, M. E., Fairbairn, D. J., \& Paulsen, Y. R. (2012). Guidelines for estimating repeatability. Methods in Ecology and Evolution, 3, 129-137. http://doi.org/10.1111/j.2041-210X.2011.00125.x

Woodgate, J. L., Bennett, A. . D., Leitner, S., Catchpole, C. K., \& Buchanan, K. L. (2010). Developmental stress and female mate choice behaviour in the zebra finch. 
Animal Behaviour, 79(6), 1381-1390. http://doi.org/10.1016/j.anbehav.2010.03.018

Woodring, J. P., Clifford, C. W., \& Beckman, B. R. (1979). Food utilization and metabolic efficiency in larval and adult house crickets. Journal of Insect Physiology, 25(12), 903-912. http://doi.org/10.1016/0022-1910(79)90102-1

Woods, H. A., Fagan, W. F., Elser, J. J., \& Harrison, J. F. (2004). Allometric and phylogenetic variation in insect phosphorus content. Functional Ecology, 18, 103109.

Woods, H. A., Perkins, M. C., Elser, J. J., \& Harrison, J. F. (2002). Absorption and storage of phosphorus by larval Manduca sexta. Journal of Insect Physiology, 48, 555-564. http://doi.org/Absorption and storage of phosphorus by larval Manduca sexta

Yuval, B., Kaspi, R., Shloush, S., \& Warburg, M. S. (1998). Nutritional reserves regulate male participation in Mediterranean fruit fly leks. Ecological Entomology, 23(2), 211-215. http://doi.org/10.1046/j.1365-2311.1998.00118.x

Zahavi, A. (1975). Mate selection-a selection for a handicap. Journal of Theoretical Biology, 53, 205-214. http://doi.org/10.1016/0022-5193(75)90111-3

Zahavi, A. (1977). The cost of honesty (further remarks on the handicap principle). Journal of Theoretical Biology, 67, 603-605. http://doi.org/10.1016/00225193(77)90061-3

Zanotto, F. P., Simpson, S. J., \& Raubenheimer, D. (1993). The regulation of growth by locusts through post-ingestive compensation for variation in the levels of dietary 
protein and carbohydrate. Physiological Entomology, 18, 425-434.

Zera, A. J., \& Mole, S. (1994). The physiological costs of flight capability in wingdimorphic crickets. Researches on Population Ecology, 36(2), 151-156. http://doi.org/10.1007/BF02514930

Zera, A. J., \& Rankin, M. A. (1989). Wing dimorphism in Gryllus rubens: genetic basis of morph determination and fertility differences between morphs. Oecologia, 80 , 249-255.

Zera, A. J., Sall, J., \& Grudzinski, K. (1997). Flight-muscle polymorphism in the cricket Gryllus firmus: Muscle characteristics and their influence on the evolution of flightlessness. Physiological Zoology, 70(5), 519-529. http://doi.org/10.1086/515865

Zera, A. J., Strambi, C., Tiebel, K. C., Strambi, A., \& Rankin, M. A. (1989). Juvenile hormone and ecdysteroid titres during critical periods of wing morph determination in Gryllus rubens. Journal of Insect Physiology, 35(6), 501-511. http://doi.org/10.1016/0022-1910(89)90057-7

Zera, A. J., \& Tiebel, K. C. (1989). Differences in juvenile hormone esterase activity between presumptive macropterous and brachypterous Gryllus rubens: implications for the hormonal control of wing polymorphism. Journal of Insect Physiology, 35(1), 7-17. http://doi.org/10.1016/0022-1910(89)90031-0

Zhang, Z., Elser, J. J., Cease, A. J., Zhang, X., Yu, Q., Han, X., \& Zhang, G. (2014). Grasshoppers regulate N:P stoichiometric homeostasis by changing phosphorus 
contents in their frass. PLoS ONE, 9, e103697.

http://doi.org/10.1371/journal.pone.0103697

Zittle, C. A., \& O'Dell, R. A. (1941). Chemical studies of bull spermatozoa. Lipid, sulfur, cystine, nitrogen, phosphorus, and nucleic acid content of whole spermatozoa and of the parts obtained by physical means. Journal of Biological Chemistry, 140, 899907.

Zuk, M. (1988). Parasite load, body size, and age of wild-caught male field crickets (Orthoptera: Gryllidae): effects on sexual selection. Evolution, 42, 969-976.

Zuk, M., \& Simmons, L. W. (1997). Reproductive strategies of the crickets (Orthoptera: Gryllidae). In J. C. Choe \& B. J. Crespi (Eds.), The evolution of mating systems in insects and arachnids. Cambridge University Press, Cambridge. 
Appendices 
Appendix 1

Tables for Chapter 3 
Table A.1.1. Results of generalized linear models for showing the linear and non-linear effects of protein (P), carbohydrates (C), and phosphorus $(\mathrm{PH})$ intake on adult male and female lifespan, body weight gain, male signalling parameters, and female egg production. Significant $P$-values are in boldface, negative regression coefficients $(\beta)$ for quadratic intake terms indicate a concave (peak) relationship, and positive regression coefficients for quadratic intake terms indicate a convex (trough) relationship. The corrected alpha $\mathrm{FDR}_{\mathrm{B}-\mathrm{Y}}$ level of significance is $P<0.009$.

\begin{tabular}{|c|c|c|c|c|c|c|c|c|c|c|c|c|}
\hline \multirow[b]{2}{*}{ Response Variable } & & \multicolumn{4}{|c|}{ Linear } & \multicolumn{3}{|c|}{ Quadratic } & \multicolumn{4}{|c|}{ Correlational } \\
\hline & & Size PC1 & $\mathbf{P}$ & $\mathbf{C}$ & $\mathbf{P H}$ & $\mathbf{P} * \mathbf{P}$ & $C^{*} \mathrm{C}$ & $\mathbf{P H}{ }^{*} \mathbf{P H}$ & $\mathbf{P} * \mathbf{C}$ & $\mathbf{P} * \mathbf{P H}$ & $\mathrm{C} * \mathrm{PH}$ & $\mathbf{P} * \mathbf{C} * \mathbf{P H}$ \\
\hline \multicolumn{13}{|l|}{$\overline{\text { MALES }}$} \\
\hline \multirow[t]{3}{*}{ Weight Gain } & $\beta$ & -6.904 & 0.266 & 0.119 & 0.381 & -0.001 & $4.2 \times 10^{-4}$ & 0.952 & 0.002 & 0.120 & 0.129 & -0.002 \\
\hline & $\mathrm{SE}$ & 1.657 & 0.047 & 0.049 & 1.579 & 0.001 & 0.001 & 1.275 & 0.002 & 0.077 & 0.072 & 0.001 \\
\hline & $\mathrm{P}$ & $<0.001$ & $<0.001$ & 0.015 & 0.809 & 0.292 & 0.651 & 0.455 & 0.270 & 0.121 & 0.073 & 0.025 \\
\hline \multirow[t]{3}{*}{ Lifespan } & $\beta$ & -0.211 & 0.038 & 0.158 & -0.435 & $-1.0 \times 10^{-4}$ & -0.001 & 0.160 & $-2.3 \times 10^{-4}$ & 0.007 & $0.011-$ & $.9 \times 10^{-4}$ \\
\hline & $\mathrm{SE}$ & 0.478 & 0.014 & 0.014 & 0.455 & 0.000 & 0.000 & 0.361 & 0.001 & 0.022 & 0.020 & 0.000 \\
\hline & $\mathrm{P}$ & 0.659 & 0.005 & $<0.001$ & 0.339 & 0.701 & $<0.001$ & 0.658 & 0.716 & 0.762 & 0.575 & 0.340 \\
\hline Time Spent & $\beta$ & 0.668 & 0.570 & 0.754 & -1.017 & -0.002 & -0.003 & -2.960 & 0.002 & 0.255 & 0.292 & -0.002 \\
\hline \multirow[t]{2}{*}{ Signalling } & $\mathrm{SE}$ & 3.185 & 0.091 & 0.094 & 3.034 & 0.002 & 0.002 & 2.455 & 0.004 & 0.148 & 0.138 & 0.001 \\
\hline & $\mathrm{P}$ & 0.834 & $<0.001$ & $<0.001$ & 0.737 & 0.193 & 0.144 & 0.228 & 0.573 & 0.085 & 0.035 & 0.075 \\
\hline
\end{tabular}


Table A.1.1. Continued

\begin{tabular}{|c|c|c|c|c|c|c|c|c|c|c|c|c|}
\hline \multirow[t]{3}{*}{ Pulse Duration } & $\beta$ & 0.323 & 0.001 & 0.003 & -0.010 & $-8.0 \times 10^{-6}$ & $5.2 \times 10^{-5}$ & 0.026 & $-3.3 \times 10^{-5}$ & -0.002 & -0.003 & $1.9 \times 10^{-5}$ \\
\hline & $\mathrm{SE}$ & 0.050 & 0.001 & 0.001 & 0.047 & 0.000 & 0.000 & 0.038 & 0.000 & 0.002 & 0.002 & 0.000 \\
\hline & $\mathrm{P}$ & $<0.001$ & 0.681 & 0.023 & 0.837 & 0.777 & 0.065 & 0.493 & 0.621 & 0.293 & 0.193 & 0.371 \\
\hline \multirow[t]{3}{*}{ Interpulse Duration } & $\beta$ & -0.070 & -0.018 & -0.022 & 0.050 & $8.5 \times 10^{-5}$ & $1.4 \times 10^{-4}$ & -0.010 & $3.0 \times 10^{-5}$ & -0.003 & -0.005 & $4.4 \times 10^{-5}$ \\
\hline & $\mathrm{SE}$ & 0.099 & 0.003 & 0.003 & 0.093 & 0.000 & 0.000 & 0.075 & 0.000 & 0.005 & 0.004 & 0.000 \\
\hline & $\mathrm{P}$ & 0.479 & $<0.001$ & $<0.001$ & 0.594 & 0.122 & 0.009 & 0.893 & 0.821 & 0.482 & 0.244 & 0.290 \\
\hline \multirow[t]{3}{*}{ Pulses Per Chirp } & $\beta$ & 0.043 & 0.003 & 0.003 & -0.016 & $-1.8 \times 10^{-5}$ & $1.8 \times 10^{-5}$ & 0.005 & $-3.8 \times 10^{-5}$ & -0.001 & -0.001 & $1.2 \times 10^{-5}$ \\
\hline & $\mathrm{SE}$ & 0.022 & 0.001 & 0.001 & 0.020 & 0.000 & 0.000 & 0.016 & 0.000 & 0.001 & 0.001 & 0.000 \\
\hline & $\mathrm{P}$ & 0.047 & $<0.001$ & $<0.001$ & 0.442 & 0.138 & 0.126 & 0.751 & 0.190 & 0.225 & 0.136 & 0.179 \\
\hline \multirow[t]{3}{*}{ Chirp Duration } & $\beta$ & 0.676 & 0.034 & 0.024 & 0.092 & $-4.0 \times 10^{-4}$ & 0.001 & 0.068 & $6.6 \times 10^{-5}$ & -0.014 & -0.024 & $1.4 \times 10^{-4}$ \\
\hline & $\mathrm{SE}$ & 0.602 & 0.017 & 0.018 & 0.567 & 0.000 & 0.000 & 0.457 & 0.001 & 0.028 & 0.026 & 0.000 \\
\hline & $\mathrm{P}$ & 0.261 & 0.044 & 0.167 & 0.871 & 0.239 & 0.026 & 0.881 & 0.935 & 0.621 & 0.346 & 0.589 \\
\hline \multirow[t]{3}{*}{ Interchirp Duration } & $\beta$ & -20.845 & -1.220 & -1.322 & 17.734 & 0.001 & -0.003 & -0.722 & 0.005 & 0.068 & -0.065 & $1.7 \times 10^{-4}$ \\
\hline & $\mathrm{SE}$ & 7.378 & 0.209 & 0.216 & 6.948 & 0.004 & 0.004 & 5.646 & 0.010 & 0.342 & 0.318 & 0.003 \\
\hline & $\mathrm{P}$ & 0.005 & $<0.001$ & $<0.001$ & 0.011 & 0.773 & 0.538 & 0.898 & 0.584 & 0.841 & 0.837 & 0.957 \\
\hline
\end{tabular}


Table A.1.1. Continued

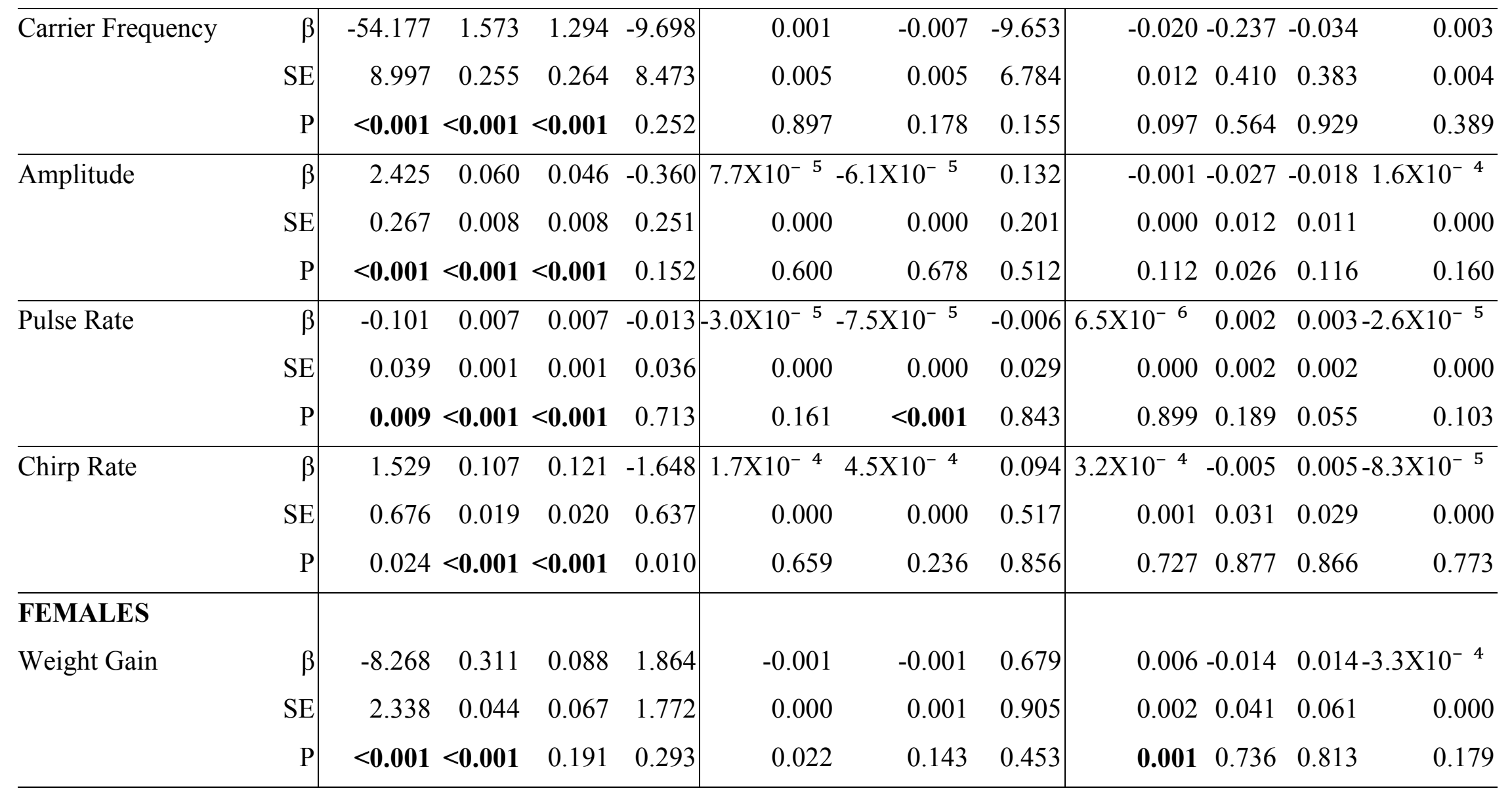


Table A.1.1. Continued

\begin{tabular}{|c|c|c|c|c|c|c|c|c|c|c|c|c|}
\hline \multirow[t]{3}{*}{ Lifespan } & $\beta$ & 0.014 & -0.018 & 0.061 & 0.435 & \multirow{3}{*}{$\begin{array}{r}3.1 \times 10^{-5} \\
0.000 \\
0.747\end{array}$} & \multirow{3}{*}{$\begin{array}{r}-0.001 \\
0.000 \\
\mathbf{0 . 0 0 2}\end{array}$} & \multicolumn{2}{|c|}{\begin{tabular}{l|l|}
$-0.236-2.0 \times 10^{-4}$
\end{tabular}} & \multirow{2}{*}{$\begin{array}{l}0.009 \\
0.010\end{array}$} & \multicolumn{2}{|c|}{$0.035-4.4 \times 10^{-5}$} \\
\hline & $\mathrm{SE}$ & 0.542 & 0.010 & 0.016 & 0.411 & & & 0.214 & 0.000 & & 0.014 & 0.000 \\
\hline & $\mathrm{P}$ & 0.980 & 0.074 & $<0.001$ & 0.290 & & & 0.269 & 0.622 & 0.333 & 0.015 & 0.447 \\
\hline \multirow[t]{3}{*}{ Egg Production } & $\beta$ & 8.151 & 1.135 & 0.384 & 2.301 & -0.002 & -0.003 & -3.539 & -0.002 & 0.041 & 0.179 & 0.001 \\
\hline & $\mathrm{SE}$ & 4.098 & 0.078 & 0.118 & 3.106 & 0.001 & 0.002 & 1.543 & 0.003 & 0.071 & 0.104 & 0.000 \\
\hline & $\mathrm{P}$ & 0.047 & $<0.001$ & 0.001 & 0.459 & 0.004 & 0.044 & 0.022 & 0.450 & 0.558 & 0.085 & 0.074 \\
\hline
\end{tabular}


Table A1.2. Within-sex comparison of linear, quadratic, and correlational effects of nutrient intake on lifespan, weight gain, and reproductive proxies (egg production and time spent calling). Significant $P$-values are in boldface; if $P<0.05$, then linear/quadratic/correlational effects of nutrient intake differ between response variables being compared. The corrected alpha FDR $\mathrm{B}_{\mathrm{B}-\mathrm{Y}}$ level of significance is $P<0.014$.

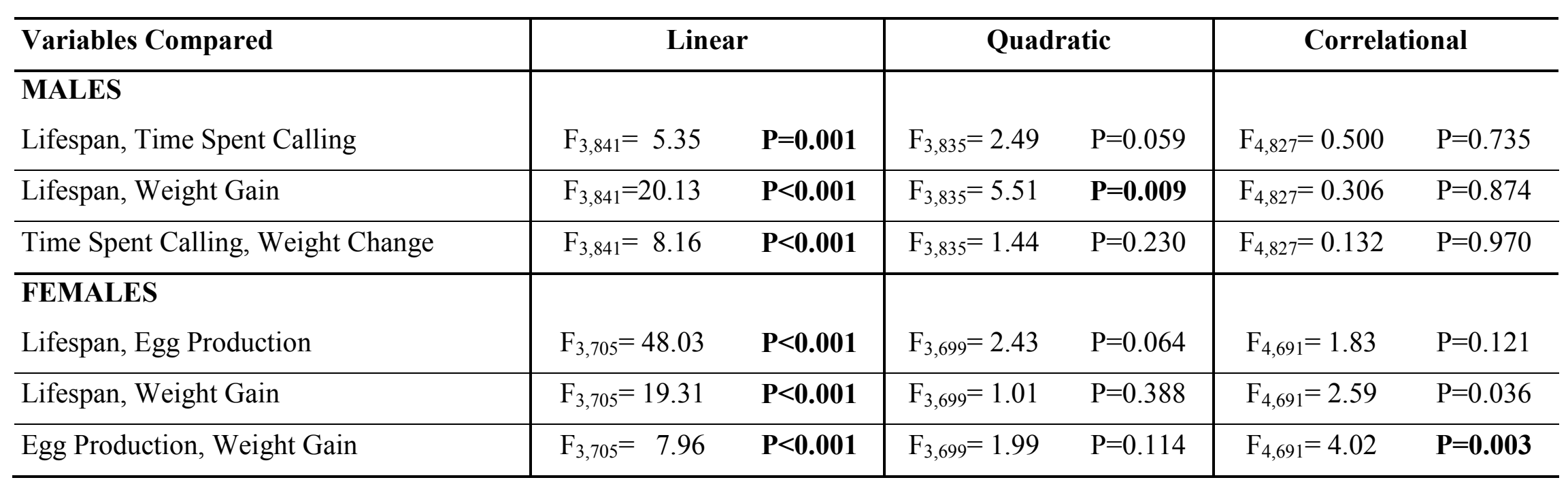


Table A1.3. Between-sex comparison of linear, quadratic, and correlational effects of nutrient intake on lifespan, weight gain, and reproductive proxies (egg production and time spent calling). Significant $P$-values are in boldface; if $P<0.05$, then linear/quadratic/correlational effects of nutrient intake differ between the sexes for the response variable in question. The corrected alpha $\mathrm{FDR}_{\mathrm{B}-\mathrm{Y}}$ level of significance is $P<0.017$

\begin{tabular}{|c|c|c|c|c|c|c|}
\hline \multirow{2}{*}{$\begin{array}{l}\text { Variables Compared } \\
\text { Male \& Female Weight Gain }\end{array}$} & \multicolumn{2}{|c|}{ Linear } & \multicolumn{2}{|c|}{ Quadratic } & \multicolumn{2}{|c|}{ Correlational } \\
\hline & $\mathrm{F}_{3,773}=0.27$ & $\mathrm{P}=0.845$ & $\mathrm{~F}_{3,767}=1.83$ & $\mathrm{P}=0.141$ & $\mathrm{~F}_{4,759}=3.10$ & $\mathrm{P}=\mathbf{0 . 0 1 5}$ \\
\hline Male \& Female Lifespan & $\mathrm{F}_{3,773}=9.16$ & $\mathbf{P}<0.001$ & $\mathrm{~F}_{3,767}=2.46$ & $\mathrm{P}=0.062$ & $\mathrm{~F}_{4,759}=1.80$ & $\mathrm{P}=0.127$ \\
\hline Male \& Female Reproductive Proxies & $\mathrm{F}_{3,773}=7.58$ & $\mathrm{P}<\mathbf{0 . 0 0 1}$ & $\mathrm{F}_{3,767}=2.58$ & $\mathrm{P}=0.052$ & $\mathrm{~F}_{4,759}=1.86$ & $\mathrm{P}=0.116$ \\
\hline
\end{tabular}


Table A1.4. Results of general linear mixed models testing whether total consumption differed between foods within a treatment pair and whether total consumption was influenced by sex or body size. Estimates $\pm \mathrm{SE}$ are in relation to the sex and food indicated in [brackets] in the effect column. Significant effects are in boldface. The corrected alpha FDR $\mathrm{B}_{\mathrm{Y}}$ level of significance is $P<0.012$.

\begin{tabular}{|c|c|c|c|c|c|c|c|c|}
\hline Diet Pair & $\mathbf{R}_{\text {Adj }}^{2}$ & $\begin{array}{c}\text { Individual Var } \\
\text { (\% of total) }\end{array}$ & $\begin{array}{l}\text { Block Var } \\
\text { (\% of total) }\end{array}$ & Effect & Estimate \pm SE & df & $F$ & $P$ \\
\hline \multirow[t]{4}{*}{1} & 0.648 & 7.247 & 42.093 & Size PC1 & $9.961 \pm 7.529$ & $1,15.65$ & 1.750 & 0.205 \\
\hline & & & & Food $[\mathrm{A}]$ & $1.417 \pm 5.489$ & $1,19.00$ & 0.067 & 0.799 \\
\hline & & & & $\operatorname{Sex}[\mathbf{F}]$ & $23.505 \pm 7.245$ & $1,12.69$ & 10.524 & 0.007 \\
\hline & & & & Sex $[\mathrm{F}]^{*}$ Food $[\mathrm{A}]$ & $2.518 \pm 5.489$ & $1,19.00$ & 0.210 & 0.652 \\
\hline \multirow[t]{4}{*}{2} & -0.634 & 0.000 & 13.222 & Size PC1 & $0.757 \pm 6.840$ & $1,16.22$ & 0.012 & 0.913 \\
\hline & & & & Food $[\mathrm{B}]$ & $13.643 \pm 7.290$ & $1,20.00$ & 3.503 & 0.076 \\
\hline & & & & $\operatorname{Sex}[F]$ & $11.916 \pm 4.432$ & $1,9.87$ & 7.228 & 0.023 \\
\hline & & & & Sex $[\mathrm{F}]^{*}$ Food $[\mathrm{B}]$ & $-3.843 \pm 7.290$ & $1,20.00$ & 0.278 & 0.604 \\
\hline \multirow[t]{4}{*}{3} & 0.713 & 61.631 & 0.000 & Size PC1 & $6.930 \pm 6.992$ & $1,15.01$ & 0.982 & 0.337 \\
\hline & & & & Food $[\mathrm{A}]$ & $-5.870 \pm 5.519$ & $1,20.00$ & 1.131 & 0.300 \\
\hline & & & & $\operatorname{Sex}[F]$ & $21.951 \pm 11.762$ & $1,10.83$ & 3.483 & 0.089 \\
\hline & & & & $\operatorname{Sex}[\mathrm{F}] *$ Food $[\mathrm{A}]$ & $-0.857 \pm 5.519$ & $1,20.00$ & 0.024 & 0.878 \\
\hline
\end{tabular}


Table A1.4. Continued

\begin{tabular}{|c|c|c|c|c|c|c|c|c|}
\hline \multirow[t]{4}{*}{4} & 0.836 & 62.305 & 0.000 & Size PC1 & $1.491 \pm 9.453$ & $1,17.49$ & 0.025 & 0.876 \\
\hline & & & & Food $[\mathrm{B}]$ & $3.057 \pm 4.013$ & $1,20.00$ & 0.580 & 0.455 \\
\hline & & & & $\operatorname{Sex}[\mathbf{F}]$ & $32.229 \pm 8.403$ & $1,9.35$ & 14.709 & 0.004 \\
\hline & & & & Sex $[\mathrm{F}]^{*}$ Food $[\mathrm{B}]$ & $4.620 \pm 4.013$ & $1,20.00$ & 1.325 & 0.263 \\
\hline \multirow[t]{4}{*}{5} & 0.835 & 18.277 & 16.979 & Size PC1 & $10.958 \pm 7.514$ & $1,16.16$ & 2.127 & 0.164 \\
\hline & & & & Food $[D]$ & $-69.994 \pm 6.516$ & $1,19.00$ & 115.380 & $<.0001$ \\
\hline & & & & $\operatorname{Sex}[\mathrm{F}]$ & $20.860 \pm 8.392$ & $1,10.65$ & 6.178 & 0.031 \\
\hline & & & & Sex $[\mathrm{F}]^{*}$ Food $[\mathrm{D}]$ & $-5.329 \pm 6.516$ & $1,19.00$ & 0.669 & 0.424 \\
\hline \multirow[t]{4}{*}{6} & 0.834 & 13.610 & 0.000 & Size PC1 & $9.970 \pm 3.039$ & $1,13.64$ & 10.760 & 0.006 \\
\hline & & & & Food $[E]$ & $-42.902 \pm 3.474$ & $1,20.00$ & 152.555 & $<.0001$ \\
\hline & & & & $\operatorname{Sex}[\mathbf{F}]$ & $15.904 \pm 3.984$ & $1,9.26$ & 15.933 & 0.003 \\
\hline & & & & Sex $[\mathrm{F}]^{*}$ Food $[\mathrm{E}]$ & $1.307 \pm 3.474$ & $1,20.00$ & 0.142 & 0.711 \\
\hline \multirow[t]{4}{*}{7} & 0.848 & 47.283 & 0.000 & Size PC1 & $6.847 \pm 4.802$ & $1,18.76$ & 2.033 & 0.170 \\
\hline & & & & Food $[D]$ & $-35.580 \pm 3.429$ & $1,20.00$ & 107.687 & $<.0001$ \\
\hline & & & & $\operatorname{Sex}[F]$ & $9.509 \pm 5.737$ & $1,9.66$ & 2.747 & 0.129 \\
\hline & & & & Sex $[\mathrm{F}]^{*}$ Food $[\mathrm{D}]$ & $5.448 \pm 3.429$ & $1,20.00$ & 2.525 & 0.128 \\
\hline
\end{tabular}


Table A1.4. Continued

\begin{tabular}{|c|c|c|c|c|c|c|c|c|}
\hline \multirow[t]{4}{*}{8} & 0.674 & 5.184 & 0.000 & Size PC1 & $19.477 \pm 6.452$ & $1,17.96$ & 9.114 & 0.007 \\
\hline & & & & Food $[\mathbf{F}]$ & $66.748 \pm 7.107$ & $1,19.00$ & 88.213 & $<.0001$ \\
\hline & & & & $\operatorname{Sex}[F]$ & $16.962 \pm 7.495$ & $1,10.07$ & 5.122 & 0.047 \\
\hline & & & & Sex $[\mathrm{F}]^{*}$ Food $[\mathrm{F}]$ & $-4.283 \pm 7.107$ & $1,19.00$ & 0.363 & 0.554 \\
\hline \multirow[t]{4}{*}{9} & 0.873 & 52.378 & 12.948 & Size PC1 & $23.212 \pm 9.480$ & $1,18.03$ & 5.996 & 0.025 \\
\hline & & & & Food $[\mathrm{H}]$ & $3.350 \pm 4.013$ & $1,20.00$ & 0.697 & 0.414 \\
\hline & & & & $\operatorname{Sex}[F]$ & $31.652 \pm 8.050$ & $1,9.61$ & 15.459 & 0.003 \\
\hline & & & & Sex $[\mathrm{F}]^{*}$ Food $[\mathrm{H}]$ & $-5.036 \pm 4.013$ & $1,20.00$ & 1.575 & 0.224 \\
\hline
\end{tabular}


Appendix 2

Parameter estimates tables for Chapter 4 
Table A2.1. Parameter estimates for the model that best explained aggression score (AggPC1). For categorical predictor variables associated with diet, redundant model terms with regression coefficients of 0 (i.e. reference categories) are omitted from the table. Estimates associated with the remaining model term(s) indicate contrasts with the missing reference category. $\mathrm{FDR}_{\mathrm{B}-\mathrm{Y}}$ corrected level of significance is $P=0.024$.

\begin{tabular}{|c|c|c|c|c|c|}
\hline Model & Model Parameter & $\beta$ & SE & $t$ & df \\
\hline \multirow[t]{6}{*}{ AggPC1 } & Intercept & -0.987 & 0.678 & -1.455 & 106.060 .149 \\
\hline & Age & 0.075 & 0.055 & 1.346 & 101.580 .181 \\
\hline & SizePC1 & 0.102 & 0.049 & 2.066 & 97.370 .042 \\
\hline & Protein:Carbohydrate $\left[1_{\mathrm{P}}: 1_{\mathrm{C}}\right]$ & 0.105 & 0.177 & 0.594 & 203.710 .553 \\
\hline & Protein:Carbohydrate $\left[3_{\mathrm{P}}: 1_{\mathrm{C}}\right]$ & 0.101 & 0.177 & 0.572 & 204.380 .568 \\
\hline & Phosphorus $[0.45 \% \mathrm{PH}]$ & 0.046 & 0.144 & 0.320 & 202.570 .750 \\
\hline
\end{tabular}


Table A2.2. Parameter estimates for the models that best explained pre-fight signalling (signalling factors 1-3). For categorical predictor variables associated with diet, redundant model terms with regression coefficients of 0 (i.e. reference categories) are omitted from the table. Estimates associated with the remaining model term(s) indicate contrasts with the missing reference category. FDR $_{\mathrm{B}-\mathrm{Y}}$ corrected level of significance is $P$ $=0.022$. Significant terms are bolded.

\begin{tabular}{llrrrrr}
\hline Model & Model Parameter & $\boldsymbol{\beta}$ & SE & $\boldsymbol{t}$ & $\mathbf{d f}$ & $\boldsymbol{P}$ \\
\hline Signalling Factor 1 & Intercept & 0.264 & 0.615 & 0.429 & 189.95 & 0.669 \\
& Age & -0.030 & 0.050 & -0.602 & 193.32 & 0.548 \\
& SizePC1 & 0.088 & 0.047 & 1.895 & 184.46 & 0.060 \\
& AggPC1 & 0.067 & 0.047 & 1.417 & 208.82 & 0.158 \\
& Protein:Carbohydrate $\left[1_{\mathrm{P}}: 1_{\mathrm{C}}\right]$ & 0.048 & 0.126 & 0.385 & 187.35 & 0.701 \\
& Protein:Carbohydrate $\left[3_{\mathrm{P}}: 1_{\mathrm{C}}\right]$ & -0.098 & 0.126 & -0.773 & 188.93 & 0.441 \\
& Phosphorus $\left[\mathbf{0 . 4 5 \%} \mathrm{p}_{\mathrm{PH}}\right]$ & $\mathbf{0 . 2 5 8}$ & $\mathbf{0 . 1 0 1}$ & $\mathbf{2 . 5 4 5}$ & $\mathbf{1 8 4 . 6 4}$ & $\mathbf{0 . 0 1 2}$ \\
\hline Signalling Factor 2 & Intercept & 0.225 & 0.610 & 0.369 & 200.35 & 0.712 \\
& Age & -0.017 & 0.050 & -0.339 & 204.52 & 0.735 \\
& SizePC1 & $\mathbf{0 . 1 3 5}$ & $\mathbf{0 . 0 4 6}$ & $\mathbf{2 . 9 1 5}$ & $\mathbf{1 9 6 . 5 6}$ & $\mathbf{0 . 0 0 4}$ \\
& AggPC1 & -0.034 & 0.046 & -0.745 & 208.06 & 0.457 \\
& Protein:Carbohydrate $\left[1_{\mathrm{P}}: 1_{\mathrm{C}}\right]$ & 0.075 & 0.122 & 0.617 & 189.63 & 0.538 \\
& Protein:Carbohydrate $\left[3_{\mathrm{P}}: 1_{\mathrm{C}}\right]$ & -0.169 & 0.123 & -1.375 & 191.10 & 0.171 \\
& Phosphorus $\left[0.45 \% \mathrm{p}_{\mathrm{PH}}\right]$ & 0.135 & 0.098 & 1.375 & 187.20 & 0.171 \\
\hline Signalling Factor 3 3 & Intercept & 0.470 & 0.568 & 0.827 & 190.07 & 0.410 \\
& Age & -0.031 & 0.046 & -0.669 & 104.03 & 0.505 \\
& SizePC1 & $\mathbf{- 0 . 1 9 0}$ & $\mathbf{0 . 0 4 3}$ & $-\mathbf{4 . 4 5 8}$ & $\mathbf{1 0 4 . 9 2}$ & $<\mathbf{0 . 0 0 1}$ \\
& AggPC1 & -0.114 & 0.052 & -2.192 & 227.01 & 0.029 \\
& Protein:Carbohydrate $\left[1_{\mathrm{P}}: 1_{\mathrm{C}}\right]$ & -0.009 & 0.145 & -0.062 & 189.32 & 0.951 \\
& Protein:Carbohydrate $\left[3_{\mathrm{P}}: 1_{\mathrm{C}}\right]$ & -0.060 & 0.146 & -0.411 & 190.81 & 0.682 \\
& Phosphorus $\left[0.45 \% \mathrm{p}_{\mathrm{PH}}\right]$ & -0.105 & 0.117 & -0.898 & 185.45 & 0.370 \\
\hline & & & & & & \\
\hline
\end{tabular}


Table A2.3. Parameter estimates for models that best explained change in signalling following aggression trials (signalling change factors 1-3). Redundant model terms with regression coefficients of 0 (i.e. reference categories) are omitted from the table.

Estimates associated with the remaining model term(s) indicate contrasts with the missing reference category. $\mathrm{FDR}_{\mathrm{B}-\mathrm{Y}}$ corrected level of significance is $P=0.022$ for signalling change factors $1 \& 2$, and $P=0.020$ for signalling change factor 3 . Significant terms are bolded.

\begin{tabular}{|c|c|c|c|c|c|c|}
\hline $\begin{array}{l}\text { Model } \\
\text { Term } \\
\end{array}$ & Model Parameter & $\boldsymbol{\beta}$ & SE & $t$ & df & $\boldsymbol{P}$ \\
\hline \multirow{7}{*}{$\begin{array}{l}\text { Signalling } \\
\text { Change } \\
\text { Factor } 1\end{array}$} & Intercept & -0.572 & 0.642 & -0.891 & 130.20 & 0.374 \\
\hline & Age & 0.049 & 0.052 & 0.932 & 127.49 & 0.353 \\
\hline & SizePC1 & -0.049 & 0.049 & -1.018 & 130.15 & 0.311 \\
\hline & AggPC1 & 0.025 & 0.054 & 0.454 & 213.78 & 0.650 \\
\hline & Protein:Carbohydrate $\left[1_{\mathrm{P}}: 1_{\mathrm{C}}\right]$ & 0.199 & 0.151 & 1.323 & 182.56 & 0.188 \\
\hline & Protein:Carbohydrate $\left[3_{\mathrm{P}}: 1_{\mathrm{C}}\right]$ & 0.056 & 0.152 & 0.370 & 185.13 & 0.712 \\
\hline & Phosphorus $[0.45 \% \mathrm{PH}]$ & -0.183 & 0.122 & -1.493 & 180.92 & 0.137 \\
\hline \multirow{7}{*}{$\begin{array}{l}\text { Signalling } \\
\text { Change } \\
\text { Factor } 2\end{array}$} & Intercept & 1.115 & 0.636 & 1.755 & 135.50 & 0.082 \\
\hline & Age & -0.075 & 0.052 & -1.447 & 133.52 & 0.150 \\
\hline & SizePC1 & -0.064 & 0.048 & -1.339 & 134.85 & 0.183 \\
\hline & AggPC1 & 0.023 & 0.053 & 0.437 & 211.28 & 0.663 \\
\hline & Protein:Carbohydrate $\left[1_{\mathrm{P}}: 1_{\mathrm{C}}\right]$ & -0.282 & 0.145 & -1.943 & 180.25 & 0.054 \\
\hline & Protein:Carbohydrate $\left[3_{P}: 1_{C}\right]$ & -0.342 & 0.146 & -2.336 & 182.91 & 0.021 \\
\hline & Phosphorus $[0.45 \% \mathrm{PH}]$ & -0.011 & 0.118 & -0.093 & 178.57 & 0.926 \\
\hline \multirow{8}{*}{$\begin{array}{l}\text { Signalling } \\
\text { Change } \\
\text { Factor } 3\end{array}$} & Intercept & 0.786 & 0.564 & 1.394 & 93.85 & 0.166 \\
\hline & Age & -0.052 & 0.046 & -1.130 & 88.66 & 0.261 \\
\hline & SizePC1 & 0.060 & 0.043 & 1.398 & 97.49 & 0.165 \\
\hline & AggPC1 & -0.257 & $\mathbf{0 . 0 7 3}$ & -3.516 & 218.96 & $<0.001$ \\
\hline & Protein:Carbohydrate $\left[1_{\mathrm{P}}: 1_{\mathrm{C}}\right]$ & 0.006 & 0.154 & 0.039 & 184.22 & 0.969 \\
\hline & Protein:Carbohydrate $\left[3_{\mathrm{P}}: 1_{\mathrm{C}}\right]$ & -0.375 & 0.155 & -2.421 & 186.92 & 0.016 \\
\hline & Phosphorus $[0.45 \% \mathrm{PH}]$ & -0.093 & 0.125 & -0.744 & 182.41 & 0.458 \\
\hline & AggPC1* Phosphorus $[0.45 \% \mathrm{PH}]$ & 0.406 & 0.105 & 3.867 & 216.20 & $<0.001$ \\
\hline
\end{tabular}


Appendix 3

Parameter estimates tables for Chapter 5 
Table A3.1. Parameter estimates for the models examining factors influencing juvenile and adult female life-history traits. Redundant parameter estimates with regression coefficients of 0 (i.e. reference categories) are omitted from the table, and estimates associated with the remaining model parameter(s) indicate contrasts with the missing reference category. Significant model effects and parameters are bolded. Significant parameter estimates are bolded. The FDR $\mathrm{B}_{\mathrm{Y}}$ corrected level of significance is $P=0.018$ for the wing-muscle morph model, $P=0.015$ for the egg model, and $P=0.019$ for all remaining models.

\begin{tabular}{llrrrr}
\hline Model & Model Parameter & $\boldsymbol{\beta}$ & SE & $\boldsymbol{z} / \boldsymbol{t}$ & $\boldsymbol{P}$ \\
\hline Probability of Survival to & Intercept & -0.388 & 0.751 & -0.517 & 0.605 \\
Adulthood & Initial Weight & $\mathbf{0 . 0 1 6}$ & $\mathbf{0 . 0 0 4}$ & $\mathbf{3 . 8 7 7}$ & $<\mathbf{0 . 0 0 1}$ \\
& Protein:Carbohydrate $\left[\mathbf{1}_{\mathbf{P}}: \mathbf{1}_{\mathbf{C}}\right]$ & $\mathbf{1 . 2 1 2}$ & $\mathbf{0 . 4 9 2}$ & $\mathbf{2 . 4 6 6}$ & $\mathbf{0 . 0 1 4}$ \\
& Protein:Carbohydrate $\left[3_{\mathrm{P}}: 1_{\mathrm{C}}\right]$ & 0.016 & 0.370 & 0.044 & 0.965 \\
& Phosphorus $\left[0.45 \%{ }_{\mathrm{PH}}\right]$ & -0.079 & 0.339 & -0.234 & 0.815 \\
\hline Development Time & Intercept & $\mathbf{3 . 2 0 0}$ & $\mathbf{0 . 0 5 8}$ & $\mathbf{5 5 . 2 6 6}$ & $<\mathbf{0 . 0 0 1}$ \\
& Initial Weight & $\mathbf{- 0 . 0 0 1}$ & $\mathbf{0 . 0 0 0}$ & $\mathbf{- 4 . 9 3 8}$ & $<\mathbf{0 . 0 0 1}$ \\
& Protein:Carbohydrate $\left[\mathbf{1}_{\mathbf{P}}: \mathbf{1}_{\mathbf{C}}\right]$ & $\mathbf{- 0 . 1 4 5}$ & $\mathbf{0 . 0 3 4}$ & $\mathbf{- 4 . 3 1 1}$ & $<\mathbf{0 . 0 0 1}$ \\
& Protein:Carbohydrate $\left[\mathbf{3}_{\mathrm{P}}: \mathbf{1}_{\mathbf{C}}\right]$ & $\mathbf{0 . 1 9 1}$ & $\mathbf{0 . 0 3 5}$ & $\mathbf{- 5 . 4 4 5}$ & $<\mathbf{0 . 0 0 1}$ \\
& Phosphorus $\left[0.45 \%{ }_{\mathrm{PH}}\right]$ & 0.025 & 0.028 & 0.872 & 0.384 \\
\hline
\end{tabular}


Table A3.1. Continued

\begin{tabular}{|c|c|c|c|c|c|}
\hline \multirow[t]{5}{*}{ Adult Eclosion Weight } & Intercept & 138.919 & 8.855 & 15.687 & $<0.001$ \\
\hline & Initial Weight & 0.704 & 0.040 & 17.591 & $<0.001$ \\
\hline & Protein:Carbohydrate $\left[1_{\mathrm{P}}: 1_{\mathrm{C}}\right]$ & 42.787 & 5.237 & 8.170 & $<\mathbf{0 . 0 0 1}$ \\
\hline & Protein:Carbohydrate $\left[3_{\mathrm{P}}: 1_{\mathrm{C}}\right]$ & 30.728 & 5.347 & 5.747 & $<0.001$ \\
\hline & Phosphorus $[0.45 \% \mathrm{PH}]$ & -2.290 & 4.303 & -0.532 & 0.595 \\
\hline \multirow{9}{*}{$\begin{array}{l}\text { Probability of Forewing } \\
\text { Deformity }\end{array}$} & Intercept & 0.299 & 0.406 & 0.736 & 0.462 \\
\hline & Initial Weight & -0.005 & 0.002 & -2.262 & 0.024 \\
\hline & Protein:Carbohydrate $\left[1_{\mathrm{P}}: 1_{\mathrm{C}}\right]$ & -1.314 & 0.623 & -2.109 & 0.035 \\
\hline & Protein:Carbohydrate $\left[\mathbf{3}_{\mathrm{P}}: \mathbf{1}_{\mathrm{C}}\right]$ & -3.003 & 0.811 & -3.706 & $<0.001$ \\
\hline & Phosphorus $[0.45 \% \mathrm{PH}]$ & -0.173 & 0.203 & -0.853 & 0.394 \\
\hline & Protein:Carbohydrate $\left[1_{\mathrm{P}}: 1_{\mathrm{C}}\right] *$ Phosphorus $[0.45 \% \mathrm{PH}]$ & -0.594 & 0.340 & -1.748 & 0.080 \\
\hline & Protein:Carbohydrate $\left[3_{\mathrm{P}}: 1_{\mathrm{C}}\right] *$ Phosphorus $[0.45 \% \mathrm{PH}]$ & 0.532 & 0.386 & 1.377 & 0.168 \\
\hline & Initial Weight $*$ Protein:Carbohydrate $\left[1_{\mathrm{P}}: 1_{\mathrm{C}}\right]$ & 0.005 & 0.003 & 1.495 & 0.135 \\
\hline & Initial Weight * Protein:Carbohydrate $\left[3_{\mathrm{P}}: 1_{\mathrm{C}}\right]$ & 0.008 & 0.004 & 2.402 & 0.016 \\
\hline \multirow{7}{*}{$\begin{array}{l}\text { Probability of Long } \\
\text { Hindwing Morph }\end{array}$} & Intercept & -6.706 & 1.147 & -5.846 & $<0.001$ \\
\hline & Initial Weight & 0.018 & 0.004 & 4.193 & $<0.001$ \\
\hline & Protein:Carbohydrate $\left[1_{\mathrm{P}}: 1_{\mathrm{C}}\right]$ & 3.586 & 1.321 & 2.714 & 0.007 \\
\hline & Protein:Carbohydrate $\left[3_{P}: 1_{C}\right]$ & 4.805 & 1.332 & 3.608 & $<0.001$ \\
\hline & Phosphorus $[0.45 \% \mathrm{PH}]$ & -0.125 & 0.226 & -0.551 & 0.582 \\
\hline & Initial Weight $*$ Protein:Carbohydrate $\left[1_{\mathrm{P}}: 1_{\mathrm{C}}\right]$ & -0.010 & 0.005 & -1.970 & 0.049 \\
\hline & Initial Weight * Protein:Carbohydrate $\left[3_{P}: 1_{C}\right]$ & -0.016 & $\mathbf{0 . 0 0 5}$ & -3.093 & 0.002 \\
\hline
\end{tabular}


Table A3.1. Continued

\begin{tabular}{|c|c|c|c|c|c|}
\hline \multirow{6}{*}{$\begin{array}{l}\text { Wing-Muscle Morph } \\
\left(\mathrm{LW}_{\mathrm{w}} \text { vs. } \mathrm{LW}_{\mathrm{p}}\right)\end{array}$} & Intercept & -5.277 & 51.322 & -0.103 & 0.918 \\
\hline & SizePC1 & -0.335 & 0.278 & -1.204 & 0.228 \\
\hline & Age & -0.190 & 0.418 & -0.454 & 0.650 \\
\hline & Protein:Carbohydrate $\left[1_{P}: 1_{C}\right]$ & 8.853 & 50.838 & 0.174 & 0.862 \\
\hline & Protein:Carbohydrate $\left[3_{P}: 1_{C}\right]$ & 9.000 & 50.838 & 0.177 & 0.859 \\
\hline & Phosphorus $[0.45 \% \mathrm{PH}]$ & 0.078 & 0.776 & 0.100 & 0.920 \\
\hline \multirow{6}{*}{$\begin{array}{l}\text { Wing-Muscle Morph } \\
\left(\mathrm{LW}_{\mathrm{y}} \text { vs. } \mathrm{LW}_{\mathrm{p}}\right)\end{array}$} & Intercept & -0.872 & 6.211 & -0.140 & 0.888 \\
\hline & SizePC1 & -0.256 & 0.235 & -1.091 & 0.275 \\
\hline & Age & 0.125 & 0.364 & 0.343 & 0.731 \\
\hline & Protein:Carbohydrate $\left[\mathbf{1}_{\mathrm{P}}: \mathbf{1}_{\mathrm{C}}\right]$ & 0.309 & 0.920 & 0.336 & 0.737 \\
\hline & Protein:Carbohydrate $\left[3_{\mathrm{P}}: 1_{\mathrm{C}}\right]$ & -0.133 & 0.940 & -0.142 & 0.887 \\
\hline & Phosphorus $[0.45 \% \mathrm{PH}]$ & -0.206 & 0.653 & -0.316 & 0.752 \\
\hline \multirow[t]{9}{*}{ Number of Eggs } & Intercept & 0.785 & 0.602 & 1.304 & 0.193 \\
\hline & SizePC1 & 0.169 & 0.021 & 8.119 & $<0.001$ \\
\hline & Age & 0.072 & 0.034 & 2.122 & 0.035 \\
\hline & Hindwing-Muscle Morph [LWw] & 0.612 & 0.255 & 2.401 & 0.017 \\
\hline & Hindwing-Muscle Morph [LWy] & 1.136 & 0.226 & 5.031 & $<0.001$ \\
\hline & Hindwing-Muscle Morph [SWw] & 1.008 & 0.214 & 4.705 & $<0.001$ \\
\hline & Protein:Carbohydrate $\left[1_{P}: 1_{C}\right]$ & 1.618 & 0.128 & 12.619 & $<0.001$ \\
\hline & Protein:Carbohydrate $\left[3_{\mathrm{P}}: 1_{\mathrm{C}}\right]$ & 1.814 & 0.127 & 14.289 & $<0.001$ \\
\hline & Phosphorus $[0.45 \% \mathrm{PH}]$ & 0.090 & 0.063 & 1.425 & 0.155 \\
\hline
\end{tabular}


Table A3.2. Parameter estimates for the models examining factors influencing the amount of food juvenile females ate when given pairs of diets differing in either protein:carbohydrate ratio (diet $\mathrm{B} ; 3_{\mathrm{P}}: 1_{\mathrm{C}}, 1.45 \% \mathrm{PH}$ and $\operatorname{diet} \mathrm{F} ; 1_{\mathrm{P}}: 3_{\mathrm{C}}, 1.45 \%{ }_{\mathrm{PH}}$ ) or phosphorus level (diet $\mathrm{C} ; 1_{\mathrm{P}}: 1_{\mathrm{C}}, 0.45 \% \mathrm{PH}$ and diet $\mathrm{D} ; 1_{\mathrm{P}}: 1_{\mathrm{C}}, 1.45 \% \mathrm{PH}$ ). Redundant parameter estimates with regression coefficients of 0 (i.e. reference categories) are omitted from the table, and estimates associated with the remaining model parameter(s) indicate contrasts with the missing reference category. Significant model effects and parameters are bolded. The $\mathrm{FDR}_{\mathrm{B}-\mathrm{Y}}$ corrected level of significance is $P=0.027$.

\begin{tabular}{llrrrr}
\hline Model & Model Parameter & $\boldsymbol{\beta}$ & SE & $\boldsymbol{t}$ & $\boldsymbol{P}$ \\
\hline Amount Eaten & Intercept & 44.155 & 33.240 & 1.328 & 0.195 \\
(Diets B \& F) & Initial Weight & -0.119 & 0.154 & -0.772 & 0.447 \\
& Diet [F] & 12.894 & 47.009 & 0.274 & 0.786 \\
& Initial Weight * Diet [F] & $\mathbf{0 . 5 6 7}$ & $\mathbf{0 . 2 1 8}$ & $\mathbf{2 . 6 0 5}$ & $\mathbf{0 . 0 1 5}$ \\
\hline Amount Eaten & Intercept & 22.895 & 33.155 & 0.690 & 0.495 \\
(Diets C \& D) & Initial Weight & 0.284 & 0.145 & 1.963 & 0.060 \\
& Diet [D] & 0.633 & 10.234 & 0.062 & 0.951 \\
\hline
\end{tabular}


Appendix 4

Parameter estimates tables for Chapter 6 
Table A4.1. Parameter estimates for the models examining factors influencing female preference function traits. Redundant parameter estimates with regression coefficients of 0 (i.e. reference categories) are omitted from the table, and estimates associated with the remaining model parameter(s) indicate contrasts with the missing reference category. Significant model effects and parameters are bolded. The FDR $\mathrm{B}_{\mathrm{B}-\mathrm{Y}}$ corrected level of significance is $P=0.017$.

\begin{tabular}{|c|c|c|c|c|c|}
\hline Model & Model Parameter & $\beta$ & SE & $z / t$ & $\boldsymbol{P}$ \\
\hline \multirow{7}{*}{$\begin{array}{l}\text { Peak Stimulus } \\
\text { [Low vs. High] }\end{array}$} & Intercept & 0.155 & 0.703 & 0.221 & 0.825 \\
\hline & Call Treatment [Chirp Rate] & -0.054 & 0.279 & -0.193 & 0.847 \\
\hline & Adult Eclosion Weight & 0.001 & 0.002 & 0.490 & 0.624 \\
\hline & Residual Eggs & -0.002 & 0.003 & -0.840 & 0.401 \\
\hline & Protein:Carbohydrate $\left[1_{\mathrm{P}}: 1_{\mathrm{C}}\right]$ & -0.373 & 0.412 & -0.904 & 0.366 \\
\hline & Protein:Carbohydrate $\left[3_{\mathrm{P}}: 1_{\mathrm{C}}\right]$ & -0.277 & 0.437 & -0.634 & 0.526 \\
\hline & Phosphorus $[0.45 \% \mathrm{PH}]$ & 0.501 & 0.280 & 1.791 & 0.073 \\
\hline \multirow{7}{*}{$\begin{array}{l}\text { Peak Stimulus } \\
\text { [Low vs. Intermediate] }\end{array}$} & Intercept & -0.014 & 0.768 & -0.019 & 0.985 \\
\hline & Call Treatment [Chirp Rate] & -0.532 & 0.304 & -1.750 & 0.080 \\
\hline & Adult Eclosion Weight & 0.001 & 0.003 & 0.419 & 0.675 \\
\hline & Residual Eggs & -0.003 & 0.003 & -1.044 & 0.296 \\
\hline & Protein:Carbohydrate $\left[1_{\mathrm{P}}: 1_{\mathrm{C}}\right]$ & 0.158 & 0.442 & 0.358 & 0.720 \\
\hline & Protein:Carbohydrate $\left[3_{\mathrm{P}}: 1_{\mathrm{C}}\right]$ & 0.073 & 0.477 & 0.154 & 0.878 \\
\hline & Phosphorus $[0.45 \% \mathrm{PH}]$ & -0.052 & 0.305 & -0.169 & 0.866 \\
\hline
\end{tabular}


Table A4.1. Continued

\begin{tabular}{|c|c|c|c|c|c|}
\hline \multirow[t]{7}{*}{ Strength } & Intercept & -1.593 & 0.420 & -3.797 & $<0.001$ \\
\hline & Call Treatment [Chirp Rate] & 0.037 & 0.166 & 0.223 & 0.824 \\
\hline & Adult Eclosion Weight & -0.001 & 0.001 & -0.665 & 0.507 \\
\hline & Residual Eggs & -0.001 & 0.002 & -0.438 & 0.662 \\
\hline & Protein:Carbohydrate $\left[1_{\mathrm{P}}: 1_{\mathrm{C}}\right]$ & 0.211 & 0.242 & 0.874 & 0.383 \\
\hline & Protein:Carbohydrate $\left[3_{\mathrm{P}}: 1_{\mathrm{C}}\right]$ & 0.382 & 0.259 & 1.474 & 0.142 \\
\hline & Phosphorus $[0.45 \% \mathrm{PH}]$ & 0.086 & 0.166 & 0.514 & 0.607 \\
\hline \multirow[t]{7}{*}{ Tolerance } & Intercept & 3.107 & 0.378 & 8.215 & $<0.001$ \\
\hline & Call Treatment [Chirp Rate] & -0.224 & 0.150 & -1.498 & 0.135 \\
\hline & Adult Eclosion Weight & 0.002 & 0.001 & 1.886 & 0.060 \\
\hline & Residual Eggs & 0.003 & 0.001 & 2.163 & 0.031 \\
\hline & Protein:Carbohydrate $\left[1_{\mathrm{P}}: 1_{\mathrm{C}}\right]$ & -0.264 & 0.218 & -1.212 & 0.227 \\
\hline & Protein:Carbohydrate $\left[3_{\mathrm{P}}: 1_{\mathrm{C}}\right]$ & -0.515 & 0.234 & -2.202 & 0.028 \\
\hline & Phosphorus $[0.45 \% \mathrm{PH}]$ & -0.144 & 0.150 & -0.961 & 0.337 \\
\hline \multirow[t]{7}{*}{ Responsiveness } & Intercept & 55.355 & 9.501 & 5.826 & $<0.001$ \\
\hline & Call Treatment [Chirp Rate] & -0.481 & 3.757 & -0.128 & 0.898 \\
\hline & Adult Eclosion Weight & 0.117 & 0.032 & 3.684 & $<0.001$ \\
\hline & Residual Eggs & 0.055 & 0.035 & 1.588 & 0.113 \\
\hline & Protein:Carbohydrate $\left[1_{\mathrm{P}}: 1_{\mathrm{C}}\right]$ & -7.103 & 5.470 & -1.298 & 0.195 \\
\hline & Protein:Carbohydrate $\left[\mathbf{3}_{\mathrm{P}}: \mathbf{1}_{\mathrm{C}}\right]$ & -18.586 & 5.875 & -3.163 & 0.002 \\
\hline & Phosphorus $[0.45 \% \mathrm{PH}]$ & -3.554 & 3.770 & -0.943 & 0.347 \\
\hline
\end{tabular}


Table A4.2. Parameter estimates for the models examining factors influencing preference function shape across chirp rate and carrier frequency call treatments. Redundant parameter estimates with regression coefficients of 0 (i.e. reference categories) are omitted from the table, and estimates associated with the remaining model parameter(s) indicate contrasts with the missing reference category.

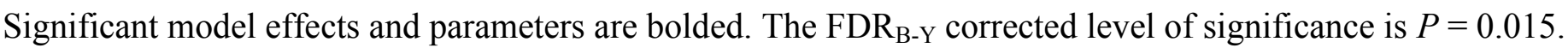

\begin{tabular}{llrrrrr}
\hline Model & Model Parameter & $\boldsymbol{\beta}$ & SE & df & $\boldsymbol{t}$ & $\boldsymbol{P}$ \\
\hline Chirp Rate & Intercept & $\mathbf{4 0 . 5 7 3}$ & $\mathbf{1 2 . 6 6 3}$ & $\mathbf{2 0 2 . 3}$ & $\mathbf{3 . 2 0 4}$ & $\mathbf{0 . 0 0 2}$ \\
Preference & Trial Number & 4.277 & 1.807 & 1596.0 & 2.367 & 0.018 \\
& Trial Number & $\mathbf{0 . 4 4 5}$ & $\mathbf{0 . 1 4 7}$ & $\mathbf{1 5 9 6 . 0}$ & $\mathbf{- 3 . 0 3 3}$ & $\mathbf{0 . 0 0 2}$ \\
& Adult Eclosion Weight & $\mathbf{0 . 1 3 4}$ & $\mathbf{0 . 0 4 0}$ & $\mathbf{1 5 4 . 0}$ & $\mathbf{3 . 3 5 5}$ & $\mathbf{0 . 0 0 1}$ \\
& Residual Eggs & 0.025 & 0.045 & 154.0 & 0.553 & 0.581 \\
& Protein:Carbohydrate $\left[1_{\mathrm{P}}: 1_{\mathrm{C}}\right]$ & -7.308 & 7.093 & 154.0 & -1.030 & 0.304 \\
& Protein:Carbohydrate $\left[\mathbf{3}_{\mathbf{P}}: \mathbf{1}_{\mathbf{C}}\right]$ & -12.336 & 7.443 & 154.0 & -1.657 & 0.099 \\
& Phosphorus $[0.45 \%$ PH $]$ & -0.140 & 4.845 & 154.0 & -0.029 & 0.977 \\
& Standard Deviation & -6.180 & 3.904 & 1596.0 & -1.583 & 0.114 \\
& Adult Eclosion Weight * Standard Deviation & $\mathbf{0 . 0 3 1}$ & $\mathbf{0 . 0 1 3}$ & $\mathbf{1 5 9 6 . 0}$ & $\mathbf{2 . 4 7 5}$ & $\mathbf{0 . 0 1 3}$ \\
\hline
\end{tabular}


Table A4.2. Continued

\begin{tabular}{|c|c|c|c|c|c|c|}
\hline \multirow{9}{*}{$\begin{array}{l}\text { Carrier Frequency } \\
\text { Preference }\end{array}$} & Intercept & 74.196 & 15.296 & 164.5 & 4.851 & $<0.001$ \\
\hline & Trial Number & -0.661 & 0.393 & 1597.2 & -1.683 & 0.093 \\
\hline & Adult Eclosion Weight & 0.094 & 0.051 & 154.0 & 1.848 & 0.067 \\
\hline & Residual Eggs & 0.089 & 0.053 & 154.0 & 1.672 & 0.096 \\
\hline & Protein:Carbohydrate $\left[1_{\mathrm{P}}: 1_{\mathrm{C}}\right]$ & -7.026 & 8.359 & 154.0 & -0.841 & 0.402 \\
\hline & Protein:Carbohydrate $\left[3_{P}: 1_{C}\right]$ & -24.809 & 9.184 & 154.0 & -2.701 & 0.008 \\
\hline & Phosphorus $[0.45 \% \mathrm{PH}]$ & -7.081 & 5.826 & 154.0 & -1.215 & 0.226 \\
\hline & Standard Deviation & 1.750 & 0.786 & 1597.2 & 2.228 & 0.026 \\
\hline & Standard Deviation $^{2}$ & -1.736 & 0.563 & 1597.2 & -3.085 & 0.002 \\
\hline
\end{tabular}

